\title{
Essays in Political Economy
}

\section{Citation}

Teso, Edoardo. 2018. Essays in Political Economy. Doctoral dissertation, Harvard University, Graduate School of Arts \& Sciences.

\section{Permanent link}

http://nrs.harvard.edu/urn-3:HUL.InstRepos:41128493

\section{Terms of Use}

This article was downloaded from Harvard University's DASH repository, and is made available under the terms and conditions applicable to Other Posted Material, as set forth at http:// nrs.harvard.edu/urn-3:HUL.InstRepos:dash.current.terms-of-use\#LAA

\section{Share Your Story}

The Harvard community has made this article openly available.

Please share how this access benefits you. Submit a story.

Accessibility 


\title{
Essays in Political Economy
}

\author{
A dissertation presented \\ by \\ Edoardo Teso
}

to

The Department of Economics

in partial fulfillment of the requirements

for the degree of

Doctor of Philosophy

in the subject of

Political Economy and Government

Harvard University

Cambridge, Massachusetts

April 2018 
(C) 2018 Edoardo Teso

All rights reserved. 
Dissertation Advisor:

Professor Alberto Alesina
Author:

Edoardo Teso

\title{
Essays in Political Economy
}

\begin{abstract}
This dissertation is composed of three essays in Political Economy. The first essay investigates the role and consequences of political connections in the selection of public sector employees. The second essay examines the determinants of individual attitudes towards gender roles in the labor market. The third essay investigates the relationship between individual perceptions about intergenerational mobility and preferences for redistributions.

In the first essay, which is joint work with Emanuele Colonnelli and Mounu Prem, we study patronage in the allocation of public sector jobs in Brazilian local governments. We first document the presence of significant political favoritism in the allocation of jobs throughout the entire Brazilian public sector hierarchy. We then show that patronage is the leading explanation behind this favoritism and that patronage has significant real consequences for the quality of the selected public workers. Finally, we present evidence suggesting that patronage practices are associated with a worse provision of public services.

In the second essay, I ask whether demographic shocks can affect the long-run evolution of female labor force participation and gender norms. I trace current variation in women's participation in the labor force within Sub-Saharan Africa to the emergence of a femalebiased sex ratio during the centuries of the transatlantic slave trade: women whose ancestors were more exposed to this historical shock are today more likely to be in the labor force, have lower levels of fertility, and are more likely to participate in household decisions. I provide evidence that the marriage market and the cultural transmission of internal norms across generations represent important mechanisms explaining this long-run persistence.

In the third essay, which is joint work with Alberto Alesina and Stefanie Stantcheva,
\end{abstract}


we use new cross-country survey and experimental data, to investigate how beliefs about intergenerational mobility affect preferences for redistribution. We find that Americans are more optimistic than Europeans about social mobility. We show that individuals who have more pessimistic views about mobility are more in support of redistributive policies. However, this effect is present only among left-wing respondents, possibly because right-wing respondents see the government as a "problem" and not as the "solution." 


\section{Contents}

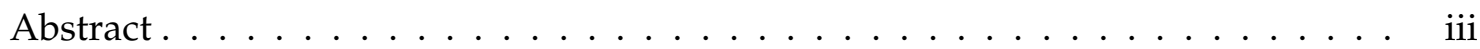

Acknowledgments ..................... xiv

$\begin{array}{ll}\text { Introduction } & 1\end{array}$

1 Patronage in the Allocation of Public Sector Jobs 3

1.1 Introduction . . . . . . . . . . . . . . . . . . 3

1.2 Institutional Context . . . . . . . . . . . . . . . . . . . . 11

1.2.1 Local Politics in Brazil . . . . . . . . . . . . . . . . . . . 11

1.2.2 The Allocation of Jobs in the Public Sector . . . . . . . . . . . . . . 13

1.3 Data . . . . . . . . . . . . . . . . . . . . 15

1.3 .1 Electoral Data . . . . . . . . . . . . . . . . . . 15

1.3.2 Labor Market Data . . . . . . . . . . . . . . . . . . . . . . 17

1.3.3 Matching and Final Dataset . . . . . . . . . . . . . . . . . 18

1.3.4 Descriptive Facts About the Brazilian Public Sector . . . . . . . . . . . 19

1.4 Measuring Favoritism: Empirical strategy . . . . . . . . . . . . . . . . . 26

1.4.1 Main Regression Discontinuity Design Estimates . . . . . . . . . . . 26

1.4.2 The Effect of Gaining Versus Losing a Connection . . . . . . . . . . . . 33

1.4.3 Difference-in-differences Estimates: Non-Supporters as Control Group 34

1.5 Estimates of Favoritism in Public Sector Employment . . . . . . . . . . . . . 36

1.5.1 Main Regression Discontinuity Estimates . . . . . . . . . . . . . . . . 36

1.5.2 Gaining Versus Losing a Connection . . . . . . . . . . . . . . . . . . . . . . . 45

1.5.3 Difference-in-Differences Estimates . . . . . . . . . . . . . . . . . 47

1.5.4 Favoritism is Widespread Throughout the Entire Hierarchy . . . . . . 47

1.6 Patronage as Mechanism, and Impact on Selection to Public Employment . . 50

1.6.1 Political Favoritism is Increasing in the Amount of Political Support . 50

1.6.2 Providing Political Support Decreases Screening on Education . . . . 52

1.6.3 Providing Political Support Decreases Screening on Skills Valued by the Private Sector . . . . . . . . . . . . . . . . . . . . . . . 56

1.6.4 Is the mayor successfully screening on unobservables? . . . . . . . . 58

1.6.5 Is the mayor's goal to create an ideologically cohesive team? . . . . . 64 
1.7 Patronage and Public Services Provision . . . . . . . . . . . . 66

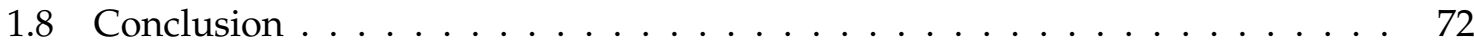

2 The Long-Term Effect of Demographic Shocks on the Evolution of Gender Roles: Evidence from the transatlantic Slave Trade $\quad 74$

2.1 Introduction . . . . . . . . . . . . . . . . . . . . . . 74

2.2 Historical Background and Conceptual Framework . . . . . . . . . . . . . . 81

2.2.1 Historical Background . . . . . . . . . . . . . . . . . . . . . . . . . . . . . . 81

2.2.2 Conceptual Framework . . . . . . . . . . . . . . . . . . . . 84

2.3 Data and Empirical Specification . . . . . . . . . . . . . . . . 87

2.3 .1 Contemporaneous Data . . . . . . . . . . . . . . . . 88

2.3 .2 Historical Data . . . . . . . . . . . . . . . . . . . 90

2.3.3 Empirical Specification . . . . . . . . . . . . . . . . . . . 92

2.4 The Long-Run Impact of the Transatlantic slave trade On FLFP . . . . . . . . 94

2.4 .1 Main Results . . . . . . . . . . . . . . . . . . . . . . . . 94

2.4.2 Men's employment as a falsification test . . . . . . . . . . . . . 101

2.4 .3 The marriage market channel . . . . . . . . . . . . . . . . . 103

2.4.4 Isolating the Cultural Transmission Channel . . . . . . . . . . . . . . . . . . . . . . . . . . . .

2.4.5 Heterogeneous effects across cohorts . . . . . . . . . . . . . . . 109

2.4 .6 Instrumental Variable Strategy . . . . . . . . . . . . . . . . . . . . 110

2.5 The Effect on Fertility and Gender Norms in Other Domains . . . . . . . . 113

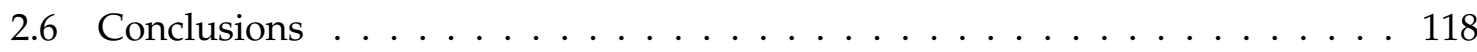

3 Intergenerational Mobility and Preferences for Redistribution 119

3.1 Introduction . . . . . . . . . . . . . . . . . . . . . . . . . . . 119

3.2 Data, Survey, and Methodology . . . . . . . . . . . . . . . . 125

3.2.1 Data on Actual Intergenerational Mobility Across Countries . . . . . . 125

3.2.2 Survey Data Collection . . . . . . . . . . . . . . . . . . 126

3.2 .3 The Survey . . . . . . . . . . . . . . . . . . . 127

3.2.4 Ensuring Data Quality . . . . . . . . . . . . . . . . . . . . 131

3.2 .5 Sample Characteristics . . . . . . . . . . . . . . 133

3.3 Mobility (Mis)perceptions . . . . . . . . . . . . . . . . . . . . 134

3.3.1 Actual and Perceived Mobility . . . . . . . . . . . . . . . . . . 134

3.3 .2 Heterogeneity in perceptions . . . . . . . . . . . . . . . . . . 139

3.3.3 Perceived Role of Individual Effort and Hard Work . . . . . . . . . . . 143

3.3.4 Geography of Perceptions in the U.S. . . . . . . . . . . . . . . . . . 145

3.4 Perceptions of Mobility and Policy Preferences . . . . . . . . . . . . . . . . . 148

3.4 .1 Views on Fairness . . . . . . . . . . . . . . . . . . 148

3.4 .2 Views of Government . . . . . . . . . . . . . . . . . . 151 
3.4.3 Policy Preferences and Views on Mobility . . . . . . . . . . . . . . . 154

3.5 Randomized Perception Experiment . . . . . . . . . . . . . . . . . . . . . . . . . . . . . . . . . . . . . . .

3.5 .1 The Experiment . . . . . . . . . . . . . . . . . . 158

3.5.2 First Stage: Treatment Effects on Perceptions . . . . . . . . . . . . . . 160

3.5.3 Treatment Effects on Policy Preferences . . . . . . . . . . . . . . . 161

3.5.4 Polarization: Left versus Right . . . . . . . . . . . . . . . . 166

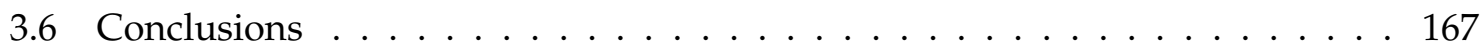

$\begin{array}{lr}\text { References } & 169\end{array}$

$\begin{array}{ll}\text { Appendix A Appendix to Chapter 1 } & 180\end{array}$

A.1 Additional Tables and Figures . . . . . . . . . . . . . . . . . . . 180

$\begin{array}{lll}\text { Appendix B Appendix to Chapter 2 } & 204\end{array}$

B.1 Data Sources and Description of Variables . . . . . . . . . . . . . . . . . . 204

B.2 Additional Results . . . . . . . . . . . . . . . . . . . . 211

B.3 Duration of the shock . . . . . . . . . . . . . . 231

Appendix C Appendix to Chapter 3

C.1 Survey Information . . . . . . . . . . . . . . . . . . . . 233

C.2 Variable Definitions . . . . . . . . . . . . . . . . . . 237

C.3 Links to surveys . . . . . . . . . . . . . . . . . . . . . 241

C.4 Detailed Survey Questionnaires . . . . . . . . . . . . . . . . . . . . . . . 241

C.5 Additional Tables and Figures . . . . . . . . . . . . . . . . . . . . . . . . . . . . . 254

C.6 (Mis)perceptions of inequality . . . . . . . . . . . . . . . . . 280

C.7 Data Sources for Population Statistics . . . . . . . . . . . . . . . . 285

C.8 Information on construction of the French transition matrix . . . . . . . . 285 


\section{List of Tables}

1.1 Election Cycles in Municipal Public Employment and Budget Outcomes . . . 22

1.2 Descriptive Statistics on Supporters' Labor Market . . . . . . . . . . . . . . 24

1.3 Covariates Balance for Candidates . . . . . . . . . . . . . . 30

1.4 Covariates Balance for Donors . . . . . . . . . . . . . . . . . 32

1.5 Effect of Supporting the Winning Party on Public Sector Outcomes . . . . . . 37

1.6 Effect of Supporting the Winning Party on Formal Sector Employment . . . . 42

1.7 Effect of Supporting the Winning Party on Public Employment Probability By Public Actor Allocating Jobs . . . . . . . . . . . . . . . . . . . . . . . . 44

1.8 Effect of Supporting the Winning Party On Public Employment Probability Across the Public Sector Hierarchy . . . . . . . . . . . . . . . . . . . . . . . 49

1.9 Providing Political Support Decreases the Importance of Education as a Hiring

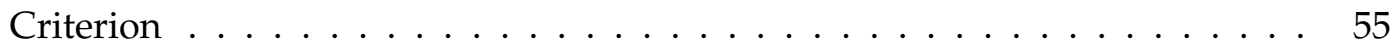

1.10 Extent of Public Employees' Unqualification is Larger Among Mayor's Sup-

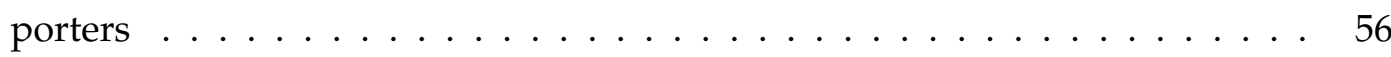

1.11 Favoritism Stronger for Supporters with Lower Private Sector Opportunities 58

1.12 Favoritism Stronger for Supporters with Lower Residual Ability . . . . . . . 61

1.13 Patronage And Municipal-Level Outcomes . . . . . . . . . . . . . . . 71

2.1 OLS estimates, the effect of the slave trade on FLFP . . . . . . . . . . . . 98

2.2 OLS estimates, the effect of the slave trade on occupational choices . . . . . . 101

2.3 OLS estimates, Women's versus Men's Employment . . . . . . . . . . . . . . . 102

2.4 OLS estimates, the marriage market channel . . . . . . . . . . . . . . . 105

2.5 OLS estimates, the cultural transmission channel . . . . . . . . . . . . 108

2.6 IV estimates, the effect of the slave trade on women's labor market . . . . . . 112

2.7 OLS estimates, the effect of the slave trade on fertility . . . . . . . . . . . . . 114

2.8 OLS estimates, the effect of the slave trade on women's empowerment . . . . 116

3.1 Sample Characteristics . . . . . . . . . . . . . . . . . . . . 133

3.2 Perceived and Actual Transition Probabilities Across Countries . . . . . . . 135

3.3 Cross-sectional Relation between Perceptions and Policy Preferences . . . . . 155

3.4 First Stage Treatment Effects on Mobility Perceptions . . . . . . . . . . . . 163 
3.5 Persistence of Treatment Effects on Mobility Perceptions . . . . . . . . . . . . 164

3.6 Treatment Effects on Policy Preferences . . . . . . . . . . . . . . 165

A.1 Summary Statistics - Universe of Candidates to the Local Council . . . . . 188

A.2 Summary Statistics - Universe of Donors to Local Elections . . . . . . . . . 188

A.3 Public Sector Wage Premium ． . . . . . . . . . . . . . . . . . . . . . . . . . 189

A.4 Covariates Balance for Candidates Gaining a Connection . . . . . . . . . . . 189

A.5 Covariates Balance for Candidates Losing a Connection . . . . . . . . . . . . 190

A.6 Covariates Balance for Donors - Gaining a Connection . . . . . . . . . . . . . 191

A.7 Covariates Balance for Donors - Losing a Connection . . . . . . . . . . . . . . 192

A.8 Effect of Supporting the Winning Party on Public Sector Outcomes - Optimal Bandwidth . . . . . . . . . . . . . . . . . . . . . 193

A.9 Effect of Supporting the Winning Party on Public Sector Outcomes - 3\% Margin of Victory Bandwidth . . . . . . . . . . . . . . . . . . . . . . . . . 194

A.10 Effect of Supporting the Winning Party on Public Sector Outcomes $-1 \%$ Margin of Victory Bandwidth . . . . . . . . . . . . . . . . . . . . . . . . . 194

A.11 Effect of Supporting the Winning Party on Public Sector Outcomes, By Election Cycle . . . . . . . . . . . . . . . . . . . . 195

A.12 Effect of Supporting the Winning Party on Public Sector Outcomes - By Type of Connection . . . . . . . . . . . . . . . . . . . . 196

A.13 Effect of Supporting the Winning Party on Public Sector Outcomes - Winning versus Losing Candidates . . . . . . . . . . . . . . . . . . . 197

A.14 Effect of Supporting the Winning Party on Public Sector Outcomes - By Type of Contract . . . . . . . . . . . . . . . . . . . . . . . . 197

A.15 Effect On Public Sector Outcomes of Gaining versus Losing a Connection . . 198

A.16 Comparison of RDD and DID Estimates . . . . . . . . . . . . . . . . . . . 198

A.17 Effect of Supporting the Winning Party On Public Employment Probability Across the Public Sector Hierarchy - Optimal Bandwidth . . . . . . . . . . . 199

A.18 Public Sector Returns Are Increasing in Amount of Support . . . . . . . . . . 200

A.19 Patronage Decreases the Importance of Education in Public Sector Hiring Non-Supporters as Control Group . . . . . . . . . . . . . . . . . . . . . . . 201

A.20 Favoritism Stronger for Supporters with Lower Private Sector Opportunities Non-Supporters as Control Group . . . . . . . . . . . . . . . . . . . . 202

A.21 Effect of Supporting the Winning Party Among Switchers and Loyals . . . . 203

B.1 Summary statistics, Women Sample . . . . . . . . . . . . . . . . . . 212

B.2 OLS estimates, Historical Determinants of FLFP . . . . . . . . . . . . . 215

B.3 The Transatlantic Slave Trade and Polygyny . . . . . . . . . . . . . 216 
B.4 The effect of the slave trade on FLFP, robustness to different standard errors corrections . . . . . . . . . . . . . . . . . . . 217

B.5 The effect of the slave trade on FLFP, robustness to other slave trades . . . 218

B.6 The effect of the slave trade on FLFP, Afrobarometer sample . . . . . . . . . 219

B.7 The effect of the slave trade on occupational choices, with additional controls 220

B.8 The effect of the slave trade on FLFP, alternative slave trade measure . . . . . 221

B.9 The effect of the slave trade on occupational choices, alternative slave trade measure . . . . . . . . . . . . . . . . . . . 222

B.10 The marriage market channel, with additional controls . . . . . . . . . . 223

B.11 The cultural transmission channel, occupational choices . . . . . . . . . . . 224

B.12 The cultural transmission channel, heterogeneous effects in "mover" status . 225

B.13 IV estimates of the effect of the slave trade on occupational choices . . . . . 226

B.14 V estimates of the effect of the slave trade, with additional controls . . . . . . 227

B.15 The effect of the slave trade on fertility, controlling for education and polygyny 228

B.16 IV estimates of the effect of the slave trade on fertility . . . . . . . . . . . . 229

B.17 IV estimates of the effect of the slave trade on women's empowerment . . . . 230

B.18 Does the duration of the historical shock matter? . . . . . . . . . . . . . . 232

C.1 Survey waves, Dates and Sample Sizes . . . . . . . . . . . . . . . . . . . 234

C.2 Randomization Groups . . . . . . . . . . . . . . . . . . 235

C.3 Response Patterns . . . . . . . . . . . . . . . . . . . . . . . . . 235

C.4 Covariates Balance Across Groups . . . . . . . . . . . . . . . 236

C.5 Detailed perceived transition probabilities . . . . . . . . . . . . 254

C.6 The perceived role of effort . . . . . . . . . . . . . . . . . 255

C.7 Heterogeneity in perceptions: partial effects . . . . . . . . . . . . 256

C.8 The perceived role of talent . . . . . . . . . . . . . . . . . 257

C.9 Heterogeneity in perceptions conditional on effort: partial effects . . . . . . 258

C.10 Heterogeneity in perceptions conditional on talent: partial effects . . . . . . . 259

C.11 Commuting Zone Characteristics and Mobility Perceptions: Partial Effects . 260

C.12 Minorities, Immigrants, and Redistributive Preferences . . . . . . . . . . . . 261

C.13 Perceptions of Government . . . . . . . . . . . . . . . . . . . . . . . 262

C.14 Views on Taxes and Public Spending . . . . . . . . . . . . . . . . . . 263

C.15 Views of government and policy preferences, left versus right . . . . . . . . . 264

C.16 Correlation between views of government, policy preferences, and pessimism 265

C.17 Regressing policy preferences on mobility perceptions: US . . . . . . . . . . 266

C.18 Regressing policy preferences on mobility perceptions: UK . . . . . . . . 267

C.19 Regressing policy preferences on mobility perceptions: France . . . . . . . . 268

C.20 Regressing policy preferences on mobility perceptions: Italy . . . . . . . . . 269 
C.21 Regressing policy preferences on mobility perceptions: Sweden . . . . . . . . 270

C.22 Persistence of Treatment Effects on Mobility Perceptions - Left-Wing respondents . . . . . . . . . . . . . . . . . . . . . . 271

C.23 Persistence of Treatment Effects on Mobility Perceptions - Right-Wing respon-

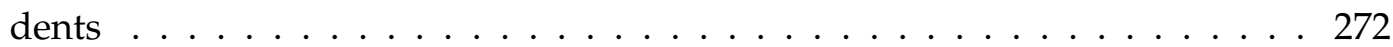

C.24 Correlation between perceptions of mobility and perceptions of inequality and taxes . . . . . . . . . . . . . . . . . . 283 


\section{List of Figures}

1.1 Turnover and Growth in Municipal Public Employment are Higher Following Elections . . . . . . . . . . . . . . . . . 20

1.2 Political Supporters Are More Likely to Be Public Employees When their Party is in Power . . . . . . . . . . . . . . . . 26

1.3 Effect of Supporting the Winning Party on Public Sector Outcomes - Dynamics of the Effect . . . . . . . . . . . . . . . . . . . 38

1.4 Trends in Political Supporters' Mean Public Sector Outcomes Around the Election . . . . . . . . . . . . . . . . . . . . . 39

1.5 Post-Election Public Sector Employment Probability Around the Discontinuity

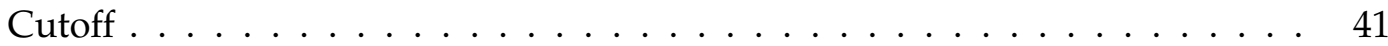

1.6 Effect on Public Sector Employment Probability of Gaining versus Losing a Connection . . . . . . . . . . . . . . . . . . 46

1.7 Public Sector Returns Are Increasing in Amount of Support Provided . . . . 53

1.8 Supporters' Public Sector Employment Probability Depends on Party Fortune 64

1.9 Effect of Supporting the Winning Party Among Switchers and Loyals . . . . 66

1.10 Distribution of Patronage Across Elections . . . . . . . . . . . . . 68

2.1 The Demographic Impact of the transatlantic Slave Trade. Source: Manning

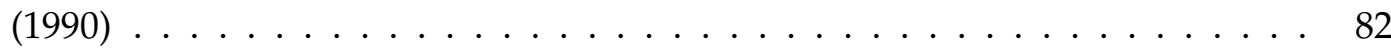

2.2 Countries and number of surveys in the DHS sample . . . . . . . . . . 88

2.3 Ethnic group-level exposure to the transatlantic slave trade . . . . . . . . . 91

2.4 Historical exposure to the transatlantic slave trade leads to higher current FLFP 99

2.5 Heterogeneous effects of the transatlantic slave trade across cohorts . . . . 110

3.1 Ladder Question to Elicit Perceived Mobility . . . . . . . . . . . . . . . . . . 129

3.2 Actual and Perceived Mobility Across Countries . . . . . . . . . . . . . . . . . . 137

3.3 Accuracy of Individual Level Perceptions . . . . . . . . . . . . . . . . . . . 139

3.4 Heterogeneity in Mobility Perceptions . . . . . . . . . . . . . . . . . . . . 141

3.5 The Perceived Role of Effort . . . . . . . . . . . . . . . . . . . . . 144

3.6 Actual and perceived probability of moving from the bottom to the top quintile across U.S. states . . . . . . . . . . . . . . . . 147 
3.7 Perceptions of Government and Fairness ～. . . . . . . . . . . . . . . . . 150

A.1 Turnover in Private Sector Employment Does Not Spike Following Elections 180

A.2 Turnover in Municipal Public Employment By Type of Contract . . . . . . . . 181

A.3 Turnover in Municipal Public Employment By Job Category . . . . . . . . . . 182

A.4 Effect of Supporting the Winning Party on Public Sector Outcomes - NonSupporters as Control Group . . . . . . . . . . . . . . . . . . . . . 183

A.5 Mayor's Supporters and Employed Supporters as a Share of the Municipality Population . . . . . . . . . . . . . . . . . . . . 184

A.6 Distribution of Ability Scores in the Population and Among Supporters . . . 185

A.7 Distribution of Ability Scores Among Candidates Supporting the Mayor or a Different Mayoral Candidate . . . . . . . . . . . . . . . . . . 186

A.8 Distribution of Ability Scores Among Donors Supporting the Mayor or a Different Mayoral Candidate . . . . . . . . . . . . . . . 187

B.1 Exposure to the Transatlantic Slave Trade and Current Sex Ratio . . . . . . . 211

C.1 Question on preferred income tax rates for various income groups . . . . . . 249

C.2 Question on preferred allocation of government budget . . . . . . . . . . 250

C.3 First page of the survey (English version) . . . . . . . . . . . . . 251

C.4 Treatment animation - introduction . . . . . . . . . . . . . . . 252

C.5 Treatment animation . . . . . . . . . . . . . . . . . 253

C.6 Heterogeneity in Mobility Perceptions Conditional on Effort . . . . . . . . . . 273

C.7 Heterogeneity in Mobility Perceptions: U.S. . . . . . . . . . . . . . . . . . . . 274

C.8 Heterogeneity in Mobility Perceptions: U.K. . . . . . . . . . . . . . . . . 275

C.9 Heterogeneity in Mobility Perceptions: France . . . . . . . . . . . . . . . 276

C.10 Heterogeneity in Mobility Perceptions: Italy . . . . . . . . . . . . . . . 277

C.11 Heterogeneity in Mobility Perceptions: Sweden . . . . . . . . . . . . . 278

C.12 Actual and Perceived Transition Probabilities Across U.S. States . . . . . . . . 279

C.13 Heterogeneity in Treatment Effects By Political Affiliation . . . . . . . . . . 282

C.14 Actual and Perceived Inequality . . . . . . . . . . . . . . . . . . . 284 


\section{Acknowledgments}

I am indebted to my committee members, colleagues, friends, and family.

My amazing group of advisors - Alberto Alesina, Nathan Nunn, Horacio Larreguy, and Andrei Shleifer - provided me with constant support, ideas, and invaluable suggestions. I have been really fortunate to have them on my side throughout the past six years.

My research also benefited greatly from the constant interactions with a long list of faculty members in the Economics department, in the Government department, and at the Harvard Kennedy School, including Emily Breza, Filipe Campante, Jeff Frieden, Asim Khwaja, Michael Kremer, Rohini Pande, Gautam Rao, Ken Shepsle, and Jim Snyder. Special thanks to my coauthors Alberto Alesina, Emanuele Colonnelli, Mounu Prem, and Stefanie Stantcheva.

My research, and more in general my life in Cambridge, have benefited from the presence of many friends: special thanks to Mitra Akhtari, Edoardo Acabbi, Max Eber, Xavier Jaravel, Luca Maini, Andrea Passalacqua, Matteo Paradisi, Sid George.

My biggest thanks go to my family, and in particular to my parents, Donatella Munaretto and Stefano Teso, for giving me their continuous and unconditional support, without which none of this would have been possible.

Finally, Maria Carreri has shared the happy and stressful moments with me during the past six years, and her love contributed in a unique way to make this a successful journey. 
Ai miei genitori. 


\section{Introduction}

This dissertation is composed of three essays in Political Economy. The first essay studies the personnel economics of the State, by investigating the role and consequences of political connections in the selection of public sector employees. The second essay examines the determinants of individual attitudes towards gender roles in the labor market. The third essay investigates the relationship between individual perceptions about intergenerational mobility and preferences for redistributions.

In the first essay, which is joint work with Emanuele Colonnelli and Mounu Prem, we study patronage - the use of public sector jobs to reward political supporters of the party in power - in the context of Brazilian local governments. We use longitudinal data on the universe of Brazilian public sector employees over the 1997-2014 period, matched with information on more than 2,000,000 political supporters of Brazilian local parties. Using a regression discontinuity design that generates exogenous variation in individuals' connection to the party in power, we first document the presence of significant political favoritism in the allocation of jobs throughout the entire Brazilian public sector hierarchy. Leveraging detailed information on supporters' and jobs' characteristics, we then show that patronage is the leading explanation behind this favoritism, with jobs in the public sector being used as reward for political supporters. We find that patronage has significant real consequences for selection to public employment, as the amount of support provided to the party in power substitutes qualifications as determinant of hiring decisions.. Finally, consistent with this negative impact on the quality of the selected public workers, we present evidence suggesting that patronage practices are associated with a worse provision of public 
services.

In the second essay, I ask whether demographic shocks can affect the long-run evolution of female labor force participation and gender norms. I trace current variation in women's participation in the labor force within Sub-Saharan Africa to the emergence of a femalebiased sex ratio during the centuries of the transatlantic slave trade. This historical shock affected the division of labor along gender lines in the remaining African population, as women substituted for the missing men by taking up areas of work that were traditionally male tasks. By exploiting variation in the degree to which different ethnic groups were affected by the transatlantic slave trade, I show that women whose ancestors were more exposed to this historical shock are today more likely to be in the labor force, have lower levels of fertility, and are more likely to participate in household decisions. I also provide evidence that the marriage market and the cultural transmission of internal norms across generations represent important mechanisms explaining this long-run persistence.

In the third essay, which is joint work with Alberto Alesina and Stefanie Stantcheva, we use new cross-country survey and experimental data, to investigate how beliefs about intergenerational mobility affect preferences for redistribution. We collect original survey data from representative samples of individuals from five countries: France, Italy, Sweden, the U.K., and the U.S.. We find that Americans are more optimistic than Europeans about social mobility, and they are over-optimistic relative to actual mobility in the U.S., especially about the probability of a child from a family in the bottom quintile making it to the top quintile - the "American dream." We show that individuals who have more pessimistic views about mobility are more in support of redistributive policies, mostly of "equality of opportunity" policies. However, we find strong political polarization. Left-wing respondents are more pessimistic about mobility; their preferences for redistribution are correlated with their mobility perceptions; and they support more redistribution after seeing pessimistic information. None of this is true for right-wing respondents, possibly because they see the government as a "problem" and not as the "solution." 


\section{Chapter 1}

\section{Patronage in the Allocation of Public Sector Jobs ${ }^{1}$}

\subsection{Introduction}

The quality of individuals employed in the public sector is a crucial determinant of government performance. While studies in this area have analyzed how various incentives shape the pool of individuals who decide to apply for public jobs, we know little about the process through which governments select public employees (Finan et al., 2015). Despite the introduction of rigid civil service systems, in virtually all countries politicians retain some discretion in this selection process (Evans and Rauch, 1999). ${ }^{2}$ While this flexibility can allow politicians to select individuals deemed able and motivated to perform the job, it can also be susceptible to patronage: public sector jobs could be used to reward political supporters of the party in power. $^{3}$ As political support substitutes quality as a hiring criterion, patronage

\footnotetext{
${ }^{1}$ Co-authored with Emanuele Colonnelli and Mounu Prem

${ }^{2}$ As described by Grindle (2012), despite the establishment of civil service systems throughout the world, political actors often manage to retain discretion in the allocation of jobs through the use of temporary contracts and the reliance on job categories exempted from the formal selection rules.

${ }^{3}$ The term patronage indicates a quid pro quo relationship between the party in power and its political supporters, in which public jobs are used as a reward and exchanged for political support (Weingrod, 1968).
} 
represents a potentially key impediment to the efficient recruitment of public sector workers.

Although accounts of this phenomenon are common, ${ }^{4}$ we have little systematic evidence on the role of patronage in selection to public employment. Does patronage affect hiring in a modern bureaucracy? And if so, what is the impact of patronage on the quality of the public workforce and, ultimately, on public service delivery? The lack of data and suitable empirical settings has made it challenging to convincingly document the presence of patronage in public employment, let alone to study its consequences.

In this paper, we aim to fill this gap by testing for the presence and consequences of patronage in Brazilian local governments. First, we causally identify the effect of supporting the party in power on the probability of obtaining a public sector job. We identify the presence of significant political favoritism in the allocation of jobs throughout the entire Brazilian public sector hierarchy. We then show that patronage is the leading explanation behind this result, ruling out alternative mechanisms that could explain the presence of this favoritism. In line with political support substituting individual quality as determinant of hiring decisions, we find that supporters of the party in power are screened less on the basis of education and of skills valued by the private sector. Consistent with this negative effect on the quality of the public workforce, we then show that patronage practices are associated with a worse provision of public services.

Brazilian local governments represent a very interesting setting to study patronage in public employment. ${ }^{5}$ Among Latin American countries, Brazil is considered a primary example of a de jure professionalized and meritocratic civil service (Iacoviello, 2006); yet, de facto politicians can use temporary contracts and other exempt job categories to exert significant influence in the selection of public sector workers (Grindle, 2012). In this sense, Brazil is a paradigmatic example of the way in which political elites of developing countries

\footnotetext{
${ }^{4}$ Patronage was at the core of local political machines in the early twentieth century United States (Riordon (1905), Wilson (1961)). Chubb (1982) (p. 91) writes that in Southern Italy "a substantial part of politics revolves around the posto ('job or position') [...] a job signifies a vote and vice versa". "[The use of patronage] in the governance of Latin America has a long tradition [...] easily dating to the conquest" (Grindle, 2010).

${ }^{5}$ Brazil is a highly decentralized country, with municipalities responsible for hiring the majority of public sector employees.
} 
manage to retain discretion in the allocation of public jobs after the introduction of a civil service system, potentially leaving the door open to patronage practices.

The main challenge in the empirical investigation of patronage is the lack of comprehensive information on both the careers of public sector workers and their connections with the political power. We build a new dataset that allows us to overcome this challenge. To do so, we combine data from two sources. First, we use a matched employer-employee dataset covering the entire Brazilian public sector for the 1997-2014 period. Second, we use administrative data on about 2,000,000 political supporters of Brazilian local parties. These supporters are either i) local candidates, namely party members running for a seat in a Brazilian municipal council, or ii) campaign donors to a local party. ${ }^{6}$ Based on a candidate's party affiliation or on the recipient of a donor's contribution, we can clearly link these individuals to the local party that they support. The data allow us to track the labor market careers of supporters of different parties, investigating whether those supporting the party in power are favored in accessing public jobs. Crucially, the availability of data on the universe of public jobs allows us to analyze favoritism at all layers of the public hierarchy, from high level bureaucratic positions, to the middle-tiers of the bureaucracy and to jobs as front service providers. Moreover, we have rich information on the characteristics of political supporters, such as their education, private sector careers, and amount of support provided to a party, and of the public jobs that they obtain, such as the specific occupation and length of the employment spell. This allows us to conduct several empirical tests to show that patronage is the key driver of political favoritism in public employment, and to study its effects.

To isolate the causal link between the provision of political support and an individual's public sector career, we exploit quasi-experimental variation in connection to the party in power generated by very competitive municipal electoral races. Our regression discontinuity

\footnotetext{
${ }^{6}$ Most of the candidates running for a seat in a municipal council are not ultimately elected. Given the part-time nature of the job, even those elected to the council are allowed by law to have jobs outside of politics. This makes both elected and non-elected local candidates well suited to study how political supporters' careers in the public sector are affected by the power of the party to which they are connected. Importantly, throughout the whole paper, being a member of a local council is not considered a "public sector job".
} 
design compares supporters of the winning party in a municipal election (i.e. the party of the elected mayor) to supporters of the losing party in the same election (i.e. the party of the runner-up mayoral candidate). We focus on elections where the margin of victory of the winning party over the runner-up is small, and we show that supporters of the two sides in these elections are not different along a wide set of pre-treatment characteristics. ${ }^{7}$

In the first step of our analysis, we show that supporters of the party in power are significantly favored in accessing public sector jobs. We find that providing political support to the party in power increases the probability of being employed in the public sector by 10.5 percentage points. Relative to a $22.5 \%$ employment probability for supporters of the runner-up party, this represents a $47 \%$ increase. ${ }^{8}$ This effect is large and statistically significant for both groups of supporters we analyze, implying that the provision of both electoral and financial support matters. Importantly, this political favoritism is not limited to a specific layer of the public sector hierarchy, but it is present across all categories of jobs, from managerial positions at the top of the bureaucracy, to lower levels of the bureaucracy, and to professional and blue collar jobs. In other words, political favoritism in public hiring does not merely affect the careers of high level bureaucrats, but it is a widespread phenomenon across the whole Brazilian public sector hierarchy. ${ }^{9}$

In the second step of the analysis, we show that patronage is the leading explanation behind this favoritism in public employment: public sector jobs are exchanged for political support, in a quid pro quo relationship in which the amount of support provided substitutes

\footnotetext{
${ }^{7}$ In our baseline specification, we focus on elections where the margin of victory is lower than $5 \%$, but we show robustness of our estimates to restricting this bandwidth to $3 \%$ or $1 \%$.

${ }^{8}$ Our regression discontinuity design uses supporters of the losing mayoral candidate as a control group for supporters of the elected mayor. While this ensures that we are comparing individuals with similar pre-treatment unobservable characteristics, it also raises the potential concern that our estimate of political favoritism not only captures a "reward" for the supporters of the mayor but also a "punishment" for the supporters of the runner-up (Labonne and Fafchamps, 2017). To evaluate the magnitude of this "punishment" component, we use data on the careers of all individuals who were employed in a municipality in the years leading up to the election and did not support any party. Using these individuals as a control group, in a difference-in-differences design, we find estimates that are very similar to the ones obtained from the regression discontinuity design, suggesting that the "punishment" component of our estimates of favoritism is limited.

${ }^{9}$ This political favoritism in accessing public sector jobs translates into a net increase in supporters' labor market earnings: on average, supporters of the mayor increase their earnings in the formal economy by $25 \%$.
} 
qualifications as hiring criterion. We first document that a supporter's public sector return is proportional to the amount of support provided to the party. For a candidate running for a seat in a local council, we use the number of votes she brought to the party as a measure of the amount of support. For a donor, we use the amount of money donated to the campaign of the party. We show that, while all supporters of the party in power enjoy a certain degree of favoritism, the extent of preferential access to public jobs and the associated monetary returns are monotonically increasing in the amount of support provided.

We then establish that providing political support to the party in power acts as a substitute for individual quality. First, we collect information on the educational requirements to adequately perform each occupation in the Brazilian public sector. Coupled with information on supporters' educational attainment, this allows us to analyze whether supporters of the party in power are more likely to be hired in a public job for which they do not have the required educational level. We find that supporters of the party in power are screened less on education than supporters of the runner-up party. Among public sector workers, individuals in the former group are 17\% more likely to be unqualified in terms of education than those in the latter. Second, we use supporters' private sector wages before the election as a measure of skills and productivity. We find that supporters of the party in power are screened less also along this dimension of quality. Political favoritism is particularly concentrated among supporters with lower private sector earnings.

We also evaluate whether two alternative interpretations of the political favoritism that we documented are consistent with the empirical evidence. In the first alternative interpretation, mayors are using their discretion to hire individuals who have higher ability, despite being less qualified on observable dimensions. In other words, political favoritism is the result of mayors having better "soft" information about members of their network, and thus being able to screen them on dimensions of talent that we cannot observe. We evaluate the plausibility of this interpretation in two ways. First, we calculate a measure of pre-election personal ability conditional on observables, as in Besley et al. (2017) and Dal Bó et al. (2017). That is, we calculate private sector earnings residuals from a Mincer 
regression controlling for an individual's demographic and job characteristics. ${ }^{10}$ Using this measure, we find that supporters of the party in power are screened less on this metric of residual personal ability. Second, we analyze political supporters' long-run careers. Ex-ante unobservable dimensions of "talent" should be revealed and become common knowledge after several years on a public job. ${ }^{11}$ Hence, if mayors are using hiring discretion to select talented individuals in their political network, these talented workers, once hired, should keep their job even if the party in power changes. However, we find that this is not the case. The career of these individuals is strictly linked to the fortune of the party they support, as they lose their job as soon as their own party loses power.

In the second alternative interpretation, political favoritism is the result of the mayor's desire to hire individuals with similar ideological views, as the matching between the ideology of the mayor and that of her bureaucrats increases organizational efficiency. ${ }^{12}$ However, contrary to this interpretation, we do not find that, among the mayor's supporters, those who have a stronger ideological link to the party enjoy a higher degree of favoritism in accessing public jobs. Supporters who recently switched political alliances are as likely to be allocated a public sector job as individuals who have been loyal to the party for a long period of time. ${ }^{13}$

Taken together, these results indicate that patronage negatively affects selection to public employment, as the supporters who benefit most from patronage are less qualified on

\footnotetext{
${ }^{10}$ Specifically, we estimate earnings residuals from a fully saturated Mincer regression using information on private sector earnings for all Brazilian workers and controlling for a full-set of interactions between age, education, gender, and sector and location of employment.

${ }^{11}$ An important dimension of "talent" to perform a public job is an individual's public service motivation, which could be not captured by our measure based on private sector earnings, and which mayors could better observe among members of their political network.

${ }^{12}$ Pursuing this goal can be especially valuable at high level of the public sector hierarchy, as having highlevel bureaucrats who are ideologically aligned with the political power can facilitate policy implementation. However, this ideological alignment can be beneficial also at lower levels of the hierarchy, if workers exert more effort when they care about the mission of the organization (Ashraf et al., 2014). However, see Rasul and Rogger (2015) for evidence that ethnic heterogeneity within bureaucracies leads to better organizational performance.

${ }^{13}$ This is true for both the groups of supporters analyzed. Candidates who in the previous election were affiliated with a different party are as likely to benefit from favoritism as candidates who have remained loyal to the same party. Donors who were contributing to a different party are as likely to benefit from favoritism as donors who were loyal to the same party in their contributions.
} 
observable dimensions, are not characterized by better unobservable characteristics, and are not more ideologically aligned to the party in power. However, there may still be positive effects of patronage which we are unable to investigate. For instance, loyalty between supporters and parties could limit agency problems and increase supporters' effort on the job. ${ }^{14}$ In other words, whether patronage is associated with a net negative effect on the quality of public services is an empirical question.

In the final part of the paper, we move a first step towards understanding the ultimate effect of patronage on the quality of public goods provision. To do so, we use our data to build an estimate of patronage that is specific to each municipality and election in the 2004-2012 period. We then exploit differential changes in within-municipality variation in the extent of patronage over time to test whether patronage is associated with the quality of public goods provision. We focus on one of the main responsibilities of Brazilian local governments: primary education. We use data on students' standardized test scores as an objective measure of students' achievements. We show that an increase in patronage in a municipality is associated with lower students' test scores in the local public schools. This result provides suggestive evidence that patronage has significantly negative welfare consequences. ${ }^{15}$

Our paper contributes to a recent body of research on the personnel economics of the bureaucracy. Papers in this growing literature have analyzed the role of incentives in the selection and performance of public sector workers (Dal Bó et al. (2013), Ashraf et al. (2014), Ashraf et al. (2016), Bertrand et al. (2016), Deserranno (2017)), the impacts of political oversight over the bureaucracy (Iyer and Mani (2011), Rogger (2014), Akhtari et al. (2016), Gulzar and Pasquale (2016), Ornaghi (2016)), and bureaucrats' management practices (Rasul and Rogger, 2017). ${ }^{16}$ Weaver (2017) shows how corruption in hiring for public sector

\footnotetext{
${ }^{14}$ A likely additional effect of patronage is to lead to an inefficiently large public sector workforce (Shleifer and Vishny, 1994).

${ }^{15}$ Consistent with politicians increasing the size of the bureaucracy in presence of incentives to engage in patronage practices, we also show that a higher extent of patronage is associated with higher growth in the municipality personnel.

${ }^{16}$ Best et al. (2016) quantify how much of the variation in state effectiveness is due to individual bureaucrats'
} 
jobs can lead to the selection of higher quality workers if quality and willingness to bribe are positively correlated. ${ }^{17} \mathrm{Xu}$ (2017) studies patronage in the historical context of the British colonies, showing that socially connected governors performed worse during the historical period characterized by political discretion in the appointment of governors. ${ }^{18}$ We contribute to this literature by providing the first causal analysis of the presence and extent of patronage in a contemporary setting, and along the whole public sector hierarchy, and by studying how patronage (negatively) affects the process of selection to public employment. More generally, by showing how political incentives affect a government's allocation of public jobs and the quality of the pool of hires, we speak to the literature on the role of social incentives in organizations (Ashraf and Bandiera, 2017). Finally, we contribute to a long literature on the role of political connections for firms (Fisman (2001), Khwaja and Mian (2005), Faccio (2006), Faccio et al. (2006), Cingano and Pinotti (2013), Schoenherr (2017)) and individuals (Markussen and Tarp (2014), Gagliarducci and Manacorda (2017), Folke et al. (2017), Labonne and Fafchamps (2017)).

The rest of the paper is organized as follows. In Section 1.2 we provide details on key features of the Brazilian institutional context that are of interest for our analysis. In Section 1.3 we describe the data sources. In Section 1.4 we present the empirical strategy. In Section 1.5 we present our estimates of political favoritism in public employment. In Section 1.6 we investigate the nature of this favoritism, showing that patronage is its leading explanation and that this negatively affects selection to public employment. In section 1.7 we discuss the relationship between patronage and the quality of public goods provision. Section 1.8 effectiveness, in the context of Russian public procurement agencies.

${ }^{17}$ Guardado (2017) studies office-selling in the context of colonial provincial governorships in Peru in the 17th-18th centuries, linking the type of the appointed governors to long-run development.

\footnotetext{
${ }^{18}$ Other studies of patronage include Folke et al. (2011) and Ujhelyi (2014), who exploit the different timing of the introduction of civil service systems across U.S. states to study its impact on incumbents' re-election probability and allocation of government spending, respectively. The theoretical literature on patronage has emphasized how redistribution through public sector jobs emerges as a credible way of rewarding clients since it solves the political-commitment problem between the client and the patron (Robinson and Verdier (2013)) Acemoglu et al. (2011) argue that inefficient states based on patronage can emerge and persist as the result of a winning coalition between the elite, that is interested in limiting redistribution, and the bureaucrats, who are interested in maintaining their rents. Drugov (2015) underlines how patronage can lead workers to increase effort due to the prospects of promotion.
} 
concludes.

\subsection{Institutional Context}

In this section, we first describe the main features of Brazilian municipal elections and the role played by the two groups of political supporters which are the focus of our paper, namely candidates to Brazilian local councils and individual donors. We then discuss the selection process of public sector workers in Brazil.

\subsubsection{Local Politics in Brazil}

Brazil's 5,570 municipalities are governed by a mayor (prefeito) together with a council of local legislators (Camara de Vereadores), simultaneously elected every four years. A voter can cast two votes in a municipal election: one for a mayoral candidate and one for an individual candidate to the council (or, alternatively, a generic vote for a party).

Mayors are term-limited, allowed to be in office in a municipality for a maximum of two consecutive terms. Mayors are elected by plurality rule, with municipalities with more than 200,000 registered voters holding a second round if no candidate has received a majority in the first round. While mayors are associated with a party, they are typically supported by a coalition of parties. $^{19}$

The first group of political supporters analyzed in this paper are candidates who run for a seat in the council of local legislators. Candidates for the local council run individually in a unique "at-large" district comprising the whole municipality, and they are elected using an open-list proportional representation system. ${ }^{20}$ Unlike mayors, members of the council

\footnotetext{
${ }^{19} 81 \%$ of mayoral candidates over the $2000-2012$ period were supported by a coalition of parties (authors' own calculations using electoral data from the TSE).

${ }^{20}$ The number of council seats, ranging from 9 to 55 , varies as a function of the population in the municipality. The allowed number of seats was established by the 1988 Brazilian Constitution up until the 2000 elections, by Resolution 21.702 elaborated by the Tribuanal Superior Eleitoral for the 2004 and 2008 elections, and by the 58th amendment to the Brazilian Constitution for the 2012 elections. These rules leave a degree of discretion to local legislators with respect to the choice of the number of council seats, establishing only a maximum (but not a minimum) number of seats as a function of population size (Dahis, 2015).
} 
do not face term limits. Candidates are members of a party, with parties generally forming pre-election coalitions. ${ }^{21}$

Council seats are awarded to a coalition in proportion to the total number of "personal" votes received by its candidates and of "generic" votes received by the parties comprising the coalition. ${ }^{22}$ The seats allocated to a coalition are then assigned to the candidates of the coalition who received the highest number of "personal" votes. Therefore, the electoral system gives strong incentive to parties and coalitions to present lists with large numbers of candidates, since even votes for non-viable candidates are valuable as they contribute to increase the number of seats allocated to the coalition. ${ }^{23}$

Although being a local legislator is remunerative, with the average legislator earning a wage that is approximately 2.6 times the average wage in her municipality (Ferraz and Finan, 2011), elected candidates are not required to give up their outside jobs upon election, as being a legislator is a part-time activity. ${ }^{24}$

The second group of political supporters analyzed in this paper are donors to a municipal election campaign. Up until the 2012 municipal elections, mayoral candidates and candidates to the local council could receive campaign donations from both corporations and individuals, with the latter being allowed to donate up to $10 \%$ of their gross annual income. ${ }^{25}$ Law no. $8713 / 1993$ requires candidates to submit to electoral courts a detailed

\footnotetext{
${ }^{21} 87 \%$ of parties running in a local election over the $2000-2012$ period were part of an electoral coalition. Parties supporting different mayors cannot be part of the same coalition for the local council election.

${ }^{22}$ Specifically, seats are awarded using an electoral quota and the d'Hondt formula.

${ }^{23}$ Electoral rules limit the number of candidates on the ballot by specifying that each party (respectively, coalition) can present a maximum of $1.5 S$ (respectively, $2 S$ ) candidates, where $S$ is the total number of council seats in the municipality. For the elections from 2000 to 2012, we find that coalitions take advantage of this rule, with each additional seat in the council being associated with a 1.7 increase in the number of candidates running in a coalition. However, the fact that the coefficient is less than 2 potentially implies that intra-coalition competition introduces some incentive to limit the number of candidates on the ballot.
}

${ }^{24}$ As described in Ferraz and Finan (2011), 98 percent of legislators elected in the 2004 election reported having another professional activity outside of politics. In our data, we indeed find no evidence that candidates elected to the council give up their external jobs. Members of the local council review and approve the local budget proposed by the mayor (with the power of vetoing certain budget items), and can submit bills mainly directed to the adoption of social programs.

\footnotetext{
${ }^{25}$ Until 2015, there was no limit on the total amount of donations a candidate or a party could receive. Donations from corporations have been prohibited by Law 13.165/2015. Therefore, since 2016, candidates can
} 
overview of all the campaign contributions received in the election cycle. In the 2008 and 2012 elections, the average share of funds that came from individuals was $28 \%$ for mayoral candidates and $40 \%$ for candidates to the local council. ${ }^{26}$ Individual donors make up a very small share of the population, with only $0.42 \%$ of Brazilians who were at least 18 years old donating in the 2012 municipal election. ${ }^{27}$

\subsubsection{The Allocation of Jobs in the Public Sector}

Spending by Brazilian municipalities is mainly financed by transfers from the state and federal government, with municipalities being responsible for the provision of a wide range of public goods in areas such as education, health and transportation. (Afonso and Araújo, 2000, Souza, 2002). Municipalities employ the largest share of Brazilian public sector employees $-56 \%$ as of 2014 , up from $40 \%$ in $1997 .{ }^{28}$

Selection in most public sector jobs is based on objective selection criteria: applicants present academic and professional credentials, and undertake a formal civil service examination (Concurso Publico), which is job-specific and consists of a combination of written and oral tests. Article 37 of the Constitution establishes clear transparency requirements for the selection of public sector workers. ${ }^{29}$ Public sector workers hired through this procedure acquire tenure after three years of service, following which they can be fired only for reasons of misconduct after a judicial decision.

finance their campaign only with donations from individuals or using party funds.

${ }^{26}$ These shares are based on the authors' calculations using the campaign data from the Tribunal Superior Eleitoral described in section 1.3.1.

${ }^{27}$ While most of the amounts donated are relatively small, cases of large donations by individuals related to corporations are not uncommon. In the 2012 election, the largest single donor was a businessman of the luxury real estate sector, who donated a total of 2.85 million Reais (about 900,000 USD). See http:/ /veja.abril.com.br/brasil/empresario-da-construcao-da-r-3-milhoes-a-campanhas/, accessed October 2017.

\footnotetext{
${ }^{28}$ These shares are based on the authors' calculations using data from the RAIS dataset described in section 1.3.2.

${ }^{29}$ Article 37 of the Constitution states: "The governmental entities and entities owned by the Government in any of the powers of the union, the states, the federal district and the Municipalities shall obey the principles of lawfulness, impersonality, morality, publicity, and efficiency..."
} 
Individuals can be hired in a public sector position without passing the civil service examination under three special exempt categories of jobs: commissioned posts (cargos comissionados), positions of trust (função de confiança), and temporary jobs (emprego temporario). Hiring in the first two categories is limited to positions of manager, supervisor or advisor, allowing politicians discretion in the selection of people in leadership roles. ${ }^{30}$ In practice, the vague language used by the law leaves ample discretion to politicians, with possible cases of violations when individuals are hired in a commissioned post or in a position of trust even though their occupation does not fall under the leadership categories required by the Brazilian Constitution. ${ }^{31}$

Politicians can also hire temporary public servants to "meet a temporary need of exceptional public interest" (Artcle 37 IX of the Brazilian Constitution). In these cases, the law states that no civil service exam is necessary and that the selection process can be limited to the analysis of an applicant's curriculum, without other formal criteria of objective measurement. The law also contains a detailed list of the instances that fall under this category, and politicians can be prosecuted in case they hire temporary workers without justification. $^{32}$

In addition to the above exempt categories, there is some anecdotal evidence of cases of fraud in public examinations, especially at the local level. In 2012, a reportage by the team of journalists of Fantastico, one of the most popular TV shows of the premier Brazilian network "Globo," uncovered an astonishing number of such cases across the country. ${ }^{33}$

\footnotetext{
${ }^{30}$ The difference between positions of trust and commissioned posts is that the former requires that the individual is already employed as a civil servant, whereas the latter allows for the hiring of individuals who have never passed the civil service examination.

${ }^{31}$ For example, in 2012 the mayor of the municipality of Jundiai exploited commissioned posts and ad-hoc laws to appoint more than 300 people to jobs that did not fall under a leadership category. The public prosecutor of Sao Paulo ordered all individuals to be fired, and initiated a trial against the mayor. See http://www.mpsp.mp.br/portal/page/portal/noticias/noticia?id oticia $=14608320 \mathrm{id}_{\mathrm{g}} \mathrm{rupo}_{\mathrm{p}}=$ 118 , accessedOctober 2017.

${ }^{32}$ For instance, in 2015 the public prosecutor of Pernambuco accused the mayor of the municipality of Belo Jardim of illegally hiring 574 teachers through temporary contracts. See http://www.mppe.mp.br/mppe/index.php/comunicacao/noticias/ultimas-noticias-noticias/5162-mppedenuncia-ex-prefeito-de-belo-jardim-por-contratacoes-ilicitas-de-professores, accessed October 2017.
}

${ }^{33}$ See "Golpe transforma concursos publicos em cabides de emprego": 
Illegal interference with the public examinations is typically achieved by (i) providing individuals with the answer sheet prior to the exam, (ii) ex-post replacing specific individual tests with better ones, and (iii) directly changing the list of winning candidates. ${ }^{34}$

\subsection{Data}

We use information from two main sources. Data on electoral results, candidates to municipal councils, and individual donors come from the Brazilian Electoral Commission (TSE). Data on public sector employment come from the Relação Anual de Informações Sociais database (RAIS). In this section we (i) provide a description of the data sources, (ii) discuss the matching of the datasets, and (iii) present a number of descriptive facts that show the importance of political dynamics in driving public employment. ${ }^{35}$

\subsubsection{Electoral Data}

We obtain the publicly available electoral data for the 2000, 2004, 2008, and 2012 municipal elections from the Tribunal Superior Eleitoral (TSE). The data contain electoral results for both mayoral elections and elections for the local council. ${ }^{36}$ We also have information on the coalition each candidate belongs to, and on the mayoral candidate supported by the coalition.

The TSE provides demographic information on the candidates, including their education and the amount of money raised during the campaign. Importantly, we have information

http://g1.globo.com/fantastico/noticia/2012/06/golpe-transforma-concursos-publicos-em-cabides-deemprego.html, accessed October 2017.

\footnotetext{
${ }^{34}$ For example, in the municipality of Novo Barreiro, in the state of Rio Grande do Sul, the public prosecutor found the mayor and other members of the local administration guilty of such a fraudulent scheme: a company bidding to administer the test won the tender under the condition that a few specific jobs were "kept available" for specific political appointees. In the nearby municipality of Itati, an exam's supervisor noticed that several applicants turned in blank tests, and then ended up being selected for the position.

${ }^{35}$ In the analysis of section 1.7 we use a number of additional municipal-level variables. We describe these variables and their sources in that section of the paper.

${ }^{36}$ For the remainder of the paper, we use the term "candidate" to refer to a candidate to the local council; we use the expression "mayoral candidate" to refer to a candidate who run for mayor of a municipality.
} 
on each candidate's individual tax identification number, called CPF (Cadastro de Pessoas Físicas). There are 1,034,194 candidates who run for a seat in the local council over this period, with about $27 \%$ of candidates running in more than one election. After dropping the few cases $(0.3 \%)$ of candidates without valid information on their $C P F$, we are left with a sample of 1,031,083 unique members of a political party who run in an election for the local council over the 2000-2012 period. We code each candidate as a supporter of a specific mayoral candidate if she belongs to a party in the coalition that supports that mayoral candidate. $^{37}$

For the 2004, 2008, and 2012 municipal elections, TSE provides data on all individuals' campaign contributions in municipal elections. We keep all records for which the data contain valid information on a donor's CPF. We code each donor as a supporter of a specific mayoral candidate if she either (i) contributed to that mayoral candidate's campaign, or (ii) contributed to the campaign of a candidate to the local council who belongs to the coalition that supports that mayoral candidate. ${ }^{39}$ It is extremely rare for an individual to donate to the campaign of parties that support different mayoral candidates, and we drop the few cases $(0.32 \%)$ where this happens, since this prevents us from identifying the donor as a supporter of a unique mayoral candidate in an election. Our final sample includes donations by $1,057,216$ unique individuals. ${ }^{40}$

\footnotetext{
${ }^{37}$ Appendix Table A.1 provides summary statistics for the universe of candidates in our dataset. Only $7 \%$ of candidates in our dataset are ever elected to the council. Conditional on running in multiple elections, it is not rare for a candidate to change party (the average number of parties is 1.72). The large majority of candidates is male, and there is wide variation in candidates' level of education.

${ }^{38}$ Missing information on a donor's CPF is extremely rare for the 2008 and 2012 elections, but about $36 \%$ of donations in the 2004 elections do not include this information. We also drop donors who are also political candidates during the 2000-2012 period, since these individuals enter our first group of supporters.

${ }^{39}$ While we choose to identify an individual as a supporter simply based on the extensive margin of her donations (whether she donated to a candidate) and not on the intensive margin (how much she donated), we will also leverage information on the amount donated to investigate possible heterogeneous effects in the amount of financial support provided.

${ }^{40}$ Appendix Table A.2 provides summary statistics for the universe of donors in our dataset. The large majority of donors are active only in one election and donate only to a single party. The average donation is of $\mathrm{R} \$ 727$, corresponding to about USD230.
} 


\subsubsection{Labor Market Data}

The principal source of employment data is the RAIS (Relação Anual de Informações Sociais) database. The RAIS database provides a unique picture of the universe of Brazilian public sector workers, as well as a general picture of private sector employment in the Brazilian formal economy. RAIS is an administrative matched employer-employee dataset managed by the Brazilian Ministry of Labor (Ministério do Trabalho e Emprego - MTE). The dataset covers the universe of workers among those employed in the Brazilian public sector and in the formal private sector (Menezes-Filho et al., 2008). ${ }^{41}$ Each individual in RAIS is assigned a unique administrative worker identifier, which allows for tracking of the individual over time and across employers. We use data for the years 1997 to 2014.

Two categories of individuals who are formally employed do not appear in RAIS: elected politicians and self-employed individuals. However, in such circumstances, only the specific job as politician or self-employed worker is missing: all other jobs of the politician or self-employed individual do appear in the dataset. Importantly, throughout the analysis, when we talk about labor market outcomes in the public sector we are excluding the jobs of elected candidates as local legislators.

For each worker-job pair, the RAIS database contains information on payroll, hiring and separation dates, employer identifier, as well as location and industry of the employer. Additionally, it contains details on the hours worked by contract, the type of contract (permanent or temporary), the specific occupation of each worker, and the worker's level of education. Finally, the data contain information on a worker's CPF.

The Brazilian official occupational classification system divides the Brazilian labor market in 2,511 occupations. We complement the data from RAIS with information from the Classificação Brasileira de Ocupações 2002 (CBO), an official publication by the Brazilian Ministry of Labor which describes, among other things, the educational level typically required to properly perform a specific occupation. We use this information to code, for each worker-job pair in RAIS, whether the worker is qualified for the job (namely, whether

\footnotetext{
${ }^{41}$ The dataset also includes information on employees of no-profit and international organizations.
} 
her educational level is the same or higher than the educational level typically required to perform her occupation). ${ }^{42}$

\subsubsection{Matching and Final Dataset}

We match our datasets of candidates and donors to RAIS using the individual identifier $C P F$, which is available in both datasets. We match $66.9 \%$ of political supporters to RAIS (67.3\% of candidates and $66.4 \%$ of donors). Of these, $69 \%$ of candidates and $52 \%$ of donors are employed in the public sector for at least one year in the period 1997-2014. ${ }^{43}$

We construct a panel dataset at the supporter-year level, with information on employment status, annual earnings, and job characteristics, for the public and the private sector separately. ${ }^{44}$ Each individual is allowed to have both a public sector and a private sector job in the same year. ${ }^{45}$

We have detailed information on a supporter's occupation. We can categorize each public sector job as a "permanent job", or as a "temporary job", the latter being one for which the worker has been hired through a temporary contract or through an exempt occupational category. We also categorize each job into one of five broad occupational categories following the CBO classification: managerial, professional, high skilled technical, clerical, and blue collar. ${ }^{46}$ Finally, as described in the previous section, information from

\footnotetext{
${ }^{42}$ We code this variable as missing for the few occupations for which the $C B O$ publication does not clearly specify a required educational level.

${ }^{43}$ The $33.1 \%$ of supporters who are not matched to RAIS are never employed in the public sector or as employees in the formal private sector in this period. These supporters are either unemployed, working in the informal economy, self-employed, or holding a job as elected politician (or a combination of these) during the entire 1997-2014 period. Importantly, the presence of an administrative individual identifier in both datasets means that there is no error in the matching procedure. This allows us to include also the unmatched supporters in the analysis, coding them as never employed in the public or private sector in the 1997-2014 period.

${ }^{44}$ If an individual does not work in a specific sector in a given year we impute 0 earnings to the respective variable. All earnings measures are expressed in 2000 Brazilian Reals. To reduce the possible influence of outliers in the earnings variables in our main analysis, we winsorize the earnings variables at the $1 \%$ in our sample of political supporters.

${ }^{45} \mathrm{~A}$ small subset of individuals have multiple occupations within the same sector in the same year. For these cases, we keep the job with the highest wage, following the common practice of other studies that use the RAIS dataset (Menezes-Filho et al., 2008, Colonnelli and Prem, 2017).

${ }^{46}$ In the public sector, the most represented jobs in the managerial category are: manager of public sector
} 
the $C B O$ categorization of occupations allows us to code each supporter employed in the public sector as qualified or unqualified, in terms of education, to perform her specific occupation. $^{47}$

\subsubsection{Descriptive Facts About the Brazilian Public Sector}

The first interesting stylized fact that emerges from the data is that electoral cycles are a crucial determinant of the size and composition of the public sector workforce. Panel A of Figure 1.1 plots the average share of yearly new hires and terminations in the municipal public sector in Brazilian municipalities over the 1999-2014 period. ${ }^{48}$ We compute shares using as denominator the total number of public sector workers in the municipality in the previous year.

Local public sector turnover is significantly higher in a year that immediately follows a local election (indicated by a green vertical line in the figure).$^{49}$ As it is clear from Appendix Figure A.1, there is no significant spike in private-sector turnover following an election year.

We formally investigate the magnitude of this turnover effect in Table 1.1.50 Years following a municipal election see an increase in the share of new hires in the local public

agency, school headmaster, administrative director, health services manager; the most represented jobs in the professional category are: primary school teacher, secondary school teacher, doctor, nurse; the most represented jobs in the high skilled technical jobs category are: primary school teacher, nursing assistant; the most represented jobs in the clerical category are: administrative assistant, administrative supervisor, receptionist; the most represented jobs in the blue collar category are: garbage collector, community health worker, driver.

\footnotetext{
${ }^{47}$ Before 2003, RAIS uses a previous occupational classification. While it is possible to construct a matching between the previous and the current classification, the former is less detailed and the same occupational code matches multiple, more detailed occupational codes in the latter. For this reason, when we exploit information on a worker's specific occupation we will focus on the 2003-2014 period.

${ }^{48}$ For each municipality, the new hires are defined as the public sector workers employed by the municipality who where not public sector workers in the same municipality in the previous year. The terminations are defined as the municipal public sector workers who were employed by the municipality in the previous year and are not employed in the current year.

${ }^{49}$ This is consistent with Akhtari et al. (2016), who document the high rate of turnover for teachers and headmasters in local schools following the change of the party in power in a municipality.

${ }^{50}$ The panel of municipalities is not balanced since some municipalities are merged or split during this period. We obtain very similar estimates if we restrict the sample to a balanced panel of municipalities that exist and have positive local public sector employment throughout the entire period.
} 

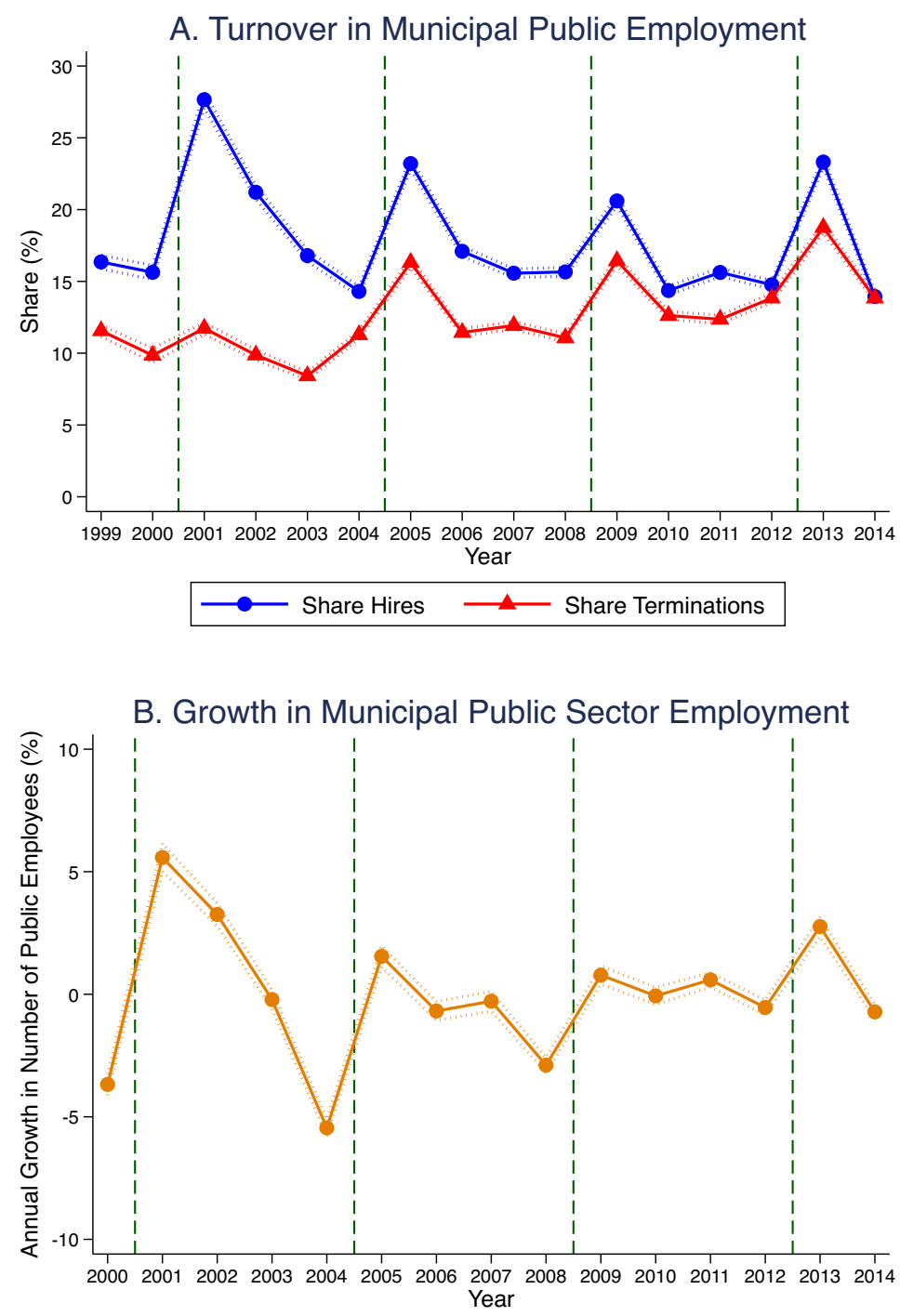

Notes: The figure shows the average share of hires and terminations in the local public sector (top panel), and (detrended) average annual growth in municipal public sector workforce (bottom panel) by year in Brazilian municipalities. Each observation in the data is a municipality-year pair. 95\% confidence intervals are shown as dashed lines around the means. The green lines indicate the time of local elections, which were held in November of 2000, 2004, 2008, 2012, with the mayor taking office in January of 2001, 2005, 2009, 2013.

Figure 1.1: Turnover and Growth in Municipal Public Employment are Higher Following Elections 
sector of about 7.9 percentage points, and an increase in the share of terminations of about 4.2 percentage points (columns 1 and 2). These represent a 50\% and 36\% increase relative to other years. ${ }^{51}$ The larger increase in the share of new hires relative to the increase in terminations translates into a significant net increase in local public sector employment following an election year: the number of public sector employees in municipal governments grows $62 \%$ more in years following a local election (see column 3 of the table and panel B of Figure 1.1).

\footnotetext{
${ }^{51}$ In all specifications, we include municipality-specific time trends to account for municipality-specific trends in public sector employment over the period.
} 


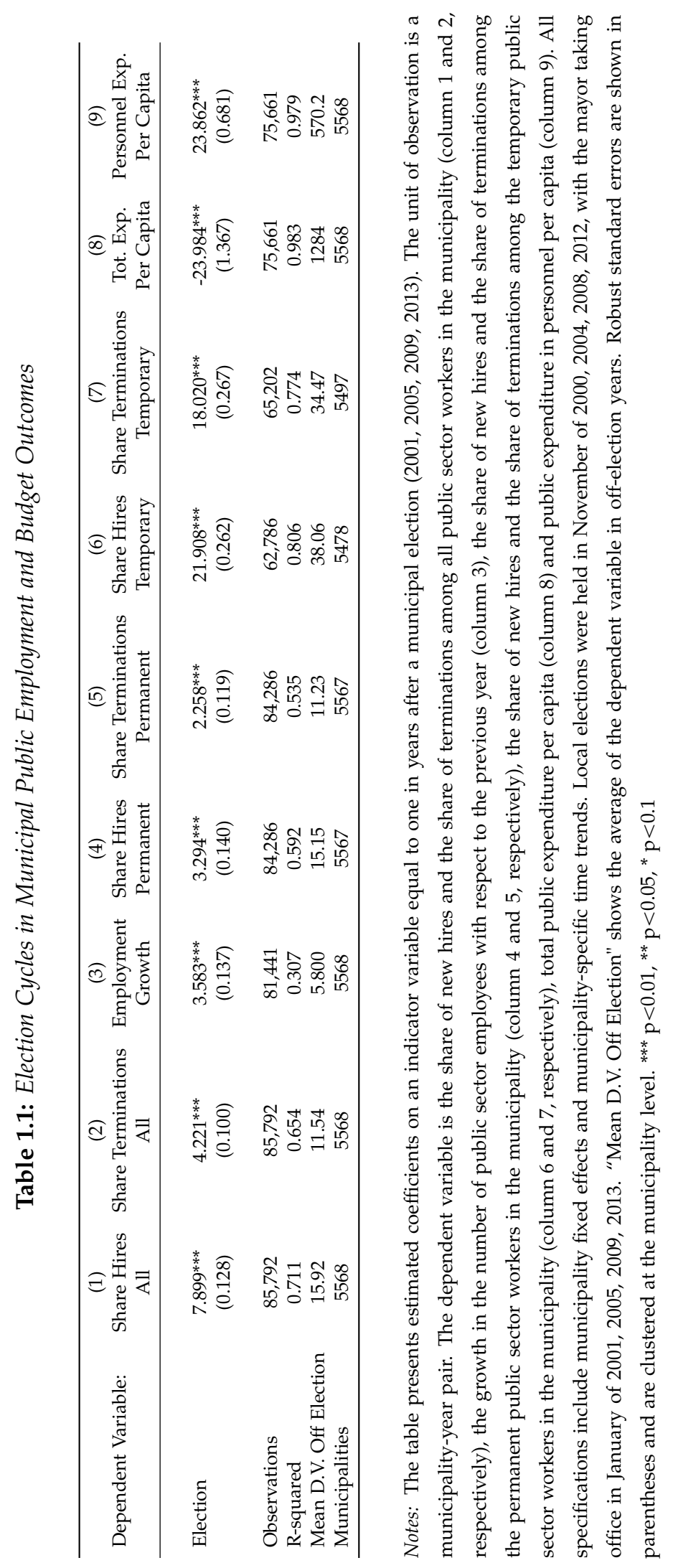


As shown in columns 4-7 of Table 1.1 (and in Appendix Figures A.2), most of the abnormal turnover is driven by temporary jobs in the public sector, although the effect is significant also for permanent positions. Furthermore, Appendix Figures A.3 show that these trends are significant for all categories of jobs, from managerial and professional positions to clerical and blue collar jobs.

While post-election years see lower municipal government expenditures (see column 8 of Table 1.1), expenditures in personnel is higher (see column 9 of Table 1.1), consistent with the higher growth in local public employment discussed above. ${ }^{52}$

Table 1.2 provides an overview of the labor market careers of political supporters in the period 1997-2014. We compare local candidates and donors to the population of 87.5 millions workers who enter the RAIS dataset during this period, having been employed in the formal economy for at least one year. For the purpose of this table, we exclude the $33.1 \%$ of supporters who are not present in RAIS, since they are never employed in the formal economy in the 1997-2014 period.

The most striking point of the table is the over-representation of political supporters among public sector employees. Political supporters are significantly more likely than the average Brazilian worker to have been ever employed in the public sector: among the universe of workers, $19 \%$ are employed in the public sector on at least one year over the $1997-2014$ period, while this share is $52 \%$ for donors and $69 \%$ for local candidates. This is true for both temporary and permanent positions, and especially for public sector jobs at the municipal level. ${ }^{53}$

Additional interesting facts emerge from the data. Public sector occupations are lucrative relative to private sector ones: the average annual earnings of a job in the public sector are about $90 \%$ higher than the average earnings in the private sector $(13,659$ Brazilian Reals

\footnotetext{
${ }^{52}$ The fact that we do not see higher municipal expenditures in budget items other than personnel suggest that the higher growth in public employment cannot be explained by the mayor's need to hire new workers in post-election years because of an overall municipal increase in investment or the implementation of new policies promised during the campaign.

${ }^{53}$ Political supporters are instead significantly less likely to be ever employed in the private sector.
} 
Table 1.2: Descriptive Statistics on Supporters' Labor Market

\begin{tabular}{|c|c|c|c|c|c|c|c|c|c|}
\hline & \multicolumn{3}{|c|}{$\begin{array}{l}\text { Candidates } \\
\text { (694,273 obs.) }\end{array}$} & \multicolumn{3}{|c|}{$\begin{array}{c}\text { Donors } \\
\text { (701,954 obs.) }\end{array}$} & \multicolumn{3}{|c|}{$\begin{array}{c}\text { Universe of Workers } \\
(87,528,336 \text { obs. })\end{array}$} \\
\hline & \multicolumn{9}{|c|}{ Panel A: Employment conditional on being in RAIS } \\
\hline Ever employed in: & & Share & & & Share & & & Share & \\
\hline Public Sector & & $68.6 \%$ & & & $51.9 \%$ & & & $18.6 \%$ & \\
\hline Public Municipal & & $55.7 \%$ & & & $39.2 \%$ & & & $11.3 \%$ & \\
\hline Public State & & $20.9 \%$ & & & $17.9 \%$ & & & $6.7 \%$ & \\
\hline Public Federal & & $4.1 \%$ & & & $5.0 \%$ & & & $2.8 \%$ & \\
\hline Public Permanent & & $49.1 \%$ & & & $35.3 \%$ & & & $13.8 \%$ & \\
\hline Public Temporary & & $41.6 \%$ & & & $32.8 \%$ & & & $8.7 \%$ & \\
\hline \multirow[t]{2}{*}{ Private Sector } & & $62.1 \%$ & & & $75.5 \%$ & & & $91.5 \%$ & \\
\hline & \multicolumn{9}{|c|}{ Panel B: Earnings conditional on employment } \\
\hline Annual Earnings: & Mean & Median & $S D$ & Mean & Median & $S D$ & Mean & Median & $S D$ \\
\hline Public Sector & 12,123 & 7,548 & 117,475 & 17,300 & 10,088 & 41,390 & 13,659 & 7,678 & 62,697 \\
\hline Public Permanent & 12,546 & 7,829 & 132,088 & 18,518 & 10,655 & 47,130 & 14,994 & 8,643 & 52,146 \\
\hline Public Temporary & 10,881 & 6,695 & 57,636 & 14,519 & 8,832 & 23,542 & 8,233 & 4,718 & 94,425 \\
\hline \multirow[t]{3}{*}{ Private Sector } & 7,775 & 4,620 & 29,739 & 10,551 & 4,807 & 70,710 & 7,070 & 4,128 & 61,299 \\
\hline & \multicolumn{9}{|c|}{ Panel C: Occupational category conditional on public employment } \\
\hline & & Share & & & Share & & & Share & \\
\hline Employed as: & All & Permanent & Temporary & All & Permanent & Temporary & All & Permanent & Temporary \\
\hline Manager & $15.8 \%$ & $9.8 \%$ & $31.0 \%$ & $17.8 \%$ & $11.6 \%$ & $29.8 \%$ & $8.2 \%$ & $6.6 \%$ & $13.6 \%$ \\
\hline Professional & $20.5 \%$ & $22.9 \%$ & $14.6 \%$ & $27.0 \%$ & $32.2 \%$ & $17.0 \%$ & $23.4 \%$ & $24.0 \%$ & $21.5 \%$ \\
\hline High Skilled Technical & $16.5 \%$ & $19.1 \%$ & $10.2 \%$ & $13.9 \%$ & $16.8 \%$ & $8.4 \%$ & $20.5 \%$ & $21.5 \%$ & $17.0 \%$ \\
\hline Clerical & $24.0 \%$ & $21.0 \%$ & $31.8 \%$ & $26.8 \%$ & $22.1 \%$ & $35.7 \%$ & $21.6 \%$ & $20.1 \%$ & $26.6 \%$ \\
\hline Blue Collar & $23.1 \%$ & $27.3 \%$ & $12.5 \%$ & $14.5 \%$ & $17.4 \%$ & $9.1 \%$ & $26.3 \%$ & $27.8 \%$ & $21.3 \%$ \\
\hline
\end{tabular}

Notes: The table provides a summary of the labor market careers of political supporters and of the universe of workers in RAIS in the period 1997-2014. See Section 1.3.3 for details on the definition of the variables.

versus 7,070 Reals). ${ }^{54}$ Conditional on being employed in the public sector, earnings of local candidates are on average slightly lower than the earnings in the population (median wages are very similar), while local candidates earn more in the private sector. Consistent with donors belonging to a relatively wealthy group of citizens, their earnings in both the public and the private sector are on average the highest across the three groups of workers.

Figure 1.2 reveals that the public sector careers of political supporters seem affected by the fortunes of the political party that they support. We plot the evolution of supporters'

${ }^{54}$ Appendix Table A.3 presents a more extensive investigation of the public sector wage premium, by comparing log wages in the public and private sector controlling for the worker's job tenure, the worker's age, municipality fixed effects, year fixed effects, and 43 occupations fixed effects. Even after conditioning on job's and worker's characteristics, a public job pays on average $7 \%$ more than a private sector job, with a significant premium in all occupational categories. The wage gap is even larger if we consider hourly wages. 
employment probability in the public sector around the time of a municipal election, from 3 years before to 6 years after the election. Supporters are divided between candidates and donors, and we further differentiate between those who supported the mayor who ends up winning the election and those who supported one of the losing mayoral candidates. Supporters of the party who wins the mayoral elections experience a sharp increase in public sector employment probability that takes place precisely in the year of the election and somewhat dissipates at the end of the term. In the next section, we will use an identification strategy based on close races to identify whether these trends underline a causal relationship between political support and an individual's public sector career. 


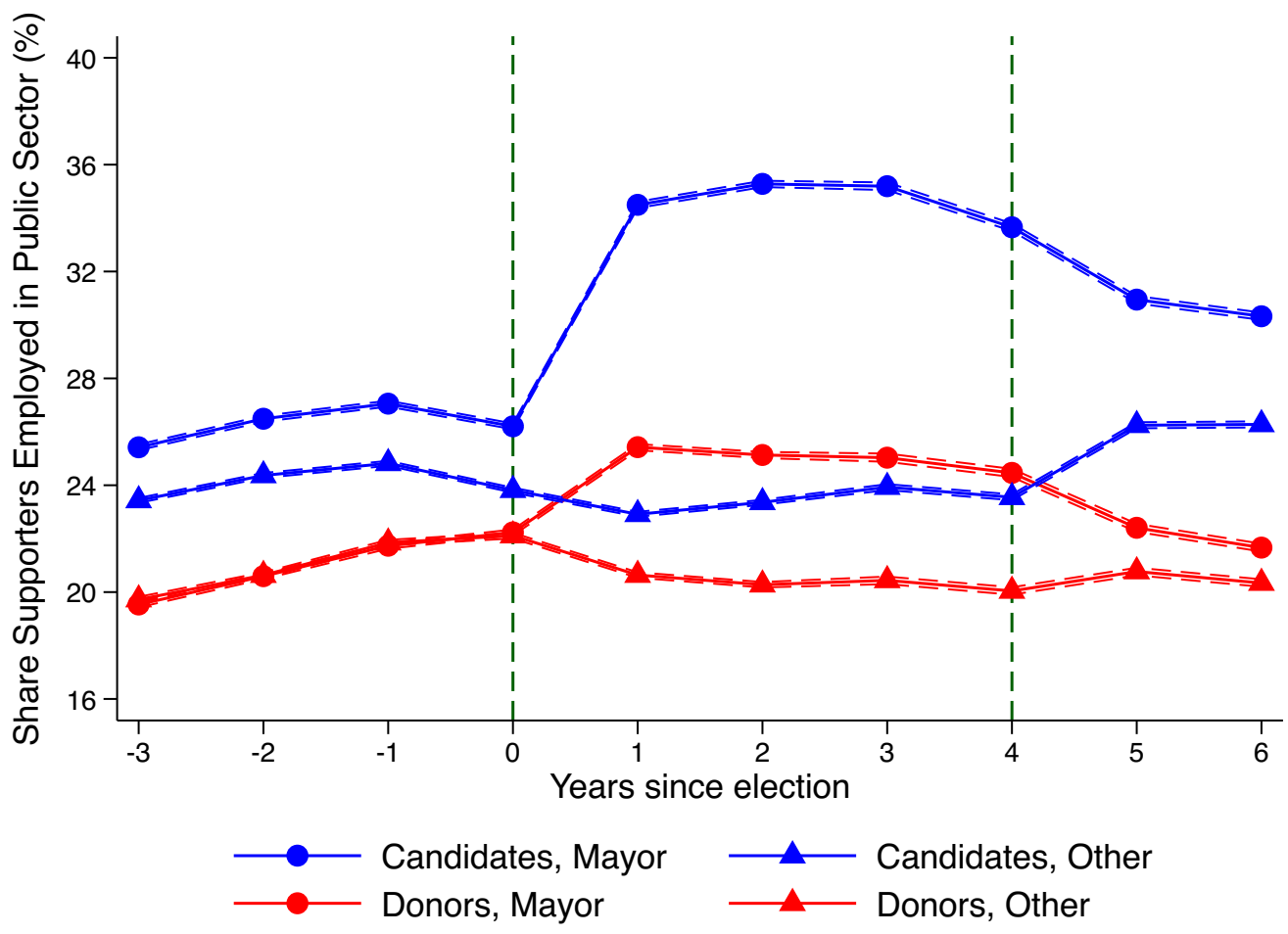

Notes: The figure plots the share of political supporters (of the elected mayor or of one of the parties running against the elected mayor) employed in the public sector from three years before to six years after the municipal election. The sample of supporters is split between candidates who run for a seat in the local council (in blue) and donors (in red). The sample of elections is 2000, 2004, 2008, 2012 for candidates and 2004, 2008, 2012 for donors. The election is held in period 0 and the elected mayor is in power until period 4 . The dotted lines show $95 \%$ confidence intervals around the means. The sample is composed of 508,218 candidates supporting the mayor, 682,206 candidates supporting one of the opposition parties, 522,708 donors supporting the mayor, and 571,595 donors supporting one of the opposition parties.

Figure 1.2: Political Supporters Are More Likely to Be Public Employees When their Party is in Power

\subsection{Measuring Favoritism: Empirical strategy}

\subsubsection{Main Regression Discontinuity Design Estimates}

Our first goal is to estimate the extent of political favoritism in Brazilian public sector employment, that is the causal effect of supporting the party in power on an individual's probability of having a public sector job. In the ideal experiment, we would compare the public sector employment probability of supporters of the party in power, with their 
employment probability in the counterfactual scenario in which they had not been supporters of the party in power. In order to approximate this ideal experiment, we need to find a suitable control group for supporters of the party in power. Clearly, supporters of the party in power are not a random subset of the population. One important source of unobservable heterogeneity is public service motivation: individuals with stronger public service motivation will be more likely to both be employed in the public sector and support a political party.

For this reason, our identification strategy compares the labor market outcomes of supporters (candidates and donors) of the successful mayoral candidate with the outcomes of supporters of the runner-up mayoral candidate who runs in the same election (i.e. in the same municipality and in the same year). While both these groups of individuals are political supporters, the choice of which party to support is not random. For instance, individuals who are actively seeking access to public sector employment may be more likely to decide to support the stronger party in the election. For this reason, we further restrict the sample to elections where the margin of victory of the winning party over the losing party is small. The identification assumption is that, for these very competitive electoral races, whether a party wins or loses the election is "as good as" random. If this assumption holds, then whether a supporter becomes connected to the party in power or to the losing party is also "as good as" random. ${ }^{55}$

In our main specification, we use a local linear regression approach (Gelman and Imbens, 2016) restricting the sample to elections where the winning mayoral candidate has a margin of victory over the runner up of $5 \%$ or less. ${ }^{56}$ We pool all the close elections in our sample

\footnotetext{
${ }^{55}$ This approach is similar to the one used by Fisman et al. (2014), who compare the wealth accumulation of losing and winning politicians who run in the same (very competitive) constituency.

${ }^{56}$ We compute also the optimal bandwidth following the procedure in Calonico et al. (2014). This selection procedure is specific to each outcome and sample, and, in our specifications, it always delivers an optimal bandwidth larger than $5 \%$. In order to maintain the same sample of supporters and elections across all our results, throughout the paper we always use the more conservative $5 \%$ margin of victory cutoff to define an election as "close". Results in the paper appendix show that our estimates are highly robust to the use of the less conservative optimal bandwidths, and to the use of even more conservative bandwidths ( $3 \%$ or $1 \%$ margin of victory).
} 
and include observations for the four years after the municipal election. We estimate the following model:

$$
y_{i k c m t}=\text { BMayor }_{c m t}+\sum_{k=1}^{+4} \theta_{k} M V_{c m t}+\gamma_{k m t}+\epsilon_{i k c m t}
$$

where $y_{i k c m t}$ is the labor market outcome (employment or earnings) of supporter $i$, who supports mayoral candidate $c$ in the election taking place in municipality $m$ and election year $t$, measured $k$ periods (i.e. years) after the election year. $\gamma_{k m t}$ are period-municipalityelection year fixed effects. ${ }^{57} \mathrm{MV} V_{c m t}$ measures the margin of victory of mayoral candidate $c$ over the opponent in the election taking place in municipality $m$ and election year $t .^{58}$ Mayor $_{c m t}$ is an indicator variable that equals one if mayoral candidate $c$ won the election taking place in municipality $m$ and election year $t$, becoming the municipality mayor for the following four years. To extend the RDD approach to our setting, we allow the effect of the running variable $M V_{c m t}$ to vary flexibly over time. The coefficient $\beta$ measures the average treatment effect, namely the average difference in employment probability/earnings, over the four years following the election, between the supporters of the winning mayor and the supporters of the runner-up in the same election. We present results both pooling all supporters (candidates and donors) and estimating the effect separately for the two types of supporters. Throughout the analysis, standard errors are double clustered at the supporter and election level.

In order to document the dynamics of the effect over time (both in the years before and

\footnotetext{
${ }^{57}$ Since candidates can run, and donors can contribute, in multiple elections, each supporter can enter the sample multiple times as part of different "natural experiments." The inclusion of period-municipality-election year fixed effects ensures that the outcomes of supporters of the winning mayor are compared to those of the supporters of the runner-up in the election taking place in the same municipality and same election year (as well as restricting the comparison to the same period relative to the election year, which increases precision). While the inclusion of $\gamma_{k m t}$ increases precision, the validity of the identification assumption of the RDD does not rest on its inclusion, and results are robust to excluding this set of fixed effects from the estimating equation. In $0.4 \%$ of the cases a donor is a supporter of the winning mayor in a municipality, and of the runner-up in a different municipality in the same election year. We do not drop these cases from the analysis and we consider them as both "treated" and "control" observations, depending on the municipality considered. Dropping these few cases from the analysis does not affect the results.

${ }^{58}$ The margin of victory will be positive for supporters of the elected mayor, and negative for supporters of the runner-up mayoral candidate.
} 
after the election), we also estimate the following more flexible specification, in which the treatment effect is allowed to vary over time:

$$
y_{i k c m t}=\sum_{k=-3}^{+4} \beta_{k} \text { Mayor }_{c m t}+\sum_{k=-3}^{+4} \theta_{k} M V_{c m t}+\gamma_{k m t}+\epsilon_{i k c m t}
$$

The coefficients $\beta_{k}$ captures the effect of supporting the party in power on employment probability/earnings $k$ years before/after the year of the election. ${ }^{59}$ We include observations for the three years before the election to document the absence of significant differences in the outcome variables between supporters of the winning mayor and of the runner-up in the years leading up to the election.

The identification assumption of our design is that potential outcomes are continuous around the zero margin of victory cutoff. That is, we assume that, for close electoral races, whether a political supporter ends up being connected to the party in power or to the losing side in the election is essentially random. While the validity of this assumption is ultimately untestable, we can show that supporters of the two sides are similar in observables before the election, which lends credibility to the assumption that the two groups are comparable, except for their different treatment status. Tables 1.3 and 1.4 provide evidence supporting this assumption using information on a wide array of pre-treatment covariates, including labor market outcomes in the election year and in the year before the election, political characteristics, and supporters' demographic characteristics. We find no evidence of discontinuity in pre-treatment covariates at the zero margin of victory cutoff. ${ }^{60}$

\footnotetext{
${ }^{59}$ Differently from a difference-in-differences specification, where one of the coefficients is constrained to zero, this specification estimates the treatment effects for each of the eight years ranging from three years before the election to four years after the election.

${ }^{60}$ Only 2 out of 41 covariates are significantly different between candidates of the two sides, while no covariate is statistically different in the sample of donors.
} 
Table 1.3: Covariates Balance for Candidates

\begin{tabular}{|c|c|c|c|c|c|c|}
\hline $\begin{array}{c}(1) \\
\text { Covariate }\end{array}$ & $\begin{array}{l}(2) \\
\text { Coefficient }\end{array}$ & $\begin{array}{c}(3) \\
\text { P-value }\end{array}$ & $\begin{array}{c}(4) \\
\text { Mean Cont. Group }\end{array}$ & $\begin{array}{c}(5) \\
\text { Observations }\end{array}$ & $\begin{array}{c}(6) \\
\text { Supporters }\end{array}$ & $\begin{array}{c}(7) \\
\text { Elections }\end{array}$ \\
\hline Earnings Public $\mathrm{t}=0$ & 66.332 & 0.389 & 2613 & 254,848 & 233238 & 5413 \\
\hline Earnings Private $\mathrm{t}=0$ & 21.740 & 0.454 & 794.3 & 254,848 & 233238 & 5413 \\
\hline Earnings Total $\mathrm{t}=0$ & 69.593 & 0.407 & 3697 & 254,848 & 233238 & 5413 \\
\hline Employed Private $t=0$ & -0.004 & 0.179 & 0.113 & 254,848 & 233238 & 5413 \\
\hline Employed Public $\mathrm{t}=0$ & 0.008 & 0.14 & 0.255 & 254,848 & 233238 & 5413 \\
\hline Employed Any $\mathrm{t}=0$ & 0.002 & 0.696 & 0.379 & 254,848 & 233238 & 5413 \\
\hline Employed Qualified t=0 & 0.004 & 0.451 & 0.216 & 191,805 & 178993 & 4154 \\
\hline Employed Unqualified $t=0$ & 0.003 & 0.364 & 0.057 & 191,805 & 178993 & 4154 \\
\hline Employed Managerial $\mathrm{t}=0$ & 0.002 & 0.588 & 0.038 & 192,232 & 179338 & 4154 \\
\hline Employed Professional $\mathrm{t}=0$ & $0.005^{* *}$ & 0.037 & 0.057 & 192,232 & 179338 & 4154 \\
\hline Employed HS Technical $t=0$ & -0.000 & 0.829 & 0.045 & 192,232 & 179338 & 4154 \\
\hline Employed Clerical t=0 & -0.001 & 0.862 & 0.063 & 192,232 & 179338 & 4154 \\
\hline Employed Blue Collar $\mathrm{t}=0$ & 0.001 & 0.75 & 0.072 & 192,232 & 179338 & 4154 \\
\hline Earnings Public $\mathrm{t}=-1$ & 95.992 & 0.188 & 2664 & 254,848 & 233238 & 5413 \\
\hline Earnings Private $t=-1$ & 34.461 & 0.234 & 816.5 & 254,848 & 233238 & 5413 \\
\hline Earnings Total $\mathrm{t}=-1$ & 124.925 & 0.111 & 3778 & 254,848 & 233238 & 5413 \\
\hline Employed Private $t=-1$ & -0.000 & 0.97 & 0.118 & 254,848 & 233238 & 5413 \\
\hline Employed Public t=-1 & 0.007 & 0.172 & 0.267 & 254,848 & 233238 & 5413 \\
\hline Employed Any $t=-1$ & 0.007 & 0.16 & 0.396 & 254,848 & 233238 & 5413 \\
\hline Employed Qualified t=-1 & 0.003 & 0.51 & 0.223 & 191,191 & 178466 & 4154 \\
\hline Employed Unqualified $\mathrm{t}=-1$ & 0.003 & 0.318 & 0.062 & 191,191 & 178466 & 4154 \\
\hline Employed Managerial t=-1 & 0.003 & 0.339 & 0.044 & 191,710 & 178881 & 4154 \\
\hline Employed Professional $\mathrm{t}=-1$ & 0.004 & 0.126 & 0.055 & 191,710 & 178881 & 4154 \\
\hline Employed HS Technical $t=-1$ & 0.000 & 0.884 & 0.046 & 191,710 & 178881 & 4154 \\
\hline Employed Clerical $t=-1$ & -0.001 & 0.656 & 0.069 & 191,710 & 178881 & 4154 \\
\hline Employed Blue Collar t=-1 & 0.001 & 0.724 & 0.071 & 191,710 & 178881 & 4154 \\
\hline Mincer Sample & 0.004 & 0.242 & 0.264 & 254,848 & 233238 & 5413 \\
\hline Mincer Ability & -0.065 & 0.478 & -0.681 & 67,445 & 63423 & 5060 \\
\hline Secondary School & -0.002 & 0.7 & 0.216 & 252,805 & 231500 & 5413 \\
\hline High School & -0.002 & 0.639 & 0.347 & 252,805 & 231500 & 5413 \\
\hline University Degree & $0.008^{* *}$ & 0.015 & 0.147 & 252,805 & 231500 & 5413 \\
\hline
\end{tabular}


Table 1.3 (continued): Covariates Balance for Candidates

\begin{tabular}{lcccccc}
\hline \multicolumn{1}{c}{$\begin{array}{c}(1) \\
\text { Covariate }\end{array}$} & $\begin{array}{c}(2) \\
\text { Coefficient }\end{array}$ & $\begin{array}{c}(3) \\
\text { P-value }\end{array}$ & $\begin{array}{c}(4) \\
\text { Mean Cont. Group }\end{array}$ & $\begin{array}{c}(5) \\
\text { Observations }\end{array}$ & $\begin{array}{c}(6) \\
\text { Supporters }\end{array}$ & $\begin{array}{c}(7) \\
\text { Elections }\end{array}$ \\
\hline Age & 0.075 & 0.457 & 43.44 & 254,676 & 233092 & 5411 \\
Male & 0.000 & 0.929 & 0.762 & 254,824 & 233216 & 5413 \\
Run Past Election & -0.000 & 0.993 & 0.343 & 254,848 & 233238 & 5413 \\
Incumbent & -0.002 & 0.651 & 0.129 & 254,848 & 233238 & 5413 \\
Party Already in Power & 0.013 & 0.457 & 0.354 & 194,252 & 180895 & 4154 \\
Governor Party & 0.005 & 0.819 & 0.220 & 254,848 & 233238 & 5413 \\
Fed. Government Party & 0.014 & 0.321 & 0.483 & 254,848 & 233238 & 5413 \\
President Party & 0.012 & 0.472 & 0.109 & 254,848 & 233238 & 5413 \\
Contributions Received & 98.115 & 0.395 & 2111 & 194,252 & 180895 & 4154 \\
Contributions Spent & 94.133 & 0.413 & 2105 & 194,252 & 180895 & 4154 \\
\hline
\end{tabular}

Notes: The table shows balance tests for candidates' covariates in the pre-election period. The coefficients and p-values in columns 2 and 3 are from regressions of the covariate in column 1 on an indicator for treatment status (supporting the winning mayor), controlling for margin of victory and including election (i.e. municipality times election year) fixed effects, focusing on mayoral races decided by a margin of victory of $5 \%$ or less. Column 4 reports the mean of the covariate in the control group, namely among supporters of the runner-up mayoral candidate. Earnings Public/Private/Total are annual earnings in the public, private, and formal economy, respectively, in the year of the election $(\mathrm{t}=0)$ or the year before the election ( $\mathrm{t}=-1)$. Employed Public/Private/Any are indicators taking value one if the supporter is employed in the public, private, and formal economy, respectively, in the year of the election $(\mathrm{t}=0)$ or the year before the election $(\mathrm{t}=-1)$. Employed Managerial/Professional/HS Technical/Clerical/Blue Collar are indicators taking value one if the supporter is employed in a public sector occupation in the specific category, in the year of the election $(\mathrm{t}=0)$ or the year before the election ( $\mathrm{t}=-1)$. Employed Qualified/Unqualified are indicators taking value one if the supporters is employed in a public sector job for which she is qualified/unqualified in terms of education, in the year of the election $(t=0)$ or the year before the election ( $t=-1)$. Mincer Sample is an indicator taking value one if the supporter was ever employed in the private sector before her first election. Mincer Ability is a continuous measure of ability derived using the approach described in section 1.6.4. Secondary School, High School, and University Degree are indicators taking value one if the supporter's highest level of education is secondary school, high school, or university, respectively. Age is the supporters' age at the time of the election. Male is an indicator for the supporter being male. Run Past Election is an indicator taking value one if the candidate run also in the previous election. Incumbent is an indicator taking value one if the candidate had a seat in the municipal council at the time of the election. Party Already in Power, Governor Party, Fed. Government Party, President Party are indicators taking value one if the candidate's party is in the ruling coalition in power in the municipality at the time of the election, is the same as the state governor's party, is in the coalition of parties in the federal government, is the party of the Federal President, respectively. Contributions Received are the amount of contributions received by the candidate. Contributions Spent are the amount of contributions spent by the candidate in the race. P-values are based on standard errors clustered at the election level. ${ }^{* * *} \mathrm{p}<0.01,{ }^{* *} \mathrm{p}<0.05,{ }^{*}$ $\mathrm{p}<0.1$. 
Table 1.4: Covariates Balance for Donors

\begin{tabular}{|c|c|c|c|c|c|c|}
\hline $\begin{array}{c}(1) \\
\text { Covariate }\end{array}$ & $\begin{array}{c}(2) \\
\text { Coefficient }\end{array}$ & $\begin{array}{c}(3) \\
\text { P-value }\end{array}$ & $\begin{array}{c}(4) \\
\text { Mean Cont. Group }\end{array}$ & $\begin{array}{c}\text { (5) } \\
\text { Observations }\end{array}$ & $\begin{array}{c}(6) \\
\text { Supporters }\end{array}$ & $\begin{array}{c}(7) \\
\text { Elections }\end{array}$ \\
\hline Earnings Public $\mathrm{t}=0$ & 181.207 & 0.404 & 3211 & 180,886 & 177590 & 3162 \\
\hline Earnings Private $t=0$ & -42.408 & 0.594 & 1481 & 180,886 & 177590 & 3162 \\
\hline Earnings Total $t=0$ & -2.222 & 0.993 & 5344 & 180,886 & 177590 & 3162 \\
\hline Employed Private $t=0$ & -0.001 & 0.857 & 0.192 & 180,886 & 177590 & 3162 \\
\hline Employed Public t=0 & 0.010 & 0.342 & 0.222 & 180,886 & 177590 & 3162 \\
\hline Employed Any $\mathrm{t}=0$ & 0.009 & 0.359 & 0.423 & 180,886 & 177590 & 3162 \\
\hline Employed Qualified t=0 & 0.007 & 0.496 & 0.183 & 180,040 & 176783 & 3162 \\
\hline Employed Unqualified $t=0$ & 0.003 & 0.342 & 0.035 & 180,040 & 176783 & 3162 \\
\hline Employed Managerial $t=0$ & 0.006 & 0.287 & 0.044 & 180,463 & 177178 & 3162 \\
\hline Employed Professional t=0 & -0.001 & 0.866 & 0.06 & 180,463 & 177178 & 3162 \\
\hline Employed HS Technical $t=0$ & 0.002 & 0.458 & 0.029 & 180,463 & 177178 & 3162 \\
\hline Employed Clerical $\mathrm{t}=0$ & 0.001 & 0.758 & 0.056 & 180,463 & 177178 & 3162 \\
\hline Employed Blue Collar $\mathrm{t}=0$ & 0.002 & 0.473 & 0.032 & 180,463 & 177178 & 3162 \\
\hline Earnings Public $\mathrm{t}=-1$ & 130.829 & 0.517 & 3013 & 180,886 & 177590 & 3162 \\
\hline Earnings Private $t=-1$ & -117.652 & 0.126 & 1487 & 180,886 & 177590 & 3162 \\
\hline Earnings Total $\mathrm{t}=-1$ & -151.033 & 0.539 & 5116 & 180,886 & 177590 & 3162 \\
\hline Employed Private $t=-1$ & -0.002 & 0.802 & 0.198 & 180,886 & 177590 & 3162 \\
\hline Employed Public t=-1 & 0.010 & 0.336 & 0.220 & 180,886 & 177590 & 3162 \\
\hline Employed Any t=-1 & 0.006 & 0.496 & 0.427 & 180,886 & 177590 & 3162 \\
\hline Employed Qualified t=-1 & 0.008 & 0.372 & 0.181 & 180,052 & 176800 & 3162 \\
\hline Employed Unqualified $t=-1$ & 0.001 & 0.63 & 0.036 & 180,052 & 176800 & 3162 \\
\hline Employed Managerial t=-1 & 0.006 & 0.31 & 0.045 & 180,497 & 177210 & 3162 \\
\hline Employed Professional t=-1 & 0.002 & 0.647 & 0.057 & 180,497 & 177210 & 3162 \\
\hline Employed HS Technical $t=-1$ & -0.000 & 0.893 & 0.029 & 180,497 & 177210 & 3162 \\
\hline Employed Clerical $t=-1$ & 0.000 & 0.917 & 0.055 & 180,497 & 177210 & 3162 \\
\hline Employed Blue Collar t=-1 & 0.002 & 0.348 & 0.031 & 180,497 & 177210 & 3162 \\
\hline Mincer Sample & 0.002 & 0.745 & 0.384 & 180,886 & 177590 & 3162 \\
\hline Mincer Ability & -0.481 & 0.107 & 0.320 & 68,134 & 67243 & 2828 \\
\hline Party Already in Power & 0.039 & 0.367 & 0.435 & 180,886 & 177590 & 3162 \\
\hline Governor Party & 0.005 & 0.909 & 0.208 & 180,886 & 177590 & 3162 \\
\hline Fed. Government Party & 0.039 & 0.457 & 0.546 & 180,886 & 177590 & 3162 \\
\hline President Party & 0.030 & 0.475 & 0.119 & 180,886 & 177590 & 3162 \\
\hline Amount of Contributions & -17.667 & 0.842 & 1387 & 180,886 & 177590 & 3162 \\
\hline
\end{tabular}

Notes: The table shows balance tests for donors' covariates in the pre-election period. The coefficients and p-values in columns 2 and 3 are from regressions of the covariate in column 1 on an indicator for treatment status (supporting the winning mayor), controlling for margin of victory and including election (i.e. municipality times election year) fixed effects, focusing on mayoral races decided by a margin of victory of $5 \%$ or less. Column 4 reports the mean of the covariate in the control group, namely among supporters of the runner-up mayoral candidate. Amount of Contributions is the donor's amount contributed to the party and coalition of the supported mayor. See Table 1.3 for a description of the other covariates listed in column 1. P-values are based on standard errors clustered at the election level. ${ }^{* * *} \mathrm{p}<0.01,{ }^{* *} \mathrm{p}<0.05,{ }^{*} \mathrm{p}<0.1$. 


\subsubsection{The Effect of Gaining Versus Losing a Connection}

While the estimates from equations 1.1 and 1.2 measure the causal effect of being a supporter of the party in power on post-election public sector outcomes, they do not allow us to fully capture the labor market dynamics behind the effect. In particular, when a supporter gains a political connection, we expect her to experience a higher probability of hiring in the public sector (if she was not already employed in the public sector). Similarly, when a supporter loses a political connection, she will be more likely to lose her public sector job (if she had one) ${ }^{61}$ By measuring the average difference in outcomes between supporters of the two sides in the post-election period, estimates from equations 1.1 and 1.2 cannot capture these dynamics.

To separately identify the effect on public sector employment of gaining a political connection and the effect of losing one, we estimate two additional equations of the form:

$$
y_{i k c m p t}=\sum_{k=-3}^{+4} \beta_{k} S h o c k_{c m t}+\sum_{k=-3}^{+4} \theta_{k}^{1} M V_{c m t}+\sum_{k=-3}^{+4} \theta_{k}^{2} M V_{c m t} S h o c k_{c m t}+\gamma_{k p t}+\delta_{i p t}+\epsilon_{i k c m t}
$$

where $p$ indexes the party of supporter $i, \gamma_{k p t}$ are period-party-election year fixed effects, and $\delta_{i p t}$ are supporter-party-election year fixed effects.

In the first exercise, we restrict the sample to political supporters of a party that was not in the coalition in power in the municipality in the previous election cycle. We compare the labor market outcomes of those whose supported mayor wins the election $\left(\operatorname{Shock}_{c m t}=1\right)$ with the labor market outcomes of supporters of the same party but whose supported mayor loses the election $\left(S_{\text {hock }} c_{c m t}=0\right.$ ). This exercise allows us to identify the change in public sector outcomes that takes place when a political supporter gains a connection to the party in power. The inclusion of period-party-election year fixed effects restrict the comparison to individuals who support the same party in the same election year, and with the inclusion of

\footnotetext{
${ }^{61}$ The two effects will be symmetric if hired supporters keep their job only until their party maintains power. Alternatively, some hired supporters could manage to keep their job beyond the period of tenure of their party, resulting in an effect of gaining a connection which is larger (in absolute terms) than the effect of losing one.
} 
supporter-party-election year fixed effects we exploit only within-supporter variation over time. We normalize the coefficient $\beta_{0}$ to zero, so that $\beta_{k}$ measures the change in employment probability in period $k$ relative to the election year, for individuals in municipalities where the supported mayor wins the election versus the change for individuals in municipalities where the supported mayor loses the election. ${ }^{62}$

In a similar vein, in the second exercise we restrict the sample to political supporters of a party that was already in the coalition in power in the municipality in the previous election cycle. We compare the labor market outcomes of those whose supported mayor loses the election $\left(\right.$ Shock $\left._{c m t}=1\right)$ with the labor market outcomes of supporters of the same party but whose supported mayor wins the election $\left(\right.$ Shock $\left._{c m t}=0\right)$. This exercise allows us to identify the change in public sector outcomes that takes place when a political supporter loses a connection to the party in power. ${ }^{63}$

\subsubsection{Difference-in-differences Estimates: Non-Supporters as Control Group}

Our regression discontinuity design uses supporters of the losing mayoral candidate as a control group for supporters of the elected mayor. While this ensures that we are comparing individuals with similar pre-treatment unobservable characteristics, it also raises two potential concerns. First, supporters of the runner-up could be punished for their opposition to the mayor and find it more difficult to enter the public sector relative to the counterfactual scenario in which they were not supporters of any party. If this is the case, our estimate of political favoritism would include this additional "punishment" effect. ${ }^{64}$

Second, political supporters of the runner-up party could be more likely to turn down

\footnotetext{
${ }^{62}$ The estimation of equation 1.3 uses only elections in the 2004, 2008 and 2012 election cycles. We do not use elections from the 2000 election cycle as we do not have information on the parties belonging to the coalition in power in a municipality in the $1997-2000$ period.

${ }^{63}$ The identifying assumption of these two similar empirical designs is once again that, for the supporters in both specifications, potential outcomes are continuous around the zero margin of victory cutoff. Appendix Tables A.4, A.5, A.6 and A.7 provide evidence supporting this assumption.

${ }^{64}$ See Labonne and Fafchamps (2017) for a discussion of this point in the context of local elections in the Philippines.
} 
offers of employment in the public sector because of an ideological aversion to the party in power. If this is the case, then our estimates would not merely capture a demand side effect (the mayor granting preferential access to her own supporters), but also a supply side effect (supporters of the losing side being less likely to apply to a public sector job, or more likely to turn down offers of employment).

To evaluate whether these two factors play a major role in our estimates, we can use individuals who were not supporters of any party as a control group, in a differencein-differences design. Under the assumption of no time-varying heterogeneity between supporters of the mayor and non-supporters, we can estimate the causal impact of providing political support to the party in power relative to the counterfactual scenario in which no party was supported.

For each municipality and each election year, we use as a control group all individuals who appear in the RAIS dataset as employed in the municipality in the years before the election. We use as treated group political supporters of a party that was not in the coalition in power in the municipality in the previous election cycle, as in the specification of section 1.4.2. ${ }^{65}$ Therefore, in the pre-election period neither group of individuals is connected to the party in power in the municipality. In order to compare the magnitude from the difference-in-differences model to our regression discontinuity design, we again focus only on election decided by a margin of victory of $5 \%$ or less. ${ }^{66}$

We estimate the following difference in differences specification, using observations from 3 years before to 4 years after the election:

$$
y_{i k m t}=\sum_{k=-3}^{+4} \beta_{k} \text { Mayor }_{i m t}+\gamma_{k m t}+\delta_{i m t}+\epsilon_{i k m t}
$$

Where $i$ indexes an individual, $m$ indexes a municipality, $t$ indexes an election-year, and $k$ indexes the year relative to the election. $\gamma_{k m t}$ are period-municipality-election year

\footnotetext{
${ }^{65}$ As for the strategy described in that section, we do not use the 2000 election cycle.

${ }^{66}$ As for the control group, also for supporters of the party in power we restrict the attention only to those who appear in the RAIS dataset as employed in the municipality in the years before the election.
} 
fixed effects and $\delta_{i m t}$ are individual-municipality-election year fixed effects. We normalize the coefficient $\beta_{0}$ to zero, so that each coefficient $\beta_{k}$ captures the effect of being a political supporter of the party in power (as opposed to not being a supporter of any party) in year $k$ relative to the election.

In order to measure the average treatment effect, we also estimate the following more parsimonious equation:

$$
y_{i k m t}=\beta^{D I D} \text { Mayor }_{i m t} * \text { Post }_{k m t}+\gamma_{k m t}+\delta_{i m t}+\epsilon_{i k m t}
$$

in which the indicator variable Mayor M $_{i m t}$ is interacted with the variable Post $_{k m t}$, an indicator taking value one for the post-election period.

\subsection{Estimates of Favoritism in Public Sector Employment}

\subsubsection{Main Regression Discontinuity Estimates}

Table 1.5 shows the results of the estimation of equation (1.1), pooling all supporters and separately differentiating between candidates and donors. Figure 1.3 shows the results of the estimation of equation (1.2), while Figure 1.4 reports a non-parametric representation of the results by plotting the dynamics of mean public sector outcomes for supporters of the two sides. ${ }^{67}$

We estimate a large and statistically significant impact of supporting the party in power on the probability of being employed in the public sector and on annual public sector earnings. The estimates of Table 1.5 provide the average causal effect pooling all postelection periods: supporters of the winning mayoral candidate are 10.5 percentage points more likely to have a public sector job in the post-election period $-47 \%$ more likely than the supporters of the runner-up mayoral candidate. The effect is sizable for both groups of supporters: a 51\% higher probability for candidates and a 33\% higher probability for

\footnotetext{
${ }^{67}$ Appendix Tables A.8, A.9, and A.10 present results when we use a local linear regression using the optimal bandwidth selection procedure following (Calonico et al., 2014), or restricting the margin of victory to define an election as "close" to $3 \%$ or $1 \%$.
} 
donors. ${ }^{68}$ As shown in Figures 1.3 and 1.4, the effect fully materializes at the time of the election and it persists for the whole post-election period. These effects translate into a significant increase in public sector earnings: relative to the supporters of the runner-up mayoral candidate, candidates supporting the winning mayor have earnings that are $53 \%$ higher, and donors have earnings that are $29 \%$ higher. ${ }^{69} 70$

Table 1.5: Effect of Supporting the Winning Party on Public Sector Outcomes

\begin{tabular}{|c|c|c|c|c|c|c|}
\hline \multirow{3}{*}{$\begin{array}{l}\text { Dependent Variable: } \\
\text { Group of Supporters: }\end{array}$} & $(1)$ & (2) & (3) & (4) & (5) & (6) \\
\hline & \multicolumn{3}{|c|}{ Employed Public } & \multicolumn{3}{|c|}{ Earnings Public } \\
\hline & All & Candidates & Donors & All & Candidates & Donors \\
\hline Mayor & $\begin{array}{c}0.105^{* * *} \\
(0.005)\end{array}$ & $\begin{array}{c}0.124^{* * *} \\
(0.005)\end{array}$ & $\begin{array}{c}0.067^{* * *} \\
(0.009)\end{array}$ & $\begin{array}{c}1,224.376^{* * *} \\
(94.321)\end{array}$ & $\begin{array}{c}1,369.761^{* * *} \\
(74.758)\end{array}$ & $\begin{array}{c}858.287^{* * *} \\
(188.512)\end{array}$ \\
\hline Observations & $1,447,538$ & 867,888 & 550,832 & $1,447,538$ & 867,888 & 550,832 \\
\hline R-squared & 0.322 & 0.358 & 0.296 & 0.208 & 0.239 & 0.207 \\
\hline Mean D.V. Runner-up & 0.225 & 0.241 & 0.199 & 2702 & 2565 & 2935 \\
\hline Supporters & 418146 & 233238 & 177590 & 418146 & 233238 & 177590 \\
\hline Elections & 5419 & 5413 & 3162 & 5419 & 5413 & 3162 \\
\hline
\end{tabular}

Notes: The table presents the estimated coefficients of $\beta$ from equation (1.1) using as dependent variable an indicator for employment in the public sector (columns 1-3) and public sector earnings (columns 4-6). Results in columns (1) and (4) are estimated on the sample of all supporters. Results in columns (2) and (5) are estimated on the sample of candidates to the local council, and results in columns (3) and (6) are estimated on the sample of donors. See section 1.3.3 for a description of the outcome variables. The sample is composed of supporters of the winning mayoral candidate or the close loser, using a 5\% margin of victory to define close races. The sample of elections is 2000, 2004, 2008, 2012 in columns 1, 2, 4, 5, and 2004, 2008, 2012 in columns 3, 6. "Mean D.V. Runner-up" shows the average of the dependent variable for the supporters of the runner-up in the post-election period. Robust standard errors are shown in parentheses and are double clustered at the supporter and election level. ${ }^{* * *} \mathrm{p}<0.01,{ }^{* *} \mathrm{p}<0.05,{ }^{*} \mathrm{p}<0.1$.

${ }^{68}$ As shown in Appendix Table A.11, we estimate a sizable presence of patronage in all election years over the 2000-2012 period.

${ }^{69}$ While we take the electoral coalition as our unit of analysis, one may wonder whether the effect is present only, or mainly, for supporters of the same party of the elected mayor. In Appendix Table A.12 we find that all supporters enjoy a significant preferential treatment. Among candidates, those of the same party of the mayor benefits more, but the effect is sizable also for those belonging to a different party in the mayor's coalition. Among donors, the largest treatment effect is for those who contributed to the mayor directly, but we find large and significant effects also among those who contributed to other candidates in the mayor's party or coalition.

${ }^{70}$ As shown in Appendix Table A.13, most of the effect for candidates is driven by those who fail to win a council seat. However, the effect is significant also for the subset of candidates elected to the council, consistent with the part-time nature of the job as local councilor, which allows successful candidates to have also a job in the public sector. These results can suggest the presence of an informal within-coalition insurance. Candidates may spend considerable financial resources as well as time in the race, and can therefore be attracted to politics by the promise of a public sector job in the negative state of the world in which they do not win a council seat, while they are automatically rewarded with the political wage and other perks from office if they are elected. 
(a) Candidates' Employment Probability

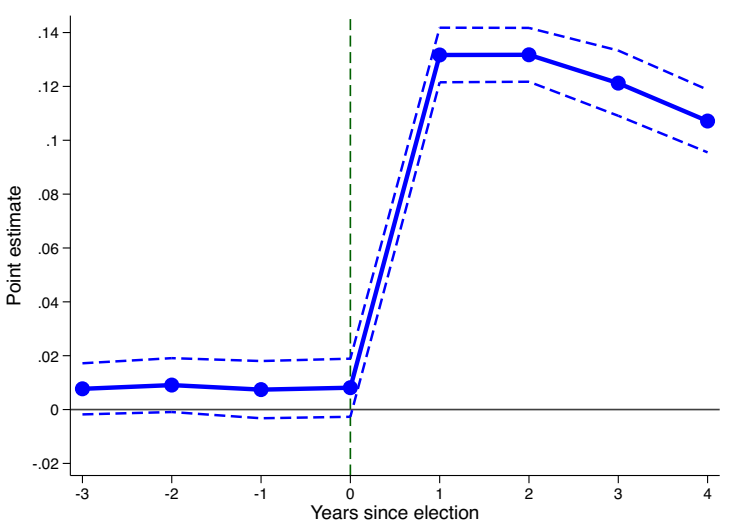

(c) Candidates' Earnings

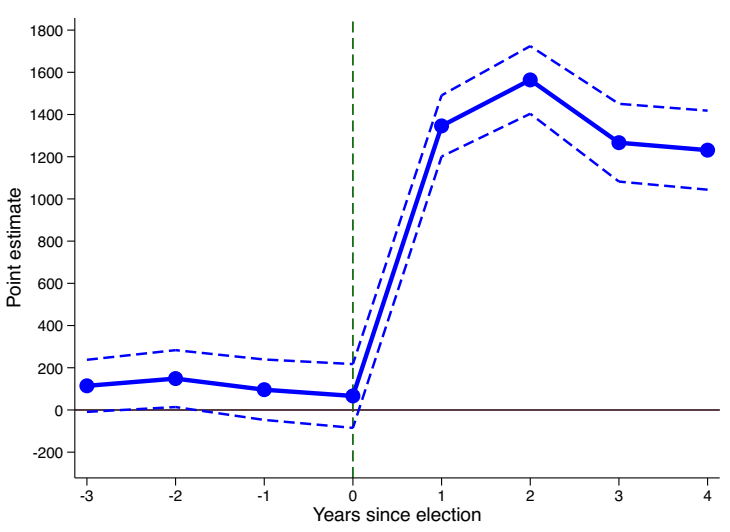

(b) Donors' Employment Probability

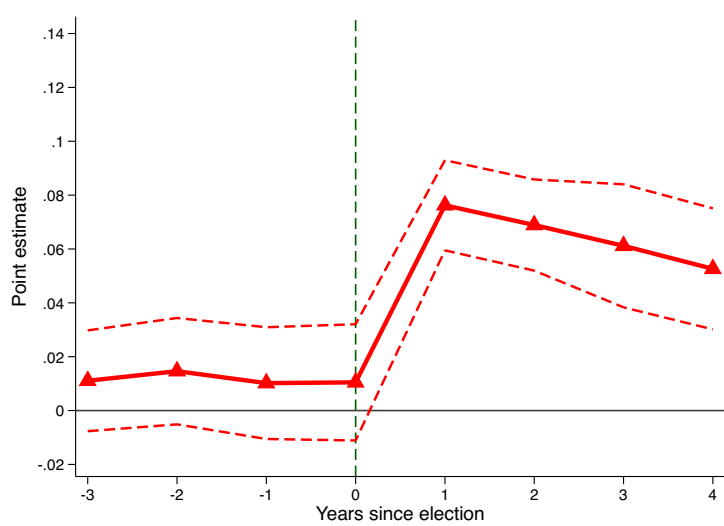

(d) Donors' Earnings

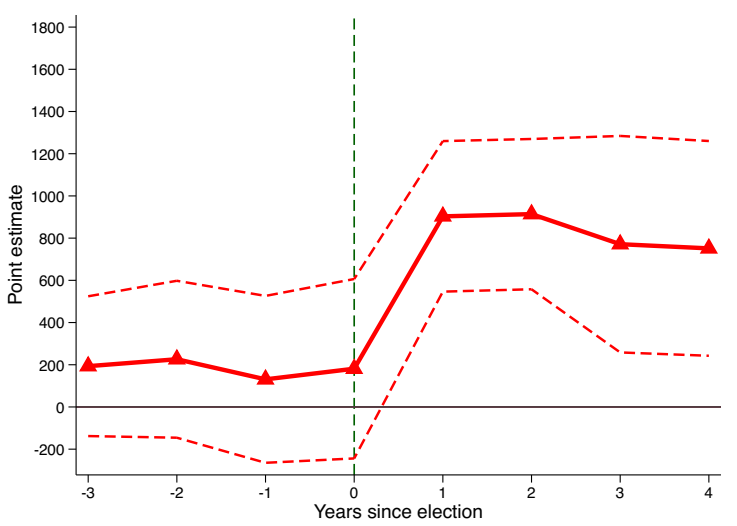

Notes: The figure presents the estimated effect of supporting the winning party on probability of employment in the public sector (top panels) and annual public sector earnings (bottom panels). The figure shows the dynamics of the regression discontinuity design estimates over time, by plotting the estimated $\beta_{k}$ coefficients from equation (1.2). Panels ( $a$ ) and (c) present estimates from the sample of candidates, while panels $(b)$ and (d) present estimates from the sample of donors. See section 1.3.3 for a description of the outcome variables. The sample of elections is 2000,2004, 2008, 2012 for candidates and 2004, 2008, 2012 for donors. The sample is composed of supporters of the winning mayoral candidate or the close loser, using a $5 \%$ margin of victory to define close races. The sample of candidates includes 233,238 supporters across 5,413 elections. The sample of donors includes 177,590 supporters across 3,162 elections. The dotted lines show $95 \%$ confidence intervals and are based on standard errors double clustered at the supporter and election level.

Figure 1.3: Effect of Supporting the Winning Party on Public Sector Outcomes - Dynamics of the Effect 
(a) Candidates' Employment Probability

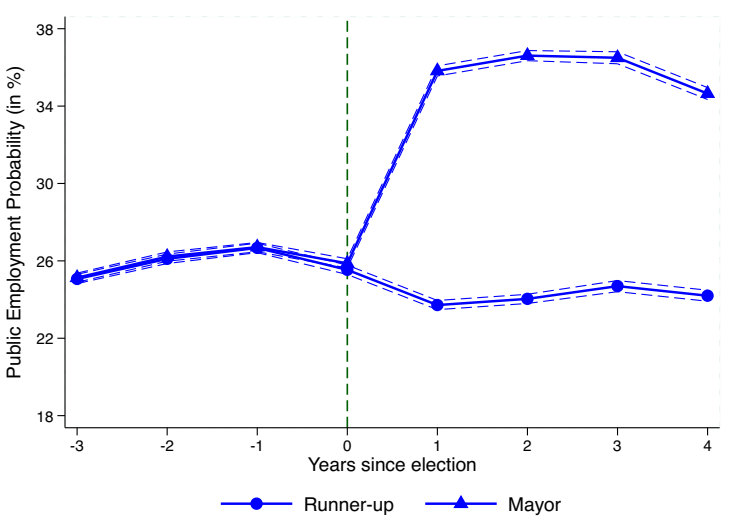

(c) Candidates' Earnings

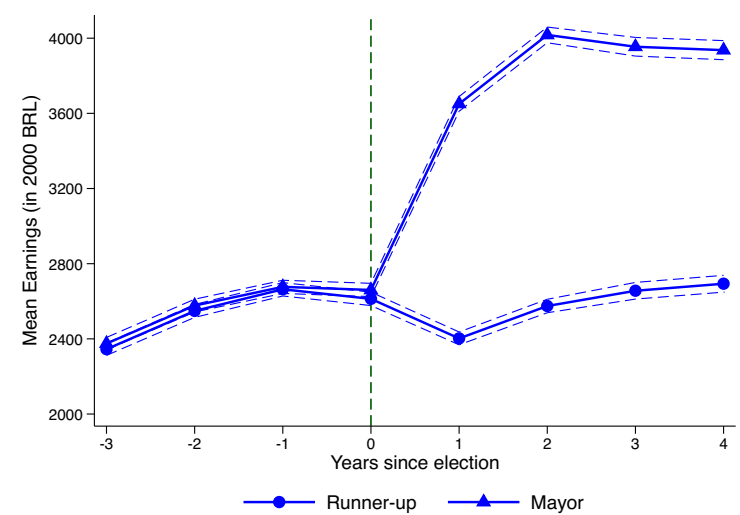

(b) Donors' Employment Probability

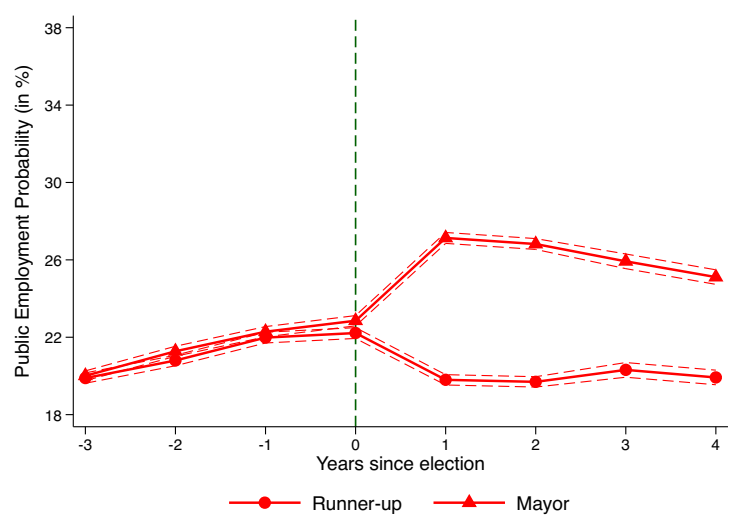

(d) Donors' Earnings

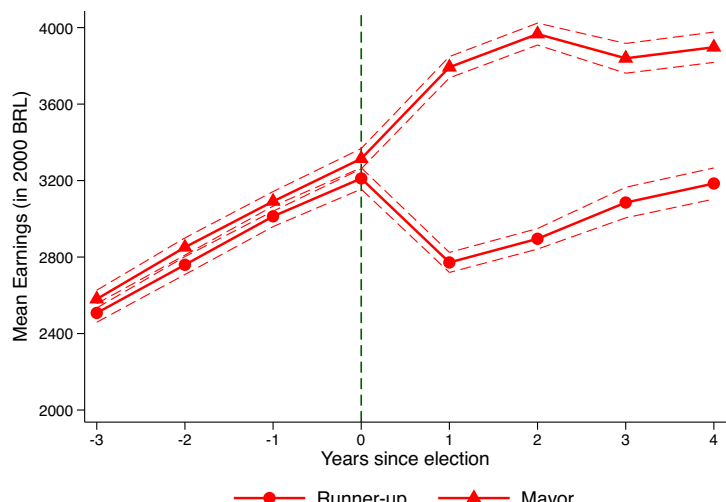

Notes: The figure shows the trends in mean public sector outcomes from three years before to four years after the election, for supporters of the winning mayoral candidate or the close loser, using a 5\% margin of victory to define close races. Panels ( $a$ ) and (b) focus on public sector employment probability for the subsample of candidates to the local council and of donors, respectively. Panels (c) and (d) focus on public sector earnings (in 2000 BRL) for the subsample of candidates to the local council and of donors, respectively. The samples are composed of 233,238 candidates across 5,413 elections, and 177,590 donors across 3,162 elections. See section 1.3.3 for a description of the outcome variables. The sample of elections is 2000, 2004, 2008, 2012 for candidates and 2004, 2008, 2012 for donors. The dotted lines show 95\% confidence intervals around the mean.

Figure 1.4: Trends in Political Supporters' Mean Public Sector Outcomes Around the Election

Figure 1.5 shows the discontinuous jump in public sector employment probability after the election that takes place at the zero margin of victory cutoff, for candidates (Panel A) and donors (Panel B). Interestingly, the effect looks largely independent of the distance from the zero margin of victory cutoff. While differences between supporters of the two 
sides cannot be interpreted as causal as we move far away from the discontinuity, the figure suggests that the effect that we uncover is likely to generalize to municipalities where the mayoral race was decided by larger vote margins.

This preferential access to public sector jobs translate into a net increase in supporters' labor market earnings. Panel A of Table 1.6 shows only a limited crowding out effect of supporting the winning mayor on supporters' private sector earnings (a 9.5\% reduction relative to supporters of the runner-up) and employment probability (a 14.8\% reduction relative to supporters of the runner-up). As a consequence, Panel B shows that there is a sizable net increase in earnings in the formal economy for supporters of the winning mayor: total annual earnings in the formal economy are 34\% higher for candidates in the winning coalition and $10 \%$ higher for donors in the winning coalition. 
(a) Candidates

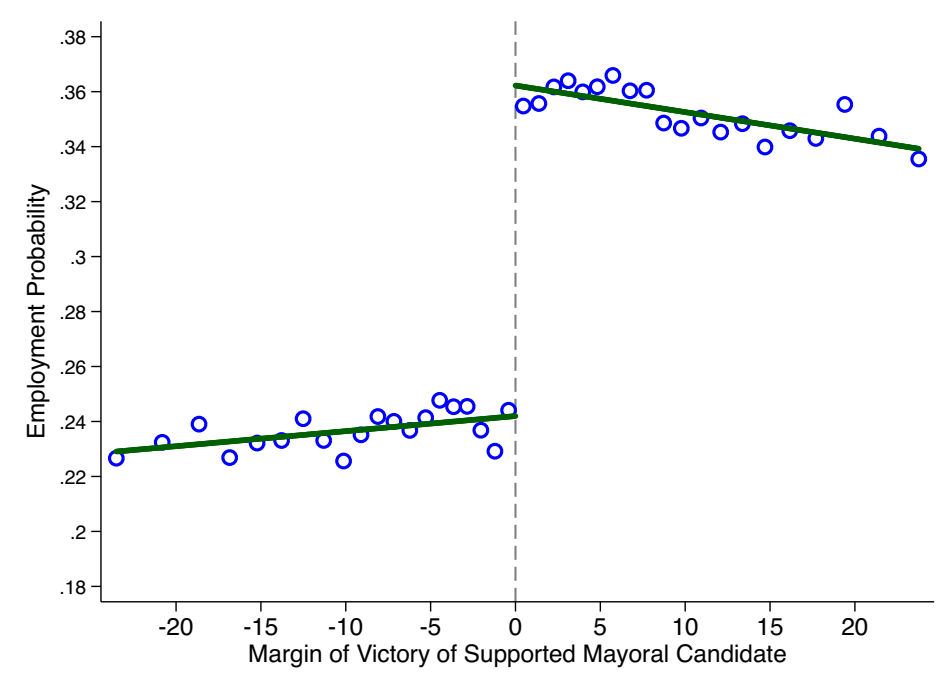

(b) Donors

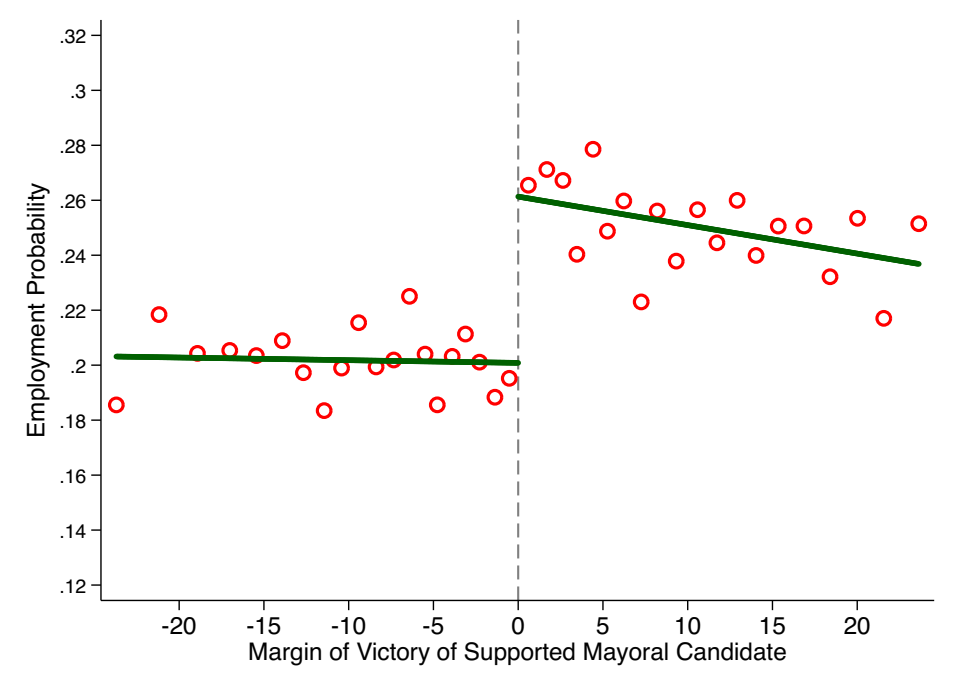

Notes: The figure shows the average public sector employment probability in the 4 years after the election, by bins of the margin of victory of the mayoral candidate supported over the opponent. Supporters whose supported mayoral candidate lost have a negative margin of victory, while supporters of the winning mayoral candidate have a positive margin of victory. Panel A focuses on the sample of candidates, and Panel $B$ focuses on the sample of donors. The best-fit lines on both sides of the discontinuity are computed on the underlying data. The sample of elections is 2000, 2004, 2008, 2012 for the sample of candidates and 2004, 2008, 2012 for the sample of donors.

Figure 1.5: Post-Election Public Sector Employment Probability Around the Discontinuity Cutoff

Since our data have information on the specific job within the public sector obtained by 
Table 1.6: Effect of Supporting the Winning Party on Formal Sector Employment

\begin{tabular}{|c|c|c|c|c|c|c|}
\hline \multicolumn{7}{|l|}{ Panel A: Private Sector } \\
\hline & $(1)$ & $(2)$ & (3) & $(4)$ & (5) & $(6)$ \\
\hline \multirow{2}{*}{$\begin{array}{l}\text { Dependent Variable: } \\
\text { Group of Supporters: }\end{array}$} & \multicolumn{3}{|c|}{ Employed Private Sector } & \multicolumn{3}{|c|}{ Earnings Private Sector } \\
\hline & All & Candidates & Donors & All & Candidates & Donors \\
\hline \multirow[t]{2}{*}{ Mayor } & $-0.023^{* * *}$ & $-0.026^{* * *}$ & $-0.016^{* *}$ & $-110.537^{* * *}$ & $-97.927^{* * *}$ & $-145.062^{*}$ \\
\hline & $(0.003)$ & $(0.003)$ & $(0.007)$ & $(35.889)$ & $(27.366)$ & $(84.661)$ \\
\hline R-squared & 0.192 & 0.164 & 0.242 & 0.112 & 0.101 & 0.146 \\
\hline \multirow{3}{*}{$\begin{array}{l}\text { Mean D.V. Runner-up } \\
\text { Panel B: Formal Sector }\end{array}$} & 0.155 & 0.125 & 0.204 & 1155 & 876.9 & 1606 \\
\hline & & & & & & \\
\hline & $(1)$ & $(2)$ & (3) & (4) & (5) & $(6)$ \\
\hline \multirow{2}{*}{$\begin{array}{l}\text { Dependent Variable: } \\
\text { Group of Supporters: }\end{array}$} & \multicolumn{3}{|c|}{ Employed Any Job } & \multicolumn{3}{|c|}{ Total Earnings } \\
\hline & All & Candidates & Donors & All & Candidates & Donors \\
\hline \multirow[t]{2}{*}{ Mayor } & $0.075^{* * *}$ & $0.090^{* * *}$ & $0.046^{* * *}$ & $1,077.973^{* * *}$ & $1,281.960^{* * *}$ & $533.717^{* *}$ \\
\hline & $(0.004)$ & $(0.005)$ & $(0.008)$ & $(118.237)$ & $(82.704)$ & $(252.499)$ \\
\hline R-squared & 0.456 & 0.463 & 0.467 & 0.261 & 0.280 & 0.274 \\
\hline Mean D.V. Runner-up & 0.389 & 0.376 & 0.413 & 4322 & 3749 & 5262 \\
\hline Observations & $1,447,538$ & 867,888 & 550,832 & $1,447,538$ & 867,888 & 550,832 \\
\hline Supporters & 418146 & 233238 & 177590 & 418146 & 233238 & 177590 \\
\hline Elections & 5419 & 5413 & 3162 & 5419 & 5413 & 3162 \\
\hline
\end{tabular}

Notes: The table presents the estimated coefficients of $\beta$ from equation (1.1) using as dependent variable an indicator for employment in the private sector (Panel A, columns 1-3) and private sector earnings (Panel A, columns 4-6), an indicator for employment in the formal sector (Panel B, columns 1-3) and total earnings in the formal sector (Panel B, columns 4-6). Results in columns (1) and (4) are estimated on the sample of all supporters. Results in columns (2) and (5) are estimated on the sample of candidates to the local council, and results in columns (3) and (6) are estimated on the sample of donors. See section 1.3.3 for a description of the outcome variables. The sample is composed of supporters of the winning mayoral candidate or the close loser, using a 5\% margin of victory to define close races. The sample of elections is 2000, 2004, 2008, 2012 in columns 1, 2, 4, 5, and 2004, 2008, 2012 in columns 3, 6. "Mean D.V. Runner-up" shows the average of the dependent variable for the supporters of the runner-up in the post-election period. Robust standard errors are shown in parentheses and are double clustered at the supporter and election level. ${ }^{* * *} p<0.01,{ }^{* *} p<0.05,{ }^{*} p<0.1$.

a candidate, we can break down public sector jobs among those under the jurisdiction of the local, state, and federal government. In Table 1.7 we present the results of the estimation of equation (1.1) using employment probabilities in a municipal, state or federal public sector job as separate dependent variables (and further differentiating between municipal jobs in the supporter's municipality and in a different municipality). In line with the mayor being able to allocate to political supporters only jobs over which she has discretion, the whole effect is concentrated at the municipal level and driven by municipal jobs in the supporter's municipality. ${ }^{71}$

\footnotetext{
${ }^{71}$ In Appendix Table A.14 we investigate whether the effect is entirely driven by temporary employment contracts. While the estimates are significantly larger for temporary contracts, supporters of the winning side are also significantly more likely to be employed in permanent positions. This is consistent with the evidence presented in section 1.3.4, which showed significant turnover also in permanent public sector jobs around
} 


\section{municipal elections.}




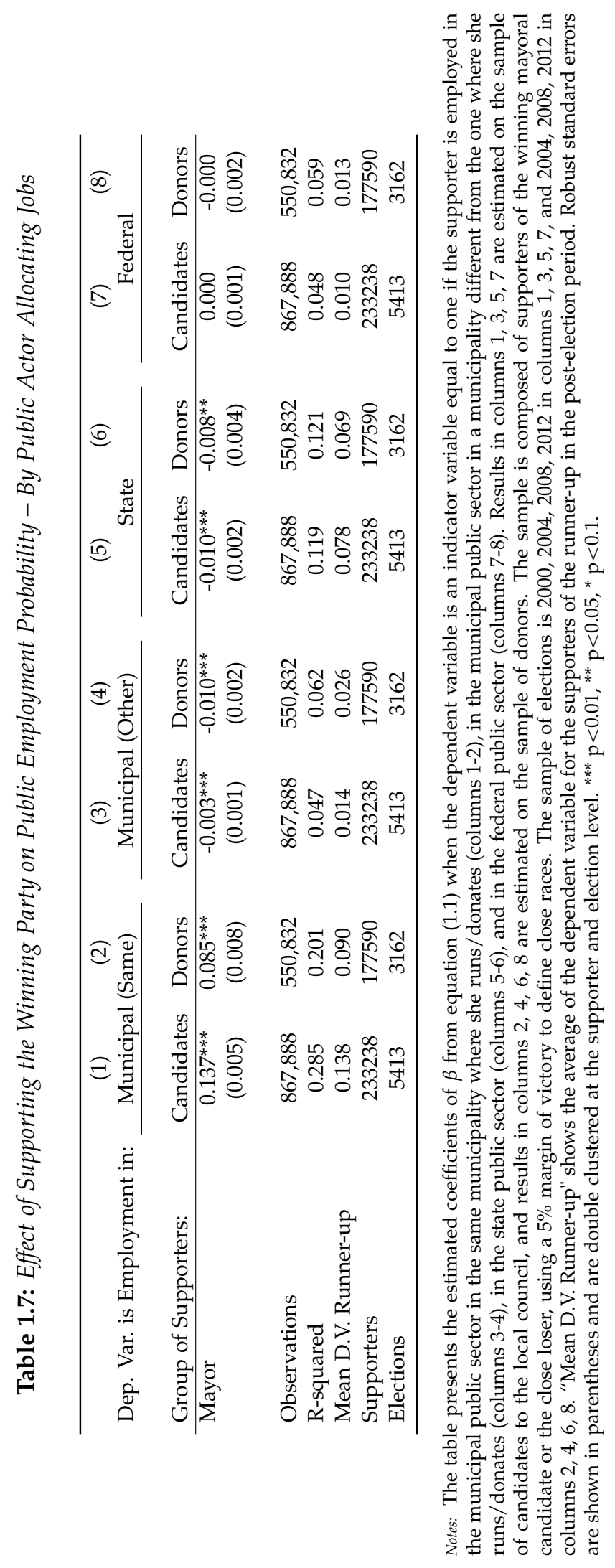




\subsubsection{Gaining Versus Losing a Connection}

Estimates from equation 1.3 allow us to separately investigate the effect of gaining a political connection and the effect of losing one. Figure 1.6 and Appendix Table A.15 present the results. ${ }^{72}$ When a supporter of a party that was previously not in the ruling coalition in the municipality gains a connection (i.e. the mayor she supports is elected), she experiences a large increase in the probability of having a public sector job (an increase of 10.2 p.p, or $46 \%$ relative to the pre-election period) and in public sector earnings (a 46\% increase relative to the pre-election period). When instead a supporter of a party that was previously in the ruling coalition in the municipality loses her connection (i.e. the mayor she supports loses the election), she experiences a large (although relatively smaller) decrease in the probability of having a public sector job (by 8.7 p.p, or $30 \%$ of the average probability in the pre-election period) and in public sector earnings (31\% relative to the pre-election period). These estimates are significant for both candidates and donors. Both the acquisition and the loss of a connection to the party in power imply a significant shock to a political supporter's public employment prospects.

\footnotetext{
${ }^{72}$ In Appendix Table A.15 we present estimates from a more parsimonious version of equation 1.3, in which we estimate the average treatment effect in the post-election period, rather than separate coefficients for each post-election period.
} 
(a) Candidates Gaining Connection

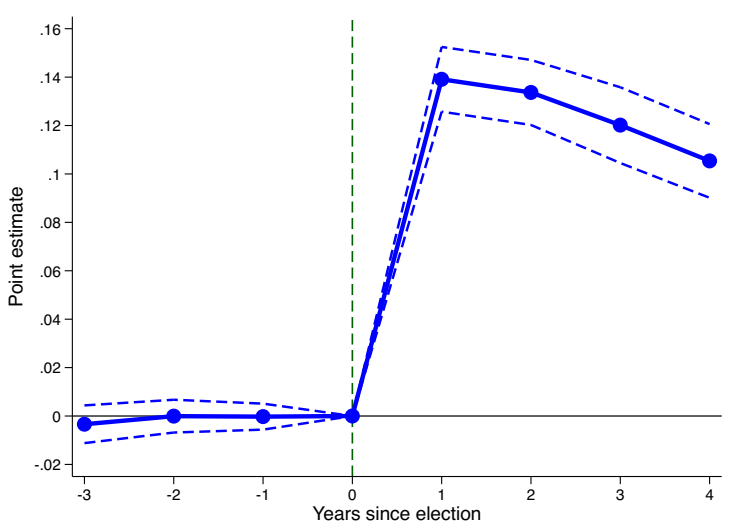

(c) Candidates Losing Connection

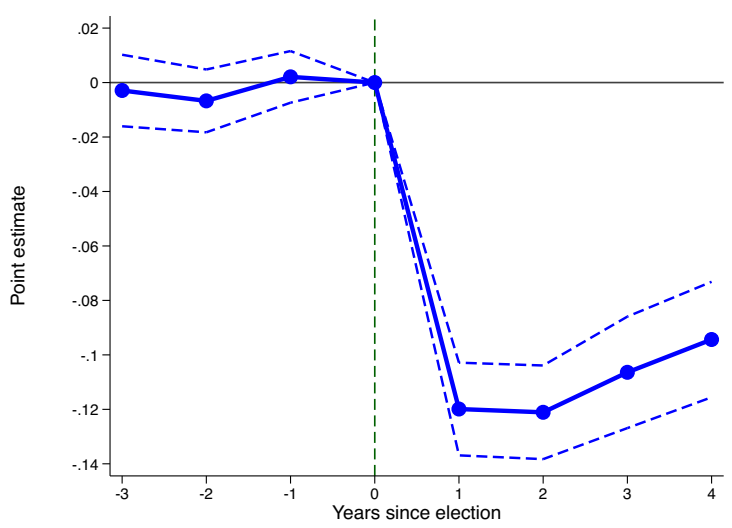

(b) Donors Gaining Connection

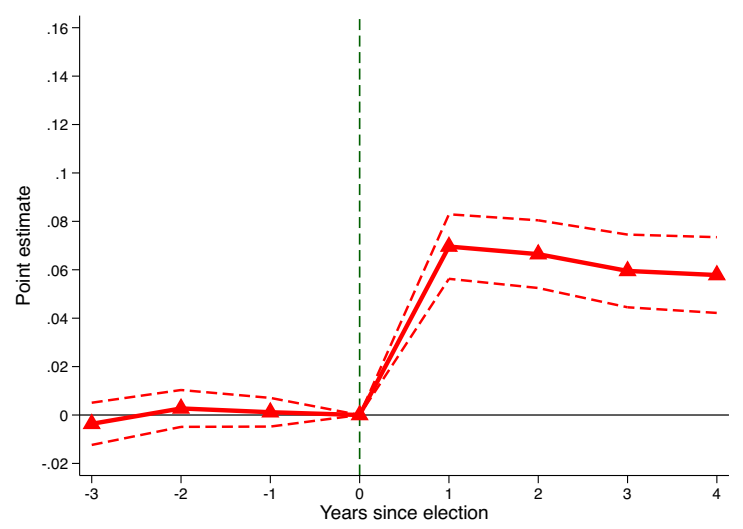

(d) Donors Losing Connection

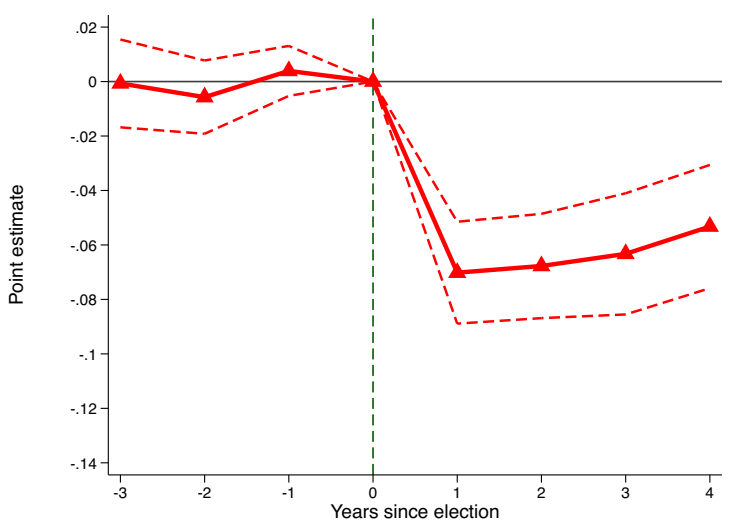

Notes: The figure presents the estimated effect of gaining a connection to the party in power (top panels) or losing a connection to the party in power (bottom panels) on a supporter's probability of employment in the public sector. The figure plots the estimated effect over time, by plotting the estimated $\beta_{k}$ coefficients from equation (1.3). In the top panels the treatment is gaining a connection to the party in power, i.e the sample is restricted to supporters of a party who was not in the ruling coalition in the previous election cycle, and the variable Shock in equation (1.3) is an indicator taking value one if the supported mayoral candidate wins the election. In the bottom panels the treatment is losing a connection to the party in power, i.e the sample is restricted to supporters of a party who was already in the ruling coalition in the previous election cycle, and the variable Shock in equation (1.3) is an indicator taking value one if the supported mayoral candidate loses the election. In all specifications we restrict the sample to elections decided by a margin of victory of $5 \%$ or less. Panels (a) and (c) present estimates from the sample of candidates, while panels (b) and (d) present estimates from the sample of donors. See section 1.3.3 for a description of the outcome variables. The sample of elections is 2004, 2008, 2012 in all panels. The top panels include 121,064 candidates and 106,945 donors. The bottom panels include 65,997 candidates and 79,663 donors. The dotted lines show 95\% confidence intervals and are based on standard errors double clustered at the candidate and election level.

Figure 1.6: Effect on Public Sector Employment Probability of Gaining versus Losing a Connection 


\subsubsection{Difference-in-Differences Estimates}

Estimates from equation 1.4 allow us to gauge the extent to which our RDD estimates of political favoritism are inflated by our use of supporters of the losing side as a control group. Figure A.4 presents the estimated coefficients $\beta_{k}$. Estimates focusing on candidates as political supporters are in blue, while estimates focusing on donors are in red. For both groups of supporters, we find no substantial differential pre-trend in public employment probability relative to non-supporters. The effect of supporting the party in power materializes at the time of the election, and it is similar in magnitude to the effect of gaining a connection reported in Panels (a) and (b) of Figure 1.6.

In Appendix Table A.16 we report a comparison of the estimated average treatment effects of the RDD and difference-in-differences specifications. ${ }^{73}$ The difference-in-differences estimates are similar in magnitude to the RDD ones, suggesting that the use of supporters of the losing side as a control group does not significantly inflate the estimates of political favoritism.

\subsubsection{Favoritism is Widespread Throughout the Entire Hierarchy}

Leveraging information on the specific job in which supporters are hired, we can investigate whether political favoritism is concentrated in specific layers of the public sector hierarchy, or whether it is instead widespread throughout the entire hierarchy.

We generate five different indicator variables, each turning to one if, in a given year, a supporter has a job belonging to one of five occupational categories - managers, professionals, technical workers, clerks, blue collar workers. Table 1.8 shows the estimated coefficients $\beta$ from estimating equation (1.1) for these five different dependent variables. ${ }^{74}$ We estimate a positive and significant effect of supporting the winning mayoral candidate throughout the whole hierarchy of occupations.

\footnotetext{
${ }^{73}$ Specifically, the RDD average treatment effects are the estimated coefficients in columns 2 and 3 of Panel A of Table A.15. For the difference-in-differences average treatment effects, we present the estimates of equation 1.5 .

${ }^{74}$ Appendix Table A.17 presents the estimates using the optimal bandwidth selection procedure.
} 
Supporters of the winning mayor are 5.3 percentage points more likely to be employed in a job at the top of the bureaucracy (in managerial occupations), relative to a $2.8 \%$ chance for supporters of the runner-up. They are also 12\% more likely to be employed as professional, $14 \%$ more likely to be employed in a high-skills technical occupation, $62 \%$ more likely to be a white-collar public sector worker, and $27 \%$ more likely to be employed in a blue collar job. All the estimates are highly significant, indicating a large presence of political favoritism for all types of public sector jobs. ${ }^{75}$

The results presented in this section document a significant presence of political favoritism in employment across all the layers of the Brazilian local public sector. The effect is not limited to a specific group of political supporters: while the magnitude of the effect is larger for candidates for a seat in a local council, individuals who provided financial support to the winning party enjoy a sizable benefit as well. ${ }^{76}$

\footnotetext{
${ }^{75}$ All the estimates are large and significant for both types of supporters, with the exception of professional and high skills technical occupations in the sample of donors.

${ }^{76}$ In this paper, we can focus only on two groups of political supporters (although arguably two important ones), not considering other individuals connected to politicians, like friends and family members. Even restricting attention only to these supporters, as shown in Figure A.5, the winning mayor's supporters make up between $0.2 \%$ and $0.8 \%$ of the population in small and medium size Brazilian municipalities. A large share of them (between one out of four and one out of two, on average) is employed in the municipal public sector.
} 
Table 1.8: Effect of Supporting the Winning Party On Public Employment Probability Across the Public Sector Hierarchy

\begin{tabular}{|c|c|c|c|c|c|}
\hline Dep. Var. is Employment in: & $\begin{array}{c}(1) \\
\text { Job }\end{array}$ & $\begin{array}{c}(2) \\
\text { Professional } \\
\text { Job }\end{array}$ & $\begin{array}{c}\text { (3) } \\
\text { High Skilled } \\
\text { Technical Job }\end{array}$ & $\begin{array}{c}(4) \\
\text { Clerical } \\
\text { Job }\end{array}$ & $\begin{array}{c}(5) \\
\text { Blue } \\
\text { Collar Job }\end{array}$ \\
\hline \multicolumn{6}{|l|}{ Panel A: All Supporters } \\
\hline Mayor & $\begin{array}{c}0.053^{* * *} \\
(0.003)\end{array}$ & $\begin{array}{c}0.007^{* * *} \\
(0.002)\end{array}$ & $\begin{array}{c}0.005^{* * *} \\
(0.002)\end{array}$ & $\begin{array}{c}0.031^{* * *} \\
(0.003)\end{array}$ & $\begin{array}{c}0.013^{* * *} \\
(0.002)\end{array}$ \\
\hline Observations & $1,186,480$ & $1,186,480$ & $1,186,480$ & $1,186,480$ & $1,186,480$ \\
\hline R-squared & 0.120 & 0.092 & 0.068 & 0.116 & 0.088 \\
\hline Mean D.V. Runner-up & 0.0280 & 0.0600 & 0.0350 & 0.0500 & 0.0490 \\
\hline Supporters & 361979 & 361979 & 361979 & 361979 & 361979 \\
\hline Elections & 4160 & 4160 & 4160 & 4160 & 4160 \\
\hline \multicolumn{6}{|l|}{ Panel B: Candidates } \\
\hline Mayor & $\begin{array}{c}0.069^{* * *} \\
(0.004)\end{array}$ & $\begin{array}{c}0.009^{* * *} \\
(0.003)\end{array}$ & $\begin{array}{c}0.006^{* * *} \\
(0.002)\end{array}$ & $\begin{array}{c}0.040^{* * *} \\
(0.003)\end{array}$ & $\begin{array}{c}0.016^{* * *} \\
(0.003)\end{array}$ \\
\hline Observations & 609,018 & 609,018 & 609,018 & 609,018 & 609,018 \\
\hline R-squared & 0.157 & 0.100 & 0.086 & 0.142 & 0.121 \\
\hline Mean D.V. Runner-up & 0.0270 & 0.0570 & 0.0420 & 0.0540 & 0.0660 \\
\hline Supporters & 177659 & 177659 & 177659 & 177659 & 177659 \\
\hline Elections & 4153 & 4153 & 4153 & 4153 & 4153 \\
\hline \multicolumn{6}{|l|}{ Panel C: Donors } \\
\hline Mayor & $\begin{array}{c}0.031^{* * *} \\
(0.004)\end{array}$ & $\begin{array}{c}0.003 \\
(0.004)\end{array}$ & $\begin{array}{c}0.003 \\
(0.002)\end{array}$ & $\begin{array}{c}0.020^{* * *} \\
(0.004)\end{array}$ & $\begin{array}{c}0.010^{* * *} \\
(0.002)\end{array}$ \\
\hline Observations & 548,694 & 548,694 & 548,694 & 548,694 & 548,694 \\
\hline R-squared & 0.114 & 0.112 & 0.071 & 0.114 & 0.067 \\
\hline Mean D.V. Runner-up & 0.0300 & 0.0620 & 0.0270 & 0.0470 & 0.0310 \\
\hline Supporters & 177011 & 177011 & 177011 & 177011 & 177011 \\
\hline Elections & 3159 & 3159 & 3159 & 3159 & 3159 \\
\hline
\end{tabular}

Notes: The table presents the estimated coefficients of $\beta$ from equation (1.1) using as dependent variable an indicator for employment in the occupational category of the public sector indicated in the title of the column. Results in Panel A includes all supporters. Results in Panel B includes only candidates to the local council. Results in Panel C includes only donors. The sample is composed of supporters of the winning mayoral candidate or the close loser, using a 5\% margin of victory to define close races. The sample of elections is 2004, 2008, 2012. "Mean D.V. Runner-up" shows the average of the dependent variable for the supporters of the runner-up in the post-election period. Robust standard errors are shown in parentheses and are double clustered at the supporter and election level. ${ }^{* * *} \mathrm{p}<0.01,{ }^{* *} \mathrm{p}<0.05,{ }^{*} \mathrm{p}<0.1$. 


\subsection{Patronage as Mechanism, and Impact on Selection to Public Employment}

In this section, we show that patronage is the leading explanation behind political favoritism in public sector employment, and that this negatively affects the quality of the pool of public workers. First, we show that the political supporters enjoying the largest preferential treatment are those who provided more political support to the party in power. Second, we show that the provision of political support substitutes quality as a hiring criterion: relative to supporters of the runner-up mayoral candidate, supporters of the mayor are screened less on education and on skills valued by the private sector. Third, we present evidence against an interpretation of favoritism as the result of a mayor's better screening of her supporters on hard-to-observe dimensions of talent. Fourth, we present evidence suggesting that politicians' desire to hire individuals with similar ideological views is not a primary driver of political favoritism in hiring.

\subsubsection{Political Favoritism is Increasing in the Amount of Political Support}

If political favoritism stems from a quid pro quo relationship between a political supporter and a political party, we expect the extent of the reward to be dependent on the amount of support provided. In this section, we ask whether this is indeed the case. For candidates to the local council, we use their electoral performance as a measure of political support. For donors, we use the amount of money contributed.

We start by looking at candidates' electoral performance. Candidates obtaining a large number of personal votes are valuable to the mayor's coalition for two reasons. First, since council seats are awarded to a coalition in proportion to the total number of votes received by its candidates, more successful candidates increase the overall number of seats awarded to the coalition. Second, personal votes for a candidate to the local council are also likely to translate into votes for the mayor supported by the candidate. As shown in Appendix Table A.13, most of the political favoritism for candidates is driven by those failing to win a 
council seat. Therefore, in this section we focus on this subset of candidates.

We calculate, for each losing candidate, the quintile of the vote share distribution within her coalition (either the mayor's or the runner-up's coalition) in which she falls (considering only votes brought by losing candidates). We are therefore categorizing losing candidates on the basis of the number of votes that they contributed to their coalition. We then create five indicator variables (Quintile ${ }_{i m t}^{q}$ ), turning to one if candidate $i$ 's within-coalition vote share in the election in municipality $m$ and election year $t$ falls into quintile $q$. We estimate an augmented version of equation (1.1) in which we interact Mayor ${ }_{c m t}$ with these five indicator variables:

$$
\begin{aligned}
y_{i k c m t}= & \sum_{q=1}^{5} \beta^{q} \text { Quintile }_{i m t}^{q} * \text { Mayor }_{c m t}+\sum_{q=2}^{5} \theta^{q} \text { Quintile }_{i m t}^{q}+ \\
& +\sum_{k=1}^{+4} \theta_{k} M V_{c m t}+\gamma_{k m t}+\epsilon_{i k c m t}
\end{aligned}
$$

This specification allows us to investigate whether candidates who contributed relatively more votes to their coalition are more likely to enjoy a preferential access to public sector jobs. We estimate a similar version of the same equation, categorizing donors on the basis of the amount of money donated to the coalition of the mayoral candidate supported.

Figure 1.7 presents a graphical representation of the treatment effects at different quintiles of the distribution of political support, looking at employment probability in the top panel and at public sector earnings in the bottom panel. ${ }^{77}$ Consistent with the hypothesis that candidates and donors who provided more support are rewarded more, we find that the amount of political favoritism is strictly increasing in a candidate's position in the distribution of vote share, and in a donor's position in the distribution of money contributed. While the effect is positive and significant throughout the whole distribution, the treatment effect monotonically increases in the amount of support provided. For instance, the treatment effect on public sector earnings is $78 \%$ higher for candidates in the third quintile of the vote share distribution relative to candidates in the bottom quintile, and the treatment effect for

\footnotetext{
${ }^{77}$ Appendix Table A.18 presents the results in table format.
} 
candidates in the top quintile is two times higher relative to candidates in the third quintile. The patterns are similar if we look at a donor's amount of financial support: moving from the bottom to the top quintile of the money distribution increases the treatment effect on public sector earnings by $349 \% .^{78}$

\subsubsection{Providing Political Support Decreases Screening on Education}

Being a political supporter of the party in power could increase the probability of obtaining a public sector job, but only conditional on being qualified for the position. ${ }^{79}$ Alternatively, providing political support could act as a substitute for an individual's level of qualifications, decreasing the importance of qualifications for political supporters, and lowering the average quality of the workforce.

To test whether providing political support decreases screening on education, we combine information on (i) the required level of education to perform each occupation in the Brazilian public sector, collected from the Classificação Brasileira de Ocupações 2002 as described in Section 1.3.2, and (ii) information on supporters' education. Since we do not have information on the education of all supporters for the sample of donors, we exclude them from the analysis of this section. ${ }^{80}$ We estimate a series of equations of the form:

$$
\begin{aligned}
y_{\text {ikcmt }}= & \beta^{Q M} \text { Qualified }_{i} * \text { Mayor }_{c m t}+\beta^{M} \text { Mayor }_{c m t}+ \\
& +\beta^{Q} \text { Qualified }_{i}+\sum_{k=1}^{+4} \theta_{k} M V_{c m t}+\gamma_{k m t}+\epsilon_{i k c m t}
\end{aligned}
$$

where $y_{i k c m t}$ is an indicator variable equal to one if in period $k$ supporter $i$ is employed in a public sector job that requires a specific educational level, the variable Qualified $_{i}$ is

\footnotetext{
${ }^{78}$ These heterogeneous effects are similar and equally significant if we look at the effect on public sector employment probability.

${ }^{79}$ This scenario would correspond to the mayor having lexicographic preferences over a worker's qualifications and political affiliation.

${ }^{80}$ We have information on donors' education only for donors who have been matched to the RAIS dataset, but conducting the analysis only on this subset of donors would result in biased estimates since the treatment (i.e. being connected to the mayor) affects the probability of having a public sector job and thus of being matched to RAIS. Since we have data on candidates' education from the TSE, we have this information for all candidates independently on whether they were matched to RAIS.
} 
(a) Effects on Employment Probability
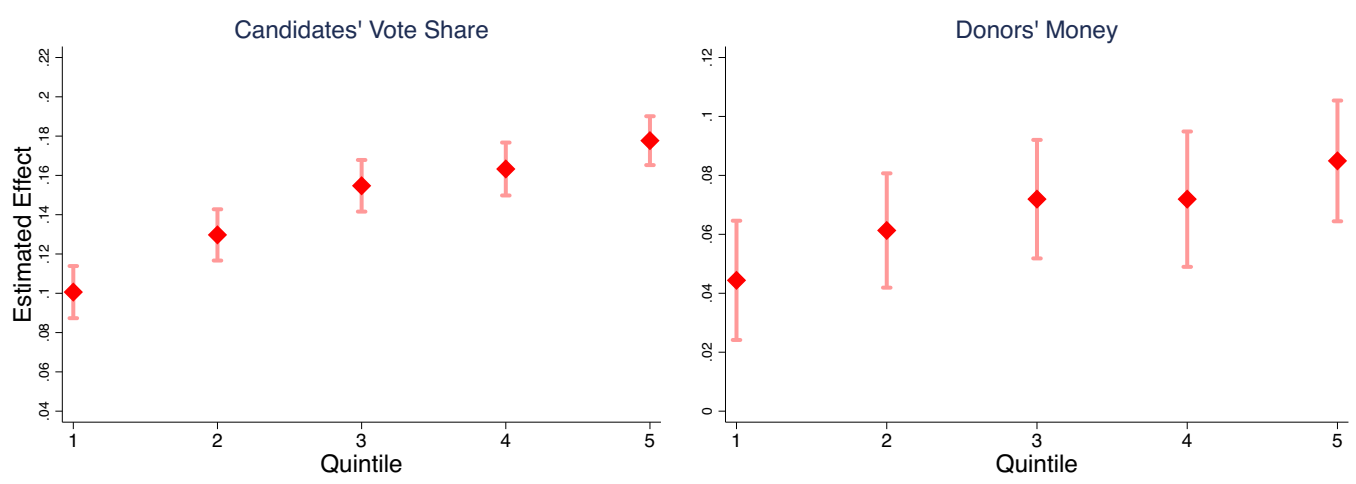

(b) Effects on Earnings
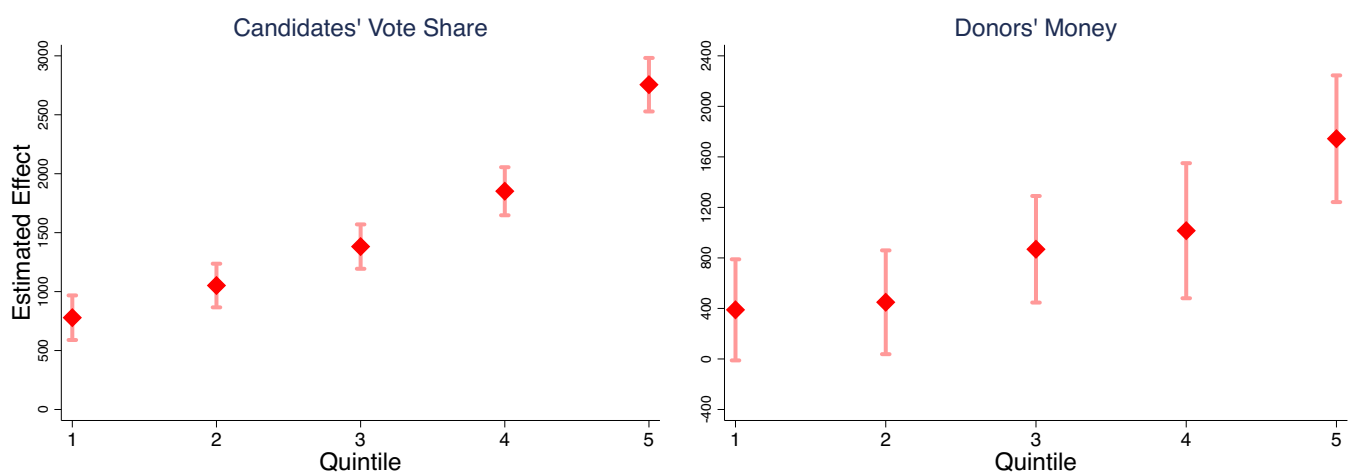

Notes: The figures present the estimated treatment effects from the estimation of equation 1.6. We report the estimated treatment effects of supporting the winning mayoral candidate, together with 95\% confidence intervals, at different quintiles of the candidates' vote share distribution (left panels) or the distribution of amount of money contributed by donors (right panels). The dependent variable is an indicator variable equal to one if the supporter is employed in a public sector job in the top figures, and annual public sector earnings in the bottom figures. The sample is composed of supporters of the winning mayoral candidate or the close loser, using a 5\% margin of victory to define close races. The samples in the left panels include candidates to the local council who were not elected. The samples in the right panels include donors. The sample of elections is 2000, 2004, 2008, 2012 in the left panels and 2004, 2008, 2012 in the right panels. 95\% confidence intervals are based on standard errors double clustered at the candidate and election level.

Figure 1.7: Public Sector Returns Are Increasing in Amount of Support Provided 
an indicator variable equal to one if supporter $i$ has a level of education that is equal or higher to the one required to perform this job, and all the other variables are defined as before. We estimate three different specifications, where we focus on jobs for which the required level of education is middle school degree, high school degree, or college degree, respectively. The coefficient $\beta^{Q M}$ measures the effect of being a supporter of the mayor on the importance of education to obtain a public sector job. If being a supporter of the mayor decreases screening on education, then $\beta^{\mathrm{QM}}$ will be negative.

Table 1.9 presents the results. Column 1 focuses on public sector jobs that require middle school education, with the coefficient on the double interaction showing that for this category of jobs the importance of education is significantly lower for supporters of the winning mayoral candidate. Put it differently, the effect of being connected to the mayor is significantly stronger among supporters who are not qualified for the position in terms of education: being a supporter of the mayor increases the chances of obtaining a job requiring a middle school degree by 1.7 percentage points conditional on not having a middle school degree, and by only 0.7 percentage points conditional on having it. Column 3 reveals a similar pattern when we focus on public sector jobs that require a university degree. The coefficient for the specification focusing on jobs requiring a high school degree is negative, but small and statistically insignificant.

As a consequence of the lower screening on education for supporters of the winning mayor, Table 1.10 shows that public sector employees who supported the mayor in the previous election are 2.7 percentage points (or 17\%) more likely to be unqualified in terms of education than public sector employees who supported the runner-up. ${ }^{81}$ This is true both at the top of the hierarchy (for managerial jobs) and for mid-level bureaucrats (for clerical

\footnotetext{
${ }^{81}$ As for all our previous results, we restrict the sample to elections decided by a $5 \%$ margin of victory between the winner and the runner-up. We focus on the sample of all public employees who are supporters of the mayor or of the runner-up in the four years after the election in which they are supporters. Each supporter enters the sample once for every year in which she has a public sector job. We then regress an indicator variable equal to one if the supporter is unqualified on an indicator for having been a supporter of the winning mayoral candidate, including election (municipality-year of the election) fixed effects and the margin of victory of the mayor supported. As these results focus on supporters employed in the public sector, and thus who appear in the RAIS dataset, we can include also donors in this set of results.
} 
jobs), as well as among professional workers. ${ }^{82}$

Table 1.9: Providing Political Support Decreases the Importance of Education as a Hiring Criterion

\begin{tabular}{lccc}
\hline $\begin{array}{l}\text { Dep. Var. is Employment } \\
\text { in Public Job Requiring: }\end{array}$ & $\begin{array}{c}(1) \\
\text { Middle } \\
\text { School Degree }\end{array}$ & $\begin{array}{c}\text { High School } \\
\text { School Degree }\end{array}$ & $\begin{array}{c}(3) \\
\text { University } \\
\text { Degree }\end{array}$ \\
\hline & & & \\
Mayor*Qualified & $-0.010^{* * *}$ & -0.003 & $-0.015^{* *}$ \\
& $(0.002)$ & $(0.003)$ & $(0.006)$ \\
Mayor & $0.017^{* * *}$ & $0.047^{* * *}$ & $0.070^{* * *}$ \\
& $(0.002)$ & $(0.004)$ & $(0.004)$ \\
Qualified & $0.011^{* * *}$ & $0.081^{* * *}$ & $0.352^{* * *}$ \\
& $(0.001)$ & $(0.002)$ & $(0.005)$ \\
Observations & & & \\
R-squared & 604,366 & 604,366 & 604,366 \\
Mean D.V. Unq. Runner-up & 0.080 & 0.178 & 0.299 \\
Supporters & 0.0270 & 0.0420 & 0.0460 \\
Elections & 176514 & 176514 & 176514 \\
\hline
\end{tabular}

Notes: The table presents the estimated coefficients from equation (1.7) using as dependent variables indicators for employment in a public sector job that requires a middle school degree (column 1), high school degree (column 2) and university degree (column 3). The sample includes only candidates to the local council, and is restricted to supporters of the winning mayoral candidate or the close loser, using a 5\% margin of victory to define close races. The sample of elections is 2004, 2008, 2012. "Mean D.V. Unq. Runner-up" shows the average of the dependent variable in the post-election period for the supporters of the runner-up who are not qualified for the job. Robust standard errors are shown in parentheses and are double clustered at the supporter and election level. ${ }^{* * *} \mathrm{p}<0.01,{ }^{* *} \mathrm{p}<0.05,{ }^{*} \mathrm{p}<0.1$.

These results show that the being a political supporter of the mayor acts as a substitute for an individual's qualification, worsening selection on education for applicants to a public sector job: having the required educational level to perform a public sector job is less relevant for supporters of the winning mayor. ${ }^{83}$

\footnotetext{
${ }^{82}$ As shown in the table, the share of unqualified public sector workers among managers is high also among supporters of the runner-up (44.2\%). If we exclude managerial occupations, which require a university degree, from the estimation in column 3 of Table 1.9, we find essentially the same result, with an estimate on the double interaction equal to -0.025 and a standard error of 0.004 .

${ }^{83}$ We also test whether supporters of the mayor are screened less on education relative to non-supporters, augmenting equation 1.5 to test for heterogeneous effects depending on a supporter's education. Specifically, we add to equation 1.5 the triple interaction between Mayor $_{i m t}$, Post $_{k m t}$ and Qualified ${ }_{i}$, and the double interaction

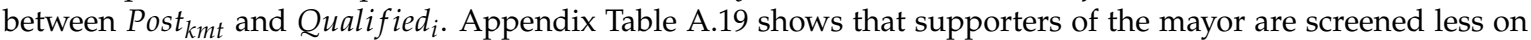
education also relative to non-supporters. For instance, results in Column 3 of Appendix Table A.19 shows that, while in the post-election period the importance of having a college degree increases for non-supporters (among non-supporters, the importance of having a college degree for obtaining a job requiring a college education increases by 11.3 percentage points in the post-election period), it decreases for supporters of the mayor (among them, the importance of having a college degree for obtaining a job requiring a college education decreases by 2 percentage points in the post-election period).
} 
Table 1.10: Extent of Public Employees' Unqualification is Larger Among Mayor's Supporters

\begin{tabular}{|c|c|c|c|c|c|c|}
\hline \multirow{4}{*}{$\begin{array}{l}\text { Sample: Supporters } \\
\text { Employed in: }\end{array}$} & \multicolumn{6}{|c|}{ Dep. Var. is Indicator for Being Unqualified for the Job } \\
\hline & (1) & (2) & (3) & (4) & (5) & $(6)$ \\
\hline & Any & Managerial & Professional & High Skilled & Clerical & Blue \\
\hline & Job & Job & Job & Technical Job & Job & Collar Job \\
\hline \multirow[t]{2}{*}{ Mayor } & $0.027^{* * *}$ & $0.074^{* * *}$ & $0.021^{* * *}$ & 0.002 & $0.039^{* * *}$ & 0.002 \\
\hline & $(0.003)$ & $(0.011)$ & $(0.005)$ & $(0.007)$ & $(0.005)$ & $(0.006)$ \\
\hline Observations & 320,233 & 49,600 & 66,266 & 36,140 & 71,257 & 56,822 \\
\hline R-squared & 0.367 & 0.257 & 0.227 & 0.244 & 0.199 & 0.203 \\
\hline Mean D.V. Runner-Up & 0.160 & 0.442 & 0.102 & 0.152 & 0.100 & 0.142 \\
\hline Supporters & 115610 & 22742 & 26364 & 15231 & 31185 & 23207 \\
\hline Elections & 4061 & 1891 & 2831 & 2124 & 2759 & 2879 \\
\hline
\end{tabular}

Notes: The table investigates the difference in the share of unqualified workers between public employees who are supporters of the mayor and those who are supporters of the runner-up, in the four years after the election in which they are supporters. We regress an indicator variable equal to one if the supporter is unqualified for the job on an indicator for having been a supporter of the winning mayoral candidate, including election (municipality-year of the election) fixed effects and the margin of victory of the mayor supported. In column 1 we pool all employees, in column 2 we focus on managerial jobs, in column 3 we focus on professionals, in column 4 we focus on high skilled technical jobs, in column 5 we focus on clerical occupations, in column 6 we focus on blue collar jobs. The sample includes both candidates to the local council and donors, and is restricted to supporters of the winning mayoral candidate or the close loser in a close race, using a $5 \%$ margin of victory to define close races. The sample of elections is 2004, 2008, 2012. "Mean D.V. Runner-Up" shows the average of the dependent variable among supporters of the runner-up mayoral candidate. Robust standard errors are shown in parentheses and are double clustered at the supporter and election level. ${ }^{* * *} \mathrm{p}<0.01,{ }^{* *} \mathrm{p}<0.05,{ }^{*} \mathrm{p}<0.1$.

\subsubsection{Providing Political Support Decreases Screening on Skills Valued by the Private Sector}

As a second measure of a supporter's quality, we use her previous earnings in the private sector. In other words, as in Dal Bó et al. (2013), we consider a supporter's private sector outside opportunity as a measure of her skills, under the assumption that workers with higher skills will be compensated with higher earnings in the private sector.

We focus on the subset of supporters who are employees in a formal private sector firm in the two years preceding the election, and we test whether political favoritism is higher for supporters with lower previous private sector earnings. ${ }^{84}$ We estimate the following

\footnotetext{
${ }^{84}$ To account for year- and location-specific factors affecting private sector earnings, we first regress private sector earnings on year times municipality fixed effects, and we take the residuals of this regression. For supporters who are employed in the formal private sector in both years preceding the election, we assign them the average of the residuals.
} 
equation:

$$
\begin{aligned}
y_{i k c m t}= & \beta^{P M} \text { PrivateEarnings }_{\text {imt }} * \text { Mayor }_{c m t}+\beta^{M} \text { Mayor }_{c m t}+ \\
& +\beta^{P} \text { PrivateEarnings } s_{i m t}+\sum_{k=1}^{+4} \theta_{k} M V_{c m t}+\gamma_{k m t}+\epsilon_{i k c m t}
\end{aligned}
$$

where $y_{i k c m t}$ is an indicator variable equal to one if in period $k$ supporter $i$ is employed in a public sector job, the variable PrivateEarnings $s_{i m t}$ is a supporter's private sector earnings before the election (in thousands $\mathrm{R} \$$ ), and all the other variables are defined as before. The coefficient $\beta^{P M}$ measures the effect of being a supporter of the mayor on the relationship between private sector opportunities and the likelihood of being employed in a public sector job. If being a supporter of the mayor decreases screening on skills valued by the private sector, then $\beta^{P M}$ will be negative.

Panel A of Table 1.11 shows that the effect of being a supporter of the mayor is significantly stronger among supporters with lower private sector skills. A one standard deviation (i.e. 6.59) increase in a supporter's private sector earnings decreases the treatment effect by 3.3 percentage points. In Panel B of Table 1.11 we present estimates of equation 1.8 in which the continuous private sector earnings measure is replaced by indicators turning to one if supporter $i$ is in the top tercile or in the second tercile of the private earnings distribution, respectively. ${ }^{85}$ Favoritism is most limited for supporters in the top tercile of the distribution: moving from the first to the third tercile of the distribution decreases the treatment effect by $38 \%$ for candidates (column 2) and by $20 \%$ for donors (column 3 ).

These results show that political favoritism brings into the public workforce a larger share of individuals with lower skills valued by the private sector. ${ }^{86}$

\footnotetext{
${ }^{85}$ We divide supporters in terciles based on the earnings distribution for all supporters in their same coalition (i.e. the coalition of the mayor or the coalition of the runner-up in the election).

${ }^{86}$ We also show these results using non-supporters as a control group, augmenting equation 1.5 to test for heterogeneous effects depending on a supporter's private sector earnings. Appendix Table A.20 shows that supporters of the mayor are screened less on skills valued by the private sector also relative to non-supporters.
} 
Table 1.11: Favoritism Stronger for Supporters with Lower Private Sector Opportunities

\begin{tabular}{lccc}
\hline \multicolumn{4}{c}{ Dep. Var. is Employment in Public Sector } \\
& $(1)$ & $(2)$ & $(3)$ \\
Group of Supporters: & All Supporters & Candidates & Donors \\
\hline Panel A: Continuous Measure of Previous & Private Earnings \\
Mayor*Private Earnings & $-0.003^{* * *}$ & $-0.005^{* * *}$ & $-0.002^{* * *}$ \\
& $(0.000)$ & $(0.001)$ & $(0.000)$ \\
Mayor & $0.093^{* * *}$ & $0.126^{* * *}$ & $0.056^{* * *}$ \\
& $(0.007)$ & $(0.010)$ & $(0.009)$ \\
R-squared & 0.270 & 0.365 & 0.228 \\
Mean D.V. Runner-Up & 0.0980 & 0.111 & 0.0850 \\
Panel B: Terciles of Previous Private Earnings & \\
Mayor* Tercile 3 & $-0.038^{* * *}$ & $-0.059^{* * *}$ & $-0.013^{*}$ \\
& $(0.006)$ & $(0.010)$ & $(0.008)$ \\
Mayor* Tercile 2 & $-0.013^{* *}$ & -0.015 & -0.010 \\
& $(0.006)$ & $(0.010)$ & $(0.008)$ \\
Mayor & $0.112^{* * *}$ & $0.154^{* * *}$ & $0.065^{* * *}$ \\
& $(0.008)$ & $(0.012)$ & $(0.011)$ \\
R-squared & 0.269 & 0.364 & 0.227 \\
Mean D.V. Runner-Up & 0.103 & 0.121 & 0.0880 \\
& & & \\
Observations & 224,132 & 104,630 & 117,202 \\
Supporters & 71515 & 31438 & 39452 \\
Elections & 4010 & 3679 & 2500 \\
\hline
\end{tabular}

Notes: The table presents the estimated coefficients from equation (1.8), estimated in the sample of all supporters (column 1), in the sample of candidates (column 2) and in the sample of donors (column 3). Panel A looks at the heterogeneous treatment effect interacting the indicator for supporting the mayor with a continuous measure of previous private sector earnings, while Panel B looks at the heterogeneous treatment effect interacting the indicator for supporting the mayor with an indicator for being in the top tercile of the distribution of previous private sector earnings and with an indicator for being in the second tercile of the distribution of previous private sector earnings. The dependent variable in all columns is an indicator equal to one if the supporter is employed in the public sector. The sample is restricted to supporters of the winning mayoral candidate or the close loser, using a 5\% margin of victory to define close races, and using only the sample of supporters employed in the private sector in at least one of the two years preceding the election. The sample of elections is 2000, 2004, 2008, 2012 in columns 1 and 2, and 2004, 2008, 2012 in column 3. "Mean D.V. Runner-up" shows the average of the dependent variable in the post-election period for the supporters of the runner-up. Robust standard errors are shown in parentheses and are double clustered at the supporter and election level. ${ }^{* *} p<0.01,{ }^{* *} p<0.05,{ }^{*} p<0.1$.

\subsubsection{Is the mayor successfully screening on unobservables?}

The mayor could be using her discretion in hiring decisions to bring into the public workforce individuals who, despite being of lower ability on observable dimensions, are more talented along hard-to-observe dimensions. In other words, political favoritism could be the result of mayors having better "soft" information about members of their network, and thus being able to screen them on dimensions of talent that we cannot observe. We investigate the plausibility of this interpretation in two ways. First, we use a measure of pre-election personal ability conditional on observables, as in Besley et al. (2017) and Dal Bó et al. (2017). 
Second, we provide a test of this theory based on political supporters' long-run careers in the public sector.

\section{Selection on residual ability}

In order to obtain a measure of supporters' individual ability that goes beyond observable individual characteristics, we follow the approach in Besley et al. (2017) and Dal Bó et al. (2017), estimating residuals from a Mincer earnings regression controlling for individual and job-specific characteristics.

The intuition for this approach is simple. Workers who have higher private sector earnings when compared to workers with the same demographic characteristics and employed in a similar job, will have higher ability. While we cannot observe what accounts for this residual higher earnings, we can use residuals from the Mincer earnings regression as a measure of unobservable ability.

We estimate one equation for each year between 1995 and 2014 using information on all Brazilian private sector employees. ${ }^{87}$ We also estimate each regression separately for men and women, in order to account for gender-specific differences in labor-market outcomes. Specifically, we obtain, for each individual $i$ and year $t$, residuals from the following specification:

$$
y_{i, m, t}=f\left(\text { age }_{i, t}, \text { education }_{i, t}, \text { sector }_{i, t}\right)+\alpha_{m}+\epsilon_{i, m, t}
$$

where $y_{i, m, t}$ are annual private sector earnings of individual $i$ working in municipality $m$ in year $t, a g e_{i, t}$ are a set of age fixed effects (over 5-years intervals), education ${ }_{i, t}$ are four fixed effects for individual educational level (less than middle school, middle school degree, high school degree, university degree), sector $r_{i, t}$ are fixed effects for the sector of $i$ 's firm. We include a full-set of interactions between these variables, as well as municipality fixed effects

\footnotetext{
${ }^{87}$ To minimize endogeneity concerns, we use observations for candidates and donors only in years before the first election in which they run/donate. This means that we can calculate this measure only for supporters who are ever employed in the formal private sector before their first election, that is $27.2 \%$ of candidates and $37.9 \%$ of donors.
} 
$\left(\alpha_{m}\right)$ to account for location-specific differences in earnings. Our residual ability score is the average of each individual's residuals across all years in which she is employed in the private sector. ${ }^{88}$

We divide supporters in terciles based on the distribution of individual ability for all supporters in their same coalition (i.e. the coalition of the mayor or the coalition of the runner-up in the election). We then estimate the following equation:

$$
\begin{aligned}
y_{\text {ikcmt }} & =\beta^{M 3} \text { Tercile }_{i} * \text { Mayor }_{c m t}+\beta^{M 2} \text { Tercile }_{i} * \text { Mayor }_{c m t}+ \\
& +\beta^{M} \text { Mayor }_{c m t}+\beta^{3} \text { Tercile }_{i}+\beta^{2} \text { Tercile }_{i}+\sum_{t=1}^{+4} \theta_{t} M V_{c m t}+\gamma_{k m t}+\epsilon_{i k c m t}
\end{aligned}
$$

where Tercile $3_{i}$ and Tercile $2_{i}$ are indicators turning to one if supporter $i$ has a high level of ability (i.e. she is in the top tercile of the ability distribution) or a medium level of ability (i.e. she is in the second tercile of the ability distribution), respectively. The coefficient $\beta^{M 3}$ (respectively, $\beta^{M 2}$ ) measures the effect of being a supporter of the mayor on the importance of having high ability (respectively, medium ability) relative to low ability (the excluded category) for the probability of obtaining a public sector job.

If being a supporter of the mayor increases screening on this residual measure of ability, then we expect $\beta^{M 3}>\beta^{M 2}>0$.

Contrary to this hypothesis, Table 1.12 shows that supporting the winning party decreases the importance of residual ability for the probability of being hired in the public sector, and this is true for both candidates and donors. Being a supporter of the mayor increases the chances of obtaining a job the most for supporters in the bottom tertile of the ability

\footnotetext{
${ }^{88}$ Dal Bó et al. (2017) calculate this measure for the Swedish population and show that, for males, it is significantly correlated with leadership and cognitive scores conducted in the Swedish military-draft system. While we cannot present a comparable test in our setting, we find that this measure of ability is a strong predictor of political success: elected candidates have a score that is 0.075 standard deviations higher than non-elected candidates. In Appendix Figure A.6, we plot the distributions of the ability score for candidates, donors, and the other 75 millions workers in the RAIS dataset: we find that candidates' average score is 0.11 standard deviations lower than that of the average Brazilian worker, while donors' average score is 0.11 standard deviations higher than that of the average Brazilian worker. These differences are statistically significant, with p-values below 0.01. In contrast, supporters (both donors and candidates) of the elected mayor have a similar ability distribution than supporters of other mayoral candidates (see Appendix Figures A.7 and A.8).
} 
distribution. High ability supporters are 3 percentage points less likely than low ability supporters to benefit from their connection to the mayor (see column 1).

Table 1.12: Favoritism Stronger for Supporters with Lower Residual Ability

\begin{tabular}{|c|c|c|c|}
\hline \multirow[b]{3}{*}{ Group of Supporters: } & \multirow{2}{*}{\multicolumn{3}{|c|}{$\begin{array}{c}(1) \\
\text { Dep. Var. is Employment in Public Sector }\end{array}$}} \\
\hline & & & \\
\hline & All Supporters & Candidates & Donors \\
\hline \multirow[t]{2}{*}{ Mayor*Tercile 3} & $-0.032^{* * *}$ & $-0.023^{* * *}$ & $-0.030^{* * *}$ \\
\hline & $(0.006)$ & $(0.087)$ & $(0.009)$ \\
\hline \multirow[t]{2}{*}{ Mayor*Tercile 2} & $-0.016^{* * *}$ & -0.007 & $-0.027^{* * *}$ \\
\hline & $(0.006)$ & $(0.008)$ & $(0.009)$ \\
\hline \multirow[t]{2}{*}{ Mayor } & $0.147^{* * *}$ & $0.175^{* * *}$ & $0.101^{* * *}$ \\
\hline & $(0.008)$ & $(0.010)$ & $(0.013)$ \\
\hline Observations & 418,012 & 211,612 & 204,864 \\
\hline R-squared & 0.362 & 0.426 & 0.334 \\
\hline Mean D.V. Tercile 1 Runner-up & 0.277 & 0.291 & 0.250 \\
\hline Supporters & 131928 & 62725 & 68826 \\
\hline Elections & 4855 & 4794 & 3086 \\
\hline
\end{tabular}

Notes: The table presents the estimated patronage effects from equation (1.10). The dependent variable is an indicator variable equal to one if the supporter is employed in a public sector job. The sample is composed of supporters of the winning mayoral candidate or the close loser, using a 5\% margin of victory to define close races, and using only the sample of supporters with a non-missing value in the Mincer ability variable. The sample in column 1 includes candidates and donors. The sample in column 2 includes candidates. The sample in column 3 includes donors. The sample of elections is 2000, 2004, 2008, 2012 in columns 1, 2, and 2004, 2008, 2012 in column 3. "Mean D.V. Tercile 1 Runner-up" shows the average of the dependent variable in the post-election period for the supporters of the runner-up who are in the bottom tertile of the ability distribution. Robust standard errors are shown in parentheses and are double clustered at the supporter and election level. $* * * \mathrm{p}<0.01,{ }^{* *} \mathrm{p}<0.05,{ }^{*} \mathrm{p}<0.1$

\section{Supporters' long-run public sector careers}

Mayors could have a superior ability to screen members of their political network along unobservable dimensions of quality that are not captured by our measure of residual private sector earnings. For instance, we cannot observe an individual's public service motivation, and favoritism could be the result of the mayor hiring members of her political network whom she can identify as being particularly motivated to work in the public sector.

We can provide a test of this hypothesis by analyzing a supporter's long-run career in the public sector. Dimensions of a supporter's quality that are ex-ante unobservable outside of the mayor's political network, should be revealed and become common knowledge after several years on a public job. Hence, if mayors are using hiring discretion to select the best individuals in their political network, these workers, once hired, should keep their job even 
if the party in power changes. If instead public sector jobs are allocated to supporters on the basis of patronage relationships, we expect them to be closely linked to the fortunes of the party supported. In this case, if the party fails to re-win the mayoral elections, the benefits to political supporters should dissipate. ${ }^{89}$

We provide evidence to adjudicate between these two hypotheses by testing whether the higher probability of having a public sector job for supporters of the winning mayor dissipates right after the party of the mayor loses power. We do so by dividing supporters in three groups: those supporting a party winning two consecutive elections in the municipality (in period 0 and period 4); those supporting a party winning the election in period 0 but losing the election in period 4 ; those supporting a party losing both the election in period 0 and the election in period $4 .{ }^{90}$ We then estimate the following equation:

$$
y_{i k c m p t}=\sum_{k=-3}^{+6} \beta_{k}^{\text {Both }} \text { MayorBoth } h_{c m t}+\sum_{k=-3}^{+6} \beta_{k}^{\text {One MayorOne }} \text { cmt }+\sum_{k=-3}^{+6} \theta_{k} M V_{c m t}+\gamma_{k p t}+\epsilon_{i k c m t}
$$

where MayorOne cmt $_{\text {is }}$ in indicator turning to one for supporters of a party that wins the election in municipality $m$ in election year $t$ (i.e. in period $k=0$ ) but loses four years later (i.e. in period $k=4)$, and MayorBoth $h_{c m t}$ is an indicator turning to one for supporters of a party that wins the election in municipality $m$ in both the elections. The excluded category of supporters is composed of those whose party loses both elections in the municipality. With the inclusion of period-party-election year fixed effects $\left(\gamma_{k p t}\right)$ we are leveraging variation in the electoral fortunes of the same party across different municipalities. We include observations in the period ranging from 3 years before to 6 years after the first election (i.e. 2 years after the second election).

The left panel of Figure 1.8 plots the estimates of $\beta_{k}^{\text {Both }}$ and $\beta_{k}^{\text {One }}$. Relative to supporters

\footnotetext{
${ }^{89}$ The crucial assumption of this argument is that the degree to which hires reveal their ex-ante unobservable ability and motivation as they perform their job is on average not lower than the private information that the new mayor has on potential replacements among individuals in her network.

${ }^{90}$ We include only supporters of parties presenting a mayoral candidate in two consecutive elections in the same municipality.
} 
whose party loses both elections, supporters whose party remains in power for both election cycles have a higher probability of public sector employment that persists beyond period 4 . On the contrary, supporters whose party loses the subsequent election see a sharp drop in public sector employment probability after period 4 .

While we restrict the sample to supporters of parties involved in a close race in the first election, one may be concerned that supporters of a party that loses power in the subsequent election are different than supporters whose party maintains power. In the right panel of Figure 1.8 we show that the patterns discussed above hold true even when we focus only on the subset of parties involved in a close mayoral race in both the election taking place in period 0 and in the election taking place in period 4 (and therefore characterized by a similar electoral strength in both elections).

These patterns show that public sector jobs allocated to supporters are deeply linked to the fortunes of their party, and cast doubts on the interpretation of political favoritism as an efficient way in which the mayor is screening members of her political network along hard-to-observe dimensions of quality. 
(a) Close Election at $\mathbf{t}=\mathbf{0}$

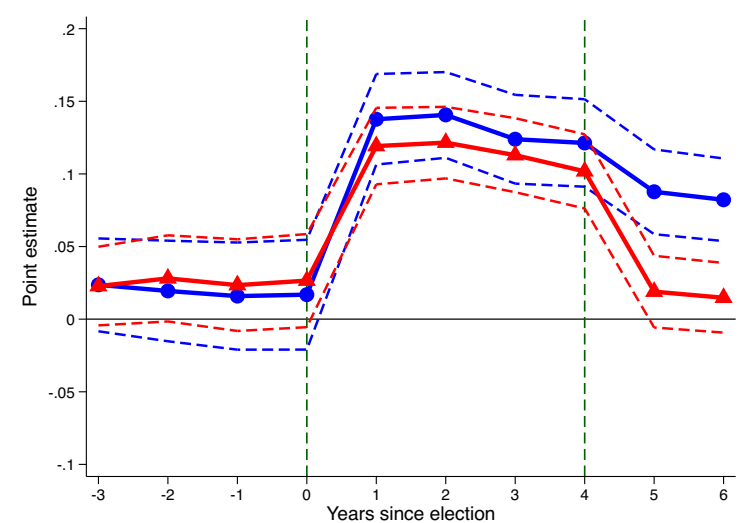

(b) Close Election at $\mathbf{t}=0$ and $\mathbf{t}=4$

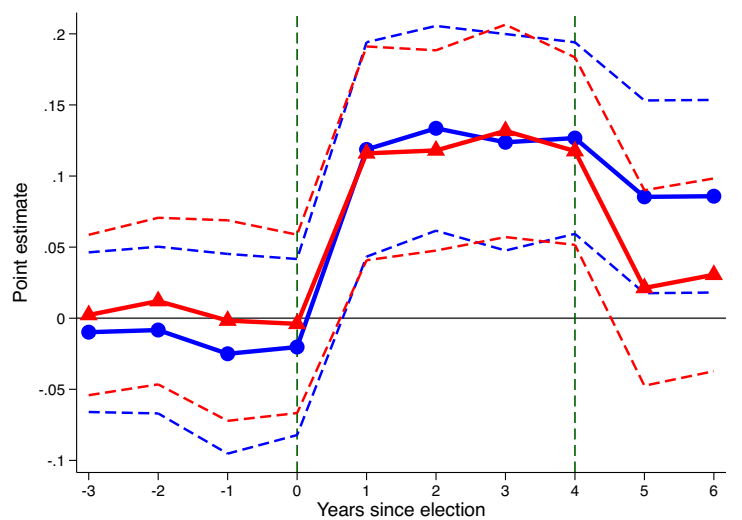

Always Connected to Mayor Connected to Mayor Until $t=4$

Notes: The figure presents the estimated $\beta_{k}^{\text {One }}$ and $\beta_{k}^{\text {Both }}$ coefficients from equation (1.11) with probability of employment in the public sector as the outcome variable. We separately focus on three groups of supporters: those supporting a party winning two consecutive elections (in year 0 and in year 4); those supporting a party winning the election in year 0 but losing the election in year 4; those supporting a party losing both the election in year 0 and the election in year 4. Plotted in blue is the effect of supporting a party winning both the elections versus supporting a party losing both the elections. Plotted in red is the effect of supporting a party winning only the first election versus supporting a party losing both the elections. In Panel (a), the sample is restricted to the subset of supporters of a party involved in a close mayoral election in year 0 . In Panel (b), the sample is restricted to the subset of supporters of a party involved in two consecutive close mayoral elections (in year 0 and in year 4). The dotted lines show 95\% confidence intervals and are based on standard errors double clustered at the supporter and election level.

Figure 1.8: Supporters' Public Sector Employment Probability Depends on Party Fortune

\subsubsection{Is the mayor's goal to create an ideologically cohesive team?}

Political supporters' preferential access to public sector jobs may be the result of the mayor's desire to hire individuals with similar ideological views. Theoretically, the matching between the political ideology of the mayor and that of her bureaucrats can increase organizational efficiency. For a politician, hiring top-level bureaucrats who share her same policy agenda could facilitate the process of policy implementation. But this ideological alignment could in principle be beneficial also at lower levels of the bureaucratic hierarchy: workers who are ideologically aligned with the party in power may be motivated to increase effort since they 
care about the mission of their organization. ${ }^{91}$

If this interpretation of political favoritism is correct, then the supporters who benefit more from favoritism should be those who have a stronger ideological link to the party in power. We test for this hypothesis by investigating whether individuals who have been supporters of the mayor's party for a longer period of time are more likely to be favored in accessing public sector jobs. For each election, we focus on the subset of supporters who had run/donated also in the previous election, and we divide them in: "party loyals", namely those who were supporters of the party of the mayoral candidate also in the previous election, and "party switchers", namely those who in the previous election were supporters of a different party.

We calculate the extent of political favoritism in these different subsamples of supporters. Figure 1.9 shows that the effects of supporting the winning party estimated on these different subsamples are very similar. ${ }^{92}$ In fact, we cannot reject the hypothesis that party switchers are rewarded less than party loyals. If anything, we find that "loyals" are rewarded less than "switchers" among donors, even if the effects are too noisily estimated to reject the hypothesis of equality of the coefficients in the different samples.

In other words, the mayor is more likely to hire her supporters irrespectively of the length of a supporter's connection to the party: individuals who recently switched political alliances are as likely to be allocated a public sector job as individuals who have been loyal to the party for multiple election cycles. This evidence cast doubts on the interpretation of political favoritism as the result of the mayor's desire to hire individuals with similar ideological views.

\footnotetext{
${ }^{91}$ There is evidence that workers exert more effort when they care about the mission of their organization (Ashraf et al. (2014), Tonin and Vlassopoulos (2010), Tonin and Vlassopoulos (2015), DellaVigna and Pope (2017)).

${ }^{92}$ Appendix Table A.21 presents the estimates in table format.
} 

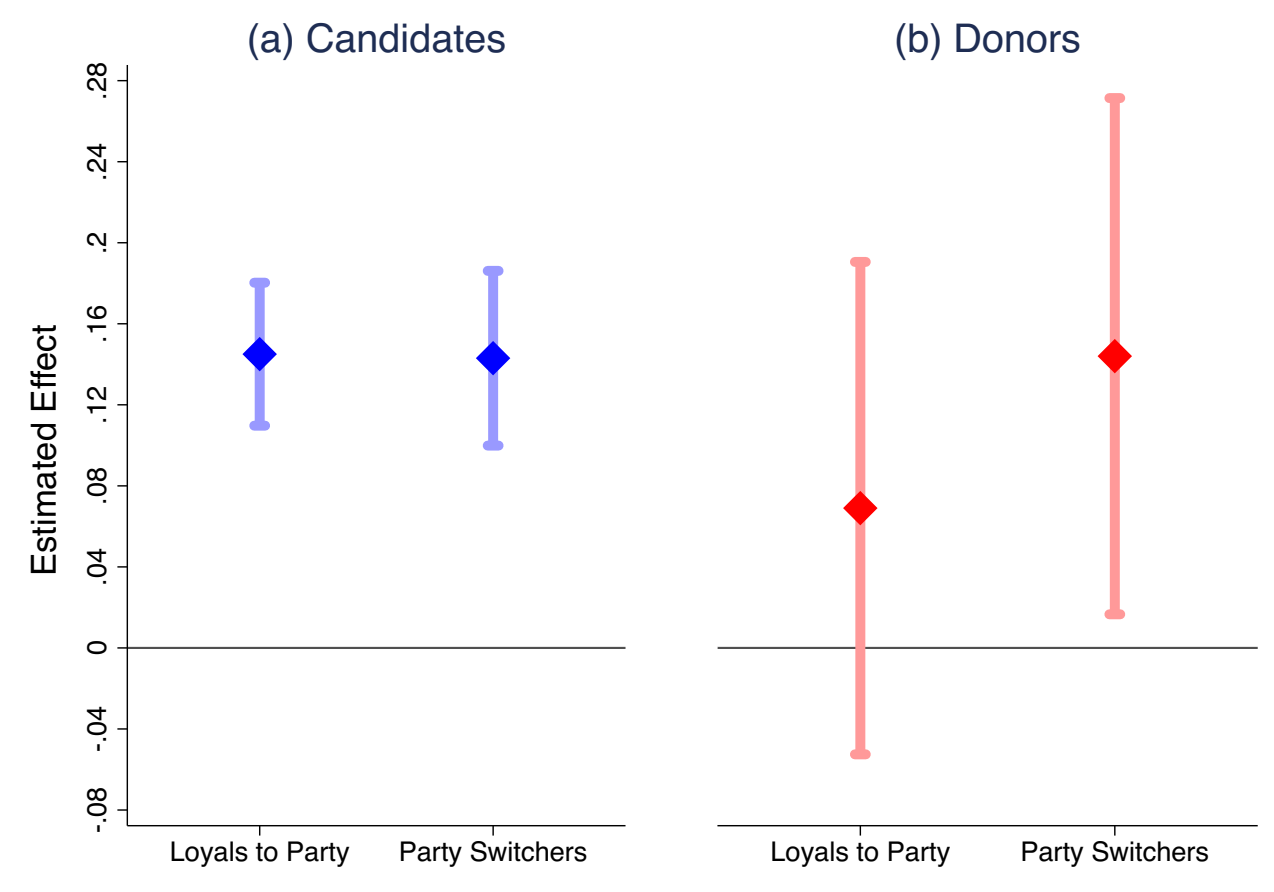

Notes: The figure shows the estimated coefficients and 95\% confidence intervals for the estimated $\beta$ from equation (1.1) with probability of employment in the public sector as the outcome variable, for different subsample supporters. "Loyals to Party" refer to candidates (respectively, donors) who in the previous election run in (respectively, donated to) the same party of the mayoral candidate supported in the current election. "Party Switchers" refer to candidates (respectively, donors) who in the previous election run in (respectively, donated to) a different party than the one of the mayoral candidate supported in the current election. Results in Panel (a) are estimated on the sample of candidates. Results in Panel (b) are estimated on the sample of donors. The sample is composed of supporters of the winning mayoral candidate or the close loser, using a 5\% margin of victory to define close races. The sample is further restricted to supporters of the winning mayoral candidate or the close loser who had run/donated also in the previous elections. The sample of elections is 2004, 2008, 2012 for candidates and 2008 and 2012 for donors. 95\% confidence intervals are based on standard errors double clustered at the candidate and election level.

Figure 1.9: Effect of Supporting the Winning Party Among Switchers and Loyals

\subsection{Patronage and Public Services Provision}

Are municipalities where patronage is more widespread characterized by a worse public goods provision? While to answer this question in a rigorous way we would need exogenous variation in the extent of patronage across municipalities, in this section we move a first step 
towards answering this question: we analyze how changes in the extent of patronage within the same municipality over time correlate with changes in the quality of education, as well as with changes in the size of the public sector workforce.

As a first step, we calculate, for each of the 7,696 elections in the 2004-2012 period decided by a margin of victory of $10 \%$ or less, an estimate of patronage, defined as the average difference in public sector employment probability, over the four years after the election, between the supporters of the mayor versus the supporters of the runner-up. ${ }^{93}$ Specifically, we pool observations for the four post-election years, and for each municipality $m$ and election year $t$ we estimate the following specification:

$$
y_{i k}=\gamma_{k}+\beta_{m t} \text { Mayor }_{i}+\epsilon_{i t}
$$

Where $y_{i k}$ is an indicator variable equal to one if supporter $i$ is employed in the municipality in period $k$ (i.e. year relative to the election year), and $\gamma_{k}$ are period fixed effects. Our estimate of patronage is the estimate of the coefficient $\beta_{m t}$ on the indicator variable turning to one for supporters of the winning mayoral candidate. Figure 1.10 plots the distribution of these estimates. Most of the elections (81.4\%) have a positive patronage estimate, indicating the widespread importance of political connections as drivers of Brazilian public sector employment.

\footnotetext{
${ }^{93}$ We do not use the 2000 election cycle since for this specific year we do not have data on donors and, in addition, we cannot control for a series of important covariates that would require electoral data for the 1996 election cycle, for which we have no information. Relative to the results presented so far, here we focus on a larger bandwidth to define a race as close. Since our analysis leverages variation within municipalities over time, if we used a smaller bandwidth we would have few municipalities experiencing multiple close elections over the sample period. However, as we showed in Figure 1.5, the magnitude of patronage seems to be very stable over different margin of victories. Additionally, the corresponding optimal bandwidth computed following (Calonico et al., 2014) is actually larger than 10 (11.3 in the sample of candidates and 11.4 in the sample of donors).
} 


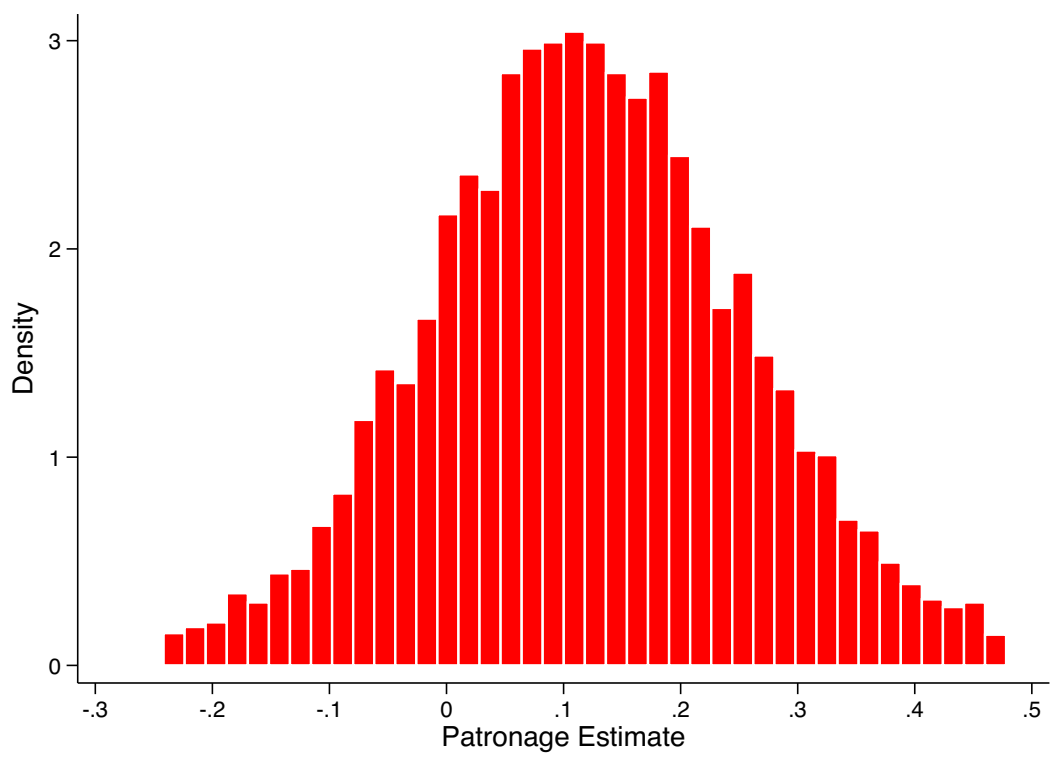

Notes: The figure shows the distribution of the estimates of patronage across the 7,696 elections over the 2004-2012 period decided by a margin of victory between the mayor and the runner-up of $10 \%$ or less. See Section 1.7 for a description of the method to calculate the election-specific patronage estimates. The average of the estimates is 0.118 .

Figure 1.10: Distribution of Patronage Across Elections

We then focus on the sample of 2,420 municipalities that experience multiple close races over the 2004-2012 period and we estimate the following model:

$$
y_{m t}=\alpha_{m}+\gamma_{t}+\delta \hat{\beta}_{m t}+\theta X_{m t}+\eta_{m t}
$$

Where $y_{m t}$ is a specific outcome in municipality $m$ in the years following election year $t, \alpha_{m}$ are municipality fixed effects, $\gamma_{t}$ are election year fixed effects, and $\hat{\beta}_{m t}$ is the patronage estimate for municipality $m$ in election year $t$, estimated from equation 1.12 .

Our empirical strategy controls for any time-invariant municipality-specific determinant of patronage that is correlated with welfare related outcomes, as well as for any unobservable that is common to all municipalities in an election year. However, it could be the case that other municipality-level time-varying heterogeneity correlated with the extent of patronage in a specific election drives also welfare outcomes. We control for an extensive set of 
time-varying municipal-level covariates to try to address this concern. First, we control for a set of characteristics of the election. ${ }^{94}$ We control for a number of time-varying municipality characteristics, which include a second order polynomial in the municipality population, the municipality per-capita gdp, and the number of private sector employees per capita. These variables are meant to address the concern that municipalities that are hit by negative economic shocks could experience worse welfare outcomes and at the same time see an increase in patronage. We also control for capital and current public expenditures per capita in the municipality. Finally, we control for the personnel turnover (the share of hires and the share of terminations) in the public sector in the year after the election. This is an important control, since patronage could be positively correlated with public sector turnover. At the same time, irrespective of whether turnover is driven by the appointment of political supporters, the disruption in the public sector personnel could lead to a worse provision of public services (Akhtari et al. (2016)).

We start by examining whether more patronage is associated with a larger public sector workforce. ${ }^{95}$ Panel A of Table 1.13 shows that municipalities with an increase in patronage relative to other elections see a larger increase in the number of public sector workers per capita. An increase of one standard deviation in patronage is associated to a 0.041 standard deviations increase in the municipality number of public sector workers per capita. ${ }^{96}$ The estimate is robust to the inclusion of the full set of controls.

Next, we investigate whether patronage is associated with a better or worse provision of

\footnotetext{
${ }^{94}$ In order to control for the extent of political turnover in the election, we include covariates for: the share of supporters of the mayor and of the runner-up whose party was already in the winning coalition, indicators for party turnover, for whether the incumbent mayor was re-elected and for whether the party of the mayor is the same in power at the state level, the share of new parties in power after the election, the share of new candidates in the winning coalition and in the winning party. We also control for the margin of victory of the winning mayoral candidate. In addition, since the identity of the elected mayor could be correlated with the extent of patronage, we control for the gender of the mayor, for a set of fixed effects for the mayor's education, and for a set of fixed effects for the mayor's party, since specific parties could be more likely to engage in patronage.

${ }^{95}$ We average the municipality-level number of public sector workers per capita over the four years after the election.

${ }^{96}$ To gauge the magnitude of the result, we find that a one standard deviation increase in the municipality gdp per capita is associated to a 0.082 standard deviations increase in the number of public sector workers per capita.
} 
public goods. We use welfare indicators related to education, one of the main responsibilities of Brazilian local governments. As a welfare indicator for education we use standardized test scores from Prova Brasil, a standardized exam administered to public schools students in the 4 th and 8 th grade. ${ }^{97}$ We average each student's test scores in math and Portuguese, and then take the average in the municipality. ${ }^{98}$

Panels B and C of Table 1.13 show that patronage is associated with significantly lower test scores for both 4 th grade and 8th grade students. Looking at the most conservative estimates (in column 4, the specification where all controls are included), a standard deviation increase in patronage is correlated with a 0.021 standard deviations decrease in 4th graders' test scores and with a 0.03 standard deviations decrease in 8th graders' test scores. ${ }^{99}$ The estimates are stable across specifications, and they remain statistically significant even after we control for the extent of public sector turnover following the election, suggesting that patronage is related to worse education outcomes even after accounting for possible disruptions in the public personnel following an election.

These results provide some suggestive evidence that patronage might have significant negative welfare consequences.

\footnotetext{
${ }^{97}$ Schools will less than 20 students enrolled in the 4th and 8th grade do not participate in the Prova Brasil exam, slightly reducing the available sample size.

${ }^{98}$ The exam is administered every two years. We use 2007 test scores for the 2004 election cycle, 2011 test scores for the 2008 election cycle, and 2013 test scores for the 2012 election cycle.

${ }^{99}$ To gauge the magnitude of the result, we find that a one standard deviation increase in the municipality gdp per capita is associated to a 0.078 standard deviations increase in 4th graders' test scores and to a 0.09 increase in 8th graders' test scores.
} 
Table 1.13: Patronage And Municipal-Level Outcomes

\begin{tabular}{|c|c|c|c|c|}
\hline & $(1)$ & $(2)$ & (3) & $(4)$ \\
\hline \multicolumn{5}{|c|}{ Panel A: Dep. Var. is Public Sector Workers Per Capita } \\
\hline Patronage & $\begin{array}{c}0.005^{* * *} \\
(0.001)\end{array}$ & $\begin{array}{c}0.005^{* * *} \\
(0.001)\end{array}$ & $\begin{array}{c}0.005^{* * *} \\
(0.001)\end{array}$ & $\begin{array}{c}0.004^{* * *} \\
(0.001)\end{array}$ \\
\hline Observations & 5,475 & 5,451 & 5,442 & 5,208 \\
\hline R-squared & 0.926 & 0.927 & 0.930 & 0.940 \\
\hline SD D.V. & 0.0180 & 0.0180 & 0.0180 & 0.0180 \\
\hline SD Patronage & 0.144 & 0.144 & 0.144 & 0.145 \\
\hline Municipalities & 2420 & 2410 & 2407 & 2314 \\
\hline \multicolumn{5}{|c|}{ Panel B: Dep. Var. is 4th Grade Test Scores } \\
\hline Patronage & $\begin{array}{l}-0.061^{*} \\
(0.032)\end{array}$ & $\begin{array}{c}-0.067^{* *} \\
(0.032)\end{array}$ & $\begin{array}{c}-0.063^{* *} \\
(0.032)\end{array}$ & $\begin{array}{c}-0.069^{* *} \\
(0.032)\end{array}$ \\
\hline Observations & 4,787 & 4,764 & 4,757 & 4,541 \\
\hline R-squared & 0.873 & 0.874 & 0.877 & 0.877 \\
\hline SD D.V. & 0.432 & 0.432 & 0.432 & 0.429 \\
\hline SD Patronage & 0.142 & 0.142 & 0.142 & 0.142 \\
\hline Municipalities & 2136 & 2126 & 2124 & 2036 \\
\hline \multicolumn{5}{|c|}{ Panel C: Dep. Var. is 8th Grade Test Scores } \\
\hline Patronage & $\begin{array}{c}-0.065^{* *} \\
(0.031)\end{array}$ & $\begin{array}{c}-0.067^{* *} \\
(0.031)\end{array}$ & $\begin{array}{c}-0.071^{* *} \\
(0.032)\end{array}$ & $\begin{array}{c}-0.076^{* *} \\
(0.032)\end{array}$ \\
\hline Observations & 3,118 & 3,101 & 3,094 & 2,931 \\
\hline R-squared & 0.880 & 0.881 & 0.882 & 0.883 \\
\hline SD D.V. & 0.352 & 0.353 & 0.353 & 0.349 \\
\hline SD Patronage & 0.140 & 0.140 & 0.140 & 0.140 \\
\hline Municipalities & 1384 & 1377 & 1375 & 1309 \\
\hline Election Controls & Yes & Yes & Yes & Yes \\
\hline Mayor Controls & No & Yes & Yes & Yes \\
\hline Municipality Controls & No & No & Yes & Yes \\
\hline Public Budget Controls & No & No & No & Yes \\
\hline
\end{tabular}

Notes: The table presents estimates of a regression of the variable listed in the title of the panel on the patronage estimate at the municipality-election level, controlling for election year fixed effects and municipality fixed effects. The sample includes only elections decided by a margin of victory of $10 \%$ or less, and is restricted to municipalities with at least two close races in the 2004-2012 period. Election controls include the share of candidates and donors supporting the mayor and the runnerup whose party was already in the winning coalition, indicators for party turnover, for whether the incumbent mayor is re-elected and for whether the party of the mayor is the same in power at the state level, the share of new parties in power after the election, the share of new candidates in the winning coalition and in the winning party, and the margin of victory of the winning mayor. Mayor controls include an indicator for whether mayor is male, mayor's education fixed effects, and fixed effects for the mayor's party. Municipality controls include a second-order polynomial in municipality population, municipality per capita gdp, and the number of private sector employees per capita. Public budget controls include capital and current expenditures per capita, and churn in the public sector in the year after the election. See Section 1.7 for a description of the method to calculate the election-specific patronage estimates. "SD D.V." shows the standard deviation of the dependent variable. "SD Patronage" shows the standard deviation of the patronage estimate. Standard errors in parentheses, clustered at the municipality level. ${ }^{* *} \mathrm{p}<0.01,{ }^{* *} \mathrm{p}<0.05,{ }^{*} \mathrm{p}<0.1$. 


\subsection{Conclusion}

In this paper we study patronage - the use of public sector jobs to reward political supporters of the party in power - in the context of Brazilian local governments. While anecdotal accounts of patronage are common, multiple empirical challenges have made it difficult to convincingly document the presence, extent, and consequences of this phenomenon. Using a unique dataset on the universe of Brazilian public sector employees over the 1997-2014 period, matched with information on more than 2,000,000 political supporters of Brazilian local parties, this paper aims to fill this gap.

First, by leveraging competitive elections to obtain exogenous shocks to an individual's connection with the party in power, we identify the presence of significant political favoritism in public employment: being a political supporter of the party in power increases the probability of having a public sector job by $47 \%$. This favoritism is large at all layers of the Brazilian public sector hierarchy.

Second, we show evidence that patronage is the crucial mechanism behind favoritism in public employment, leading to the selection of less qualified public workers. In line with a quid pro quo relationship between supporters and political parties, a supporter's public sector return is proportional to the amount of support provided. In turn, the provision of political support acts as a substitute for individual quality: supporters of the party in power are screened less in terms of education and of skills valued by the private sector. The evidence is inconsistent with a significant role played by alternative channels in explaining the existence of this favoritism. In particular, we show that the politicians' desire to hire individuals with similar ideological views is not a likely explanation for the results. Similarly, multiple pieces of evidence are inconsistent with an interpretation of favoritism as the result of politicians' efficient screening of supporters along hard-to-observe dimensions of quality.

Third, we move a first step towards understanding whether, in line with the negative impact on selection to public employment that we document, patronage negatively affects the quality of public goods provision. We do so by linking differential changes in withinmunicipality variation in the extent of patronage over time to the quality of municipal 
primary education, one of the main responsibilities of Brazilian local governments. We show that an increase in patronage is correlated with lower test scores of students enrolled in municipal public schools. In addition, an increase in the extent of patronage is associated with significant higher growth in municipal public sector personnel, consistent with politicians increasing the size of the bureaucracy in presence of incentives to engage in patronage practices.

Clearly, we do not study all the possible mechanisms through which patronage might affect welfare. Potential additional costs of patronage include the disruption in the bureaucracy that is linked to political turnover, ${ }^{100}$ or the misallocation of funds between public sector personnel and other, more productive investments. We are also unable to quantify potentially positive effects of patronage, such as possible decreases in agency problems because of loyalty between hired supporters and the party in power. Investigating the additional channels through which the presence of patronage practices might affect the quality of public service delivery represents an exciting avenue for future research.

${ }^{100}$ Akhtari et al. (2016) 


\section{Chapter 2}

\section{The Long-Term Effect of Demographic Shocks on the Evolution of Gender \\ Roles: Evidence from the transatlantic Slave Trade}

\subsection{Introduction}

The degree to which women participate in the labor force and their more general role in society differ widely across the world, and this variation goes hand in hand with variation in cultural beliefs about the appropriate role of women (Fortin (2005); Fernandez (2007); Fernandez and Fogli (2009)). History can affect the evolution of these beliefs, as specific gender norms arise following shocks to the working status of women and tend to persist as they are transmitted across generations (Alesina et al., 2013). Demographic shocks that alter a society's sex ratio can potentially have long-run effects on the role of women, if a shortage of male workers increases female labor supply and this affects the predominant views about working women. In the context of the United States during World War II, the temporary absence of men pushed women into the labor force, with effects on female labor 
supply that persisted in the decades after the end of the war (Goldin (1991); Acemoglu et al. (2004); Goldin and Olivetti (2013)).

In this paper, I ask whether demographic shocks can have an impact on female labor force participation that persists in the very long run, and I study the role played by different channels in explaining persistence. Specifically, I link current variation in women's participation in the labor force within Sub-Saharan Africa to a large demographic shock that accompanied one of the most crucial events in African history: the transatlantic slave trade.

Male slaves vastly outnumbered female slaves in the transatlantic slave trade, as males were preferred by plantation owners in the New World for their physical strength. This led to a shortage of men and to the emergence of abnormal sex ratios in the remaining African population (Lovejoy, 1989). In the areas most affected, historical estimates suggest the presence of as few as 50 men per 100 women (Miller (1988); Manning (1990)). Given the shortage of men, women had to substitute for them in the activities they used to perform, taking up areas of work that were traditionally male tasks (Thornton (1983); Manning (1990); Lovejoy (2000)). Although sex ratios reverted back to natural levels shortly after the end of the slave trade, the impact of this demographic shock on the role of women could be longlasting if it persistently affected cultural beliefs and societal norms. Theoretically, revised attitudes towards working women can persist in the long run through a marriage market channel (Fernandez et al., 2004) or a process of intergenerational learning (Fernandez, 2013), or in presence of multiple equilibria (Hazan and Maoz, 2002). I test whether the shock to the division of labor that followed the transatlantic slave trade had long-lasting consequences on gender-role attitudes and can explain current variation in women's participation in the labor force within Sub-Saharan Africa.

To test for this, I use Demographic and Health Surveys (International) data on more than 500,000 women from 21 Sub-Saharan African countries, combined with Nunn and Wantchekon (2011)'s ethnicity-level data on the number of slaves taken during the slave trades. Exploiting variation in the degree to which different ethnic groups were affected by the transatlantic slave trade, I show that women whose ancestors were more exposed to this 
slave trade are today significantly more likely to be in the labor force. In particular, they are more likely to be employed in a higher ranking occupation.

As a falsification test, I examine whether the same result is found when we consider the number of slaves taken during the Indian Ocean slave trade. Consistent with traders during this slave trade not having a preference for exporting more men, we find no evidence of increased women's participation in the labor force among the descendants of those more exposed to the Indian Ocean slave trade. While this result is consistent with the emergence of a biased sex ratio as a channel explaining this long run effect, there were other historical differences between these two slave trades. While historical accounts do not point to a clear factor that could have potentially led to a differential impact of the two slave trades on the long-run evolution of FLFP, my reduced form evidence should be read with this caveat in mind.

I show that we do not find a similar effect of the transatlantic slave trade on current men's participation in the labor force. This rules out the possibility that a greater exposure to the transatlantic slave trade led to structural changes in the economy that were conducive to a persistent higher employment across both genders.

The fact that information on the exposure to the transatlantic slave trade is measured at the level of an ethnic group, rather than at the location level, allows one to shed light on the mechanisms explaining persistence. Fernandez et al. (2004) theorize that cultural beliefs about the role of women can be transmitted through a marriage market channel. Working mothers transmit to their sons a more positive view about working women, making them more likely to have a preference for a working wife later in life. Leveraging information on the husband's ethnicity for women in my sample, I can test whether a man's ancestors' exposure to the transatlantic slave trade increases the likelihood that his wife is employed. Specifically, I compare labor force participation among women of the same ethnicity who married men whose ancestors' exposure to the transatlantic slave trade differed. Consistent with a husband's beliefs also playing an important role, the exposure of a woman's husband's ethnic group to the transatlantic slave trade is associated with higher 
women's labor force participation. ${ }^{1}$

While the focus of the paper is on the role played by cultural beliefs, an alternative explanation for the findings is that places that were more affected by the transatlantic slave trade developed markets and local institutions leading to higher female labor force participation. To estimate the role played by cultural values that are internal to individuals, I compare individuals of different ethnicities who currently live in the same village or in the same neighborhood within a city. While this specification gives an effect of the transatlantic slave trade that is about $50 \%$ lower in magnitude, the transatlantic slave trade continues to play a significant role even after we fully control for the effects of the slave trade on contemporaneous external factors that may be conducive to greater women's employment.

Finally, by looking at heterogeneous effects across cohorts of women born between the 1950s and the 1980s, I show that the positive effect of the transatlantic slave trade on FLFP has remained fairly stable over time. This confirms the high persistence of historical shocks to cultural norms, which continue to play an important role even as external factors change over time.

I show that the results presented are robust to the inclusion of a wide set of controls, including covariates capturing European influence during the colonial period, historical proxies for the initial prosperity of an ethnic group and for the complexity of its political institutions, and information on the historical structure of the ethnic group's economy. Similarly, the results are not explained by an effect of the transatlantic slave trade on polygyny, nor by higher human capital accumulation among women.

In addition, following the approach in Nunn and Wantchekon (2011), I use the historical distance of an ethnic group from the coast as an instrument for the exposure to the transatlantic slave trade. As traders purchased slaves at ports to ship them oversea, groups inhabiting areas closer to the coast were more likely to be exposed to the external demand for slaves. I further augment Nunn and Wantchekon (2011)'s IV specification by exploiting

\footnotetext{
${ }^{1}$ For a recent investigation of the role played by gender identity norms within the family, see Bertrand et al. (2015).
} 
only within-location variation: the identifying assumption requires that, among women currently living in the same location, ancestors' distance from the coast affects women's labor force participation today only through the exposure to the transatlantic slave trade. The estimates from the IV regressions confirm the OLS estimates. These results reduce possible concerns about the presence of unobservable historical factors that are correlated with both the severity of the transatlantic slave trade and current levels of women's participation in the labor force.

Consistent with a higher cost of having children for working women, I show that women whose ancestors were more heavily enslaved in the transatlantic slave trade have lower levels of fertility today. In addition, they are more likely to participate in household decisions. However, using data from the Afrobarometer surveys, I do not find strong evidence of a persistent effect of the transatlantic slave trade on general attitudes towards women in domains other than the labor market. While we may expect that, as women take up traditional male activities, this will lead to the emergence of more equal gender norms in other domains as well, theoretical models of intra-household bargaining in presence of skewed sex ratios suggest the opposite (Becker (1973). Becker (1974), Becker (1981)). A demographic shock that makes men scarce in the marriage market should have reduced women's bargaining power during the centuries of the slave trade. While this decreased bargaining power predicts a higher involvement of women in activities outside of the house, it also points towards the potential crystallization of more conservative attitudes towards women in other domains. Therefore, while the impact of the transatlantic slave trade on the involvement of women in activities outside of the house is theoretically clear, its long-run effects are ambiguous when we consider beliefs other than those affecting the division of labor in the household. The mixed evidence that I find indeed suggests that demographic shocks, while having a persistent impact on FLFP, may not have a comparable effect on gender equality in domains other than the labor market.

This paper contributes to several strands of literature. First, these findings are directly related to the literature on the impact of shocks to sex ratios on women's labor supply. 
Most of this literature focuses on the United States during World War II. ${ }^{2}$ Given the high mobilization rate of men, female labor force participation in the US dramatically increased from 1940 to 1945. ${ }^{3}$ Acemoglu et al. (2004) and Goldin and Olivetti (2013) use exogenous variation in mobilization rates across states and uncover that the impact of World War II on FLFP was still present in the 1960s, especially for more educated women. Exploiting the same source of variation, Fernandez et al. (2004) find an effect on women's participation in the labor force that persists through the 1980s, which they rationalize with the increased presence of men who were raised by working women.

I contribute to this literature by showing how the effects of demographic shocks to sex ratios can persist in the very long run, as the impact of the transatlantic slave trade on female labor force participation is still significant more than a century after sex ratios reverted back to their natural level. In addition, I rely on an ethnic-group level shock rather than a location-specific one - and on detailed data on the ethnicity of both women and their husband, as well as on their current location, to disentangle the different channels behind this very long-run effect. First, I can isolate the role played by the intergenerational transmission of cultural values vis-à-vis a persistent effect of the demographic shock on the external environment. Second, leveraging information on a woman's husband's ethnicity, I can show how persistence does not solely follow from cultural transmission of gender norms from parents to daughters, but also from cultural transmissions from parents to sons. ${ }^{4}$ Finally, the previous literature on the role of World War II focuses on a country that was experiencing a sustained period of growth and a steady increase in the service sector,

\footnotetext{
${ }^{2}$ Other studies that look at the impact of demographic shocks on the marriage market and female labor supply include Grossbard-Shechtman and Neideffer (1997), Angrist (2002), Chiappori et al. (2002), Abramitzky et al. (2011), Francis (2011), Brainerd (2017).

${ }^{3}$ Historians suggest that this represented a "watershed event" that permanently redefined the role of women in society (Chafe (1972), p.195). However, a revisionist literature has criticized this view, neglecting the role of World War II in affecting long-run gender roles and women's participation in the labor force. See Goldin (1991) for a review of these two literatures.

${ }^{4}$ The fact that I rely on an ethnic-group level shock is crucial to show the persistence of the shock and the mechanisms explaining persistence: while people relocate over the centuries, information on respondents' ethnicity and on the exposure to the shock of each African ethnic group allows me to measure the extent to which the respondents' ancestors were affected by the slave trade.
} 
which could have facilitated the persistence of more equal gender norms after the end of the demographic shock (Goldin and Olivetti, 2013). By focusing on Sub-Saharan Africa, I show that demographic shocks can persistently affect women's participation in the labor force in a setting characterized by stagnant economic conditions.

More generally, this paper contributes to a nascent literature on the historical roots of attitudes towards gender roles. Alesina et al. (2013) show that a tradition of plough cultivation is associated with more unequal gender norms, consistent with Boserup (1970)'s hypothesis. Building on Diamond (1987), Iversen and Rosenbluth (2010) and Ashraf and Galor (2011), Hansen et al. (2015) link current unequal gender norms to a long history of agriculture. Campa and Serafinelli (2016) document how more equal gender-role attitudes emerged in state-socialist regimes. Becker and Woessmann (2008) study the long-term impact of the Protestant Reformation on the gender-gap in education and literacy. The findings of my paper dovetail and complement those in Grosjean and Khattar (2015), who study the long-run effect of the male biased sex ratio that emerged in Australia by the late eighteenth century as a consequence of the inflow of British convicts. Since the great majority of the convicts were men, in the areas where the convicts were transported individuals are today characterized by more conservative attitudes towards working women.

Finally, this paper contributes to the literature on the effects of the Africa's slave trade. A growing list of studies have looked at the effect of this historical event on long term development (Nunn, 2008), interpersonal trust (Nunn and Wantchekon, 2011), the evolution of political authority (Whatley, 2013), ethnic stratification (Whatley and Gillezeau, 2011), polygyny (Dalton and Cheuk Leung (2014); Fenske (2013); Edlund and Ku (2013)), and conflict (Fenske and Kala, 2017), and at the determinants of the supply of slaves (Whatley (2014); Fenske and Kala (2015)).

The rest of the paper is organized as follows. In Section 2.2, I discuss the historical background and theoretical framework that motivate my hypothesis. Section 2.3 describes the data and the main empirical specification. The empirical results on the relationship between the transatlantic slave trade and women's labor force participation, together with 
the analysis of the mechanisms explaining persistence, are presented in Section 2.4. In Section 2.5, I look at the impact of the transatlantic slave trade on fertility and general attitudes about gender roles. Section 2.6 concludes.

\subsection{Historical Background and Conceptual Framework}

\subsubsection{Historical Background}

Between the fifteenth and the nineteenth century approximately 12 million slaves were exported from Africa during the transatlantic slave trade. The other three slave trades - the trans-Saharan, Red Sea and Indian Ocean slave trades - accounted for another 6 million slaves. These figures, together with the number of slaves who died during the raids and transportations to the ports of export, translated into severe demographic consequences. Estimates by Manning (1990) (p.171) suggest that Africa's population in 1850 was half of what it would have been in the absence of slavery.

The main destinations of the slaves in the transatlantic slave trade were the plantations of the New World. Given the physical strength necessary to perform work in the plantations, European traders had a preference for male slaves. ${ }^{5}$

These patterns dramatically altered the sex ratio in the remaining African population, with the areas more affected by the transatlantic slave trade experiencing a prolonged shortage of men. Figure 2.1 shows a simulation of the population trajectory in Western Africa - the region most heavily raided - built by Manning (1990) using available data on the size and gender composition of the slave population. The bottom panel shows the volume of exports and two estimates of the dynamics of the Western African population based on a low and a high estimate of population growth respectively, while the top panel presents the corresponding simulations for sex ratios. At the peak of the transatlantic trade at the end of the eighteenth century, the sex ratio in West Africa is estimated to be as low as 70 men per

\footnotetext{
${ }^{5}$ A British politician, writing about the business of a plantation, pointed out that "the nature of the slaveservice in the West Indies (being chiefly field labor) requires, for the immediate interest of the planter, a greater number of males" (Edwards (1801), p.118).
} 
100 women.

Miller (1988) (p.160) reports numbers from a Portuguese colonial census taken in the late 1770s in Angola, the hardest-hit area of the continent: among youths (boys age 7-15, girls age 7-14), the sex ratio was of 65 males per 100 females, while it declined to 50 males per 100 females among adults. Visitors of this area "would have gotten the impression of villages filled with women and children, with the pre-pubertal girls outnumbering the boys" Miller (1988) (p.163).
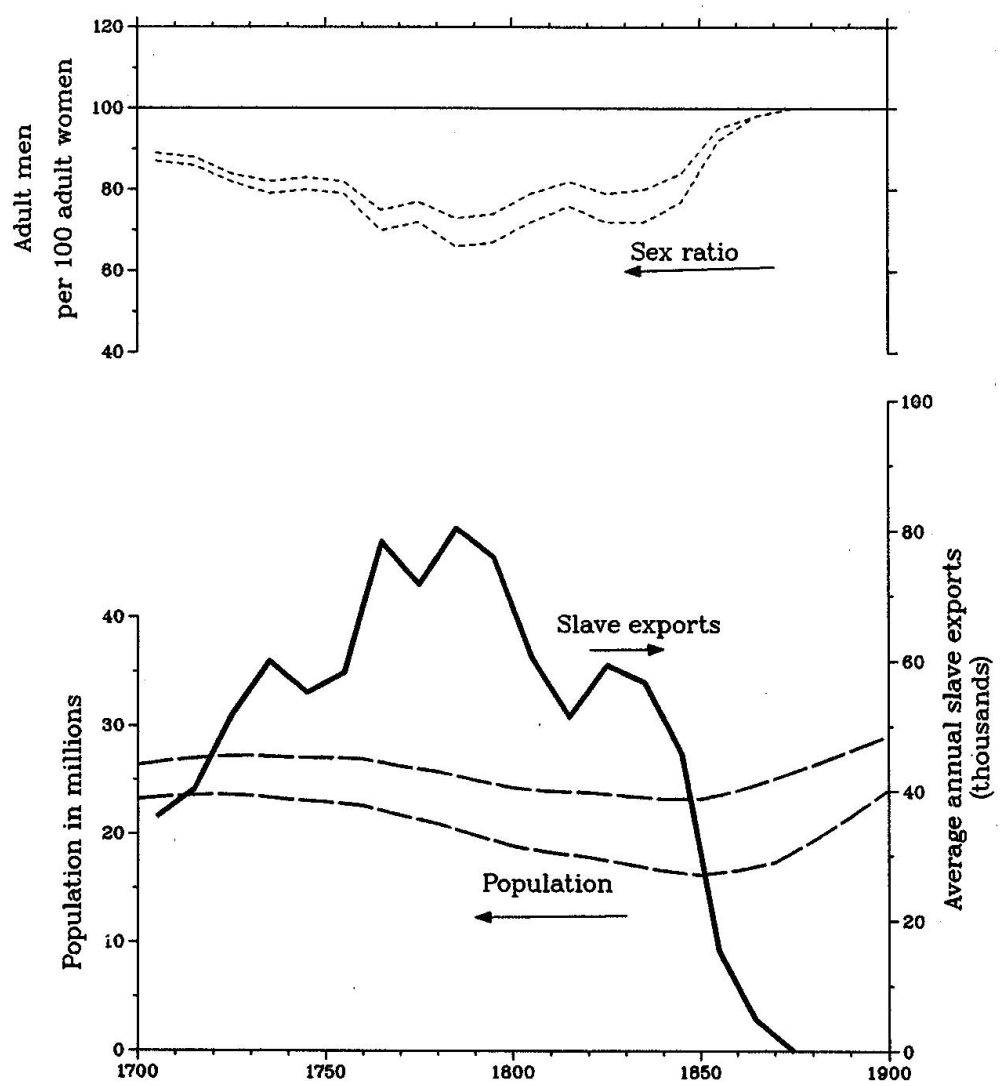

Notes: The figure shows a simulation of the population trajectory in Western Africa built by Manning (1990) using available data on the size and gender composition of the slave population. The bottom panel shows the volume of exports and two estimates of the dynamics of the Western African population based on a low and a high estimate of population growth respectively, while the top panel presents the corresponding simulations for sex ratios.

Figure 2.1: The Demographic Impact of the transatlantic Slave Trade. Source: Manning (1990)

During the other slave trades, slaves were taken across the Saharan desert to Northern 
Africa and from Eastern Africa to the Middle East and India. Slaves buyers in these destinations had a preference for female slaves, who were then employed as concubines and domestic servants (Harris, 1971). ${ }^{6}$ Manning (1990) reports that Eastern Africa, the area most severely hit by these trades, experienced a male biased sex ratio, although the impact was smaller in magnitude and shorter in time.

In the areas hit by the transatlantic slave trade, the emergence of a female biased sex ratio coincided with a more general shock to the role of women. Given the shortage of men, women had to substitute for them in the activities they used to perform. This shock affected both free women and female slaves, for which African demand had increased following the external demand for male slaves. Manning (1990) (p.132) underlines that "in areas where women had traditionally participated in agriculture, their role expanded to that of near total domination of agricultural labor", while in areas where they traditionally did less agricultural labor "the shortage of men pushed women more into commerce than into cultivation". Lovejoy (2000) (p.125) writes that in the coastal areas of West Africa female slaves "wove raffia cloth, a craft that traditionally belonged to males elsewhere in the interior. Apparently the shift from a male to a female occupation occurred because of the availability of women".

Thornton (1983) cites the notes taken by Lemos Coelho, a Portuguese resident of Guinea Bissau, who wrote in 1684 that women "are the ones who work the fields, and plant the crops, and the houses in which they live, even though small, are clean and bright, and despite all this work they still go down to the sea each day to catch shellfish" (Lemos Coelho 1953, p.178).

A telling example of the activities that women were pushed to undertake is provided by the Army of the Dahomey Kingdom, which in 1727 was reinforced by a regiment made entirely by women. Rather than being a deliberate choice, Goldstein (2003) (p.64) suggests that this was due to a severe military shortage, one of the causes of which was that the

\footnotetext{
${ }^{6}$ An exception to this pattern is represented by the predominant export of males to the plantation islands of the Indian Ocean by French traders starting at the beginning of the eighteenth century.
} 
kingdom "depended on a slave trade that gave preference to selling-off able-bodied men".

Historians suggest that another implication of the relative abundance of women in these regions was the increased incidence of polygyny. Although the relevance of polygyny before the slave trades is not known, several authors have pointed out how the unbalanced sex ratio naturally strengthened this institution (Lovejoy (1989); Manning (1990)). Empirical support for this hypothesis was recently provided by Edlund and $\mathrm{Ku}$ (2013) using cross-country evidence and by Dalton and Cheuk Leung (2014) leveraging micro-level data. However, Fenske (2013) shows that the positive relationship between exposure to the transatlantic slave trade and current polygyny depends only on a comparison of West Africa with the rest of the continent. ${ }^{7}$

The transatlantic slave trade led to a severe shock to sex ratios in the African regions more severely affected, which in turn was conducive to an increase in the share of work and in the number of activities women had to perform. My analysis tests for the long-term impact of this shock, investigating whether areas that were more severely affected by the transatlantic slave trade are today characterized by a higher participation of women in the labor market.

\subsubsection{Conceptual Framework}

The emergence of a female biased sex ratio can lead to an increase in the share of work carried out by women because of the need of substituting the missing men in the activities they used to perform, or through a marriage market mechanism. As suggested by Becker (1973) and Becker (1974), sex ratios influence intrahousehold decisions, affecting women's bargaining power and labor force participation, an hypothesis supported by empirical evidence (Grossbard-Shechtman and Neideffer (1997); Angrist (2002); Chiappori et al. (2002))

While these channels explain why the emergence of a female biased sex ratio can lead to

\footnotetext{
${ }^{7}$ Specifically, Fenske (2013) uses micro-level data from the Demographic and Health Surveys and show that the positive impact of the slave trade on polygyny that is found in the data disappears once country fixed effects are included. As discussed later in the paper, I find the same result in my sample.
} 
a temporary increase in women's participation in marketplace activities, this paper tests for the long-run effect of this historical shock on female labor force participation. As it is clear from Figure 2.1, sex ratios in Western Africa quickly converged back to a natural level after the end of the slave trade. ${ }^{8}$ As a consequence, any evidence on the long-run impact of the transatlantic slave trade on gender roles cannot be explained by a long-lasting effect on sex ratios.

A first mechanism explaining persistence rests on the hypothesis that, while temporary, the demographic shock caused by the transatlantic slave trade persistently affected cultural beliefs and norms about the appropriate role of women in society. ${ }^{9}$ In this case, even as the shock to sex ratios died out with the end of the slave trade, social attitudes about working women could have persisted until today, affecting current female labor force participation among the descendants of the populations that were more severely affected by the transatlantic slave trade.

A number of models have been proposed to explain why a temporary external factor can affect cultural norms and beliefs in a persistent way. One possible explanation is provided by a model where cultural norms present multiple equilibria, as in Guiso et al. (2008). Hazan and Maoz (2002) propose a model in this spirit to explain the evolution of FLFP in the United States in the twentieth century. In their model, a woman who works incurs the cost of violating the social norms, which is decreasing in the number of women working in the previous generation. The switch from a low to a high level of women's labor force participation leads to the convergence to an equilibrium characterized by high FLFP and equal gender norms. In the context of my hypothesis, the temporary shock to the role of women in the workforce may have led to the movement to a new equilibrium characterized

\footnotetext{
${ }^{8}$ Figure B.1 in the Appendix shows that there is no significant country-level correlation between exposure to the transatlantic slave trade and current sex ratio.

${ }^{9} \mathrm{~A}$ common problem when analyzing the role of culture in economics arises from the difficulty of providing a precise definition for this concept. Nunn (2012) proposes to use a definition taken from evolutionary anthropology (Boyd and Richerson, 1985), describing culture as a set of heuristics or rules-of-thumb in decision making that arise optimally in presence of costly information acquisition. These set of decision-making heuristics manifest themselves as values and social norms transmitted across generations.
} 
by more equal gender norms.

In the model by Fernandez (2013) beliefs evolve through a process of intergenerational learning. Women observe both a private and a public signal about the costs of working, with the latter being a function of the number of women working in the previous generation. The model delivers a coevolution of beliefs and FLFP. Every factor affecting the number of women working in one generation affects beliefs about the social costs of working among women in the next generation, influencing their labor force participation choices.

Fernandez et al. (2004) theorize that a marriage market mechanism can explain why cultural beliefs about the role of women can vary over time. In their model, a man inherits from his mother his views about the appropriate role of women in society, which crucially depend on the working status of the mother. Working mothers transmit to their sons a more positive view about working women, making them more likely to have a preference for a working wife later in life. ${ }^{10}$ In addition, this marriage market effect increases women's incentive to invest in market skills. A temporary shock to the working status of women during the centuries of the slave trade could therefore have translated into a long-lasting effect on social norms and FLFP through a marriage market mechanism. Exploiting information on the exposure to the transatlantic slave trade of a woman's husband's ancestors, I will be able to investigate the role played by this mechanism.

A second alternative channel that can explain a long-run impact of the transatlantic slave trade on gender roles is not related to cultural factors, but rests on the hypothesis that the temporary shock to the role of women during the centuries of the slave trade permanently shaped the structure of the economy in a way that favors women's participation in marketplace activities. One possibility is that the shortage of men in societies that were more severely hit by the transatlantic slave trade led these societies to specialize in activities that are less capital-intensive, thus reducing women's costs of entering the labor market. I investigate this channel in two ways. First, I analyze which specific occupations are affected

\footnotetext{
${ }^{10}$ For a model with vertical transmission of cultural traits from parents to children see Bisin and Verdier (2001).
} 
by the exposure to the transatlantic slave trade. Second, I exploit within-location variation to control for any long-run effect of the slave trade on the external environment that could have led to higher FLFP, isolating the role played by cultural beliefs in explaining persistence of this historical shock to the role of women.

While all these channels point towards the evolution of more equal gender norms related to women's participation in the workforce, the impact of the transatlantic slave trade on more general attitudes towards women is less clear. One the one side, as women take up traditional male activities outside of the domestic sphere, we may expect this to be accompanied by a more general shift towards more gender equality in other domains. On the other side, the emergence of a female-biased sex ratio increased men's bargaining power in the marriage market during the centuries of the slave trade, which may have potentially led to the crystallization of more conservative gender norms. Therefore, while the long-run impact of the transatlantic slave trade on outcomes and beliefs directly related to a woman's working status are theoretically clear, its long-run effects are ambiguous when we consider beliefs other than those affecting the division of labor in the household. In the last part of the paper, I investigate the impact of the transatlantic slave trade on more general gender-roles attitudes.

\subsection{Data and Empirical Specification}

To study the long-term impact of the transatlantic slave trade on FLFP and gender norms, I match individual-level data from the Demographic and Health Surveys (DHS) and the Afrobarometer surveys with ethnic group-level data on the number of slaves exported during the slave trades. This Section describes the data. 


\subsubsection{Contemporaneous Data}

Data on participation of women in the labor force come from the DHS. I use data from 61 surveys covering 21 countries over the period 1992-2014. ${ }^{11}$ I include in the analysis all the Sub-Saharan African surveys that have data on women's employment status and on the ethnicity of the respondent, for a total of 661,718 women between 15 and 49 years of age. ${ }^{12}$ Figure 2.2 shows which countries enter the sample.

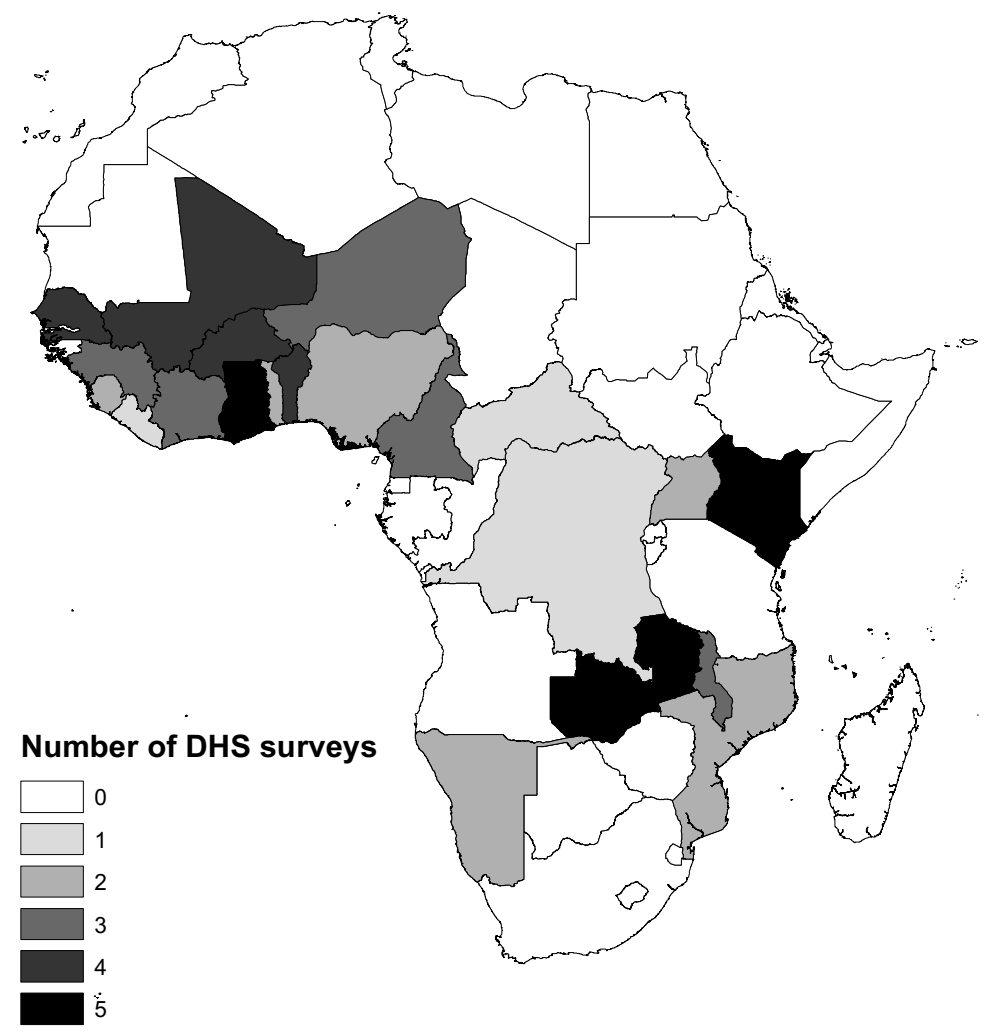

Notes: The figure shows the African countries in the DHS sample, with the corresponding number of survey rounds available for each country.

Figure 2.2: Countries and number of surveys in the DHS sample

In order to perform a falsification test, part of the analysis uses data from the DHS men

\footnotetext{
${ }^{11} \mathrm{~A}$ list of the surveys that enter the sample is provided in the Appendix. The individual-recode versions of the surveys are available at http://www.dhsprogram.com/data/available-datasets.cfm.

${ }^{12}$ Surveys from one additional country - Rwanda - respond to these criteria, but the country was not affected by the slave trade.
} 
surveys, where the respondents are the male members of the same households interviewed in the women surveys. Corresponding men surveys are available for 56 of the 61 surveys considered in the main analysis, for a total of 250,611 male respondents. ${ }^{13}$

I build an individual-level indicator variable, FLFP, that takes value one if the respondent is currently working or she has ever worked in the last twelve months (without distinction between formal and informal employment). Since the DHS does not provide information on whether an unemployed respondent is looking for a job, individuals who have been unemployed for more than one year are coded as not being in the labor force.

The DHS provides information on the occupation of the respondent. In order to investigate the effect of the slave trade on women's occupation, I aggregate the possible answers into five indicator variables. The variable Agriculture takes value one if the woman is employed in the agricultural sector; the variable Manual considers manual occupations; the variable Clerical considers women performing clerical work; the variable Domestic considers women working as domestic servants; finally, the variable High Ranking considers women having relatively higher ranking jobs, namely women working in the sales and service sectors, or as professionals or managers.

Additionally, I use two variables to analyze the effect of the transatlantic slave trade on fertility, namely a woman's number of children ever born and a woman's age at first birth.

Finally, a subset of the DHS surveys present questions that are useful measures of general attitudes about gender roles in domains other than the labor market, which I investigate in Section 2.5. The questions capture women's participation in a set of household decisions, ranging from health care to large and daily household purchases. In addition, another set of questions asks respondents whether they think there are situations in which a husband is justified in beating his wife. In Section 2.5, I use also data from rounds 3-6 of the Afrobarometer (for a total of 81 surveys from 26 countries), which contain information on individual beliefs about the appropriate role of women in politics and on whether men

\footnotetext{
${ }^{13}$ Men surveys are carried out only for a subsample of the households, resulting in a smaller sample of male respondents relative to the sample of female respondents.
} 
and women should have equal rights. Additional details on these variables are provided in Section 2.5.

\subsubsection{Historical Data}

Data on the number of slaves taken from each African ethnic group are from Nunn and Wantchekon (2011) and cover the transatlantic and the Indian Ocean slave trades - the only two slave trades for which historical sources provided detailed enough data to build reliable estimates. The dataset uses as unit of analysis Murdock (1959)'s classification of African ethnicities into 842 groups. Figure 2.3 shows the spatial distribution of the number of slaves taken from each ethnic group during the transatlantic slave trade. ${ }^{14}$ While Western Africa represented the greatest source of slaves, the Eastern coast was also affected. By comparing the maps in Figures 2.2 and 2.3, we can see how my sample comprises all the countries that were most affected by the transatlantic slave trade, with the exception of Angola.

I build two variables that measure the number of slaves taken from an ethnic group during the transatlantic and Indian Ocean slave trade, respectively. I follow Nunn and Wantchekon (2011) and, in absence of compelling population estimates for the period before the slave trade, I normalize the number of slaves taken from an ethnic group by the area of land historically inhabited by the group. The distribution of the slave trade variables is severely right skewed. To reduce the influence of outliers the variables are winsorized at the $5 \%$ level. $^{15}$

The classification of the respondents' ethnic groups used in the DHS is different from the Murdock's one, requiring a matching between the two datasets. I was able to match 90,5\% of female respondents and $89.8 \%$ of male respondents in the DHS to the ethnic groups in the slave trade dataset. ${ }^{16}$ After dropping the respondents whose ethnic group was not matched

\footnotetext{
${ }^{14}$ The map refers to locations in the late nineteenth century.

${ }^{15}$ As an alternative, we can use the natural $\log$ of one plus the normalized slave trade measures. The results are qualitatively unchanged and they are presented in the Appendix.

${ }^{16}$ Similarly, I match $90.5 \%$ of the female respondents in the Afrobarometer surveys that will be used in the analysis in Section 2.5 .
} 
to the slave trade data, we are left with a final sample of 583,562 women and 222,970 men. ${ }^{17}$

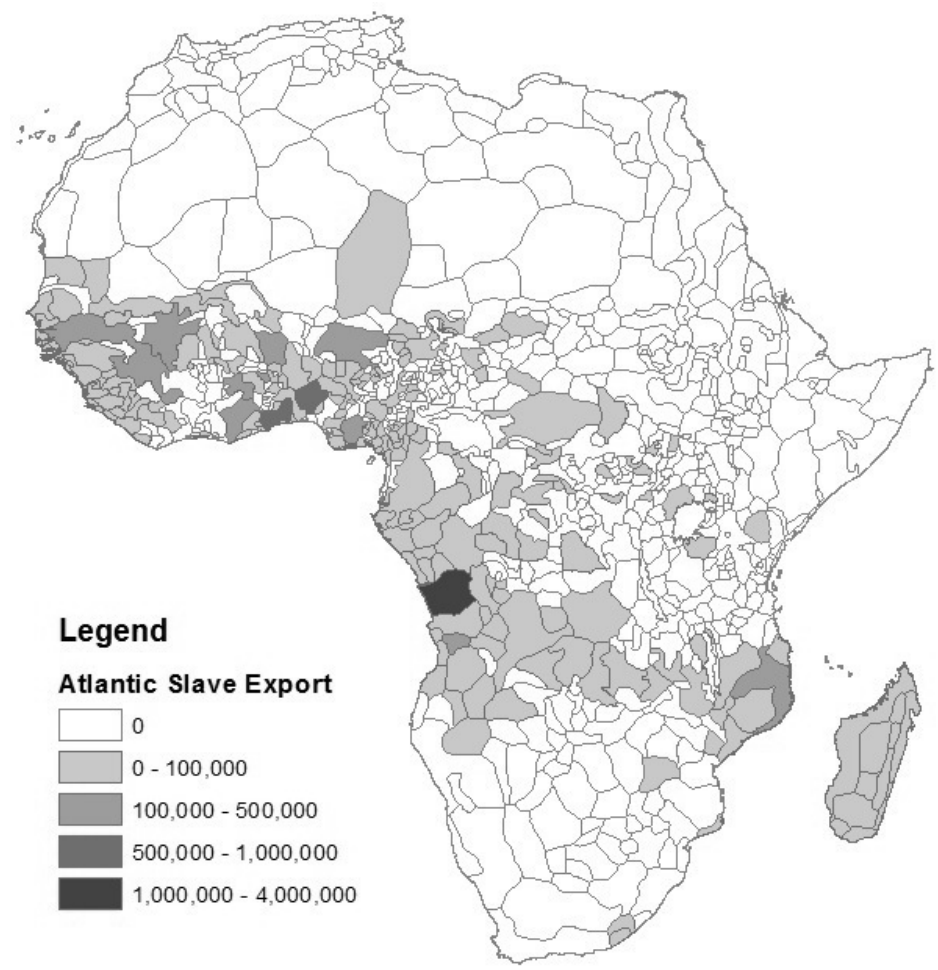

Notes: The figure shows the spatial distribution of the number of slaves taken from each ethnic group during the transatlantic slave trade. The ethnic groups and their location are from Murdock (1959). Data on the number of slaves taken from each group is from Nunn and Wantchekon (2011).

Figure 2.3: Ethnic group-level exposure to the transatlantic slave trade

In my analysis, I use a wide array of historical and geographic controls varying at the ethnic group level. I describe these controls as well as their sources in the next Section.

Table B.1 in the Appendix presents summary statistics for the main variables in the analysis.

\footnotetext{
${ }^{17}$ For many of the groups, the matching is straightforward as the name used in the DHS is the same or very similar to the one used by Murdock. When the name of an ethnic group is not found in Murdock's classification, this is typically because an alternative group's name is used. In these cases, online sources were used to correctly match the ethnicity to the slave trade data. One of the most useful sources of information on alternative ethnic groups' names was the Joshua Project website (http://www.joshuaproject.net/). For most of the unmatched ethnicities, the respondent lists her nationality as ethnicity.
} 


\subsubsection{Empirical Specification}

I explore the relationship between the exposure to the slave trade of a woman's ethnic group and her current employment status by estimating the following equation:

$$
y_{i, e, c}=\alpha_{c}+\beta \text { Transatlantic Trade } \text { Tr }_{e}+\gamma \text { Indian Ocean Trade } e_{e}+X_{i, e, c}^{\prime} \Delta+Z_{e}^{\prime} \Omega+\varepsilon_{i, e, c}
$$

where $i$ indexes a woman who belongs to ethnic group $e$ and lives in country $c$. Transatlantic Trade $e_{e}$ and Indian Ocean Trade are the number of slaves taken from an ethnic group during the transatlantic and Indian Ocean slave trades, respectively, normalized by the area of land historically inhabited by the group. The coefficient of interest is $\beta$, which captures the effect of a woman's ancestors' exposure to the transatlantic slave trade on her employment status. The inclusion of the variable Indian Ocean Trade $e_{e}$ provides a falsification test: if my hypothesis is correct, this measure should not have a positive impact on the outcome variables, since the Indian Ocean slave trade did not lead to a shortage of men in the areas affected. ${ }^{18}$

I control for a set of covariates at the individual level $\left(X_{i, e, c}^{\prime}\right)$ and at the ethnic group level $\left(Z_{e}^{\prime}\right)$. The individual-level controls include a full set of age fixed effects, a dummy for the respondent being married, an indicator turning one if the individual lives in a urban location, an indicator variable that equals one if the respondent is Christian and an indicator variable taking value one if the respondent is Muslim.

A crucial concern for the causal interpretation of the OLS estimates is the possible presence of an omitted variable that is correlated with both current women's employment status and with the degree to which different groups were affected by the transatlantic slave trade. For instance, if groups with ex-ante more equal gender norms were more likely to

\footnotetext{
${ }^{18}$ If anything, given that during the Indian Ocean slave trade the majority of slaves were females, we could find a negative impact of the Indian Ocean slave trade on women's participation in the labor force. If the same channels described in Grosjean and Khattar (2015) are at work, a shortage of females should lead to a long-run decline in women's employment. However, historical records show that the Indian Ocean slave trade was considerably less severe than the transatlantic slave trade. This is confirmed by the different mean values of the two slave trade variables in Table B.1.
} 
be affected by the transatlantic slave trade, this would translate in an estimate of $\beta$ that is biased upward. The ethnicity-level controls are meant to alleviate these concerns.

Following Nunn and Wantchekon (2011), I include four variables that capture the historical prosperity of an ethnic group, which can be correlated with initial attitudes towards gender roles and with exposure to the slave trade. First, to account for the initial disease environment, I control for the malaria ecology of the land that was inhabited by the ethnic group using the Malaria Stability Index (Kiszewski et al., 2004). Second, to account for precolonial level of urbanization, I include the number of cities with more than 20,000 inhabitants that were present in 1400 on the land inhabited by the ethnic group. Third, using data from Murdock (1967)'s Ethnographic Atlas, I include a set of fixed effects for the number of jurisdictional hierarchies beyond the local community, which captures the level of complexity of an ethnic group's political institutions. ${ }^{19}$ Fourth, using again information recorded in the Ethnographic Atlas, we can include an additional proxy for initial population density, namely a set of dummies for precolonial settlement patterns, ranging from fully nomadic to complex settlements. Finally, I control for the fraction of the land historically inhabited by the ethnic group that is suitable to the cultivation of crops, using data from the FAO's Global Agro-Ecological Zones database (GAEZ).

Groups more affected by the slave trade could have been differentially influenced by the European colonizers and this influence could translate into a higher level of female labor force participation today. For this reason, I control for an indicator variable taking value one if a part of the railway network built by the Europeans was on the land of the ethnic group. I also include a dummy that takes value one if a European explorer traveled in the land of the ethnic group. Last, I control for a variable measuring the number of religious missions per square kilometer of an ethnic group's land during the colonial period.

Data from Besley and Reynal-Querol (2014) allow me to control for an additional potential omitted variable, namely historical warfare in the precolonial period. Looking

\footnotetext{
${ }^{19}$ To match ethnic groups between Murdock's map and the Ethnographic Atlas, I use the concordance in the AfricaMap project, available at https://worldmap.harvard.edu/data/geonode: urdock $_{e} a_{2} 010_{3}$.
} 
within Africa, Besley and Reynal-Querol (2014) find that a history of precolonial conflict is associated with underdevelopment and lower levels of trust today, which could in turn be associated with women's employment status and gender norms. To account for the possibility that ethnic groups that were involved in conflicts in the precolonial period were more severely affected by the slave trade, I include as control the number of conflicts between 1400 and 1700 in the area inhabited by the ethnic group.

Hansen et al. (2015) show evidence that societies that relied more on hunting and gathering have developed more equal gender norms. Since the initial structure of an ethnic group's economy could also be correlated with its exposure to the slave trade, I use data from the Ethnographic Atlas to control for the ethnic group's reliance on hunting and gathering and for the presence of large domesticated animals. ${ }^{20}$

Finally, since in some parts of Africa proximity to the coast correlates both with historical distance from the trade networks of the Saharan Desert and with exposure to the slave trade, I control for the distance of an ethnic group's centroid to the closest city and the closest route in the Saharan trade.

In the baseline specification I include country-survey fixed effects, $\alpha_{c}$, to take into account country-level institutional factors that could potentially affect current labor force participation and also be correlated with the history of the slave trade.

Finally, in order to account for potential within-group correlation of the residuals, throughout the analysis standard errors are clustered at the ethnic group level.

\subsection{The Long-Run Impact of the Transatlantic slave trade On FLFP}

\subsubsection{Main Results}

Table 2.1 presents the OLS estimates of the effect of the slave trade on current women's participation in the labor force. In column 1 I include only individual-level controls, while

\footnotetext{
${ }^{20}$ Using information from the Ethnographic Atlas, Alesina et al. (2013) show that individuals whose ancestors used the plough have more unequal gender roles today. However, since there is essentially no variation in the historical use of the plough in Sub-Saharan Africa, this does not represent a confounder in my analysis.
} 
in column 2 I add the set of historical ethnic group-level controls. ${ }^{21}$ The coefficient on the transatlantic slave trade variable is positive, statistically significant and unaffected by the inclusion of the historical controls. The magnitude of the effect is large: a one standard deviation increase in a woman's ancestors' exposure to the transatlantic slave trade increases her likelihood of being in the labor force by between 2.7 and 3 percentage points. This effect corresponds to a $4.6-5.1 \%$ increase relative to the average female labor force participation rate among women whose ethnic group was unaffected by the transatlantic slave trade (see last row of the table). ${ }^{22}$ While the specification of column 2 includes a large set of historical controls, an additional concern is that ethnic groups with ex-ante different levels of women's involvement in activities outside the house were differentially affected by the transatlantic slave trade. To address this concern, in column 3 I use information from the Ethnographic Atlas to further control for the historical female participation in agriculture in the respondent's ethnic group, finding essentially identical results. One shortcoming is that this variable is missing for a large number of ethnic groups, significantly reducing the sample size. For this reason, I exclude this control from the rest of the analysis to focus on the full sample of respondents. ${ }^{23}$

Figure 2.4 presents a graphical representation of the effect and it shows that the result is not driven by a small number of outliers. ${ }^{24}$

\footnotetext{
${ }^{21}$ The number of observations decreases slightly as the historical controls are introduced, because of missing values in some of the historical variables for a small number of groups.

${ }^{22}$ As a comparison, Alesina et al. (2013)'s individual-level estimates imply that a one-standard-deviation increase in traditional plough use leads to a reduction in female labor force participation of 7.3 percentage points.

${ }^{23}$ In Appendix Table B.2 I show the coefficients on all the historical controls included in column 3 of Table 2.1. Consistent with the findings in Nunn (2014) on missionary influence on long-run female education, religious missions are positively correlated with today FLFP. Consistent with the findings in Hansen et al. (2015), ethnic groups that relied more on gathering have higher FLFP today. Ethnic groups that were more involved in precolonial conflicts have lower FLFP today. I do not find strong evidence that in groups that were historically more prosperous, women have different levels of participation to the labor force: while groups with a lower precolonial level of urbanization have lower FLFP today, the coefficients on precolonial settlement patterns and jurisdictional hierarchies beyond the local community are insignificant.

${ }^{24}$ The figure is constructed by first partialing out the controls included in column (2) of Table 2.1. It shows the mean of the residuals from the regression of FLFP on the controls for each equal-sized bin of the residuals from the regression of Transatlantic Trade on the controls.
} 
Importantly, the results show that, in line with the history of the Indian Ocean slave trade, this slave trade did not have an effect on the long-run evolution of gender norms. The coefficients on the variable Indian Ocean Trade are negative and statistically insignificant. ${ }^{25}$ This suggests that, rather than being a general byproduct of an ethnic group's history of slavery, the long run increase in women's labor force participation estimated in Table 2.1 is the effect of the unbalanced sex ratio generated by the slavers' preference for male slaves during the transatlantic slave trade ${ }^{26}$ Importantly, the validity of this placebo test rests on the assumption that, apart for the demographic shock that was specific to the transatlantic trade, there was no other historical difference between these two slave trades that can explain their differential impact on today FLFP. While historical accounts do not point to a clear factor that could have potentially led to such a differential impact, this placebo test should be read with this caveat in mind.

In column 4 of Table 2.1 I investigate whether the positive effect on FLFP can be fully explained by a higher educational level among the female descendants of the groups most exposed to the transatlantic slave trade. I do so by including a full set of fixed effects for the respondent's number of years of education. Despite the potential endogeneity of this variable, since the shock itself could have led to greater human capital accumulation for women, the inclusion of this control is a useful robustness check. As shown in column 4, the estimated coefficient remains virtually unchanged, suggesting that the effect cannot be explained by higher human capital among women belonging to ethnic groups more exposed to the transatlantic slave trade.

Historians have pointed to the strengthening of polygyny as a further implication of the relative abundance of women in the regions most affected by the transatlantic slave

\footnotetext{
${ }^{25}$ While the estimated coefficient is even larger than the coefficient on the Transatlantic Trade variable, the effect is very small in magnitude once we consider the distribution of the Indian Ocean Trade variable, whose mean and standard deviation are considerably smaller than those of the transatlantic slave trade measure.

${ }^{26}$ To conserve on space, I do not report the coefficients on Indian Ocean Trade in the next tables of the paper. The results are often insignificant and, in general, consistent with the Indian Ocean slave trade not affecting cultural beliefs about the role of women. The variable Indian Ocean Trade is always included as a control in all the tables throughout the paper.
} 
trade. ${ }^{27}$ Even though polygyny is typically negatively correlated with measures of female empowerment (Economics and of Women's Rights, 2012), in column 5 I investigate whether the results are robust to controlling for an indicator that takes value one if the respondent has one or more co-wives. The coefficient on the Transatlantic Trade variable remains positive and statistically significant. ${ }^{28}$ Finally, column 6 shows that the results are unchanged when both education and polygyny are included as controls. ${ }^{29}$

In the Appendix, I present additional robustness checks. First, I show that the standard errors on the main variable are very similar if adjusted for two-way clustering within ethnic group and village, or if I use Conley (1999)'s adjustment for two-dimensional spacial dependence, or if clustered by country, using a block bootstrap procedure (Table B.4). Second, in order to rule out that failing to control for the trans-Saharan and Red Sea slave trades lead to biased estimates, I show that the results are robust to the exclusion of surveys from countries that were strongly exposed to these two slave trades, i.e. Mali, Kenya, Niger, Nigeria (Table B.5). Finally, we obtain very similar results using data from the Afrobarometer (Table B.6), which provides an important robustness test given the different phrasing of the question on FLFP between the DHS and the Afrobarometer. ${ }^{30} 31$

\footnotetext{
${ }^{27}$ However, as shown in Table B.3 in the Appendix, I do not find that polygyny is more widespread among women whose ancestors were more affected by the transatlantic slave trade. This is consistent with Fenske (2013), who also shows that the positive impact of the slave trade on polygyny disappears once country fixed effects are included.

${ }^{28}$ The coefficient is larger than in the specifications in columns 1-4. However, the number of observations drops as we move from column 4 to column 5 since the question on whether a woman has co-wives is not asked to women who are not married or in a union. This change in the sample composition is responsible for the increase in the size of the coefficient: in unreported results, I find that running the specification in column 4 restricting the sample only to women who are currently married or in a union gives an estimated coefficient of 0.072 (standard error 0.012). Alternatively, instead of using an individual-level indicator of polygyny, we can control for the average share of a woman's co-ethnics that have co-wives, leaving the sample size unchanged. The estimated coefficient on Transatlantic Trade using this alternative specification is 0.053 , with a standard error of 0.011 .

${ }^{29}$ Both education and polygyny can be considered "bad controls" in the sense of Angrist and Pischke (2009). For this reason, these controls are excluded in the next part of the analysis. However, as a robustness check, I show in the Appendix that none of the results in the paper is affected by the inclusion of these controls.

${ }^{30} \mathrm{~A}$ one standard deviation increase in exposure to the transatlantic slave trade increases FLFP by 2.4 percentage points. Relative to the average female labor force participation rate among women whose ethnic group was unaffected by the transatlantic slave trade, this corresponds to a $7.7 \%$ increase.

${ }^{31}$ While results focus on the effect of the total number of slaves exported during the centuries of the slave
} 
Table 2.1: OLS estimates, the effect of the slave trade on FLFP

\begin{tabular}{lcccccc}
\hline & FLFP & FLFP & FLFP & FLFP & FLFP & FLFP \\
& $(1)$ & $(2)$ & $(3)$ & $(4)$ & $(5)$ & $(6)$ \\
\hline Translatlantic Trade & $0.048^{* * *}$ & $0.054^{* * *}$ & $0.059^{* * *}$ & $0.056^{* * *}$ & $0.073^{* * *}$ & $0.072^{* * *}$ \\
& $(0.013)$ & $(0.011)$ & $(0.013)$ & $(0.011)$ & $(0.012)$ & $(0.012)$ \\
Indian Ocean Trade & -0.059 & -0.120 & -0.061 & -0.111 & -0.146 & -0.133 \\
& $(0.140)$ & $(0.158)$ & $(0.175)$ & $(0.174)$ & $(0.205)$ & $(0.196)$ \\
Observations & 583,562 & 563,379 & 470,183 & 563,054 & 386,503 & 386,317 \\
R-squared & 0.16 & 0.17 & 0.18 & 0.18 & 0.14 & 0.14 \\
Ethnic Groups & 261 & 243 & 170 & 243 & 241 & 241 \\
Country-survey FE & Yes & Yes & Yes & Yes & Yes & Yes \\
Individual Controls & Yes & Yes & Yes & Yes & Yes & Yes \\
Historical Controls & No & Yes & Yes & Yes & Yes & Yes \\
Hist. Part. Agriculture & No & No & Yes & No & No & No \\
Education & No & No & No & Yes & Yes & Yes \\
Polygyny & No & No & No & No & Yes & Yes \\
Transatlantic std. dev. & 0.564 & 0.564 & 0.570 & 0.564 & 0.564 & 0.564 \\
Indian Ocean std. dev. & 0.033 & 0.031 & 0.034 & 0.031 & 0.031 & 0.031 \\
Dep. var. mean unaffected & 0.588 & 0.586 & 0.589 & 0.586 & 0.635 & 0.635 \\
\hline
\end{tabular}

Notes: Standard errors in parentheses, clustered at the ethnicity level. The unit of observation is a female respondent. FLFP is an indicator variable taking value one if the respondent was ever employed in the last 12 months. Transatlantic Trade is the number of slaves exported during the transatlantic slave trade normalized by the area of land historically inhabited by the ethnic group. Indian Ocean trade is the number of slaves exported during the Indian Ocean slave trade normalized by the area of land historically inhabited by the ethnic group. The baseline controls are: age fixed effects, a dummy for the respondent being married, a dummy for the respondent being Muslim, a dummy for the respondent being Christian, and a dummy for the respondent living in a urban location. The historical controls are at the ethnic group level and include: the number of cities in 1400, average malaria presence, a set of fixed effects for the number of jurisdictional hierarchies beyond the local community in the precolonial period, a set of fixed effects for precolonial settlement patterns, a dummy for integration with the colonial railway network, a dummy for a precolonial contact with European explorers, the number of missions per square kilometer during the colonial period, the number of conflicts between 1400 and 1700 in the area inhabited by the ethnic group, an ethnic group's historical reliance on hunting, an ethnic group's historical reliance on gathering, the presence of large domesticated animals, the distance of an ethnic group's centroid to the closest city and the closest route in the Saharan trade, and the fraction of the land historically inhabited by the ethnic group that is suitable to the cultivation of crops. Hist. Part. Agriculture is the historical female participation in agriculture in a woman's ethnic group. Education indicates a set of fixed effects for number of years of schooling. Polygyny is a dummy variable for a woman having co-wives. "Dep. var. mean unaffected" is the mean value of the dependent variable for the subsample of observations for which Transatlantic Trade is equal to zero.

$* * * * * *$ indicate significance at the $1 \%, 5 \%$ and $10 \%$ level.

Having shown that belonging to an ethnic group that was more exposed to the transat-

lantic slave trade is associated with greater women's participation in the labor force, we can

trades, one may wonder whether the duration of the shock matters, i.e. whether ethnic groups that were exposed to the transatlantic slave trade for more centuries are characterized by higher FLFP today. In the Appendix, I provide suggestive evidence against this hypothesis, by showing that, among groups that exported similar numbers of slaves, there is not a differential effect of the number of centuries of exposure to the transatlantic slave trade on current FLFP. This is consistent with the literature on the role of much shorter demographic shocks such as wars as drivers of changes in FLFP. 


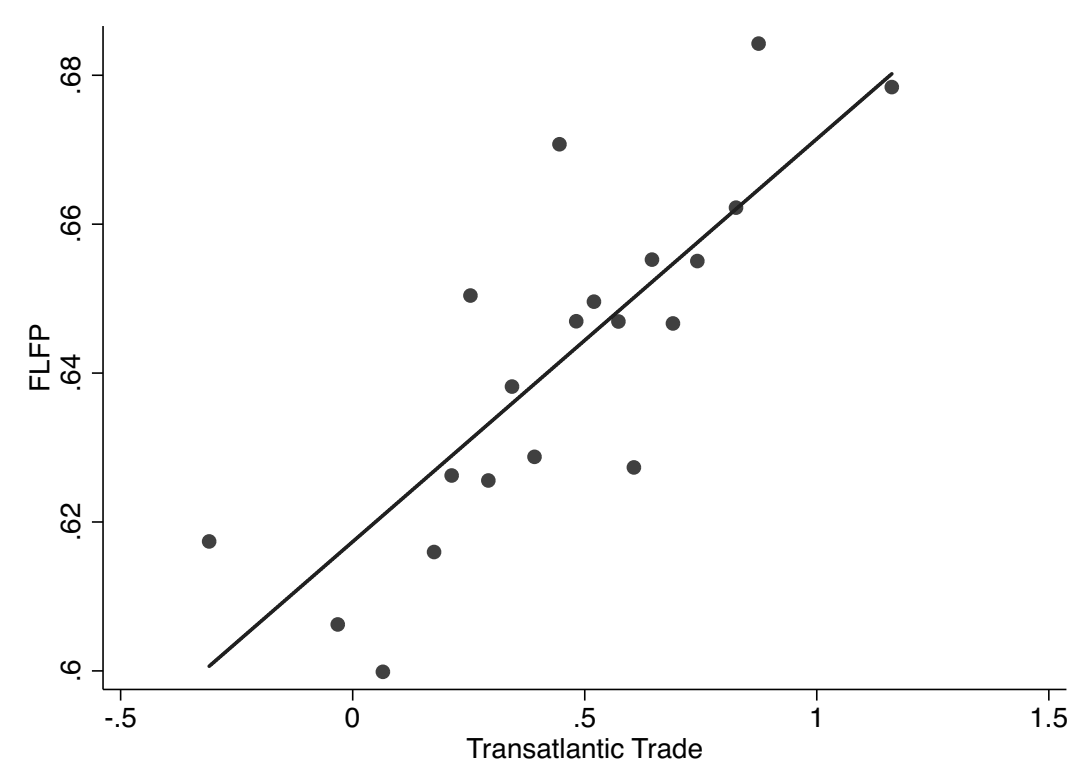

Notes: The figure presents a non-parametric representation of the results in column 2 of Table 2.1. It is constructed by first partialing out the controls included in column 2 of Table 2.1, by regressing the variables FLFP and Transatlantic Trade on the full list of controls (including the Indian Ocean slave trade variable). The residuals from the regression of Transatlantic Trade on the controls are then divided in 20 equal-sized bins and, in each bin, I plot the mean of the residuals from the regression of FLFP on the controls. The best-fit line is estimated on the underlying data.

Figure 2.4: Historical exposure to the transatlantic slave trade leads to higher current FLFP

analyze which specific occupations are responsible for the result. One potential interpretation of the results presented so far is that regions that experienced the transatlantic slave trade more severely remained predominantly agricultural-based. This would be consistent with Nunn (2008)'s finding that the slave trade led to economic underdevelopment and with Nunn and Wantchekon (2011)'s description of the culture of mistrust generated by slavery, which in turn could have hindered commerce in these areas. At the same time, the almost complete absence of plough agriculture in Sub-Saharan Africa has led to an involvement of women in the fields that has been historically greater than in other parts of the developing world. ${ }^{32}$ One could then hypothesize that the increase in FLFP found in Table 2.1 can be

\footnotetext{
${ }^{32}$ As of 2006, female employment in the agricultural sector as a share of total employment in agriculture was 43.7\% in Sub-Saharan African, in comparison to 32.3\% in Middle East and North Africa, 21\% in Latin America and the Caribbean, 36.3\% in South Asia, and 42.3\% in South East Asia and the Pacific (ILO, 2007).
} 
rationalized by an increase in the likelihood that a woman is employed in the agricultural sector.

Table 2.2 presents the results of the estimation of the main equation using specific occupational dummies as dependent variable. ${ }^{33}$ Contrary to what hypothesized in the above discussion, exposure to the transatlantic slave trade is not significantly associated with a woman's probability of being employed in agriculture. The estimate in columns 5 suggests that the increase in a woman's probability of being employed can be entirely rationalized by an increase in the likelihood that she has a relatively higher ranking occupation. A one standard deviation increase in a woman's ancestors' exposure to the transatlantic slave trade increases her likelihood of being employed in one of these occupations by 2.7 percentage points. Exposure to the transatlantic slave trade has not a significant impact on the probability of having a clerical or manual occupation, and it leads to a decrease in the probability of being employed as domestic servant, pointing towards a substitution away from women's involvement in activities within the domestic sphere.

The finding that a higher ancestors' exposure to the transatlantic slave trade leads to a higher probability of employment in a relatively higher ranking occupation is consistent with women belonging to ethnic groups that were more exposed to this shock being more likely to enter areas of work where women may face larger barriers to entry. ${ }^{34}$ Finally, this is particularly relevant given that this set of occupations are significantly more likely to be performed in the formal economy, pointing towards significant welfare gains for women subjected to this historical shock. ${ }^{35}$

\footnotetext{
${ }^{33}$ The table shows the results when only the individual-level and historical controls are included. Table B.7 in the Appendix shows that the results are unchanged if we additionally control for education and polygyny.

${ }^{34}$ Theoretically, we expect this historical shock not to have a significant impact in those areas of work where women were already present before the slave trade took place. In sub-saharan Africa, women's participation in agriculture was already very common before the slave trade, given the widespread presence of crops that do not require the use of the plough. Indeed, among the 171 ethnic groups in the dataset, only $24 \%$ of them were historically characterized by a larger participation in agriculture of men relative to women. As outlined in Section 2.1, historical evidence suggests that the demographic shock caused women to enter new areas of work. We see a large long-run effect of the slave trade in those occupations where women may face larger barriers to entry, like the sales and services sectors or professional occupations, since they require longer hours spent
} 
Table 2.2: OLS estimates, the effect of the slave trade on occupational choices

\begin{tabular}{lccccc}
\hline & $\begin{array}{c}\text { Agriculture } \\
(1)\end{array}$ & $\begin{array}{c}\text { Clerical } \\
(2)\end{array}$ & $\begin{array}{c}\text { Manual } \\
(3)\end{array}$ & $\begin{array}{c}\text { Domestic } \\
(4)\end{array}$ & $\begin{array}{c}\text { High Ranking } \\
(5)\end{array}$ \\
\hline Translatlantic Trade & 0.018 & -0.000 & -0.010 & $-0.004^{* *}$ & $0.048^{* * *}$ \\
& $(0.016)$ & $(0.001)$ & $(0.008)$ & $(0.002)$ & $(0.011)$ \\
Observations & 549,009 & 549,009 & 549,009 & 549,009 & 549,009 \\
R-squared & 0.23 & 0.02 & 0.05 & 0.07 & 0.14 \\
Ethnic Groups & 243 & 243 & 243 & 243 & 243 \\
Country-survey FE & Yes & Yes & Yes & Yes & Yes \\
Individual Controls & Yes & Yes & Yes & Yes & Yes \\
Historical Controls & Yes & Yes & Yes & Yes & Yes \\
Transatlantic std. dev. & 0.564 & 0.564 & 0.564 & 0.564 & 0.564 \\
Dep. var. mean unaffected & 0.276 & 0.011 & 0.061 & 0.026 & 0.224 \\
\hline
\end{tabular}

Notes: Standard errors in parentheses, clustered at the ethnicity level. The unit of observation is a female respondent. Agriculture is an indicator variable taking value one if the respondent is employed in agriculture. Clerical is an indicator variable taking value one if the respondent is employed in a clerical job. Manual is an indicator variable taking value one if the respondent is employed in a manual job. Domestic is an indicator variable taking value one if the respondent is employed as a domestic servant. High Ranking is an indicator variable taking value one if the respondent is employed in a higher ranking occupation. Transatlantic Trade is the number of slaves exported during the transatlantic slave trade normalized by the area of land historically inhabited by the ethnic group. Controls are described in Table 2.1. "Dep. var. mean unaffected" is the mean value of the dependent variable for the subsample of observations for which Transatlantic Trade is equal to zero. $* * * * * *$ indicate significance at the $1 \%, 5 \%$ and $10 \%$ level.

\subsubsection{Men's employment as a falsification test}

A potential alternative interpretation of the results presented so far is that the transatlantic slave trade led to structural changes in the economy that were conducive to a persistent higher employment across both genders. While previous research points towards a negative impact of the slave trade on long-term development (Nunn, 2008), no study has analyzed the long-run effects of this historical shock on the labor market at a micro-level. Therefore, analyzing the long-run impact of the transatlantic slave trade on men's employment probability represents an important falsification test.

Table 2.3 presents evidence against this alternative account. Odd columns present the estimated results on the sample of men interviewed in the DHS, while even columns outside of the domestic sphere.

${ }^{35}$ Table B.8 and B.9 in the Appendix show that the effects on FLFP and occupational choices are qualitatively identical if we use the natural log of one plus the normalized slave trade measures as explanatory variables. 
replicate the results of Table 2.1 restricting the sample of women to the surveys for which a corresponding male survey was conducted. ${ }^{36}$ If anything, we find a negative, although small, long-run effect of a man's ancestors' exposure to the transatlantic slave trade on his likelihood of being employed. ${ }^{37}$ Consistent with the transatlantic slave trade being responsible for a change in gender roles in the labor market, the results confirm that this historical shock led to higher labor force participation only among women. ${ }^{38}$

Table 2.3: OLS estimates, Women's versus Men's Employment

\begin{tabular}{lcccccc}
\hline Sample & $\begin{array}{c}\text { Men } \\
(1)\end{array}$ & $\begin{array}{c}\text { Women } \\
(2)\end{array}$ & $\begin{array}{c}\text { Men } \\
(3)\end{array}$ & $\begin{array}{c}\text { Women } \\
(4)\end{array}$ & $\begin{array}{c}\text { Men } \\
(5)\end{array}$ & $\begin{array}{c}\text { Women } \\
(6)\end{array}$ \\
\hline Translatlantic Trade & $-0.010^{* *}$ & $0.050^{* * *}$ & $-0.012^{* *}$ & $0.054^{* * *}$ & -0.008 & $0.056^{* * *}$ \\
& $(0.005)$ & $(0.013)$ & $(0.006)$ & $(0.010)$ & $(0.005)$ & $(0.010)$ \\
Observations & 222,970 & 548,178 & 216,419 & 528,006 & 216,125 & 527,687 \\
R-squared & 0.31 & 0.16 & 0.31 & 0.17 & 0.32 & 0.18 \\
Ethnic Groups & 235 & 261 & 219 & 243 & 219 & 243 \\
Country-survey FE & Yes & Yes & Yes & Yes & Yes & Yes \\
Individual Controls & Yes & Yes & Yes & Yes & Yes & Yes \\
Historical Controls & No & No & Yes & Yes & Yes & Yes \\
Education & No & No & No & No & Yes & Yes \\
Transatlantic std. dev. & 0.564 & 0.567 & 0.563 & 0.567 & 0.563 & 0.567 \\
Dep. var. mean unaffected & 0.831 & 0.593 & 0.831 & 0.591 & 0.831 & 0.591 \\
\hline
\end{tabular}

Notes: Standard errors in parentheses, clustered at the ethnicity level. In all columns, the dependent variable is an indicator variable taking value one if the respondent was ever employed in the last 12 months. Odd columns show the estimated coefficients for the sample of male respondents, while even columns show the estimated coefficients for the sample of female respondents. Transatlantic Trade is the number of slaves exported during the transatlantic slave trade normalized by the area of land historically inhabited by the ethnic group. Controls are described in Table 2.1. "Dep. var. mean unaffected" is the mean value of the dependent variable for the subsample of observations for which Transatlantic Trade is equal to zero. $* * * * * *$ indicate significance at the $1 \%, 5 \%$ and $10 \%$ level.

\footnotetext{
${ }^{36}$ Only for 5 out of 61 surveys a corresponding male survey was not conducted. Note that since men surveys are carried out only for a subsample of the households, we have a smaller sample of male respondents relative to the sample of female respondents.

${ }^{37}$ The variable on male LFP is defined in the same way as the variable FLFP.

${ }^{38}$ When viewed in combination with the insignificant effect of the Indian Ocean slave trade on FLFP, this result provides further reassurance that the demographic shock that characterized the transatlantic slave trade is the likely channel behind the effect on FLFP that I uncover. Table 2.3 shows that a potential confounding factor that would invalidate the use of the Indian Ocean slave trade as placebo test needs to both (i) vary between the two different slave trades, and (ii) predict an effect of the transatlantic slave trade on current employment probability for women but not for men.
} 


\subsubsection{The marriage market channel}

Turning to the issue of what explains the long-run effect of the transatlantic slave trade on female participation in market activities, I leverage the richness of the data to investigate the role played by cultural transmission within the family.

Fernandez et al. (2004) theorize that cultural beliefs about the role of women can be transmitted through a marriage market mechanism, according to which working mothers transmit to their sons a more positive view about working women, a view which is then reflected into the labor market decisions of the sons' future households. If this mechanism is at work, we expect women whose husband belongs to an ethnic group that was more exposed to the transatlantic slave trade to have higher levels of FLFP. The DHS provides information on a woman's husband's ethnicity, allowing us to shed light on this channel.

As a benchmark, I start by re-estimating the main specification restricting the sample to married women with non-missing information on the husband's ethnicity. The coefficient in column 1 of Table 2.4 shows that, among married women, a one standard deviation increase in a woman's ancestors' exposure to the transatlantic slave trade increases her likelihood of being in the labor force by 4 percentage points. ${ }^{39}$

Exploiting information on a woman's husband's ethnicity, we can separately isolate the effect of a husband's ancestors' exposure to the slave trade from that of a woman's own ancestors' exposure. I do so by including a full set of country-survey-woman's ethnicity fixed effects, holding constant a woman's own ancestors' exposure to the slave trades. By doing so, we are comparing women whose ancestors were hit by the slave trade in the exact same way, but who married men whose ancestors' exposure to this historical shock differed. This allows us to isolate the extent to which a woman's labor force participation depends on her husband's beliefs and historical exposure to the transatlantic slave trade. In practice, I estimate a version of the main equation in which I control for country-survey-woman's ethnicity (instead of country-survey) fixed effects and in which all the ethnic group-level

\footnotetext{
${ }^{39}$ Table B.10 in the Appendix shows that the results are unchanged if we additionally control for education and polygyny.
} 
variables are measured using the ethnicity of the husband. The results in column 2 show that the transatlantic slave trade has led to a long-run effect on males' views on gender roles, which translate in higher FLFP among women who married men whose ethnic group was more severely hit by this historical shock. Among women belonging to the same ethnic group, a one standard deviation increase in the husband's ancestors' exposure to the transatlantic slave trade is associated with a statistically significant 1.1 percentage points increase in FLFP.

The evidence that a greater number of slaves taken from a man's ethnic group affects his wife's working decisions allows us to interpret the coefficient in column 1 as the likely combination of two effects. The first effect stems from a direct impact of a woman's ancestors' attitudes about working women on her own views about gender roles and the social cost of working. The second effect works through a marriage market mechanism as described in Fernandez et al. (2004): since women are more likely to marry co-ethnics, ${ }^{40}$ a woman belonging to an ethnic group that was more severely hit by the transatlantic slave trade has greater incentives to work outside the house since her husband is on average less averse to having a working wife.

In an effort to separately identify the magnitude of these two channels, I estimate a version of the main equation which includes a full set of country-survey-husband's ethnicity fixed effects. In this way, I isolate the effect of a woman's own ethnic group's exposure to the transatlantic slave trade while holding constant the ethnicity of the husband. After directly controlling for a woman's husband beliefs, the coefficient on Transatlantic Trade provides an estimate of the direct impact of a woman's own ancestors' views on working women on her likelihood of being in the labor force.

The coefficient in column 3 reveals that, among women whose husbands belong to the same ethnic group, a one standard deviation increase in the exposure to the transatlantic slave trade of a woman's own ethnic group increases FLFP by 2.3 percentage points. The

\footnotetext{
${ }^{40}$ Among the 109,310 women in the sample of column 1 of Table $2.4,83.6 \%$ are married to a co-ethnic. Among other explanations, this is consistent with evidence on the presence of own-ethnicity bias in Africa, with individuals having more positive views of co-ethnics (Lowes et al., 2015).
} 
Table 2.4: OLS estimates, the marriage market channel

\begin{tabular}{lccc}
\hline & FLFP & FLFP & FLFP \\
& $(1)$ & $(2)$ & $(3)$ \\
\hline Translatlantic Trade & $0.071^{* * *}$ & & $0.045^{* * *}$ \\
& $(0.015)$ & & $(0.009)$ \\
Translatlantic Trade Husband & & $0.021^{* *}$ & \\
& & $(0.009)$ & \\
Observations & 109,310 & 109,294 & 109,293 \\
R-squared & 0.14 & 0.18 & 0.17 \\
Ethnic Groups & 232 & 228 & 232 \\
Country-survey FE & Yes & No & No \\
Country-survey-woman's ethnicity FE & No & Yes & No \\
Country-survey-husband's ethnicity FE & No & No & Yes \\
Individual Controls & Yes & Yes & Yes \\
Historical Controls & Yes & Yes & No \\
Transatlantic std. dev. & 0.558 & 0.559 & 0.558 \\
Dep. var. mean unaffected & 0.652 & 0.657 & 0.652 \\
\hline
\end{tabular}

Notes: Standard errors in parentheses, clustered at the ethnicity level (of the female respondent in columns 1 and 3, and of the husband in column 2). The unit of observation is a female respondent. FLFP is an indicator variable taking value one if the respondent was ever employed in the last 12 months. Transatlantic Trade is the number of slaves exported during the transatlantic slave trade normalized by the area of land historically inhabited by the ethnic group. Transatlantic Trade Husband is the number of slaves exported during the transatlantic slave trade normalized by the area of land historically inhabited by the ethnic group for the woman's husband's ethnicity. Historical controls in column 2 are measured using the ethnicity of the husband. Controls are described in Table 2.1. "Dep. var. mean unaffected" is the mean value of the dependent variable for the subsample of observations for which Transatlantic Trade (or Transatlantic Trade Husband) is equal to zero.

$* * * * * *$ indicate significance at the $1 \%, 5 \%$ and $10 \%$ level.

effect is about $40 \%$ smaller than the one estimated in column 1, suggesting that about $40 \%$ of the effect of the transatlantic slave trade on FLFP stems from an effect of the transatlantic slave trade on a woman's husband's beliefs.

The evidence in this Section shows that the historical persistence of the demographic shock caused by the transatlantic slave trade does not solely follow from cultural transmission of gender norms from parents to their daughters, but also from cultural transmissions from parents to sons, as women whose husband belongs to an ethnic group that was more affected by this historical shock are more likely to be in the labor force. Importantly, as marriage patterns are clearly not random, we cannot interpret the estimates presented in this Section as the causal effect of marrying a man whose ancestors were more exposed to the transatlantic slave trade. Clearly, women who are ex ante more likely to work outside of the 
domestic sphere will tend to match with men with more favorable views of working women. As a consequence, the estimates in Table 2.4 should be intended as the combination of two effects: first, holding fixed women's beliefs, a husband's beliefs will have an impact on the intra-household decisions about the division of labor after marriage; second, women who are ex ante more likely to work outside of the domestic sphere will match in the marriage market with men belonging to ethnic groups that were more affected by the transatlantic slave trade, as these men have on average more equal gender-roles attitudes.

\subsubsection{Isolating the Cultural Transmission Channel}

In this Section, I investigate the extent to which the long-run effect of the transatlantic slave trade of FLFP can be explained by the transmission of specific cultural values. An alternative potential mechanism explaining persistence is unrelated to cultural transmission and rests on the hypothesis that the temporary shock to the role of women during the centuries of the slave trade permanently shaped markets and local institutions in a way that favors women's participation in the labor force today. For instance, the shortage of men may have led to specialization in less capital-intensive activities, reducing women's costs of entering the labor market.

In order to identify the role played by cultural transmission, I exploit the fact that individuals of different ethnic groups have relocated over the centuries and therefore today we find respondents of different ethnic origins living in the same location. The DHS includes information on the enumeration area (EA) of the respondent, allowing to control for the specific location in which a respondent currently lives. In urban areas an EA corresponds to a city block, while in rural areas it is typically a village. In my sample, there are an average of 23 women and 2.8 different ethnic groups within each EA.

I estimate a version of the main equation in which I include EA-survey fixed effects, comparing only women currently living in the same location. ${ }^{41}$ These specifications isolate

\footnotetext{
${ }^{41}$ Using the DHS, Michalopoulos et al. (2016) employ this strategy to isolate the effect of portable traits associated with ancestral lifeways on individual wealth and education.
} 
the mechanism of cultural persistence, since relying on this finer variation allows one to isolate the impact of an individual's ethnic origin while keeping constant the current external environment, and thus controlling for any impact of the slave trade on the characteristics of the respondent's location.

Table 2.5 presents the results of this exercise. When compared to the results in Table 2.1, the coefficients on theTransatlantic Trade variable fall by about $50 \%$ but remain statistically significant. Among women currently living in the same location, a one standard deviation increase in a woman's ancestors' exposure to the transatlantic slave trade increases her likelihood of being in the labor force by 1.5 percentage points. ${ }^{42}$

Since this empirical strategy is made possible by the fact that individuals migrated over the past centuries, a potential concern is that the transatlantic slave trade affected not only FLFP but also the probability that individuals moved from the land inhabited by their ancestors. This would represent a problem for the interpretation of the estimates in Table 2.5 if there is also a differential impact of the transatlantic slave trade on FLFP between movers and non-movers. Column 1 of Table B.12 in the Appendix shows that among women currently living in the same location those belonging to ethnic groups that were hit more severely by the transatlantic slave trade are less likely to be movers. ${ }^{43}$ However, column 2 of Table B12 shows that in the specification exploiting cross-country variation there is not a differential effect of the transatlantic slave trade on FLFP for movers and non-movers, suggesting that belonging to an ethnic group that was more affected by the transatlantic slave trade does not differentially affect FLFP depending on whether a woman currently lives outside or inside the land historically inhabited by her ancestors. As a further robustness test, column 3 of Table B12 shows that the estimate of column 2 of Table 2.5 is not

\footnotetext{
${ }^{42}$ Consistent with the results of Table 2.2, Table B.11 in the Appendix shows that the effect is entirely driven by a higher likelihood of having a relatively higher ranking occupation.

${ }^{43}$ I use the term "mover" to define individuals who live today in a location that was different from the one inhabited by their ancestors. Using coordinates information provided by the DHS and information on the location historically inhabited by ethnic groups I can build an indicator taking value one if a woman currently lives outside of the land historically inhabited by her ancestors. About $58 \%$ of women are classified as movers following this definition. Coordinates of the respondent's current location are not available for about $20 \%$ of observations.
} 
affected by the inclusion of a control for the distance of the respondent's current location from the centroid of the land historically inhabited by her ethnic group. Finally, I re-estimate the within-EA specification of column 2 of Table 2.5 only on the subset of women who are movers and additionally controlling for the current distance from the respondent's ancestors' land. Column 4 of Table B12 shows that the coefficient on Transatlantic Trade is unaffected, providing further reassurance that the estimates are not driven by the comparison of movers and non-movers.

The results presented in this Section emphasize the role played by cultural beliefs in explaining variation in women's participation in the labor force, as women belonging to different ethnicities but living today in the same location have a probability of being employed that depend on the extent to which their ancestors were affected by the transatlantic slave trade. In particular, the estimates suggest that at least half of the effect of the transatlantic slave trade on FLFP is driven by cultural transmission of more equal gender norms across generations.

Table 2.5: OLS estimates, the cultural transmission channel

\begin{tabular}{lccccc}
\hline & FLFP & FLFP & FLFP & FLFP & FLFP \\
& $(1)$ & $(2)$ & $(3)$ & $(4)$ & $(5)$ \\
\hline Translatlantic Trade & $0.027^{* * *}$ & $0.029^{* * *}$ & $0.029^{* * *}$ & $0.036^{* * *}$ & $0.035^{* * *}$ \\
& $(0.007)$ & $(0.005)$ & $(0.005)$ & $(0.006)$ & $(0.006)$ \\
Observations & 583,377 & 563,092 & 562,766 & 386,121 & 385,935 \\
R-squared & 0.32 & 0.32 & 0.32 & 0.33 & 0.33 \\
Ethnic Groups & 261 & 243 & 243 & 241 & 241 \\
EA-survey FE & Yes & Yes & Yes & Yes & Yes \\
Individual Controls & Yes & Yes & Yes & Yes & Yes \\
Historical Controls & No & Yes & Yes & Yes & Yes \\
Education & No & No & Yes & No & Yes \\
Polygyny & No & No & No & Yes & Yes \\
Transatlantic std. dev. & 0.564 & 0.564 & 0.564 & 0.564 & 0.564 \\
Dep. var. mean unaffected & 0.588 & 0.586 & 0.586 & 0.635 & 0.635 \\
\hline
\end{tabular}

Notes: Standard errors in parentheses, clustered at the ethnicity level. The unit of observation is a female respondent. FLFP is an indicator variable taking value one if the respondent was ever employed in the last 12 months. Transatlantic Trade is the number of slaves exported during the transatlantic slave trade normalized by the area of land historically inhabited by the ethnic group. Controls are described in Table 2.1. "Dep. var. mean unaffected" is the mean value of the dependent variable for the subsample of observations for which Transatlantic Trade is equal to zero.

$* * *, * *, *$ indicate significance at the $1 \%, 5 \%$ and $10 \%$ level. 


\subsubsection{Heterogeneous effects across cohorts}

A natural question arising from the above analysis is whether the long-run effect of the transatlantic slave trade on FLFP has been dissipating over time. Since economic development is typically associated to more equal gender norms, the effect of historical shocks on more recent cohorts may be muted by relatively higher levels of education and standards of living. Finding a positive effect of the transatlantic slave on FLFP even for relatively younger cohorts of women would provide evidence that historical shocks continue to play an important role even as material conditions change.

I can shade light on the evolution of the impact of the transatlantic slave trade over time by exploiting the availability of repeated cross-sectional surveys conducted in the same country. ${ }^{44}$ This allows us to estimate cohort-specific effects while controlling for age fixed effects. Specifically, I estimate the following augmented version of the main estimating equation:

$$
\begin{aligned}
y_{i, e, t, c} & =\alpha_{c}+\sum_{t=1948}^{1989} \beta_{t} \text { Transatlantic Trade } e_{e}+\gamma \text { Indian Ocean Trade } \text { Tr }_{e}+ \\
& +\theta_{t}+X_{i, e, c}^{\prime} \Delta+Z_{e}^{\prime} \Omega+\varepsilon_{i, e, c}
\end{aligned}
$$

where the effect of the transatlantic slave trade on FLFP is allowed to be different for each cohort $t$ of women, I add cohort-specific fixed effects $\theta_{t}$, and $\alpha_{c}$ are country fixed effects in lieu of country-survey fixed effects. ${ }^{45}$

Figure 2.5 plots the estimated coefficients $\beta_{t}$ for each cohort of women born between 1948 and 1989. The coefficients are relatively stable for cohorts of women born between the 1950s and the 1970s and, while on average smaller in magnitude, the effect is positive and significant also for the cohorts born in the $1980 \mathrm{~s} .{ }^{46}$ The results point towards a limited

\footnotetext{
${ }^{44}$ Repeated cross-sections are available for 18 of the 21 countries covered in the analysis.

${ }^{45}$ I have to exclude women born in the 90 s as they are too young to be present in multiple cross-sections in the same country for a sufficient number of countries.

${ }^{46}$ Since, because of data availability, the effects for the cohorts of women born in the 1980s are identified using
} 
dissipation over time of the effect of the transatlantic slave trade on women's participation in the labor force, with women born in the 1980s and one standard deviation apart in the distribution of the transatlantic slave trade variable still having a 2.4 percentage points average difference in their employment probability.

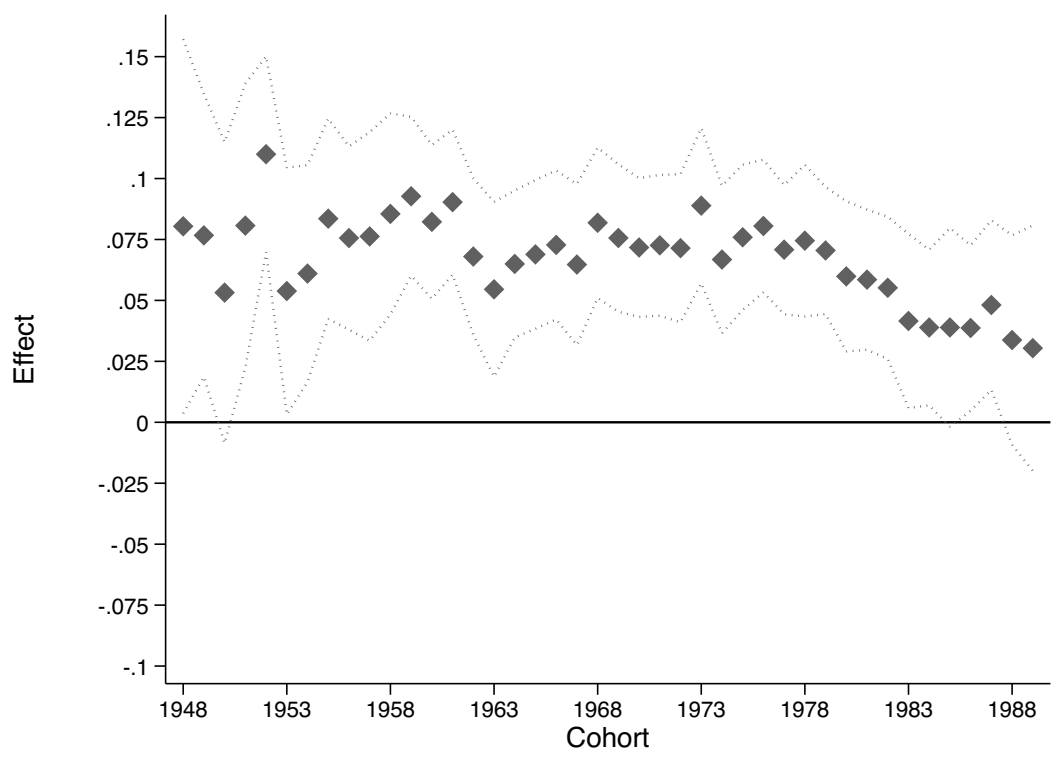

Notes: The figure presents the coefficients $\beta_{t}$ for each cohort of women born between 1948 and 1989 estimated in equation (4.1), together with $95 \%$ confidence intervals. The individual-level and historical controls included are described in Table 2.1.

Figure 2.5: Heterogeneous effects of the transatlantic slave trade across cohorts

\subsubsection{Instrumental Variable Strategy}

While the results presented so far are robust to controlling for a wide array of observable historical factors, there could still be unobservable omitted variables that are correlated with both an ethnic group's exposure to the transatlantic slave trade and current FLFP. A priori,

only variation across women in their 20s, we cannot rule out that the decreased magnitude of the estimated coefficients is the result of age-specific heterogeneous effects in the impact of the transatlantic slave trade. For instance, women born in the 1980s are significantly less likely to be married at the time in which they take the survey, and thus less likely to be affected by their husband's attitudes about working women - a factor that was shown to play a significant role. 
the direction of the potential omitted variable bias is not clear. Consider for instance the possibility that ethnic groups that were historically characterized by higher involvement in warfare may have experienced the slave trade more severely. On the one side, as more powerful military societies were probably ex-ante more likely to be male dominated, this could drive down the OLS estimates towards zero. On the other side, women belonging to these groups may have been historically more likely to work outside the house to substitute for the men involved in warfare, which would drive the estimates away from zero.

To address these concerns, in this Section I rely on the instrumental variable strategy suggested by Nunn and Wantchekon (2011). Traders purchased slaves at ports to ship them to the New World, making groups inhabiting areas closer to the coast more likely to be exposed to the external demand for slaves. Therefore I use an ethnic group's historical distance from the sea as instrument for the exposure to the transatlantic slave trade. ${ }^{47}$ In addition, the use of an IV strategy has the benefit of yielding consistent estimates in presence of measurement error in the slave export variable.

I present IV estimates both for the specification with country-survey fixed effects and for the one with EA-survey fixed effects. The latter has the additional advantage of holding constant the external environment, reducing concerns that the instrument is correlated with characteristics of the respondent's current location that in turn affect current FLFP. The identification assumption is that, after controlling for the usual set of historical variables, among women currently living in the same country (or in the same EA), the historical distance from the coast of a woman's ancestors affects her labor force participation today only through the exposure to the transatlantic slave trade.

Table 2.6 presents the estimates. The Kleibergen-Paap F statistic on the excluded instrument confirms that the instrument is a strong predictor of the exposure to the transatlantic slave trade, as places further from the coast were less likely to be affected. Most importantly, the second stage estimates confirm the OLS results: women belonging to groups that were

\footnotetext{
${ }^{47}$ An ethnic group's distance from the coast is built using Murdock (1959)'s map of the historical borders of African ethnic groups, and it measures the distance of the centroid of the area of land historically inhabited by the ethnic group to the closest point on the coast.
} 
Table 2.6: IV estimates, the effect of the slave trade on women's labor market

\begin{tabular}{lcccc}
\hline \hline & $\begin{array}{c}\text { FLFP } \\
(1)\end{array}$ & $\begin{array}{c}\text { High Ranking } \\
(2)\end{array}$ & $\begin{array}{c}\text { FLFP } \\
(3)\end{array}$ & $\begin{array}{c}\text { High Ranking } \\
(4)\end{array}$ \\
\hline Second stage: & & & & \\
Translatlantic Trade & $0.048^{*}$ & $0.072^{* * *}$ & $0.050^{* * *}$ & $0.054^{* * *}$ \\
& $(0.027)$ & $(0.021)$ & $(0.013)$ & $(0.011)$ \\
Observations & 563,379 & 549,009 & 563,092 & 548,694 \\
R-squared & 0.17 & 0.14 & 0.32 & 0.27 \\
Transatlantic std. dev. & 0.564 & 0.564 & 0.564 & 0.564 \\
Dep. var. mean unaffected & 0.586 & 0.224 & 0.586 & 0.224 \\
& & & & \\
First stage: dependent variable is Transatlantic Trade & & & \\
Historical Distance from Coast & $-0.00096^{* * *}$ & $-0.00096^{* * *}$ & $-0.00109^{* * *}$ & $-0.00107^{* * *}$ \\
& $(0.00019)$ & $(0.00019)$ & $(0.00020)$ & $(0.00019)$ \\
Observations & 563,379 & 549,009 & 563,092 & 548,694 \\
R-squared & 0.69 & 0.69 & 0.90 & 0.90 \\
Ethnic Groups & 243 & 243 & 243 & 243 \\
Fixed Effects & Country & Country & EA & EA \\
Individual Controls & Yes & Yes & Yes & Yes \\
Historical Controls & Yes & Yes & Yes & Yes \\
1st stage F-stat & 30.30 & 30.51 & 40.15 & 39.45 \\
\hline
\end{tabular}

Notes: Standard errors in parentheses, clustered at the ethnicity level. The unit of observation is a female respondent. FLFP is an indicator variable taking value one if the respondent was ever employed in the last 12 months. High Ranking is an indicator variable taking value one if the respondent is employed in a higher ranking occupation. Transatlantic Trade is the number of slaves exported during the transatlantic slave trade normalized by the area of land historically inhabited by the ethnic group. The top panel shows the second stage estimates of Transatlantic Trade, while the bottom panel shows the first stage estimates of Historical Distance from Coast. "1st stage F-stat" indicates the value of the Kleibergen-Paap F statistic on the excluded instrument. Controls are described in Table 2.1. "Dep. var. mean unaffected" is the mean value of the dependent variable for the subsample of observations for which Transatlantic Trade is equal to zero.

$* * *, * * *$ indicate significance at the $1 \%, 5 \%$ and $10 \%$ level.

more severely targeted by the transatlantic slave trade are today more likely to be employed and to have a relatively higher-ranking occupation. ${ }^{48}$ The IV estimates are slightly larger than the OLS estimates. ${ }^{49}$ This can be explained by measurement error in the slave export variable, consistent with the results in Nunn (2008). Alternatively, we cannot rule out the possibility that ethnic groups that exported more slaves in the transatlantic slave trade were

\footnotetext{
${ }^{48}$ Table B.13 in the Appendix shows the results when the other occupational dummies are used as dependent variable. Similarly to the OLS estimates, the results are generally insignificant.

${ }^{49}$ However, in three out of the four specifications of Table 2.6 we cannot reject the null hypothesis of the consistency of the OLS estimates at the $5 \%$ level or lower
} 
initially characterized by a lower participation of women in activities outside the domestic sphere, an effect that is biasing the OLS estimates towards zero. ${ }^{50}$

\subsection{The Effect on Fertility and Gender Norms in Other Domains}

In the previous Section I have presented evidence that women belonging to ethnic groups that were more severely affected by the transatlantic slave trade are today more likely to be part of the labor force. In this Section, I investigate whether the demographic shock brought about by the transatlantic slave trade affected fertility and gender norms in domains other than the labor market.

Since women whose ancestors were more heavily enslaved in the transatlantic slave trade are today more likely to be in the labor force, we expect lower levels of fertility in these ethnic groups, since the costs of having children will be higher. I test this hypothesis using information on a woman's number of children and her age at first birth. The first two columns of Table 2.7 show the results for the fertility variable. Women belonging to ethnic groups that were more exposed to the transatlantic slave trade have fewer children: a one standard deviation increase in Transatlantic Trade translates into 0.05 fewer children ever born, a $1.6 \%$ reduction relative to the average number of children of women whose ancestors were not subjected to the transatlantic slave trade. The result holds even when we leverage variation only across women currently living in the same location.

Columns 3 and 4 of Table 2.7 show results for the subsample of women with children when the dependent variable is a respondent's age at first birth. Not only is the transatlantic slave trade associated with lower fertility today, but it also increased the average age at which a woman has the first child. ${ }^{51}$

Are ethnic groups that were more heavily affected by this shock characterized by more

\footnotetext{
${ }^{50}$ Table B.14 in the Appendix replicates the results of Table 2.6 controlling for education and polygyny, finding essentially identical results.

${ }^{51}$ Tables B.15 and B.16 in the Appendix shows that the results are unchanged if I additionally control for education and polygyny, and when I instrument the transatlantic slave trade export measure with an ethnic group's historical distance from the coast.
} 
equal gender norms in domains other than the labor market? As discussed in Section 2.2, whether an increase in FLFP following the emergence of a female-biased sex ratio is accompanied by a more general shift towards more gender equality in other domains is theoretically ambiguous. A lower number of men relative to women could have decreased female bargaining power in the marriage market during the centuries of the slave trade, and result in the crystallization of less equal gender roles in spite of an increase in FLFP.

Table 2.7: OLS estimates, the effect of the slave trade on fertility

\begin{tabular}{lcccc}
\hline & $\begin{array}{c}\text { Number of } \\
\text { Children } \\
(1)\end{array}$ & $\begin{array}{c}\text { Number of } \\
\text { Children } \\
(2)\end{array}$ & $\begin{array}{c}\text { Age First } \\
\text { Birth } \\
(3)\end{array}$ & $\begin{array}{c}\text { Age First } \\
\text { Birth } \\
(4)\end{array}$ \\
\hline Translatlantic Trade & $-0.086^{* *}$ & $-0.057^{* * *}$ & $0.336^{* * *}$ & $0.231^{* * *}$ \\
& $(0.034)$ & $(0.015)$ & $(0.091)$ & $(0.046)$ \\
Observations & 563,379 & 563,092 & 416,965 & 416,639 \\
R-squared & 0.64 & 0.67 & 0.11 & 0.20 \\
Ethnic Groups & 243 & 243 & 243 & 243 \\
Fixed Effects & Country & EA & Country & EA \\
Individual Controls & Yes & Yes & Yes & Yes \\
Historical Controls & Yes & Yes & Yes & Yes \\
Transatlantic std. dev. & 0.564 & 0.564 & 0.560 & 0.560 \\
Dep. var. mean unaffected & 3.015 & 3.015 & 18.596 & 18.596 \\
\hline
\end{tabular}

Notes: Standard errors in parentheses, clustered at the ethnicity level. The unit of observation is a female respondent. Number Children is the respondent's number of children ever born. Age First Birth is the respondent's age at first birth. Transatlantic Trade is the number of slaves exported during the transatlantic slave trade normalized by the area of land historically inhabited by the ethnic group. Controls are described in Table 2.1. "Dep. var. mean unaffected" is the mean value of the dependent variable for the subsample of observations for which Transatlantic Trade is equal to zero. $* * * * *, *$ indicate significance at the $1 \%, 5 \%$ and $10 \%$ level.

To shed some light on this issue, I use a series of questions from the DHS measuring women's participation in household decision-making and attitudes towards domestic violence, and two questions from the Afrobarometer on general attitudes towards women that are not directly related to their role in the labor market.

The DHS includes a set of questions measuring a woman's degree of participation in household decisions, namely her own health care, large household purchases, daily household purchases, and visits to family and friends. ${ }^{52}$ I summarize these questions

\footnotetext{
${ }^{52}$ An additional question asks whether the woman participates in the decision about what to cook. However,
} 
building a variable that records the share of questions for which the respondent answers that she has a say in the decision. ${ }^{53}$ Another set of questions from the DHS asks the respondent whether she believes a husband is justified in beating his wife in the case she goes out without telling him, if she neglects the children, if she argues with the partner, if she refuses to have sex, or if she burns the food. I summarize this set of questions building a variable capturing the share of questions for which the respondent answers that, in that specific case, violence against a wife is justified.

The Afrobarometer surveys include a question measuring a respondent's belief about women's role in politics. The corresponding variable takes values from 1 to 5 , increasing in the respondent's agreement with the fact that men and women should have equal rights to be elected to political office. A second, more general question asks the respondent whether he believes that men and women should have equal rights. The corresponding variable takes values from 1 to 5 , increasing in the respondent's agreement with the statement that women should be treated as men. ${ }^{54}$

this question is not relevant to capture women empowerment, as this decision traditionally pertains to women in societies where women's role is confined within the house.

\footnotetext{
${ }^{53}$ For each question, the respondent is coded as having a say in the decision either if she takes the decision alone, or if she takes it together with her partner or another member of the household.

${ }^{54}$ Specifically, in the first question the respondent is asked to indicate, between two statements, which one is closest to his view. The two statements are: "Men make better political leaders than women, and should be elected rather than women" and "Women should have the same chance of being elected to political office as men". The variable takes values from 1 to 5, corresponding to "strongly agree with the first statement", "agree with the first statement", "agree with neither", 'agree with the second statement", "strongly agree with the second statement". In the second question, the respondent is asked to choose between the following two statements: "Women have always been subject to traditional laws and customs, and should remain so" and "In our country, women should have equal rights and receive the same treatment as men do". Once again, the variable takes values from 1 to 5 , increasing in the respondent's agreement with the second statement.
} 


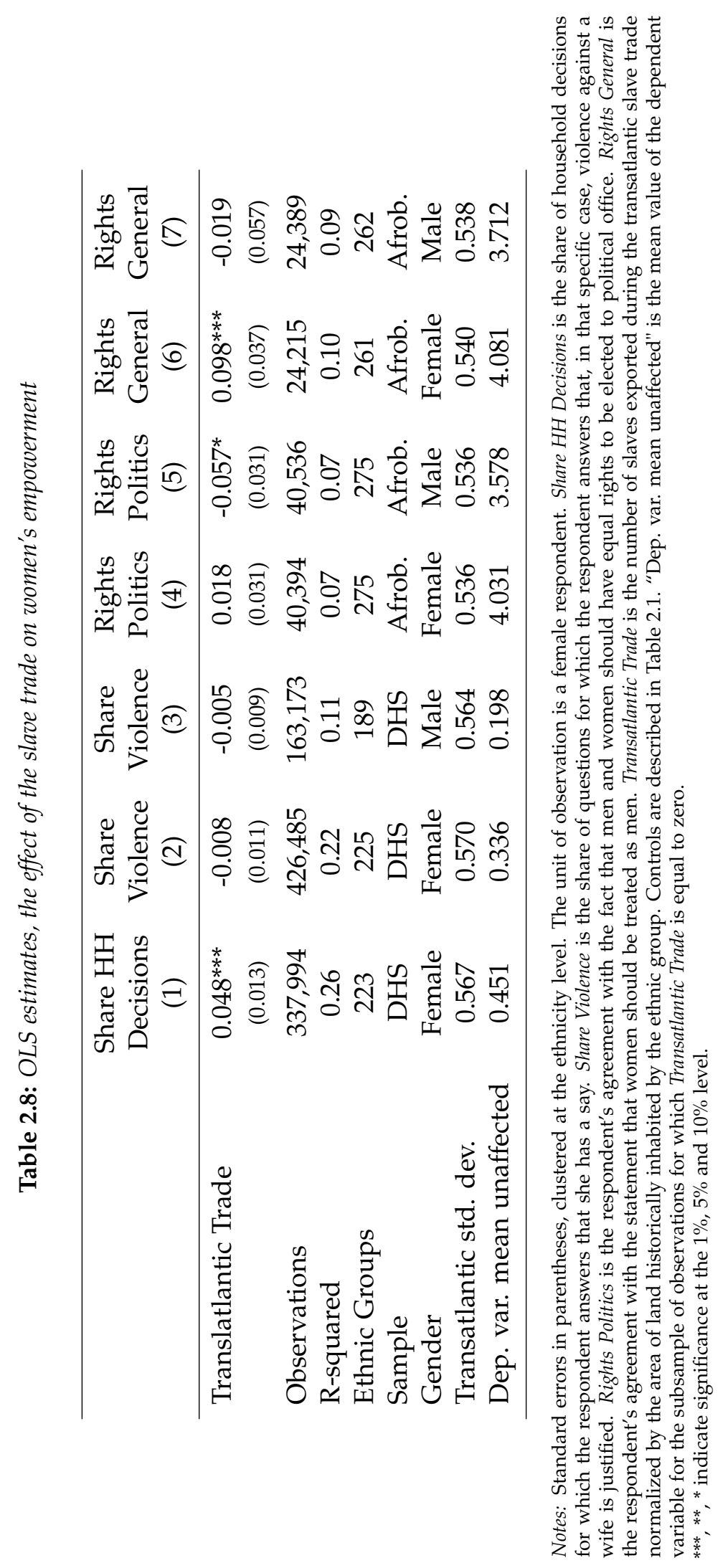


Table 2.8 presents the estimated effect of the transatlantic slave trade on these measures. For the three variables measuring a respondent's beliefs (columns 2-7), we can look separately at the coefficients for men and women. Women belonging to ethnic groups more affected by the transatlantic slave trade are today more likely to participate in household decisions, with a one standard deviation increase in Transatlantic Trade leading to a 2.5 percentage points increase in the share of household decisions to which a woman participates. Similarly, women (but not men) whose ancestors were more severely hit by this shock are more likely to believe that women and men should have equal rights. However, we do not find a significant effect of the transatlantic slave trade on attitudes towards domestic violence or on beliefs about the role of women in politics. ${ }^{55}$

Therefore, while the transatlantic slave trade led to a persistent change in the role of women in the labor market, with a consequent impact on fertility, not all the resxults point towards a significant long-run effect on more general gender roles attitudes. We do find that in groups more affected by this historical shock women have more power over household decisions today, consistent with the fact that their financial contribution to the household is higher. However, other beliefs not directly related to the role of women in the labor market are not significantly affected. In particular, we do not find an effect on beliefs about the appropriate role of women in politics, suggesting that, although the shock to sex ratios led to more equal gender norms related to participation in high-ranking occupations, it was not accompanied by a similar effect on beliefs about women's leadership ability. ${ }^{56}$

\footnotetext{
${ }^{55}$ The results are similar when I instrument the transatlantic slave trade export measure with an ethnic group's historical distance from the coast (see Table B.17 in the Appendix). The coefficient on women's beliefs about equal rights for men and women remains positive but it is now marginally insignificant, while the effect on women's attitudes towards domestic violence becomes negative and statistically significant.

${ }^{56}$ One possible, additional reason explaining the insignificant effect on the variable capturing attitudes towards domestic violence is that this variable captures a combination of attitudes towards women and attitudes towards violence. As shown by Fenske and Kala (2015) and Fenske and Kala (2017), the slave trade had a long-run effect on conflict, with areas more affected by the slave trade experiencing higher levels of violence today. To the extent that the estimated coefficients capture also this effect, this could explain the zero result.
} 


\subsection{Conclusions}

This paper shows that an historical shock that affects the division of labor between men and women can have a persistent effect on female labor force participation. Since a great majority of men were exported during the transatlantic slave trade, skewed sex ratios emerged in the African population of the regions more severely affected by this historical shock. Historical accounts show that the shortage of men pushed women into the labor force and led women into taking up new areas of work.

Using data on more than 500,000 women from 21 Sub-Saharan African countries, I show that women whose ancestors were more exposed to the transatlantic slave trade are today significantly more likely to be in the labor force.

Leveraging information on a woman's husband's ethnicity, I show that the marriage market is an important mechanism explaining persistence of this shock. In addition, comparing individuals of different ethnicities who currently live in the same village or in the same neighborhood within a city, I isolate the significant role played by cultural beliefs that are internal to individuals.

Consistent with a higher cost of having children for working women, women whose ancestors were more heavily enslaved in the transatlantic slave trade have lower levels of fertility. However, consistent with theoretical models on the impact of skewed sex ratios on intrahousehold bargaining, I find mixed evidence on the effect of the transatlantic slave trade on general attitudes towards women in domains other than the labor market. While women belonging to ethnic groups that were more affected by this historical shock are more likely to participate in household decisions, these ethnic groups are not characterized by different attitudes towards domestic violence or by different beliefs about the role of women in politics. These results suggest that demographic shocks, while having a persistent impact on FLFP, may not have a comparable effect on gender equality in domains other than the labor market. 


\section{Chapter 3}

\section{Intergenerational Mobility and Preferences for Redistribution ${ }^{1}$}

\subsection{Introduction}

In 1966, John Steinbeck conjectured that there is not much support for redistribution in America because the working poor see themselves as "temporarily embarrassed millionaires." ${ }^{2}$ Are people willing to accept high levels of inequality if they think that everyone has a shot at climbing the social ladder? Is tolerance for inequality linked to a belief in equality of opportunity? In this paper we have two objectives: First, we want to rigorously document what people think about intergenerational mobility across countries, using new detailed and quantitative survey data. Second, we will study the effect of perceptions of social mobility on support for redistribution.

The (stereo)typical view about intergenerational mobility distinguishes between "American" and "European" attitudes. Americans are thought to view the market system as relatively fair, and to believe in the "American dream," i.e., the notion that one can make it from rags to riches with sufficient effort. Thus, Americans supposedly view wealth as

\footnotetext{
${ }^{1}$ Co-authored with Alberto Alesina and Stefanie Stantcheva

${ }^{2}$ John Steinbeck, American and Americans, 1966.
} 
a reward for ability and effort, and poverty as the result of inability to take advantage of opportunities. In contrast, Europeans tend to believe that the economic system is unfair, and that wealth is the result of family history, connections, and sticky social classes. Poverty is the result of bad luck and the inability of society to take care of the needy regardless of their effort. ${ }^{3}$

However, the American dream today may have become more accurately described by the green light at the end of Daisy's dock in The Great Gatsby. Gatsby likes to contemplate it and reaches for it relentlessly: it is the embodiment of a "dream" that seems "so close that [we] could hardly fail to grasp it," and provides Gatsby with profound motivation to work hard and succeed. Yet it ends up being out of reach and unattainable. Indeed, new data (Chetty et al., 2014) suggests that intergenerational mobility in the U.S. on average may, in fact, not be higher than in Europe.

In order to document the anatomy of people's beliefs about intergenerational mobility and the fairness of their economic system, we collect new survey and experimental data for five countries (France, Italy, Sweden, the U.K., and the U.S.). Our survey design is one of our contributions; it allows us to obtain standardized, representative data from these five countries, with detailed and quantitative questions on government, a variety of policies, and perceptions. We believe this improves upon earlier surveys. The policy questions we ask reflect a realistic trade-off - e.g., we avoid having respondents think that there are "free lunches." We also randomize the order of several questions in an informative way. The questions are designed to attract respondents' attention, are visually appealing, and, in some cases, interactive or animated. ${ }^{4}$

We begin by comparing people's perceptions of mobility to recent data on actual

\footnotetext{
${ }^{3}$ These disparate attitudes are deeply ingrained in the different history of the places. Europe went through centuries of feudalism when wealth was associated with nobility and birth, and intergenerational mobility was close to non-existent. In the U.S., the first generation of rich individuals were immigrants who had started poor and represented the very finest example of the "American Dream."

${ }^{4}$ The online survey tools used in this paper can easily be scaled up and modified in future research, to collect additional data on more countries, expand the set of questions asked, or run additional experimental treatments.
} 
intergenerational mobility in the five countries to assess whether people's perceptions are realistic. We then turn to the link between perceived intergenerational mobility and redistributive policies. To get at the causal link between perceptions of mobility and redistributive preferences, we implement a randomized perception treatment, through which we aim to make respondents' perceptions of mobility more pessimistic. Throughout the paper, we use the word "optimism" to label perceptions of high social mobility, i.e., a lower perceived chance of staying stuck in the bottom quintile and a higher chance of moving to the top quintile. Conversely, "pessimism" is used to designate a low perception of mobility. "over-optimism" (respectively, "over-pessimism") is used to refer to believing in more (respectively, less) social mobility than there is in reality.

Our key findings are as follows. Americans are more optimistic than Europeans about intergenerational mobility, and they are over-optimistic relative to actual mobility in the U.S., especially about the probability of a child from a family in the bottom quintile making it to the top quintile-the "American dream." We show that, paradoxically, optimism is particularly high in U.S. states where actual mobility is particularly low. Europeans are not only more pessimistic than Americans, but they are also too pessimistic relative to the true degree of mobility, and have particularly gloomy views about the probability of a child born poor remaining stuck in the bottom quintile. Both Americans and Europeans believe that hard work increases the chances of making it out of poverty and into the middle class, but few believe that individual effort can make a large difference in reaching the very top, or that hard work can make up completely for a poor family background.

Many respondents think the government has the necessary tools to make opportunities more equal, and that unequal opportunities are a significant social problem. Even so, many do not trust the government's ability or willingness to implement appropriate policies. Views on mobility are highly correlated with policy preferences across all countries: respondents who are more pessimistic about mobility tend to favor more generous redistributive policies and higher levels of government involvement. Interestingly the correlation is stronger for "equality of opportunity" policies (e.g., public education or health spending) than for 
equality of outcome policies (e.g., progressive taxation or safety net policies). We also uncover very sharp differences between left and right leaning respondents. Among left-wing respondents, those who are more pessimistic about the level of intergenerational mobility tend to support more aggressive government intervention and more redistribution. Among right-wing respondents, those who are more pessimistic do not, presumably because they have very negative views of government. Those right wing respondents who believe there are low chances for children from the bottom quintile to make it, despite putting in a lot of effort, do support somewhat more redistribution.

Our experimental treatment, which is meant to make the treated group more pessimistic about mobility, has a large and significant first-stage effect on mobility perceptions and that effect persists one week later in a follow-up survey. The treatment has a polarizing effect on policy preferences, consistent with the descriptive correlations. Left-wing respondents become even more supportive of redistributive policies in general and especially equal opportunity policies. Right-wing respondents also change their views about social mobility, but they do not want any additional government intervention. Thus, it appears that the treatment is either "preaching to the choir" or "falling on deaf ears."

Related literature. Our work builds on the theoretical literature on the link between intergenerational mobility and support for redistributive policies. Piketty (1995) argues that individuals' views about social mobility and their support for redistribution depend on their own personal experience of mobility; heterogeneous beliefs can persist because of differing private experiences. Bénabou and Ok (2001) discuss why the median voter may prefer less redistribution if he considers the prospects of upward mobility in the future, or for future generations. Alesina and Angeletos (2005) provide models with two equilibria. In the "American" equilibrium, people believe that effort is the main source of income, and accordingly they support low redistribution and low taxes. As a result, with the low taxes, agents indeed work hard and the expectation on effort is self-fulfilling. The "European" equilibrium has the opposite features. The misperceptions of mobility we find are perfectly in line with the Bénabou and Tirole (2006) model of "ideology," where people need and 
demand "just world" beliefs to summon willpower and effort. In their "American or Belief in a Just World Equilibrium," there is overestimation of mobility and rewards for effort and low redistribution; the opposite holds true for the "European or Realistic Pessimism equilibrium."

Empirical work by Alesina and La Ferrara (2005) and Alesina and Giuliano (2011) (and the references cited therein,) confirms that views about fairness are critical determinants of preferences for redistribution. Alesina et al. (2001) and Alesina and Glaeser (2004) suggested the hypothesis that Americans may be more optimistic than Europeans about social mobility. This was based on qualitative and vastly incomplete data from the World Value Survey, and they do not investigate direct links between beliefs about mobility and policy preferences as we do in this paper. Here, we rigorously document actual, quantitative perceptions of mobility across five countries and compare them to actual data. We also provide experimental (exogenous) variation in mobility perceptions. We complement those with detailed quantitative and qualitative questions on the role of individual effort, fairness, government, and redistributive policies.

Several papers have studied actual intergenerational mobility across or within countries: Solon (2002), Björklund and Jäntti (1997), Jäntti et al. (2006), Blanden (2013), and Roine and Waldenström (2015). Peichl and Ungerer (2016) compare intergenerational mobility in Eastern and Western Germany. Technical work on the measurement of mobility is done by Niehues and Peichl (2014). ${ }^{5}$ Intergenerational mobility in Sweden has been studied by Roine and Waldenström (2009), Björklund et al. (2012), and Waldenström (2016). In the U.S., Hilger (2016a) and Hilger (2016b) document long-run trends in intergenerational mobility, including among minorities. Recent research based on new IRS tax data has highlighted strong geographical disparities in opportunities (Chetty et al. (2016) and Chetty and Hendren (2016)). Chetty et al. (2014) provide new local measures of mobility which we build on. There are also related papers on the effects of standard redistributive policies on equality of opportunity, including Peichl et al. (2011) who focus on Europe, and Gelber

\footnotetext{
${ }^{5}$ See also Gottschalk and Spolaore (2002).
} 
and Weinzierl (2016) who study optimal policy design when parents can influence their children's opportunities.

We most strongly connect to the literature on how people form preferences for redistribution. Lockwood and Weinzierl (2016) and Lockwood and Weinzierl (2015) study alternative preferences for redistribution that go beyond utilitarianism. Weinzierl (2014) and Weinzierl (2016) also use online survey tools similar to ours to elicit respondents' social welfare judgments. Ashok et al. (2015), Charite et al. (2016), Karadja et al. (2017), and Kuziemko et al. (2014) use experimental designs through online platforms to understand people's views about fairness and redistributive preferences. ${ }^{6}$ Cruces et al. (2013) study how people form their perceptions of the income distribution and how this shapes their support for redistribution. Ariely and Norton (2011) also document the biased perceptions of the income distribution. Kuziemko et al. (2015) show that shifting respondents' perceptions of inequality only mildly increases support for redistribution. ${ }^{7}$ We complement this research on inequality to provide evidence on the perception of mobility, and the effect of providing information about mobility on opinions about government intervention. Also notable, we introduce a broad international component into the experimental literature by conducting our study simultaneously in five different countries.

The rest of the paper is organized as follows: Section 3.2 explains our survey methodology and our data sources for actual intergenerational mobility. In Section 3.3, we describe the perceptions of intergenerational mobility and in Section 3.4, we turn to their correlation with redistribution. Section 3.5 analyzes the perception experiment and is followed by our concluding section.

\footnotetext{
${ }^{6}$ In the social psychology literature, Chambers and Swan (2015) confirm that perceptions of social mobility in the U.S. are deeply divided across party lines. Using survey tools, Davidai and Gilovich (2015) show that U.S. respondents have biased perceptions about mobility relative to reality, a finding we confirm here and extend to other countries. None of these papers have an experimental component or study the link to redistributive preferences.

${ }^{7}$ George (2016) studies social mobility and support for redistribution in the U.S. and finds no relationship between social mobility and redistribution preferences, but a significant effect on voting for the Republican party.
} 


\subsection{Data, Survey, and Methodology}

\subsubsection{Data on Actual Intergenerational Mobility Across Countries}

Our choice of countries - the U.S., Sweden, Italy, France, and the United Kingdom- is driven by the desire to cover a wide range of economic, social, and political experiences. To measure actual intergenerational mobility, we use what to our knowledge is the best currently available data. To describe the data sources, we refer to the first generation as the "parents" and to the second generation as the "children."

U.S.: Information on intergenerational mobility for the U.S. comes from Chetty et al. (2014), and is based on administrative tax records covering the universe of taxpayers 1996-2012. The parents' income is measured as average total pre-tax household income over the years 1996-2000. Children belong to the 1980-85 cohorts and their family income is measured in 2011 and 2012.

Italy: Data on mobility for Italy come from Acciari et al. (2016) and is based on administrative tax records covering the universe of all taxpayers aged 35-55 in 1998-99. Children's income is measured in 2011-2012, when they are age 37 or older.

Sweden: Data for Sweden are from Jäntti et al. (2006). They use administrative data from the Statistics Sweden Register, consisting of a 20\% random sample of all male children born in 1962. For the parents' generation, fathers' earnings only are measured in 1970, 1975 and 1980. The sons' earnings are measured in 1996 and 2000, when they are 34 and 38, and are averaged over these two years.

U.K.: For the U.K. our data source is the British Cohort Study on fathers and sons. The "children sample" is composed of 2806 males, all born in a single week in 1970. Their earnings are measured in 2004, when they are 34 years old. For fathers, income is the average in years 1980 and 1986, when the children were 10 and 16.

France: The France data is based on the 1977, 1985, and 2003 waves of the survey "Formation et Qualification professionnelle," conducted by the national Statistics Institute. This survey 
does not contain explicit information on income, so we compute transition probabilities between income quintiles using information on parents' and children's education, profession, year of birth, and region of residence. Appendix C.8 provides a detailed description of this procedure.

\subsubsection{Survey Data Collection}

We collected survey data in two main waves between February and October 2016. Appendix Table C.1 reports the dates and sample sizes for all survey waves carried out. The first wave was a small pilot survey, without any experimental treatment, of around 500 respondents per country. We append it to the second (main) wave for the purpose of the descriptive analysis (on the control groups only), because the questions asked were identical. The U.S. has a larger sample size because we conducted a third wave there, for the purpose of increasing the sample size for the state-level analysis in Section 3.3.4. Overall, the total sample sizes for each country are 4705 for the U.S., 2148 for the U.K., 2148 for France, 2143 for Italy, and 1494 for Sweden. We also conducted a follow-up survey (without any randomized treatment) one week after each wave on U.S. respondents to test for the persistence of the treatment effects.

U.S. respondents were contacted through the survey company C\&T Marketing; European respondents by the survey company Respondi. These companies maintain panels of respondents that they can email with survey links. The respondents who choose to respond are first channelled through some screening questions that ensure that the final sample is nationally representative along gender, age, and income dimensions. Respondents are paid if they fully complete the survey. The pay per survey completed was $\$ 2.50$ in the U.S., $\$ 2.20$

for Italy, France, and the U.K., and $\$ 5.50$ for Sweden. The average time for completion of the survey among respondents was 40 minutes and the median time of completion was 15 minutes. 


\subsubsection{The Survey}

The full survey in English is reported in Appendix C.4, while the questionnaires in Italian, French, and Swedish can be seen by following the links to the survey's web interface in the Appendix. We worked with native speakers so as to get translations that fit well with the local culture and understanding. ${ }^{8}$ All surveys followed this general structure:

Socioeconomic background and own experience of mobility: We start with questions about individuals' socioeconomic backgrounds, such as gender, income, education, ethnicity, state and zip code, marital and family status, and political leanings. We also ask questions to assess a respondent's own experience of mobility: we ask about their parents' education (which we can compare to their own education), ask them to assess the prestige of their job relative to that of their father and mother, to compare their family income when growing up to that of other families at that time, and to compare their family income now to that of other families.

Views on fairness: Respondents are asked two similar (but intentionally not identical) questions about their views on the fairness of the economic system, one before the treatment and one after the treatment. ${ }^{9}$ Before the treatment, they are asked whether they perceive the economic system in their country to be "basically fair" or "basically unfair." After the treatment, they are asked whether they believe that everyone in their country gets a chance to succeed (we call it the "American dream" question). We also ask whether they believe the main reason for being poor (respectively, rich) is the lack of effort (respectively, hard work) or rather circumstances beyond one's control (respectively, advantages).

Perceptions of mobility: The core part of the survey are questions designed to elicit respondents' beliefs about upward mobility. We ask both precise quantitative and more general qualitative questions. The main question used to elicit respondents' beliefs about

\footnotetext{
${ }^{8}$ The authors themselves are fluent in three of the four languages and native in two.

${ }^{9}$ Questions asked before the treatment can serve as covariates for studying differential treatment effects. Questions asked after the treatment serve as outcome variables, potentially affected by the treatment.
} 
mobility uses a picture with two ladders (see Figure 3.1) that represents, on the left, the parents' income distribution split into five quintiles, and, on the right the children's income distribution split into the same quintiles. Respondents have to fill out the empty fields to indicate their views on how many out of 100 children from the bottom quintile can make it to each quintile when they grow up. The answers must sum to 100. More specifically, respondents are told:

For the following questions, we focus on 500 families that represent [THE COUNTRY'S] population. We divide them into five groups on the basis of their income, with each group containing 100 families. These groups are: the poorest 100 families, the second poorest 100 families, the middle 100 families, the second richest 100 families, and the richest 100 families.

In the following questions, we will ask you to evaluate the chances that children born in one of the poorest 100 families, once they grow up, will belong to any of these income groups. Please fill out the entries to the right of the figure below to tell us, in your opinion, how many out of 100 children coming from the poorest 100 families will grow up to be in each income group.

In the control and treatment groups, respondents are then asked one of two additional questions (the question is randomly assigned): the first asks about the chances of very hard-working people making it. The second asks about very talented people. Specifically, we rephrase the earlier question, replacing the first paragraph with one of these two options:

[Perceptions conditional on "effort":] Consider 100 children coming from the poorest 100 families. These children are very determined and put in hard work both at school and, later in life, when finding $a$ job and doing that job.

[Perceptions conditional on "talent":] Consider 100 children coming from the poorest 100 families. These children are very talented.

We also ask the following qualitative versions of these questions to elicit respondents' beliefs about mobility. Although they are less precise and cannot be compared well to actual data (as we will do with the quantitative answers), they serve as robustness checks on the quantitative ones. 


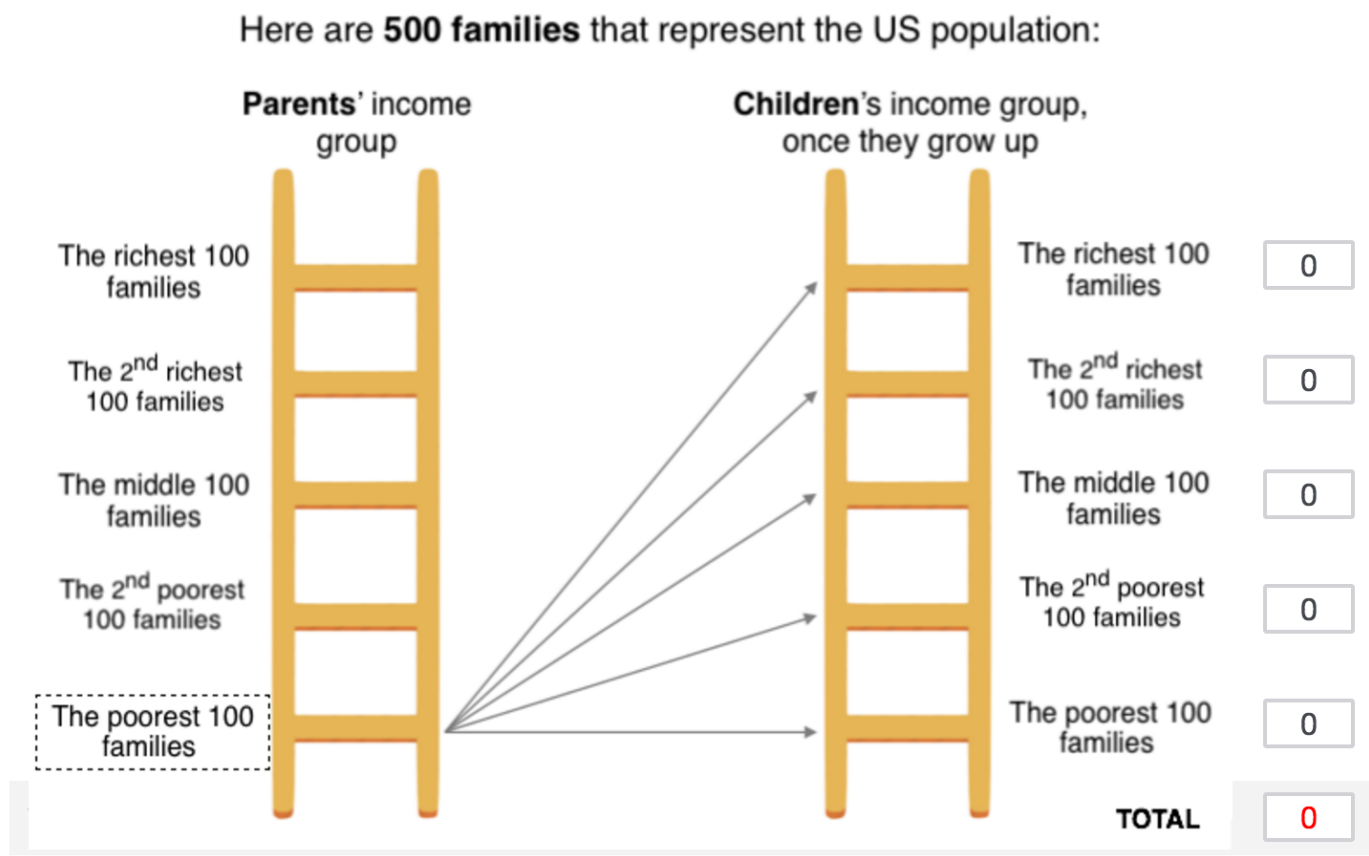

Figure 3.1: Ladder Question to Elicit Perceived Mobility

Do you think the chances that a child from the poorest 100 families will grow up to be among the richest 100 families are: [Close to zero, Low, Fairly Low, Fairly High, High].

and repeat this question for the chances of growing up to be among the second richest families.

The randomized perception treatment, which is described in detail in Section 3.5, appears at this point in the survey.

Policy preferences: We ask three groups of questions about policy preferences: 1) the overall level of government intervention that people would like (through a series of questions presented below); 2) how a fixed level of revenues should be raised; and 3) how a fixed amount of budget should be allocated to various categories of spending. This distinction is key to being able to distinguish respondents' preferred total size of government from who they think should bear the costs and benefits from it.

First, respondents are asked to choose average income tax rates for four groups ranked 
by income: the top $1 \%$, the next $9 \%$, the next $40 \%$ and the bottom $50 \%$. They are constrained to set taxes so as to raise the current level of revenue in their country, i.e., to split the current level of the tax burden in their country among the four income groups in a way that they view as fair (see Appendix Figure C.1). ${ }^{10}$

Second, we ask respondents to rate their support for the estate tax. Finally, we ask them to allocate $100 \%$ of the budget to six spending categories: 1) Defense and National Security, 2) Public Infrastructure, 3) Spending on Schooling and Higher Education, 4) Social Security, Medicare, Disability Insurance, and Supplementary Security Income, 5) Social Insurance and Income Support Programs, and 6) Public Spending on Health (see Appendix Figure C.2).

To get a sense of the desired level of intervention, we ask respondents whether they would be in favor of "more policies to increase the opportunities for children born in poor families and to foster more equality of opportunity, such as education policies," alerting them that these policy expansions would have to be financed either through higher taxes or reduced spending on other policies. ${ }^{11}$

Views on government: We ask respondents what is their desired scope of government intervention on a scale from 1 to 7 , where 1 means "that the government should not concern itself with making the opportunities for children from poor and rich families less unequal," and 7 means "that the government should do everything in its power to reduce this inequality of opportunities." They are also asked whether they think that lowering taxes to stimulate growth or raising taxes to expand programs for the poor would do more to foster equal opportunities.

We ask three additional questions in a randomized way: some respondents see these before the treatment, while others see them after. For respondents who see them before,

\footnotetext{
${ }^{10} \mathrm{To}$ do so, while respondents choose the average tax rates on each group using sliders (see Appendix Figure C.1), a fifth slider at the bottom adjusts to show what fraction of the target revenue has been raised, and alerts the respondents when the target revenue has been met.

${ }^{11}$ This question thus imposes a budget constraint in a milder way than the aforementioned budget allocation question.
} 
the responses are considered pre-existing characteristics used to study the heterogeneous effects of the treatment among groups delimited by these characteristics. For respondents who see them after the treatment, they are treated as outcomes potentially influenced by the treatment. These three questions are: 1) about trust in government ("How much of the time do you think you can trust the government to do what is right?"); 2) how much do you think that the government can do about unequal opportunities for children from poor and rich families; and 3) do you believe that if opportunities are unequal among children from poor and rich families, this is a problem. That third question is, at a general level, about whether people care about unequal opportunities and perceive them as something to be eliminated. Importantly, it does not ask about whether people think that opportunities in their country are currently too unequal or not.

Therefore, there are three randomizations in place, which create eight treatment or control groups, summarized in Appendix Table C.2: 1) the main perception treatment (see Section 3.5); 2) whether respondents are asked about the chances of very-hard working children or talented children; and 3) whether respondents are asked the three questions on government (described in the previous paragraph) before or after the questions eliciting mobility perceptions. Appendix Table C.4 shows that these three layers of randomization were balanced along observable characteristics.

The exact definition of the variables used in the tables is in Appendix C.2.

\subsubsection{Ensuring Data Quality}

Overall, the consistency and internal logic of the answers was excellent. Respondents did not express unrealistic views-i.e., levels of policies that would be difficult to justify under reasonable economic assumptions-about mobility and economic forces. We took several steps to ensure the best possible data quality. For example, in the first and consent page of the survey (see Appendix Figure C.3), we warn respondents that "responding without adequate effort may result in [their] responses being flagged for low quality." At the same time, we appeal to respondents' sense of social responsibility by saying that we are non-partisan 
researchers who seek to improve knowledge on social issues and add that "it is very important for the success of our research that you answer honestly and read the questions very carefully before answering." We also keep track of the time that respondents spend on each survey page so as to be able to flag respondents who spend an unreasonably short time on a certain question. We drop the few respondents (7.6\% across all waves and countries) who spend less than 5 minutes on the full survey or less than 30 seconds on the main mobility question. We confirm that spending a shorter time on the survey is not significantly correlated with any characteristics (such as income, education, political views, etc.)

After the section with background questions and before we show the treatment, we ask respondents whether they have "devoted [their] full attention to the questions so far" and whether, in their honest opinion, they believe that we should use their responses for the study. Only $0.54 \%$ of respondents answered that we should not use their responses for our study. This "attention check" question has been shown by Meade and Craig (2012) to stimulate respondents to pay extra attention to the subsequent questions (not to detect dishonest replies). We strategically placed this question right before one of the most important questions that elicit views on intergenerational mobility.

For the "ladder" question that elicits views on social mobility, we constrain the answers to sum to 100 . We also tell respondents that they need at least one minute to read and think through this question. We check for careless or strange answer patterns by tabulating the response distributions and by flagging responses such as " 0 " or "100." Appendix Table C.3 reports such cases: fortunately, there are very few. In our baseline results, we drop respondents who entered "100" in any quintile except Q1, but adding them back does not change any of the results appreciably. We also ask about mobility in a more qualitative way as described in Section 3.2.3.

Finally, at the end of the survey, we ask respondents for feedback including whether they believe the survey was politically biased. Only $17.7 \%$ of respondents say they felt that it was. Of these, $11.4 \%$ felt it was left-wing biased while $6.3 \%$ felt it was right-wing biased. 


\subsubsection{Sample Characteristics}

Table 3.1 shows the characteristics of our sample in each country, along with statistics from nationally representative sources. We purposely construct our samples to be almost perfectly representative along the gender, age, and income dimensions. The other nontargeted respondent characteristics shown in the table - namely, marital, employment, and immigrant statuses and education - are very representative as well.

Table 3.1: Sample Characteristics

\begin{tabular}{|c|c|c|c|c|c|c|c|c|c|c|}
\hline & \multicolumn{2}{|c|}{ US } & \multicolumn{2}{|c|}{ UK } & \multicolumn{2}{|c|}{ France } & \multicolumn{2}{|c|}{ Italy } & \multicolumn{2}{|c|}{ Sweden } \\
\hline & $\begin{array}{l}\text { Sample } \\
\text { (1) }\end{array}$ & $\begin{array}{c}\text { Pop } \\
(2)\end{array}$ & $\begin{array}{c}\text { Sample } \\
\text { (3) }\end{array}$ & $\begin{array}{c}\text { Pop } \\
(4)\end{array}$ & $\begin{array}{c}\text { Sample } \\
\text { (5) }\end{array}$ & $\begin{array}{l}\text { Pop } \\
(6)\end{array}$ & $\begin{array}{c}\text { Sample } \\
(7)\end{array}$ & $\begin{array}{l}\text { Pop } \\
(8)\end{array}$ & $\begin{array}{l}\text { Sample } \\
\text { (9) }\end{array}$ & $\begin{array}{l}\text { Pop } \\
(10)\end{array}$ \\
\hline Male & 0.48 & 0.48 & 0.48 & 0.49 & 0.50 & 0.48 & 0.50 & 0.48 & 0.47 & 0.50 \\
\hline 18-29 y.o. & 0.26 & 0.27 & 0.26 & 0.24 & 0.23 & 0.21 & 0.19 & 0.19 & 0.21 & 0.24 \\
\hline 30-39 y.o. & 0.18 & 0.19 & 0.18 & 0.20 & 0.20 & 0.19 & 0.22 & 0.21 & 0.18 & 0.19 \\
\hline 40-49 у.о. & 0.19 & 0.21 & 0.21 & 0.21 & 0.21 & 0.20 & 0.23 & 0.24 & 0.19 & 0.21 \\
\hline $50-59$ у.о. & 0.21 & 0.20 & 0.18 & 0.20 & 0.20 & 0.20 & 0.20 & 0.20 & 0.21 & 0.18 \\
\hline 60-69 у.о. & 0.16 & 0.14 & 0.16 & 0.16 & 0.16 & 0.19 & 0.17 & 0.17 & 0.21 & 0.18 \\
\hline Income Bracket 1 & 0.16 & 0.18 & 0.31 & 0.31 & 0.31 & 0.32 & 0.27 & 0.27 & 0.33 & 0.33 \\
\hline Income Bracket 2 & 0.22 & 0.20 & 0.35 & 0.35 & 0.30 & 0.30 & 0.28 & 0.28 & 0.26 & 0.29 \\
\hline Income Bracket 3 & 0.23 & 0.22 & 0.11 & 0.11 & 0.14 & 0.14 & 0.18 & 0.19 & 0.22 & 0.22 \\
\hline Income Bracket 4 & 0.39 & 0.39 & 0.23 & 0.23 & 0.25 & 0.24 & 0.27 & 0.26 & 0.18 & 0.17 \\
\hline Married & 0.51 & 0.49 & 0.47 & 0.41 & 0.44 & 0.46 & 0.55 & 0.46 & 0.41 & 0.33 \\
\hline Native & 0.94 & 0.85 & 0.89 & 0.87 & 0.94 & 0.85 & 0.97 & 0.92 & 0.91 & 0.82 \\
\hline Employed & 0.62 & 0.58 & 0.65 & 0.61 & 0.63 & 0.47 & 0.64 & 0.45 & 0.66 & 0.67 \\
\hline Unemployed & 0.08 & 0.08 & 0.05 & 0.03 & 0.12 & 0.05 & 0.11 & 0.06 & 0.07 & 0.05 \\
\hline College & 0.42 & 0.28 & 0.37 & 0.42 & 0.30 & 0.25 & 0.38 & 0.15 & 0.33 & 0.36 \\
\hline
\end{tabular}

Notes: This table displays summary statistics from our surveys (in odd columns) alongside nationally representative statistics (in even columns). Detailed sources for each variable and country are listed in the Appendix and briefly summarized here. The sources are: 1) for the U.S.: The Census Bureau and Current Population Survey. Income brackets (annual gross household income) are defined as less than $\$ 20,000 ; \$ 20,000-\$ 40,000$; $\$ 40,000-\$ 70,000$; more than $\$ 70,000$. 2) for the U.K.: Eurostat Census Data and Office of National Statistics. Income brackets (monthly net household income) are: less than $£ 1,500 ; £ 1,500-£ 2,500 ; £ 2,500-£ 3,000$; more than $£ 3,000,3)$ for France: Eurostat Census Data and INSEE. Income brackets (monthly net household income, in Euros) are: less than 1,500; 1,500-2,500; 2,500-2,000; more than 3,000; 4) for Italy: Eurostat Census Data, Bank of Italy and ISTAT. Income brackets (monthly net household income, in Euros) are: less than 1,500; 1,500-,2450; 2,450-3,350; more than 3,350; 5) for Sweden: Eurostat Census Data and Statistics Sweden. Income brackets (monthly gross household income, in SEK) are: less than 33,000; 33,000-42,000; 42,000-58,000; more than 58,000. 


\subsection{Mobility (Mis)perceptions}

\subsubsection{Actual and Perceived Mobility}

Table 3.2 displays actual intergenerational mobility in each country. For each country, each

row shows, in descending order, the probability of a child from the bottom quintile $(Q 1)$ of the income distribution moving to quintile $Q j$ with $j=1,2,3,4,5$. For each country, the first column shows the actual probability, while the second shows the perceived probability. In parentheses below the perceived probabilities are the p-values for the equality test between perception and reality. The final set of columns provide a comparison of the U.S. and Europe overall. 


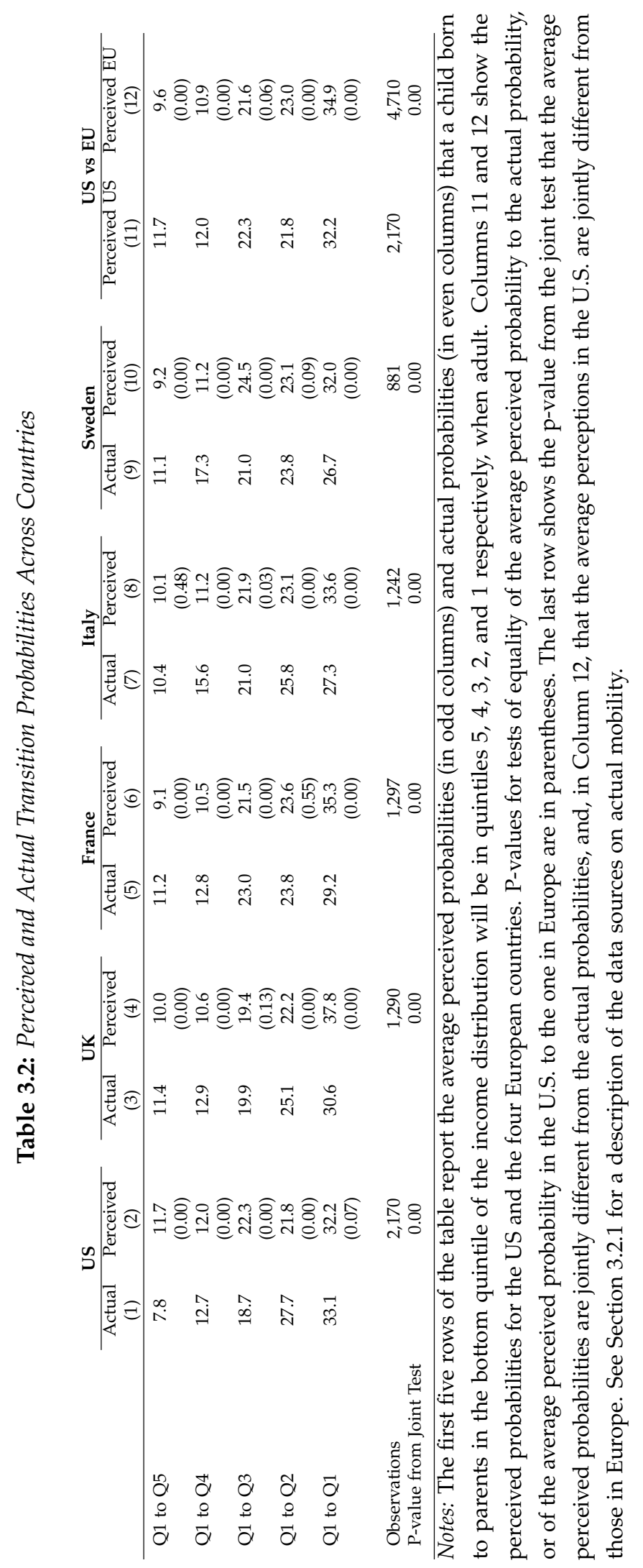


On average, social mobility is lower in the U.S. than in other countries. ${ }^{12}$ The probability of a child from the bottom quintile remaining in the bottom quintile is highest in the U.S. (33.1\%), lower in Continental Europe (below 30\%), and lowest in Sweden (26.7\%). The probabilities of moving from the bottom to the fourth or to the fifth quintiles are also lowest in the U.S.. The probability of moving to the top quintile is $7.8 \%$ in the U.S., but close to $11 \%$ on average in Europe. Note that the differences between perceptions and reality are statistically highly significant in all countries. Perceptions are also significantly different in the U.S. and Europe.

Figure 3.2 graphically illustrates these perceptions relative to reality. Panel A shows the average perceived probability of remaining in the bottom quintile against the actual probability in each country. Points above the 45 degree line indicate more pessimistic perceptions. Panel B similarly illustrates the probability of moving from the bottom to the top quintile. In this figure, being optimistic about mobility implies being above the 45 degree line. Finally, Panel $\mathrm{C}$ shows the perceived and actual probabilities of going from the bottom quintile to quintiles $Q 2, Q 3$, and $Q 4$.

This figure highlights one of our key results. In general, Europeans are not only more pessimistic than Americans, but they are also too pessimistic relative to reality, while Americans are too optimistic. Three additional facts stand out. First, Americans vastly over-estimate the probability of making it to the top of the ladder for children starting from the bottom. They believe almost 12 kids will make it from the bottom to the top while the actual number is a bit below eight. This is the embodiment of the idea of the "American dream." Second, Europeans are too pessimistic about the chances of getting out of poverty, i.e., out of the bottom quintile. For instance, French respondents think that 35 kids will be stuck in poverty, when in reality it is only 29. Third, Europeans are too pessimistic about the probability of making it to the upper middle class (the fourth quintile). The answers to the qualitative and quantitative questions are highly correlated and paint a very similar picture.

\footnotetext{
${ }^{12}$ Nevertheless, one needs to bear in mind the large spatial heterogeneity in the U.S., as described in Chetty et al. (2014) and which we consider in Section 3.3.4.
} 
A: Q1 to Q1 probability

(a)

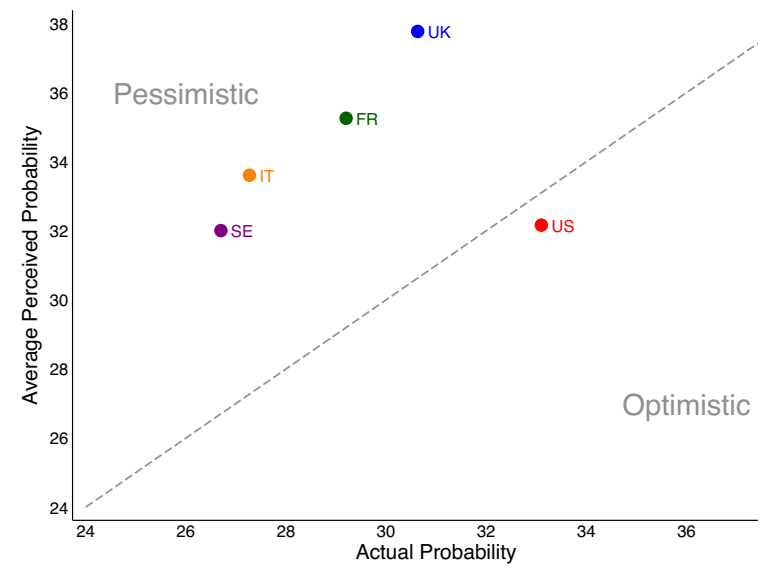

B: Q1 to Q5 probability

(b)

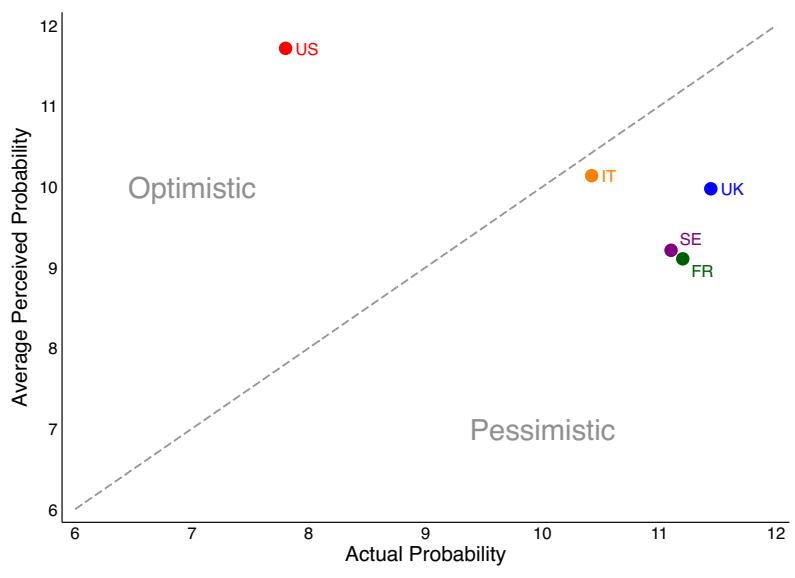

\section{C: Q1 to Q2, Q1 to Q3 and Q1 to Q4 probabilities}

(c)

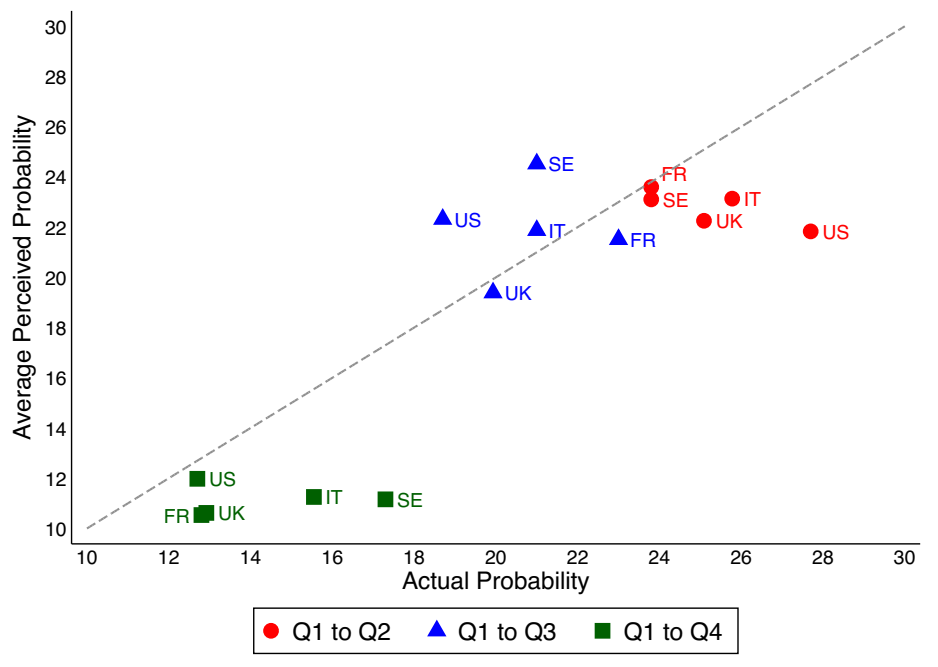

Notes: The figures shows the average perceived probability in each country (y axis) of a child from the bottom quintile remaining in the bottom quintile (Panel A), moving to the top quintile (Panel B), or moving to the second, third, or fourth quintile (Panel $C$ ) against the actual probability in the country ( $x$ axis). The dotted line is the 45 degree line.

Figure 3.2: Actual and Perceived Mobility Across Countries 
This figure also shows that, despite these systematic biases, average perceptions are not unreasonably distant from reality. For instance, the perceived probabilities of moving to quintiles 3 and 4 in the U.S. are $22.3 \%$ and 12\%, while the actual probabilities are $18.7 \%$ and $12.7 \%$. In France, the perceived probabilities of moving to quintiles 2 and 3 are, respectively, $23.6 \%$ and $21.5 \%$, while the actual probabilities are $23.8 \%$ and $23 \%$.

However, at the individual level there is considerable dispersion in the answers. Figure 3.3 shows the distribution of the negative absolute error - the absolute deviation between the actual and the perceived probability of remaining in the bottom quintile (Q1 to Q1) and of moving to the top quintile (Q1 to Q5)- in the U.S. and European samples. This is a measure of individual-level accuracy. The figure shows that at the individual level accuracy is considerably worse than average accuracy. In the U.S., 99.4\% (respectively, $68.1 \%$ ) of respondents are less accurate than average for the probability of remaining in the bottom quintile (respectively, moving to the top quintile). In Europe, 85.5\% (respectively, $89.4 \%$ ) of respondents are less accurate than average for the probability of remaining in the bottom quintile (respectively, moving to the top quintile). If we consider the probability of moving to the top quintile in the U.S., the average individual absolute error is $166 \%$ larger than the error of the average perception (10.4 percentage points vs. 3.9 percentage points). Similarly, if we consider the probability of remaining in the bottom quintile in Europe, the average individual absolute error is $211 \%$ larger than the error of the average perception (19.6 percentage points vs. 6.3 percentage points). This "wisdom of crowds" effect is also found among expert forecasts in DellaVigna and Pope (2016).

While it is beyond the scope of this paper to explain where these differing perceptions of mobility come from in the different countries, we can conjecture that part of their roots lie in the vastly contrasting histories. As explained in Cullen (2004), the U.S. was founded by poor immigrants, who were fleeing persecution and lack of freedom, and established a new living. They believed that in the New World anyone could make it if only they worked hard enough. Europe in contrast was for centuries a feudal society in which birth irrevocably determined one's place in society. These differing ideas are further perpetuated 


\section{A: United States}

(a)

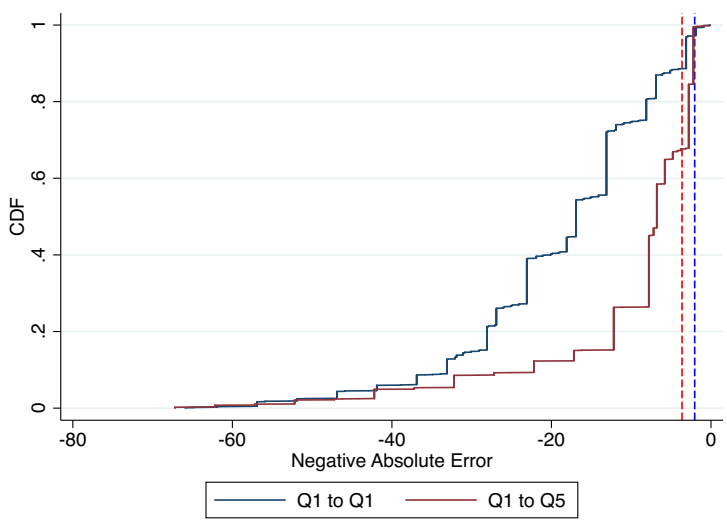

B: Europe

(b)

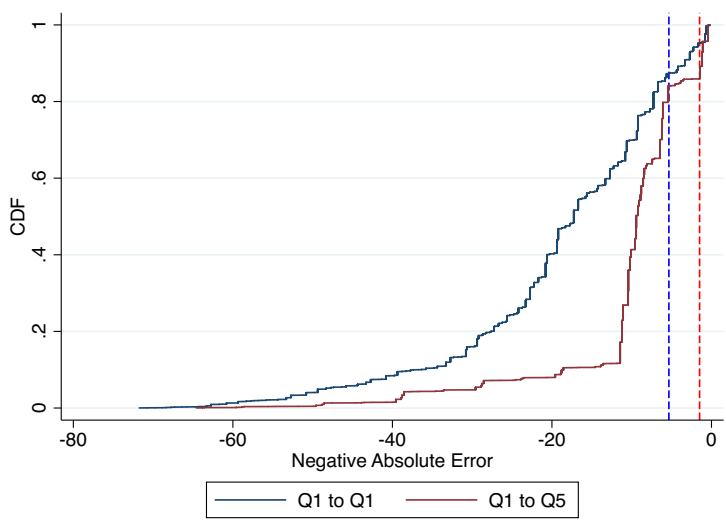

Notes: The figure shows the distribution of the negative absolute error - the absolute deviation between the actual and the perceived probability of remaining in the bottom quintile (Q1 to Q1) and of moving to the top quintile (Q1 to Q5)- in the U.S. (panel A) and European samples (panel B). The dotted red (respectively, blue) line is the negative absolute error of the average perception for the Q1 to Q5 (respectively, Q1 to Q1) transition probability. The accuracy at the individual level is considerably worse than the accuracy of the average perception.

Figure 3.3: Accuracy of Individual Level Perceptions

by each country's literature and art, and areas reinforced by the media. Indeed, as shown by DellaVigna and Kaplan (2007), the media can have a strong influence on voting patterns and political views. The U.S. media places strong focus on the American dream, opportunity, and on those successful people who have made it. In European media and public discourse, this focus is much more diluted.

\subsubsection{Heterogeneity in perceptions}

Next, we systematically analyze the individual characteristics that are most strongly correlated with perceptions of mobility. Figure 3.4 compares the mean perceptions of mobility among respondents with different characteristics. We define "left-wing" respondents as those who say they are "liberal" or "very liberal" on economic issues. "Right-wing" respondents are defined as those who report being "conservative" or "very conservative" on economic issues. Focusing our survey question exclusively on economic issues allows us to 
better compare political orientations across countries, where different parties sometimes mix traditionally liberal and traditionally conservative elements, depending upon whether one considers economic or social issues. For each of the five countries, the exact phrasing was adapted to that country's political spectrum. In France, categories were: "Extreme gauche, Gauche, Centre, Droite, Extreme droite"; in Italy, the U.K., and Sweden, it was "Left, Center-Left, Center, Center-Right, Right." 


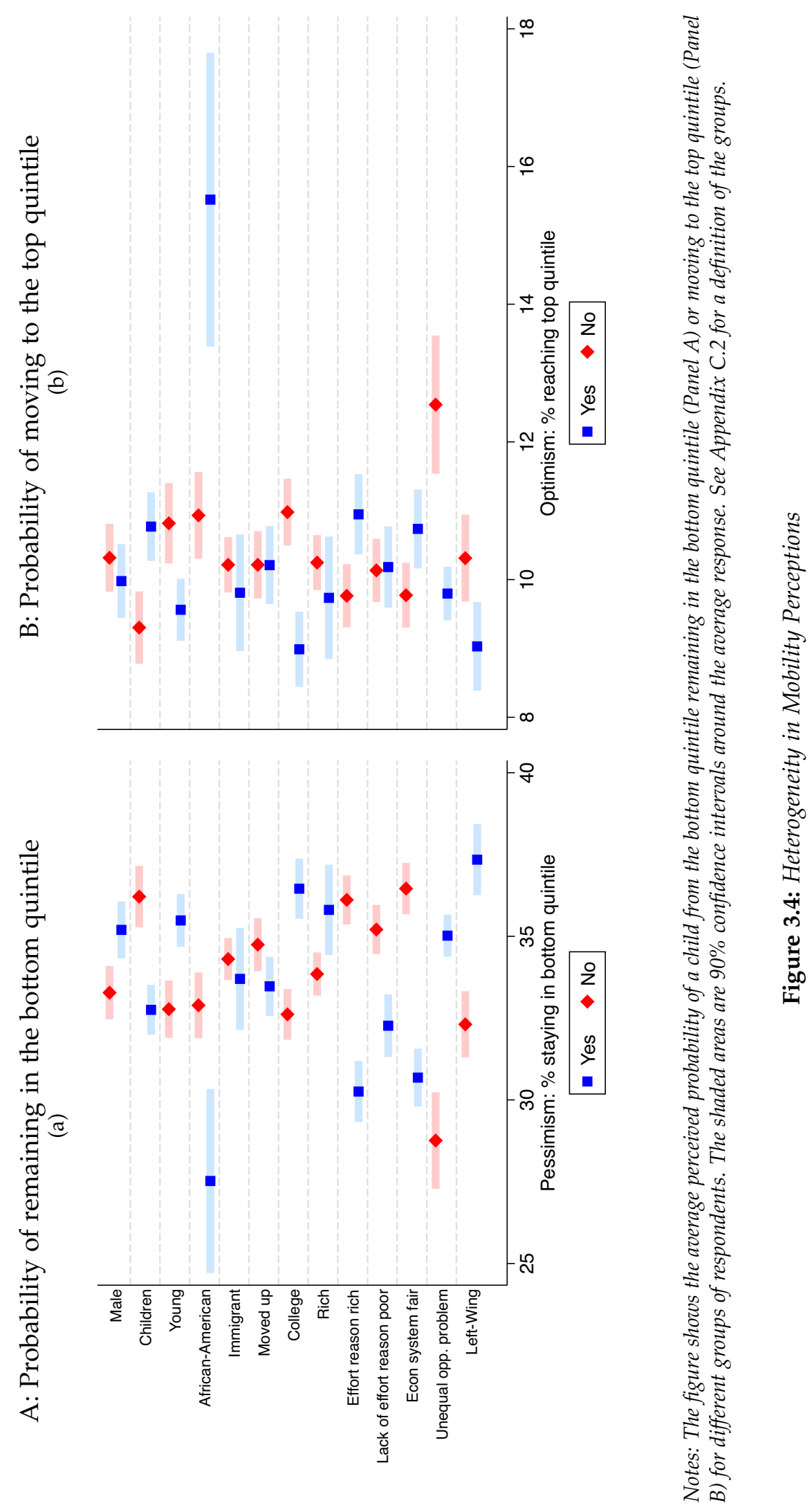


The left leaning respondents are significantly more pessimistic than the right leaning ones, an important observation for what follows. Women, parents, lower income respondents, those without a college education, and African-Americans are more likely to be optimistic about mobility. We discuss the results on African-Americans in more detail in Section 3.3.4. Those who believe that being rich or poor is mostly the result of individual effort, or who believe that the economic system is fair, or that unequal opportunities are not a problem, are also more optimistic. Another significant factor, but less so, is whether one has experienced upward mobility during one's life, ${ }^{13}$ and whether one is the child of immigrants; both predict more optimism. The young have more polarized views and they tend to assign more probability to tail outcomes: they are both more pessimistic about the likelihood of being stuck in the bottom quintile and more optimistic about the likelihood of making it to the top quintile. ${ }^{14}$

The relation between college education (or income) and pessimism is significant, even after we control for other personal characteristics, including political affiliation (see Appendix Table C.7). The psychology literature emphasizes that people tend to take excessive credit for their own success, while blaming failure on outside circumstances and luck (Frank, 2016; Gilovich et al., 2002). On the one hand, this would lead lower income or less educated agents to "self-justify" their bad economic outcomes, believing that mobility is low and the economic system is unfair. On the other hand, high income and college-educated agents would assign their success mostly (and excessively so) to their own effort, rather than to the presence of more mobility (which is not due to their own merit). Consistent with this hypothesis, we find that college educated individuals believe more in the impact of effort on the chances of making it out of poverty and becoming rich. They, and high-income individuals, are significantly more likely to reply that the main reason for being poor is lack of effort and the main reason for being rich is individual effort, even after we control for

\footnotetext{
${ }^{13}$ This is consistent with the idea in Piketty (1995) that a personal experience of mobility leads to an update of one's beliefs about the underlying social mobility mechanism.

${ }^{14}$ Results using the qualitative measures of perceptions instead are generally consistent with these quantitative ones.
} 
the full array of personal characteristics and political affiliation. Thus college-educated and high-income people may believe that making it was very difficult, and that it was their own individual effort that helped them to succeed, despite a system that features low mobility.

\section{Inequality Perceptions and Mobility Perceptions}

Are perceptions and misperceptions of social mobility related to perceptions and misperceptions of inequality? To address this question, we conducted a small additional survey on U.S. respondents: in addition to the aforementioned questions about mobility perception, we asked about perceived shares in total income, capital income, and net wealth, of the top $1 \%$, the top $10 \%$ and the bottom $50 \%$ of households, as well as the taxes paid by different groups. Figure C.14 in the Appendix shows that on average there are quite significant misperceptions of inequality in the U.S.. In particular, respondents overestimate the share of income and wealth going to the top 1\%. Appendix Table C.24 shows that respondents who think there is more inequality also think there is less mobility. Those who underestimate inequality also overestimate mobility.

\subsubsection{Perceived Role of Individual Effort and Hard Work}

In the debate about social mobility, key elements are the scope for individual responsibility and the extent to which individual effort pays off. We explore this in Figure 3.5. The vertical bars in different colors represent the different countries and the black bars are the confidence intervals at the $95 \%$ confidence level. The bars are split into five groups representing the five quintiles. For each country $c$ and quintile $j$, the height of the vertical bars represents the gap between the perceived probability of a child from the bottom quintile in country $c$ moving to quintile $j$. These results come from the question about very hard working children (i.e., the perception conditional on effort) minus the perceived probability from the baseline question (i.e., the perception unconditional on effort). This figure highlights four facts. First, respondents do not believe that individual effort can make up for a poor family background: even when thinking about very hard working people, the respondents still say that mobility is very far from perfect. This is the case despite the fact that we intentionally 


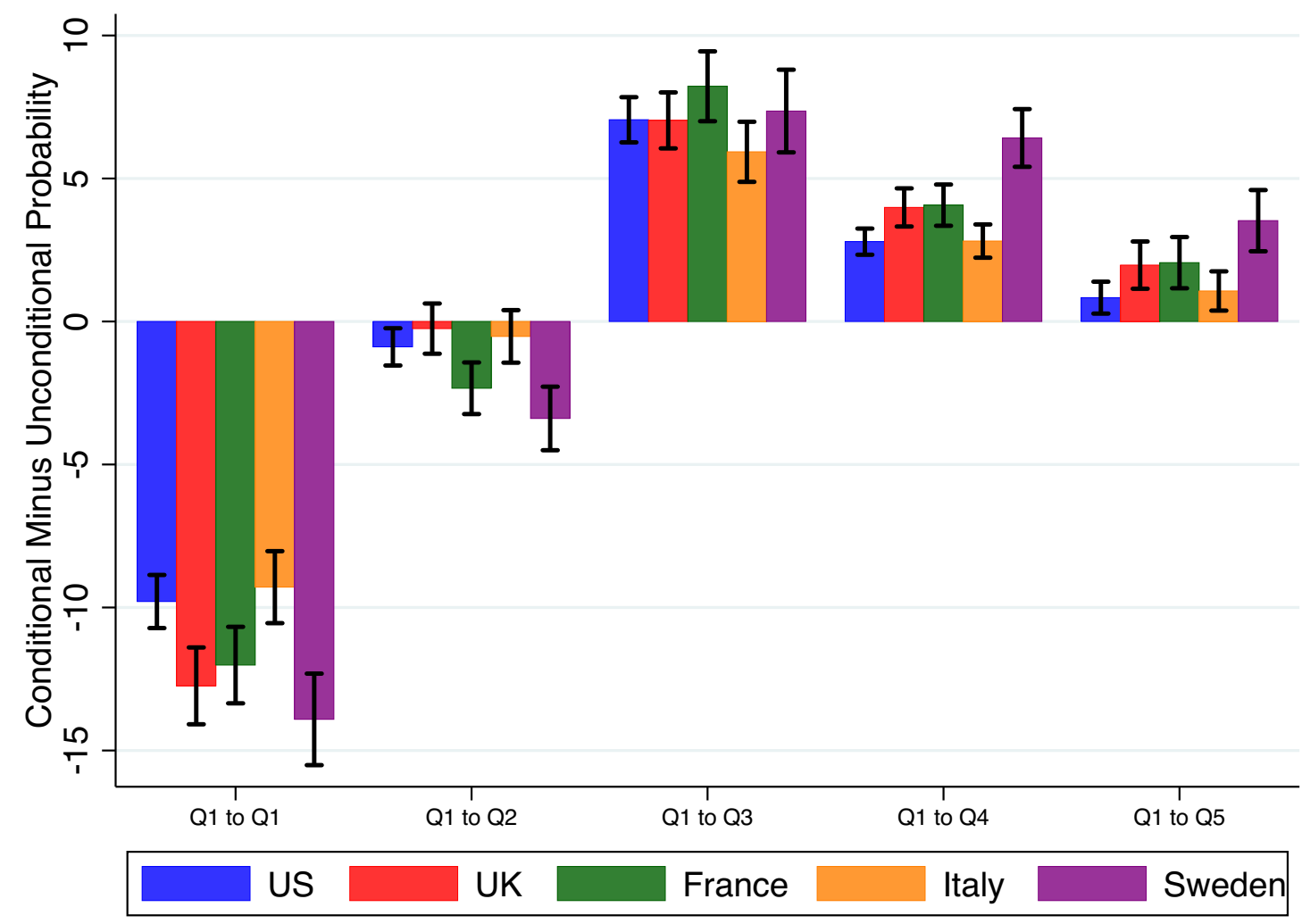

Notes: The figure shows, for each country and each quintile $i$, the means and 95\% confidence intervals for the difference between the perceived probability that a child born in a family from the bottom quintile will be in quintile i in the question that asks respondents to think about a very hard working person (i.e., mobility conditional on effort) and the perceived probability in the baseline question (i.e., unconditional on effort).

Figure 3.5: The Perceived Role of Effort

phrased the question in a strong way to emphasize a "best case" type of scenario. Second, in all countries respondents believe that individual hard work greatly decreases the probability of a child from the bottom quintile remaining in the bottom quintile. Third, in all countries respondents also believe that individual effort increases the chance of moving from poverty to the middle class (Q1 to Q3). Fourth, the perceived probability of moving from the bottom to the top quintile is only very moderately affected by the consideration of effort.

We discovered that groups that believe more in the role of effort for improving the chances of moving out of the bottom quintile are the college-educated and, understandably, 
those who believe that the reason for being poor is lack of effort. Those who believe more strongly in the role of effort for improving the chances of making it to the very top quintile are the young, the college educated, the right-wing, those who believe that the main reason for being either rich or poor is effort, and those who think that the system is broadly fair. Those who believe that unequal opportunities are, in principle, a problem do not update their beliefs conditional on effort more strongly (although they are significantly more pessimistic about mobility conditional on effort).

It is interesting that both left and right wing respondents do not update in a significantly different way their beliefs about the chances of staying stuck in the bottom quintile. In other words, across the political spectrum, respondents agree about how much individual effort improves the chances of escaping poverty. However, there are differences in how left and right wing respondents update their beliefs about making it to the top quintile conditional on effort: the right-wing respondents believe much more firmly in the impact of effort. These results are all available in the Appendix.

\subsubsection{Geography of Perceptions in the U.S.}

The work by Chetty et al. (2014) has shown that the degree of actual social mobility in the U.S. varies dramatically across regions. In our data, we can explore the geographical variation in perceptions of mobility. ${ }^{15}$

The top left panel of Figure 3.6 represents actual mobility at the state level. It is measured by the probability of a child from a family in the bottom quintile making it to the top quintile. In general, mobility is higher (as indicated by darker colors) in the North and Northwest and lower in the South and Southeast. The top right panel replicates this map, but now plots the perceptions of respondents from each state. It is easy to see the negative correlation between the two maps. The bottom left panel of Figure 3.6 shows the ratio of the perceived transition probability from the bottom to the top quintile divided by the actual probability. Overoptimism seems higher in places with lower mobility. Formally, the correlation between

\footnotetext{
${ }^{15}$ Newman et al. (2015) document the link between local inequality and the belief that the U.S. is a meritocracy.
} 
actual and perceived mobility at the state level is -0.3 (p-value of 0.047$).{ }^{16}$ The bottom right panel of Figure 3.6 shows the degree of overoptimism relative to the national average in the U.S., not relative to the mobility in the state. The same patterns are apparent, suggesting that states that are more overoptimistic relative to state-level mobility are also more overoptimistic relative to the national mobility level.

Are perceptions of mobility geographically correlated with other key socio-economic variables? We explore this systematically at the commuting zone (CZ) level, assigning respondents to CZs using their zip codes, and using actual mobility numbers and several key covariates from Chetty et al. (2014). ${ }^{17}$ We consider the effect on perceived mobility of measures of racial segregation, income segregation, social capital, the Gini coefficient, the share of employment in manufacturing, and the college graduation rate controlling for the respondent's gender, age, number of children, income, political affiliation, educational attainment, personal mobility experience, and immigrant status. we find that perceptions are more optimistic when there is more racial segregation, less income segregation, and more social capital. The latter two correlations are as one may expect: with a lot of income segregation, it may be harder to observe the growth out of poverty of certain families, because poor and rich families live separately.

The sign on the effect of racial segregation may seem odd at first. Recall from Section 3.3 that African-Americans, although a small share of our sample, were more optimistic about mobility. There are at least two possible explanations for this fact. First, it may be due to "system justification" an idea support by a large body of evidence from the social psychology literature (see the survey paper by Jost et al. (2004)) emphasizing, somewhat paradoxically, that particularly bad social and economic situations tend to be self-justified by respondents to avoid cognitive dissonance and to lend some legitimacy to the suffering caused. Second, it could be that minorities use their own racial group as a reference point

\footnotetext{
${ }^{16}$ This relation is not driven by the Southeastern states. Excluding South Carolina, North Carolina, Virginia, West Virginia, Tennessee, Kentucky, Georgia, Alabama, Mississippi, and Florida from the calculation yields a correlation of -0.348 with a p-value of 0.056 .

${ }^{17}$ These results are in Appendix Table C.11.
} 


\section{Panel A:}

(a)

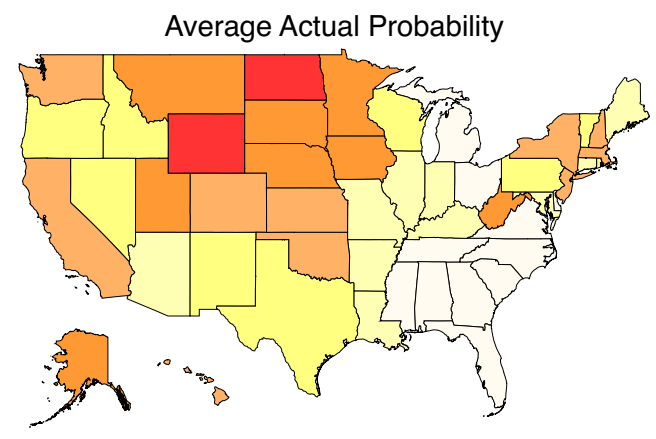

(b)

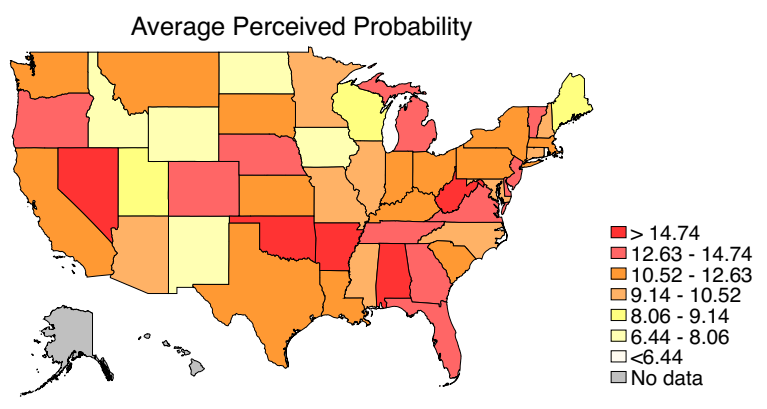

Panel B:

(c)

Ratio of Perceived to Actual State-Level Probability

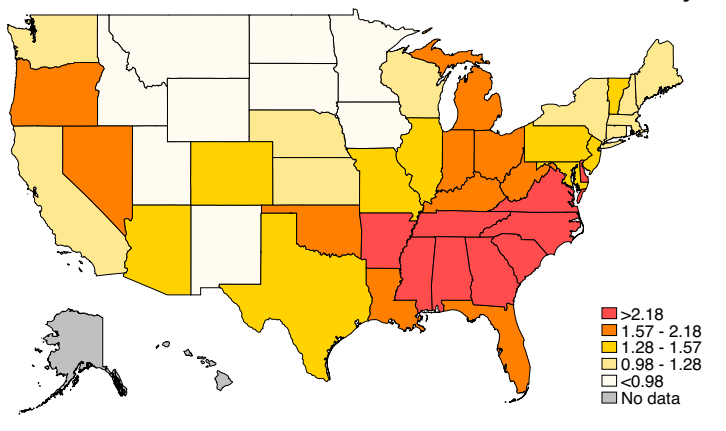

(d)

Ratio of Perceived to Actual National Probability

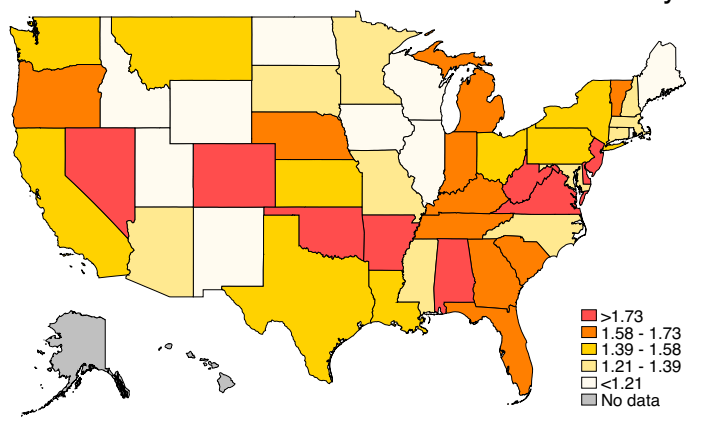

Notes: The top left panel shows the actual probability of a person born in a family in the bottom quintile moving to the top quintile in each state. The top right panel shows the corresponding average perceived probability among respondents in our survey who live in that state. The bottom left panel shows the ratio of the average state-level perceived probability to the actual state-level probability. The bottom right panel shows the ratio of average state-level perceived probability to the average real national probability. The average real national probability of moving from the bottom to the top quintile in the United States is $7.8 \%$. Data on actual transition probabilities is from Chetty et al. (2014).

Figure 3.6: Actual and perceived probability of moving from the bottom to the top quintile across U.S. states 
when there is more racial segregation, which could inflate their perceived mobility relative to true mobility (although we are not aware of studies that establish this rigorously). These are points that deserve future research, with surveys better equipped (and larger) to address these issues.

Another interesting pattern is that the presence of more minorities and immigrants in a respondent's commuting zone is significantly correlated with less support for redistribution, especially among right-wing respondents. ${ }^{18}$ It may be that right-wing respondents believe that redistributive policies will mostly benefit immigrants or minorities, which they may not want.

More generally, the geographical patterns in perceptions, and their correlations with other key socio-economic variables deserve further attention.

\subsection{Perceptions of Mobility and Policy Preferences}

Here, we discuss some views about fairness and the government and then look at the link between mobility perceptions and policy preferences.

\subsubsection{Views on Fairness}

Figure 3.7 shows respondents' views on fairness and the role of government, by country (in Panel A) and by political affiliation (in Panel B). The first row shows the fraction of respondents who think the system is "basically fair, since all [members of country $\mathrm{X}$ ] have an equal opportunity to succeed." The second row shows the fraction of respondents who agree with the statement that "in [country X] everybody has a chance to make it and be economically successful." This is the idea of the "American Dream." The next two rows focus on the roles of effort and luck. Row 3 shows the fraction of respondents who believe that a person is poor because of a lack of effort rather than due to "circumstances beyond his or her control." Row 4 shows the fraction of respondents who believe that people become

\footnotetext{
${ }^{18}$ This is shown in Appendix Table C.12.
} 
rich mostly because they "worked harder than others" and not because they "had more advantages than others." 


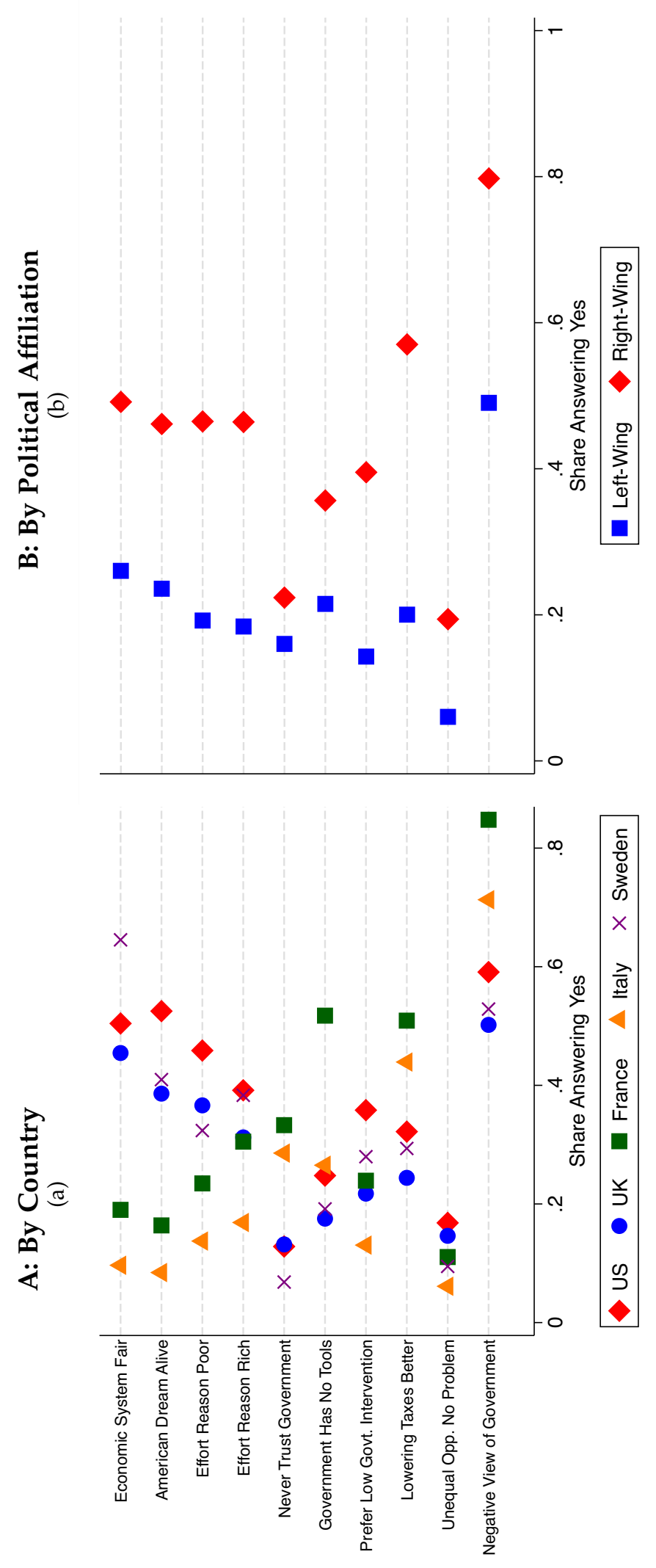

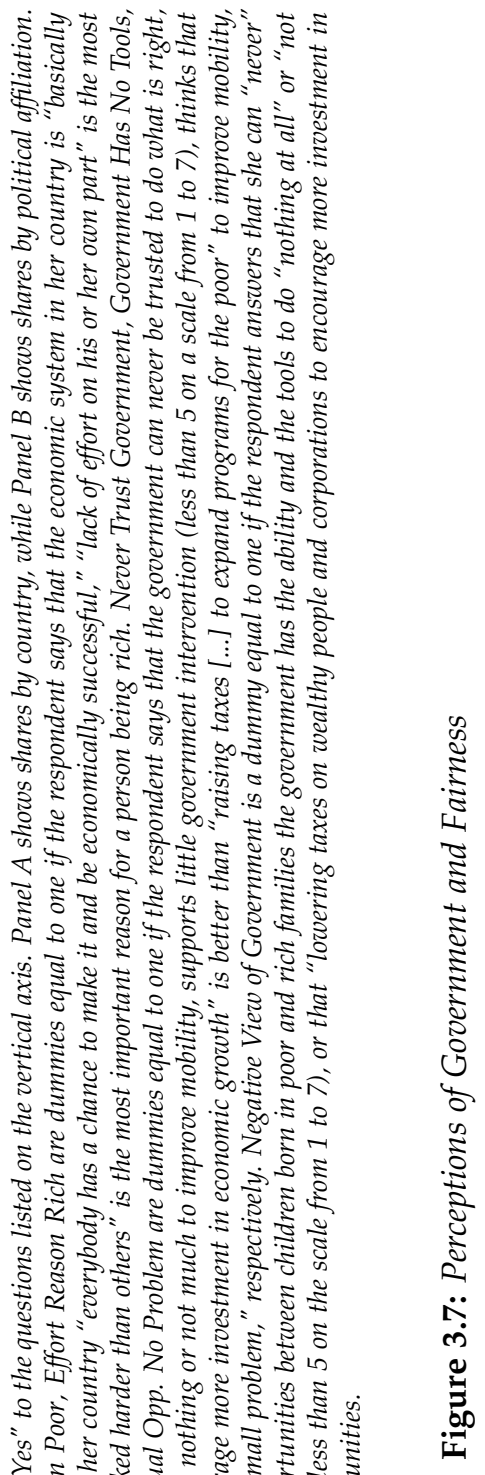

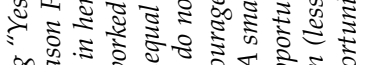

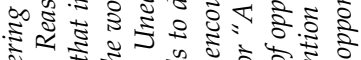

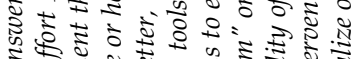

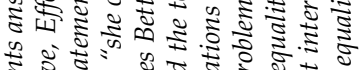

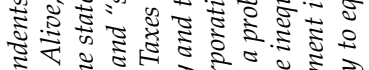
के

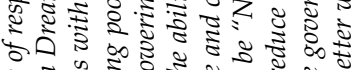

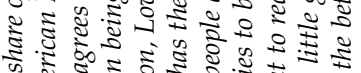

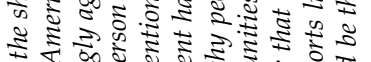

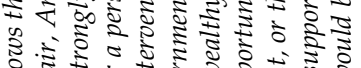

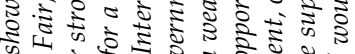
कै

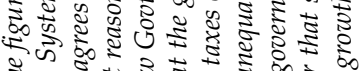

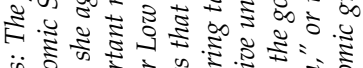

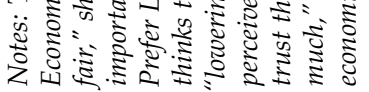


There are several noteworthy findings. First, on average, the U.S. respondents have a much higher tendency than the European respondents to agree that the system is fair ( $50 \%$ believe so) and that everyone has a chance of making it ( $53 \%$ agree). The Swedish respondents also are positively inclined on fairness issues $-65 \%$ believe in the fairness of the Swedish economic system. It is possible - although purely conjectural - that Swedish respondents believe that their welfare state delivers this perceived fairness, while Americans may believe that the market does. The Italian and French responders are extremely skeptical about the fairness of the system (only $10 \%$ and 19\%, respectively, agree that the system is basically fair). Second, U.S. respondents believe more strongly in the role of effort, both in getting out of poverty and in becoming rich. Italians believe the least in the effect of effort on economic outcomes. ${ }^{19}$

Third, as shown in Panel B, left-wing respondents hold more negative views on fairness. Only $26 \%$ of them (as opposed to $49 \%$ of right wing respondents) think that the system is "basically fair," and only $24 \%$ (as opposed to $46 \%$ of right wing respondents) think that everybody gets a fair shot. Similarly, just about 19\% and 18\% respectively think that effort or lack thereof is the main reason for being poor or rich (as opposed to $46 \%$ and $46 \%$ respectively for right-wing respondents). The political polarization of views on fairness is most prevalent in the U.S. and the U.K., but it is present in all countries. ${ }^{20}$

\subsubsection{Views of Government}

Views of government are complex and multi-faceted, so we asked five different questions on government. The answers are shown in the last rows of Figure 3.7, where we show the responses by country (in Panel A) or by political affiliation (in Panel B). We seek to understand whether respondents think that their government can be trusted to perform well; whether it has the capacity and tools to reduce unequal opportunities; whether government

\footnotetext{
${ }^{19}$ These differing perceptions about the role of effort versus luck are at the core of the multiple equilibria (called the "U.S." and the "European" equilibria) in Alesina and Angeletos (2005).

${ }^{20}$ Except perhaps in Italy where more negative views seems to reign across the political spectrum.
} 
intervention is desirable to reduce unequal opportunities; and whether, starting from the status quo, the right way to go is towards more government intervention, i.e. "raising taxes,"or less government intervention with lower taxes. Finally, we inquire about whether people perceive unequal opportunities to be a problem to start with, and hence a potential area for government intervention.

In all countries except Sweden, the fraction of people who feel they can never trust the government is high, particularly in France and Italy. The exception is Sweden. At the same time, when asked whether the government in principle has "the ability and tools" to "reduce the inequality of opportunities between children born in poor and rich families", most respondents answer that the government can do "some" or "a lot."

When asked to designate on a scale of 1 to 7 (increasing in the desired strength of intervention) the optimal scope of government intervention for reducing unequal opportunities, the U.S. respondents expressed a wish for less government intervention intensity than did those in the European countries. This does not mean that European respondents support further expansions of the role of government starting from the current status quo. Indeed, when respondents are asked about "what [they] think would do more to make the opportunities for children from poor and rich families less unequal," the fraction who think that "lowering taxes on wealthy people and corporations to encourage more investment in economic growth" would be better than "raising taxes on wealthy people and corporations to expand programs for the poor" is $32 \%$ in the U.S. but even higher in France and Italy. Given that the answer to this question depends on the starting level of taxes in a country, this may not be surprising, as the U.S. has lower taxes than either of the European countries.

In Panel B, left-wing respondents are shown to be significantly more likely to trust the government, to believe that the government has the tools and capacity to address unequal opportunities, and to think that unequal opportunities are a problem. ${ }^{21}$ They support

\footnotetext{
${ }^{21}$ The U.K. is an exception: right-wing respondents are more likely to say that they trust the government. We believe this is because "Brexit" was very salient at the time of the survey, and the right-wing government had successfully pushed through the referendum and gained a lot of popularity with the winning "leave" vote, which was the privileged vote of the right-wing. We believe this is what inflated the perceptions of right-wing respondents in favor of that particular government, and, conversely, strongly reduced perceptions among
} 
significantly higher levels of government intervention than right-wing respondents. The starkest contrast is that right-wing respondents are much more likely to think that scaling back the involvement of government in the economy is the better way to improve unequal opportunities. Overall, close to $60 \%$ of right-wing respondents believe that less government involvement, and freeing the economy, is the key to addressing unequal opportunities, as opposed to just $20 \%$ of left-wing respondents.

Particularly striking is the agreement across countries and political orientations on the view that unequal opportunities for children from poor and rich families - should they exist - would be a problem. ${ }^{22}$ Hence, in principle, we could expect that more pessimism about the fairness of opportunities would be correlated with support for policies to equalize opportunities.

A respondent may oppose more redistribution if he has a negative view of the government on any of the dimensions we ask about. The last row shows the fraction of respondents who answer: that they can "never" trust the government; or that to reduce the inequality of opportunities between children born in poor and rich families, the government has the ability and the tools to do "nothing at all" or "not much"; that they support little government intervention (less than 4 on the scale of 1 to 7 ); or that "lowering taxes on wealthy people and corporations to encourage more investment in economic growth" would be the better way to equalize opportunities.

The polarization between left-wing and right-wing respondents, and its consistency across all countries, is striking. The fraction of right-wing respondents who hold a negative view of the government along at least one of the dimensions we ask about is staggeringly high at $80 \%$. On the other hand, left-wing respondents have a much more favorable opinion of government, its role, its desirability, and its capacities.

left-wing respondents. However, even in the U.K., the views of left and right wing respondents on the other dimensions of governments are in line with those in other countries.

${ }^{22}$ Recall that this question is about respondents' general attitude towards unequal opportunities and does not specifically ask about their perceptions of the extent of mobility in their own country. 


\subsubsection{Policy Preferences and Views on Mobility}

We will use the word "pessimism" to designate a higher perceived probability of a child from a family in the bottom quintile remaining in the bottom quintile and the word "optimism" to designate a higher perceived probability of moving to the top quintile. We regress respondents' policy preferences on their perceived transition probabilities, including all individual level controls and country fixed effects. Hence, we capture the residual effect of pessimism or optimism on policy preferences, conditional on many individual characteristics, including political views. Table 3.3 shows the coefficients from these regressions.

Columns 1 and 6 focus on how respondents want to allocate the country's budget between two different spending categories: "Opportunities," which includes spending on schooling and higher education, as well as public spending on health (categories 3 and 6) ${ }^{23}$; and "Safety Net," which includes social insurance and income support programs (category 5 in the survey questionnaire, as described in Section 3.2). Column 2 shows support for the estate tax. In column 3, the dependent variable is a dummy equal to one if the respondent supports increasing government spending on "equality of opportunity policies." In column 4 , the dependent variable is the preferred level of government intervention against unequal opportunities, on a scale of 1 to 7 . In column 5, the dependent variable is a dummy equal to one if the respondent believes that unequal opportunities are a very serious problem. Columns 7 and 8 report respondents' preferred tax rate on the top 1\% and on the bottom $50 \%$ respectively. In column 9 the dependent variable is a dummy equal to one if the respondent says that to "reduce the inequality of opportunities between children born in poor and rich families,"the government can do "some" or "a lot."

\footnotetext{
${ }^{23}$ We grouped these two categories in this way for the analysis, but respondents only saw the six categories as described in Section 3.2 and in Appendix C.4.
} 


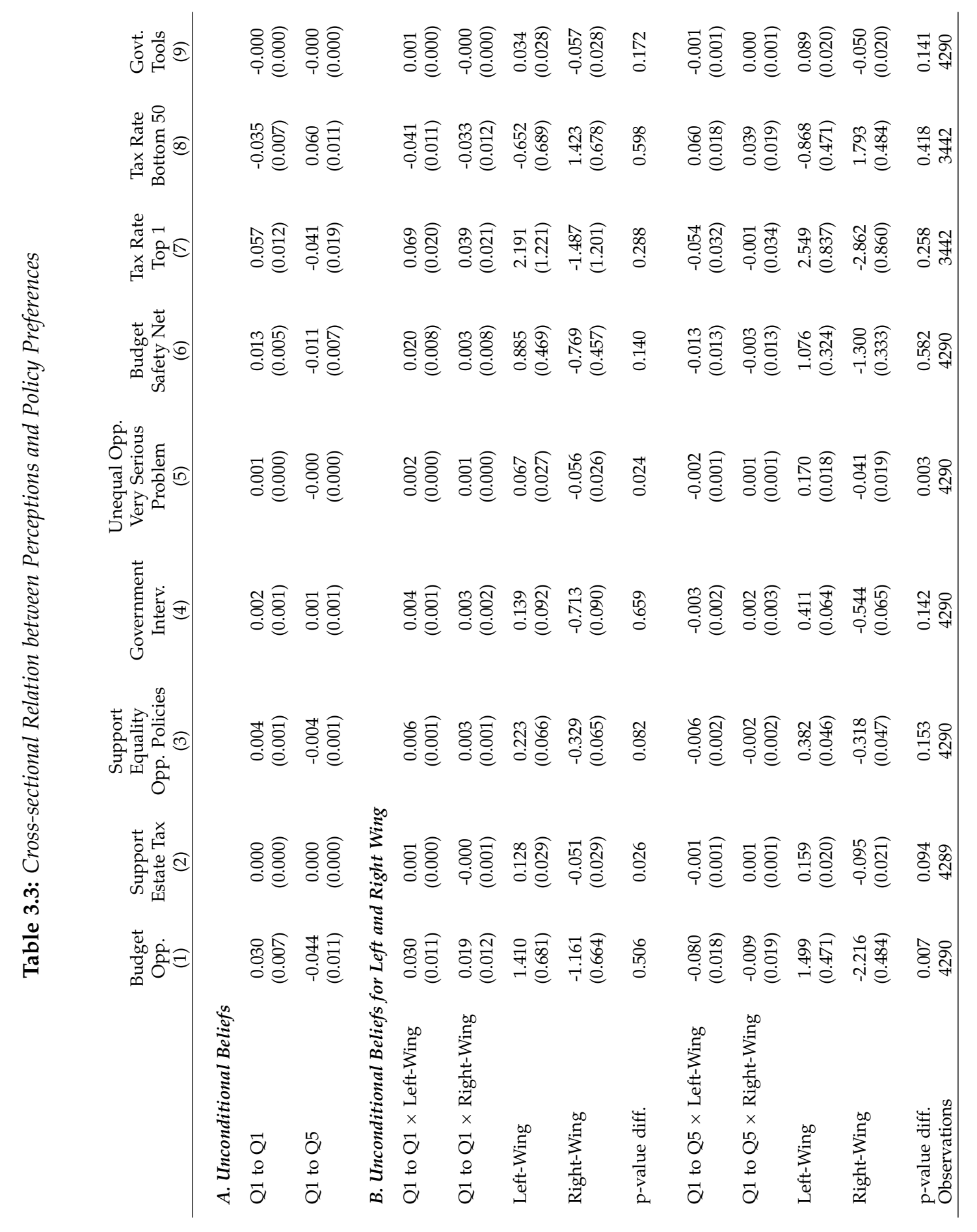




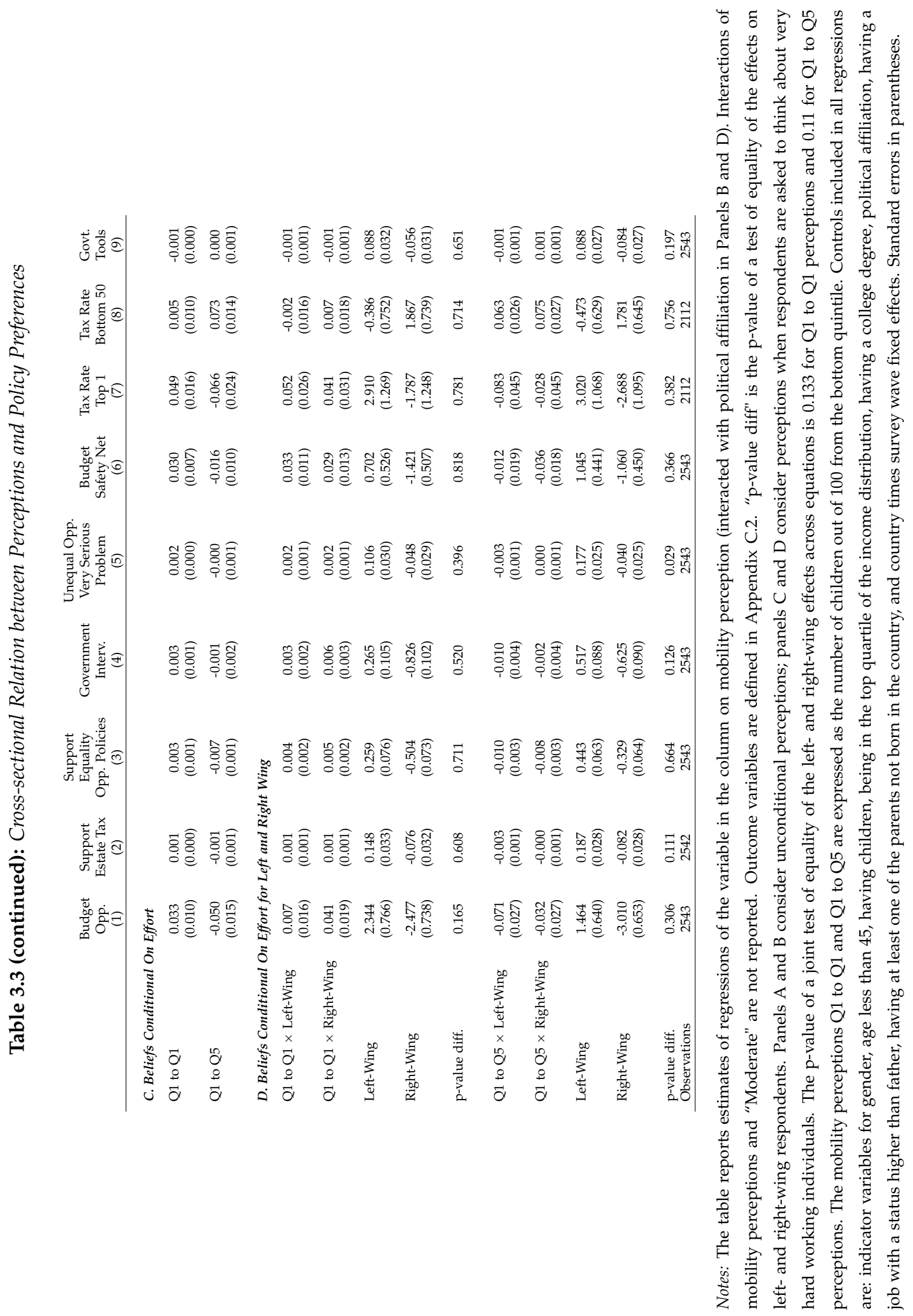


Panels $\mathrm{A}$ and $\mathrm{C}$ report the regression results for all respondents in the control group. Panel A uses as explanatory variables the unconditional mobility perceptions; Panel C uses the perceptions conditional on effort. Mobility perceptions are significantly correlated with support for redistribution, especially with support for equality-of-opportunity policies. Perceptions conditional on effort are slightly more strongly correlated with more support for redistribution than are the unconditional beliefs.

Panels B and D report the results separately for left-wing and right-wing respondents. Among left-wing respondents, pessimism is significantly positively correlated with support for redistribution along all of these dimensions. Optimism is significantly correlated with these same policies in the opposite way, except for the estate tax, overall government intervention and the budget spent on the safety net. Overall, support for equality-ofopportunity policies is much more sensitive to pessimism and optimism than is support for equality-of-outcome policies, such as safety net policies. For instance, an increase of 10 percentage points in the perceived probability of remaining in the bottom quintile increases desired spending on equality-of-opportunity policies by 0.3 percentage points, but increases spending on the safety net by only 0.2 percentage points. When asked to think conditional on effort, left-wing respondents do not drastically change their policy support.

On the other hand, right-wing respondents are less sensitive to either optimism or pessimism. It seems that right-wing respondents simply do not want much redistribution, regardless of their views on mobility. Their policy preferences do appear to be more significantly correlated with their beliefs conditional on effort. In sum, the right-wing respondents do not want much redistribution to start with, nor do they want more redistribution whether they are more pessimistic or optimistic, unless they believe that a poor kid is doomed to not make it out of the bottom quintile despite the maximal effort

\subsection{Randomized Perception Experiment}

In the previous section, we reported significant correlations between mobility perceptions and policy preferences. These correlations could reflect the causal effect of mobility per- 
ceptions on policy preferences, the opposite effect, or the effect of a third variable such as overall political views. Therefore, an experiment is needed to shift perceptions of mobility in a controlled way so as to isolate the causal effect of mobility perceptions on policy preferences. ${ }^{24}$ In this section, we turn to the experimental evidence.

\subsubsection{The Experiment}

The treatment's goal is to shift people's perceptions of mobility. To design it, several important constraints had to be taken into account.

First, all respondents' perceptions had to be shifted monotonically in the same directioni.e., either in the direction of more pessimism or more optimism. We chose to make people more "pessimistic" because the design of an appealing and convincing treatment seemed more straightforward. Second, mobility perceptions needed to be shifted without changing the respondents' perceptions of policies or the government. Otherwise, we might mechanically prime people to respond in a certain way to the policy questions. Third, the treatment had to be homogeneous across countries and to show all respondents identical information. This precluded showing them actual data about mobility per country (which are heterogeneous). As we saw in Figure 3.2, respondents in different countries are overly pessimistic or overly optimistic to varying degrees about different quintiles. For instance, Europeans are too pessimistic about the chance of staying stuck in poverty (but not so much about the chance of moving to the other quintiles), while Americans are especially optimistic about making it to the very top. Changing each of these quintiles separately in a different direction (e.g., towards the actual one) would be very difficult and probably confusing to respondents. Even within the same country, left-wing and right-wing respondents start from quite different baseline beliefs.

In that sense, our experiment differs from the "informational" treatments in Kuziemko et al. (2015), who provide information on actual inequality in the U.S.. It would of course be

\footnotetext{
${ }^{24}$ Such a controlled shift in perceptions is extremely difficult to find in a natural experiment setting, which makes an experimental approach more appealing.
} 
interesting to explore a treatment that shows people data on actual mobility in each country, but this would not be interpretable as the causal effect of more (or less) pessimistic views on mobility.

Fourth, we did not want to give actual and precise numbers in order to limit experimenter induced demand and the temptation for treated respondents to simply repeat those numbers without really thinking about the message they convey. As a result, we only used qualitative statements in the treatment. How different groups would translate those qualitative statements into quantitative facts was not clear ex ante (although the direction was clear). The goal was to prompt people to think about low mobility in a salient way rather than to target a given perception.

Fifth, the treatment had to be truthful and not provide any incorrect information. Therefore, we made general, high-level qualitative statements, not precise quantitative ones. Some perceptions, namely those that are relatively optimistic (for instance, the perceived Q1 to Q3 mobility in most countries, or the perceptions of right-wing respondents, or the perceptions of U.S. respondents) are moved in the direction of reality. However, we acknowledge that for some respondents who were already very pessimistic, or for some perceptions (such as the probability to stay stuck in the bottom in Europe), the treatment may have been misleading and moved people further away from reality. We could not think of a way to avoid this pitfall while also having the treatment satisfy all of the other criteria listed here.

To better attract and maintain respondents' attention, the treatment is animated and appears as a "movie." It consists of two animations, one related to children from low income families and the other related to children from high income families. An introductory page tells respondents that they are about to see two short animations that summarize two key findings of recent academic studies on the link between one's family background and one's chances of making it in life (see the screenshot in Appendix Figure C.4). On the first animation (see the screenshots in Appendix Figure C.5), respondents are told that:

"The chances of a poor kid staying poor as an adult are extremely large. Only very few kids from 
poor families will ever make it and become rich."

On the second animation, respondents are told that:

"Children born in rich families are extremely likely to remain rich themselves when they grow up, like their parents. It is extremely rare for a child from a rich family to become poor later in life."

\subsubsection{First Stage: Treatment Effects on Perceptions}

The "first-stage" of our treatment worked well. The treatment had a large and statistically significant effect on perceptions of social mobility. Table 3.4 shows that the perceived probability of remaining in the bottom quintile increases by 9.7 percentage points, and the probability of moving up to the third and fourth quintiles decreases significantly, by around 5.9 and 1.8 percentage points, respectively. The order of magnitude of these changes is very similar across countries. ${ }^{25}$ While there is no significant effect on the reported perceived probability of making it from the bottom to the very top quintile according to the quantitative question, the qualitative questions do show significant effects of making it to the fourth and fifth quintile. The last column shows that there is a marked decrease of 3 percentage points in the fraction of people who say that they believe that "everybody has a fair chance of making it," (our so-called "American dream" question). There are also large and significant effects on the perceived mobility conditional on effort. The table further shows that the treatment effects on mobility perceptions are equally strong for left-wing and right-wing respondents (we cannot reject the hypothesis that the effects on left and right wing are the same).

In order to test for the persistence of the treatment effects, we re-ran the survey for the U.S. one week later, checking whether people who had been treated still maintained different views relative to the control group. Table 3.5 reports the results of this follow-up survey. Overall, the originally treated individuals still exhibit increased pessimism one week later relative to the control group. ${ }^{26}$ For example, the treatment effect on the probability

\footnotetext{
${ }^{25}$ Results are available from the authors.

${ }^{26}$ The first-stage effect on left- and right-wing respondents who took the follow-up was not significantly
} 
of remaining in the first quintile among the subset of treated respondents who took both the main survey and the follow-up was 9 percentage points and it persists, significantly, at 6 percentage points. The effects on the probability of moving to the third, fourth, and fifth quintiles are very close also in magnitude and significance in the original and the follow up rounds. In the Appendix, we show that the effect decays faster among right-wing respondents.

\subsubsection{Treatment Effects on Policy Preferences}

Table 3.6 reports the treatment effects on taxes and spending in the same format as the cross-sectional relations from Table 3.3. Panels A and B present the reduced-form treatment effects: in Panel A the results are shown for all respondents; in Panel B the treatment dummy is interacted with dummies for being left-wing and right-wing. In the last column, we construct a standardized index, called "Redistribution Index," following the methodology in Kling et al. (2007). It consists in an equally weighted average of the z-scores of the policy outcomes variables from columns 1 through 9, with signs oriented so that more support for redistribution means a higher Redistribution index. Despite the significant and durable impact on perceptions of mobility, the treatment has no significant impact on the value ascribed to redistributive policies by the government. For the standardized Redistribution index, the point estimate is 0.013 with a standard error of 0.009 .

Panels B and D show that this masks considerable heterogeneity between left-wing and right-wing respondents. Amongst the former, more pessimism about mobility leads to more support for equality-of-opportunity policies. On average, treated respondents support more spending on equality-of-opportunity policies and are more likely to perceive unequal opportunities as a major problem. They also support the estate tax. There is no effect on support for equality-of-outcome policies, such as the budget allocated to the Safety Net or the income tax rates. This pattern is consistent with the cross-sectional relations from Section 3.4.3, where equality-of-opportunity policies exhibited a stronger correlation with 
mobility perceptions. The overall Redistribution index for left-wing respondents has a point estimate of 0.052 (standard error 0.015).

In contrast, for right-wing respondents, there is no effect on any measure of policy preferences, and some point estimates are even negative. Despite having become significantly more pessimistic about mobility, the treated right-wing respondents are not more likely to think that unequal opportunities are a problem. In fact, they are more likely to reduce their belief that the government has tools to act against unequal opportunities (see column 9). Left- and right-wing respondents have significantly different responses to the treatment (p-value of 0.03$)$. 
Table 3.4: First Stage Treatment Effects on Mobility Perceptions

\begin{tabular}{|c|c|c|c|c|c|c|c|c|}
\hline & $\begin{array}{l}\text { Q1 to } \\
\text { Q1 } \\
(1)\end{array}$ & $\begin{array}{l}\text { Q1 to } \\
\text { Q2 } \\
(2)\end{array}$ & $\begin{array}{l}\text { Q1 to } \\
\text { Q3 } \\
\text { (3) }\end{array}$ & $\begin{array}{l}\text { Q1 to } \\
\text { Q4 } \\
(4)\end{array}$ & $\begin{array}{l}\text { Q1 to } \\
\text { Q5 } \\
\text { (5) }\end{array}$ & $\begin{array}{c}\text { Q1 to } \\
\text { Q4 (Qual.) } \\
\text { (6) }\end{array}$ & $\begin{array}{c}\text { Q1 to } \\
\text { Q5 (Qual.) } \\
\text { (7) }\end{array}$ & $\begin{array}{c}\text { American Dream } \\
\text { Alive } \\
(8)\end{array}$ \\
\hline \multicolumn{9}{|c|}{ A. Unconditional Beliefs } \\
\hline Treated & $\begin{array}{c}9.691 \\
(0.560)\end{array}$ & $\begin{array}{c}-2.123 \\
(0.278)\end{array}$ & $\begin{array}{l}-5.885 \\
(0.304)\end{array}$ & $\begin{array}{l}-1.806 \\
(0.201)\end{array}$ & $\begin{array}{c}0.123 \\
(0.344)\end{array}$ & $\begin{array}{c}-0.197 \\
(0.018)\end{array}$ & $\begin{array}{c}-0.212 \\
(0.020)\end{array}$ & $\begin{array}{c}-0.031 \\
(0.009)\end{array}$ \\
\hline
\end{tabular}

\section{B. Unconditional Beliefs for Left and Right Wing}

$\begin{array}{lcccccccc}\text { Treated } \times \text { Left-Wing } & 10.209 & -2.126 & -6.093 & -2.053 & 0.063 & -0.189 & -0.180 & -0.010 \\ & (0.980) & (0.488) & (0.532) & (0.353) & (0.603) & (0.032) & (0.035) & (0.016) \\ \text { Treated } \times \text { Right-Wing } & 11.145 & -2.181 & -6.139 & -2.236 & -0.589 & -0.225 & -0.236 & -0.045 \\ & (0.979) & (0.487) & (0.531) & (0.352) & (0.602) & (0.032) & (0.035) & (0.016) \\ \text { Left-Wing } & 4.060 & 0.594 & -1.803 & -1.358 & -1.494 & -0.186 & -0.256 & -0.080 \\ & (0.975) & (0.485) & (0.529) & (0.351) & (0.600) & (0.032) & (0.035) & (0.016) \\ \text { Right-Wing } & -0.616 & 0.406 & 0.654 & 0.085 & -0.530 & 0.041 & -0.003 & 0.121 \\ & (0.978) & (0.487) & (0.531) & (0.352) & (0.602) & (0.032) & (0.035) & (0.016) \\ \text { p-value diff. } & & & & & & & & 0.140 \\ \text { Observations } & 0.499 & 0.937 & 0.951 & 0.713 & 0.445 & 0.422 & 0.248 & 8585\end{array}$

\section{Beliefs Conditional On Effort}

\begin{tabular}{|c|c|c|c|c|c|c|c|}
\hline Treated & $\begin{array}{c}8.016 \\
(0.663)\end{array}$ & $\begin{array}{c}0.501 \\
(0.373)\end{array}$ & $\begin{array}{c}-5.434 \\
(0.525)\end{array}$ & $\begin{array}{c}-2.642 \\
(0.307)\end{array}$ & $\begin{array}{c}-0.441 \\
(0.417)\end{array}$ & $\begin{array}{l}-0.175 \\
(0.027)\end{array}$ & $\begin{array}{c}-0.153 \\
(0.030)\end{array}$ \\
\hline \multicolumn{8}{|c|}{ D. Beliefs Conditional On Effort for Left and Right Wing } \\
\hline Treated $\times$ Left-Wing & $\begin{array}{c}8.342 \\
(1.191)\end{array}$ & $\begin{array}{c}0.837 \\
(0.671)\end{array}$ & $\begin{array}{l}-5.101 \\
(0.944)\end{array}$ & $\begin{array}{c}-3.064 \\
(0.552)\end{array}$ & $\begin{array}{l}-1.013 \\
(0.749)\end{array}$ & $\begin{array}{c}-0.172 \\
(0.049)\end{array}$ & $\begin{array}{c}-0.172 \\
(0.054)\end{array}$ \\
\hline Treated $\times$ Right-Wing & $\begin{array}{c}8.816 \\
(1.158)\end{array}$ & $\begin{array}{c}0.819 \\
(0.653)\end{array}$ & $\begin{array}{c}-5.383 \\
(0.918)\end{array}$ & $\begin{array}{l}-3.309 \\
(0.537)\end{array}$ & $\begin{array}{c}-0.943 \\
(0.728)\end{array}$ & $\begin{array}{c}-0.209 \\
(0.048)\end{array}$ & $\begin{array}{c}-0.151 \\
(0.052)\end{array}$ \\
\hline Left-Wing & $\begin{array}{c}3.976 \\
(1.161)\end{array}$ & $\begin{array}{c}0.807 \\
(0.654)\end{array}$ & $\begin{array}{c}-2.679 \\
(0.920)\end{array}$ & $\begin{array}{c}-0.966 \\
(0.538)\end{array}$ & $\begin{array}{c}-1.138 \\
(0.730)\end{array}$ & $\begin{array}{c}-0.175 \\
(0.048)\end{array}$ & $\begin{array}{c}-0.254 \\
(0.052)\end{array}$ \\
\hline Right-Wing & $\begin{array}{c}-1.546 \\
(1.146)\end{array}$ & $\begin{array}{c}-0.469 \\
(0.646)\end{array}$ & $\begin{array}{c}0.420 \\
(0.908)\end{array}$ & $\begin{array}{c}1.329 \\
(0.531)\end{array}$ & $\begin{array}{c}0.265 \\
(0.720)\end{array}$ & $\begin{array}{c}0.128 \\
(0.047)\end{array}$ & $\begin{array}{c}0.065 \\
(0.052)\end{array}$ \\
\hline p-value diff. & 0.775 & 0.985 & 0.831 & 0.751 & 0.947 & 0.592 & 0.779 \\
\hline Observations & 5118 & 5118 & 5118 & 5118 & 5118 & 5117 & 5117 \\
\hline
\end{tabular}

Notes: The table reports first-stage effects on mobility perceptions. The dependent variable in Column $j$ for $j=1,2,3,4,5$ is the perceived probability of a child from the bottom quintile moving to quintile $j$. The dependent variable in Column 6 (respectively, 7) measures qualitatively on a scale from 1 to 5 the respondent's perceived probability of moving from the first to the fourth (respectively, to the fifth) quintile for a child from the bottom quintile, where 1 means "Close to zero" and 5 means "High". Panels A and B (respectively, C and D) show the effect on unconditional probabilities (respectively, perceptions conditional on effort). The dependent variable in Column 8 is a dummy equal to one if the respondent agrees or strongly agrees with the statement that in her country "everybody has a chance to make it and be economically successful." "p-value diff" is the p-value of a test of equality of the effects among left- and right-wing respondents. "Dep. Var. Mean (Left-wing)" and "Dep. Var. Mean (Right-wing)" are the means of the dependent variable for respondents in the control group who are left-wing or right-wing, respectively. All regressions include the same controls as Table 3.3. Standard errors in parentheses. 
Table 3.5: Persistence of Treatment Effects on Mobility Perceptions

\begin{tabular}{|c|c|c|c|}
\hline & $\begin{array}{c}\text { First Survey } \\
\text { All Respondents } \\
\text { (1) } \\
\end{array}$ & $\begin{array}{c}\text { First Survey } \\
\text { Who Took Follow Up } \\
(2)\end{array}$ & $\begin{array}{l}\text { Follow up } \\
\text { Respondents } \\
(3)\end{array}$ \\
\hline \multicolumn{4}{|c|}{$Q 1$ to $Q 1$} \\
\hline Treated & $\begin{array}{c}8.308 \\
(0.899)\end{array}$ & $\begin{array}{c}9.254 \\
(1.748)\end{array}$ & $\begin{array}{c}5.671 \\
(1.675)\end{array}$ \\
\hline \multicolumn{4}{|c|}{$Q 1$ to $Q 2$} \\
\hline Treated & $\begin{array}{c}-1.731 \\
(0.444)\end{array}$ & $\begin{array}{c}-1.428 \\
(0.920)\end{array}$ & $\begin{array}{c}-0.968 \\
(0.943)\end{array}$ \\
\hline \multicolumn{4}{|c|}{ Q1 to Q3 } \\
\hline Treated & $\begin{array}{c}-5.479 \\
(0.491)\end{array}$ & $\begin{array}{c}-6.676 \\
(1.019)\end{array}$ & $\begin{array}{c}-3.945 \\
(1.013)\end{array}$ \\
\hline \multicolumn{4}{|c|}{$Q 1$ to $Q 4$} \\
\hline Treated & $\begin{array}{c}-1.733 \\
(0.335)\end{array}$ & $\begin{array}{c}-1.879 \\
(0.642)\end{array}$ & $\begin{array}{l}-1.417 \\
(0.688)\end{array}$ \\
\hline \multicolumn{4}{|c|}{ Q1 to Q5 } \\
\hline Treated & $\begin{array}{c}0.636 \\
(0.582)\end{array}$ & $\begin{array}{c}0.729 \\
(1.243)\end{array}$ & $\begin{array}{c}0.659 \\
(1.069)\end{array}$ \\
\hline \multicolumn{4}{|c|}{ Q1 to Q4 (Qual.) } \\
\hline Treated & $\begin{array}{c}-0.230 \\
(0.030)\end{array}$ & $\begin{array}{c}-0.140 \\
(0.062)\end{array}$ & $\begin{array}{c}-0.110 \\
(0.066)\end{array}$ \\
\hline \multicolumn{4}{|c|}{ Q1 to Q5 (Qual.) } \\
\hline Treated & $\begin{array}{c}-0.245 \\
(0.034)\end{array}$ & $\begin{array}{c}-0.116 \\
(0.070)\end{array}$ & $\begin{array}{c}-0.044 \\
(0.071)\end{array}$ \\
\hline Obs. & 3354 & 815 & 815 \\
\hline
\end{tabular}

Notes: The coefficients and standard errors in row $j$ refer to a regression of the variable listed in row $j$ on a dummy for being in the treatment group. Column 1 shows the effects on the full sample of respondents in the first survey, while column 2 shows the effects in the first survey, but only for respondents who also took the follow up survey. Column 3 shows the effects in the follow up survey. All regressions include the same controls as Table 3.3. Standard errors in parentheses. 


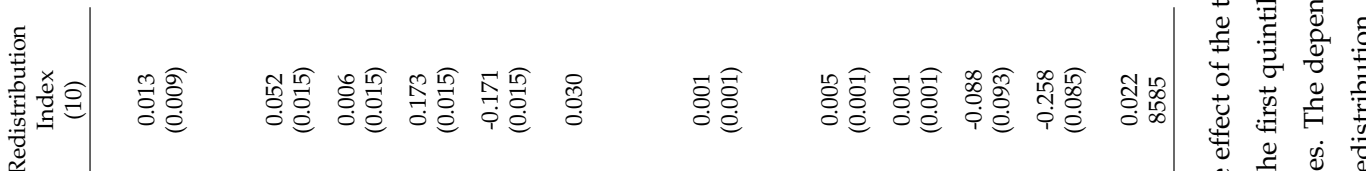

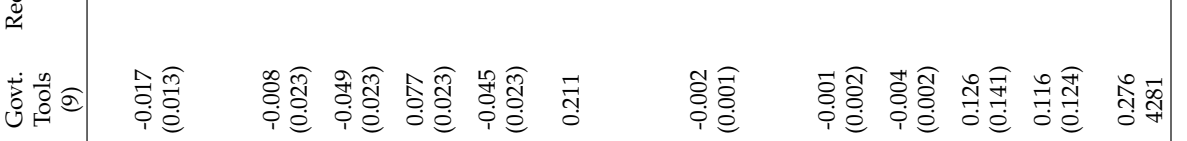

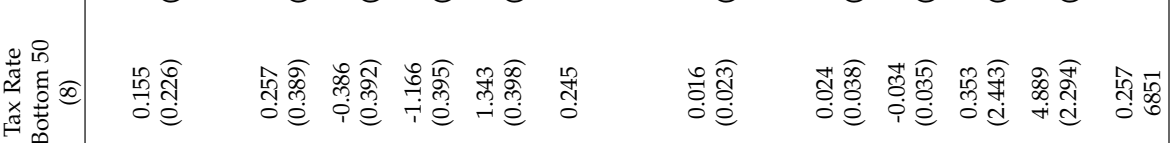

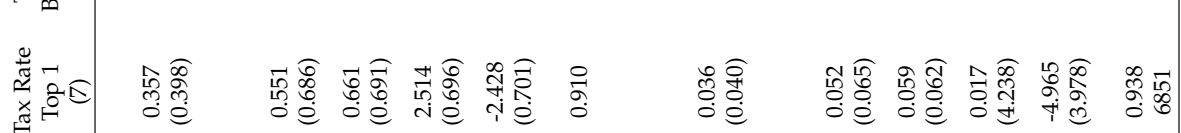

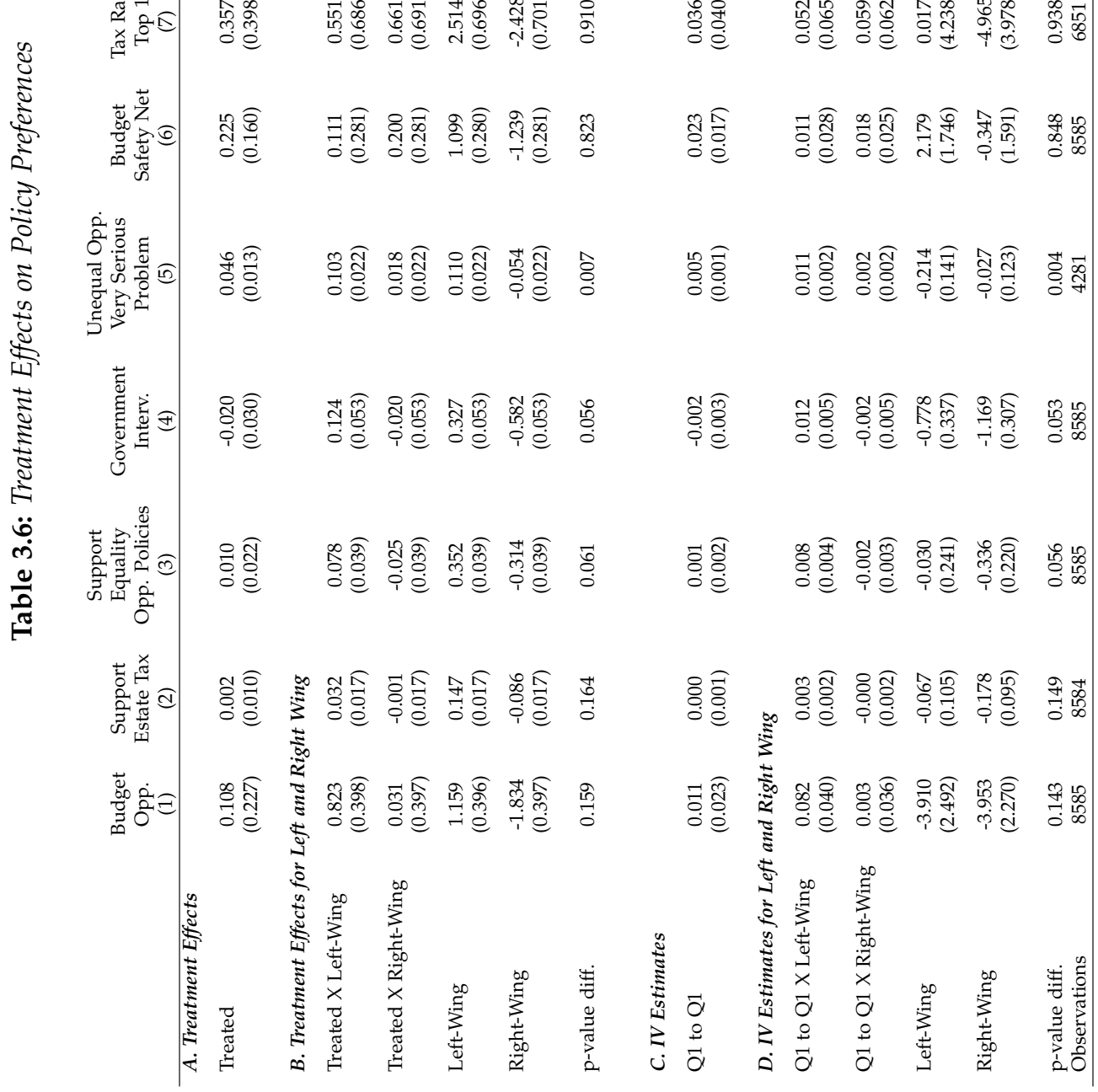

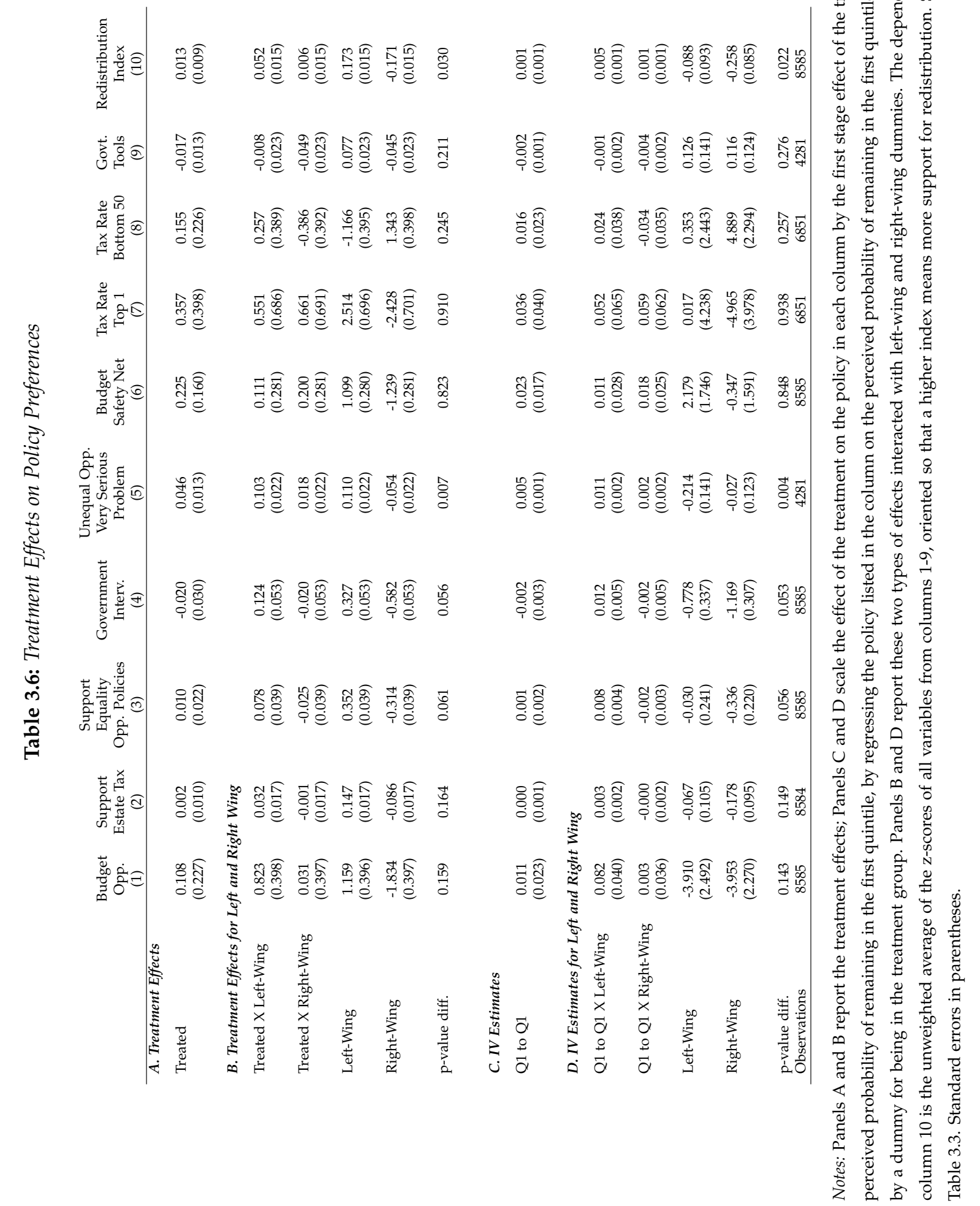


We can rescale the treatment effects on policy preferences by the first-stage effect of the treatment on mobility perceptions- i.e., we can use our treatment as an instrument for mobility perceptions. This will estimate the causal effect of mobility perceptions on support for policies only if we assume that the treatment had no direct effect on policy preferences except through mobility perceptions. We designed the treatment with this criterion in mind and, except for the aforementioned effect on the perceptions of right-wing respondents about the government's tools, we find no effect of the treatment on views of government. Nevertheless, the rescaled estimates reported in the bottom panel of Table 3.6 are only suggestive of a potential IV estimate and mainly meant to facilitate a comparison to the correlations in Table 3.3.

When comparing the rescaled treatment effects to the correlations in Table 3.3, we see an interesting pattern. Equality-of-opportunity policies show an even stronger treatment effect than the descriptive cross-sectional relations in Section 3.4.3. This supports the idea that equality of opportunity policies are causally linked to views on mobility. Equalityof-outcome policies, such as the budget spent on the Safety Net and the income tax, only showed an effect in the cross-section, not in the experiment. This indicates that the relation between pessimism and support for ex-post redistribution is in fact driven by other respondent characteristics, such as views of government, and is not causal.

\subsubsection{Polarization: Left versus Right}

Yet the message of the right is increasingly: It's not your fault that you're a loser; it's the government's fault.

J.D. Vance, Hillbilly Elegy: A Memoir of a Family and Culture in Crisis

Why do right-wing respondents react so differently from left-wing respondents to the same information about mobility? We can rule out the possibility that right-wing respondents did not believe the information in the treatment, given their equally strong 
first-stage effects on mobility perceptions. ${ }^{27}$ Also, recall from Section 3.4 .3 that for rightwing respondents pessimism and optimism were not correlated with more support for redistributive policies, except if it was conditional on effort. Here, right-wing respondents' perceptions conditional on effort also are strongly affected by the treatment, yet there is still no causal effect on support for redistribution.

The explanation probably lies in the polarized attitudes towards the government already documented in Section 3.4. The treatment is either "preaching to the choir" or "falling on deaf ears." Section 3.4 described how right-wing respondents have much worse views of government and are more averse to government intervention. In fact, the treatment itself may have further deteriorated the negative views of right-wing respondents about the government, because there is a significant treatment effect on the belief that the government does not have the tools to resolve unequal opportunities (column 9 of Table 3.6). In other words, the treatment does make respondents think that there is low social mobility, but only left-wing respondents believe that the government should do something about it. If anything, right-wing respondents may think that the government is the cause of the problem, not a solution. The treatment clearly has polarizing effects on respondents. ${ }^{28}$

\subsection{Conclusions}

In this paper, we explore the anatomy of perceptions of intergenerational mobility and fairness of opportunity, and how they shape preferences for redistribution. We develop detailed, quantitative survey questions and a randomized perception treatment to collect information on individual views of mobility, fairness, government, and support for redistributive policies in five countries on both sides of the Atlantic.

Our respondents seem to have inaccurate perceptions of actual intergenerational mobil-

\footnotetext{
${ }^{27}$ It is worth noting that relative to left-wing respondents, right-wing respondents are slightly more likely to say that they perceived the survey as being left-wing biased, but there is no difference in the perceived bias of the survey between right-wing respondents in the control and treatment groups.

${ }^{28}$ This effect is broadly consistent across all countries, although it is strongest in the European countries, except in Sweden.
} 
ity: Americans are too optimistic relative to the actual mobility in the U.S., while Europeans are too pessimistic. There is a lot of heterogeneity in perceptions based on individual characteristics, and wide geographical variation in perceptions across the U.S.. Pessimism and optimism about social mobility are significantly correlated with policy preferences: across all countries, the more pessimistic respondents tend to favor more generous redistributive policies, especially equality-of-opportunity policies. These correlations are confirmed by the exogenous treatment, which increases support for redistribution through equality-of-opportunity policies.

Furthermore, we uncovered a stark political polarization manifest not only in very different baseline views of mobility, government, and redistribution, but also in divergent responses to the same exogenously provided information. When treated with pessimistic information about mobility, only left-wing respondents want significantly more redistribution. Although the same treatment shifts right-wing respondents' perceptions of mobility, it has no effect on their support for redistribution. This is likely due to their negative views of government; they may see the latter as the cause of the problem, not the solution.

There are three directions which we believe are promising for future work using such large-scale cross-country survey tools and experimental treatments. First, the geographical disparities in perceptions in the U.S. raise the question of where people's information about mobility or inequality comes from: is it the media, interactions with their neighbors, or other sources? Second, it would be very fruitful to understand how the existence of racial inequality in the U.S. affects the link between mobility and support for redistribution. Third, one could explore how immigration (and the more or less accurate perceptions about immigrants) affect preferences for redistribution and the welfare state in Europe and the U.S.. 


\section{References}

Abramitzky, R., Delavande, A. and Vasconcelos, L. (2011). Marrying up: the role of sex ratio in assortative matching. American Economic Journal: Applied Economics, 3, 124-157.

Acciari, P., Polo, A. and Violante, G. (2016). And yet, it moves: Intergenerational economic mobility in italy. Unpublished.

Acemoglu, D., Autor, D. H. and Lyle, D. (2004). Women, war, and wages: The effect of female labor supply on the wage structure at midcentury. Journal of Political Economy, 112, 497-550.

-, Ticchi, D. and Vindigni, A. (2011). Emergence and persistence of inefficient states. Journal of the European Economic Association, 9(2), 177-208.

Afonso, J. R. R. and Araújo, É. A. (2000). A capacidade de gasto dos municípios brasileiros: arrecadação própria e receita disponível.

Akhtari, M., Moreira, D. and Trucco, L. (2016). Political turnover, bureaucratic turnover, and the quality of public services. Working Paper.

Alesina, A. and Angeletos, G.-M. (2005). Fairness and redistribution. The American Economic Review, 95 (4), 960-980.

- and Givliano, P. (2011). Preferences for redistribution. Handbook of Social Economics, pp. 93-132.

- , - and NunN, N. (2013). On the origins of gender roles: Women and the plough. Quarterly Journal of Economics, 128, 469-530.

- and Glaeser, E. L. (2004). Fighting poverty in the US and Europe: A world of difference. Oxford UK: Oxford University Press.

-, - and SACERdote, B. (2001). Why doesn't the united states have a european-style welfare state? Brookings Paper on Economics Activity, Fall, 187-278.

- and La Ferrara, E. (2005). Preferences for redistribution in the land of opportunities. Journal of public Economics, 89 (5), 897-931.

ANGRIST, J. D. (2002). How do sex ratios affect marriage and labor markets? evidence from america's second generation. Quarterly Journal of Economics, 117, 997-1038. 
— and Pischke, J.-S. (2009). Mostly Harmless Econometrics: An Empiricist's Companion. Princeton University Press.

Ariely, D. and Norton, M. I. (2011). Building a better america - one wealth quintile at a time. Perspectives on Psychological Science, 6 (1), 9-12.

Ashok, V., Kuziemko, I. and Washington, E. (2015). Preferences for redistribution in an era of rising inequality: Some new stylized facts and tentative explanations. Brookings Papers on Economic Activity, (Spring), 367-405.

Ashraf, N. and BAndiera, O. (2017). Social incentives in organizations. Working paper.

-, - and JАСK, B. K. (2014). No margin, no mission? a field experiment on incentives for public service delivery. Journal of Public Economics, 120, 1-17.

-, - , LEE, S. S. et al. (2016). Do-gooders and go-getters: career incentives, selection, and performance in public service delivery. Working paper.

Ashraf, Q. and Galor, O. (2011). Dynamics and stagnation in the malthusian epoch. American Economic Review, 101, 2003-2041.

Becker, G. (1973). A theory of marriage: Part i. Journal of Political Economy, 81 (813-846).

- (1974). A theory of marriage: Part ii. Journal of Political Economy, 82, S11-S26.

- (1981). A Treatise on the Family. Cambridge: Harvard University Press.

Becker, S. O. and Woessmann, L. (2008). Luther and the girls: Religious denomination and the female education gap in 19th century prussia. Scandinavian Journal of Economics, 110, 777-805.

BÉnabou, R. and OK, E. A. (2001). Mobility as Progressivity: Ranking Income Processes According to Equality of Opportunity. Nber working paper w8431.

— and Tirole, J. (2006). Belief in a just world and redistributive politics. Quarterly Journal of Economics, 121, 699-746.

Bertrand, M., Burgess, R., Chawla, A. and Xu, G. (2016). The costs of bureaucratic rigidity: Evidence from the indian administrative service. Working paper.

-, Kamenica, E. and Pan, J. (2015). Gender identity and relative income within households. Quarterly Journal of Economics, 130, 571-614.

Besley, T., Folke, O., Persson, T. and Rickne, J. (2017). Gender quotas and the crisis of the mediocre man: Theory and evidence from sweden. American Economic Review, forthcoming.

— and Reynal-Querol, M. (2014). The legacy of historical conflict. evidence from africa. American Political Science Review, 108, 319-336.

Best, M. C., HJort, J. and SzakonyI, D. (2016). Individuals and organizations as sources of state effectiveness, and consequences for policy design. 
Bisin, A. and Verdier, T. (2001). The economics of cultural transmission and the dynamics of preferences. Journal of Economic Theory, 97, 283-319.

BJöRKLUnd, A. and JäNTTI, M. (1997). Intergenerational income mobility in sweden compared to the united states. The American Economic Review, 87 (5), 1009-1018.

-, Roine, J. and WALDENSTRÖM, D. (2012). Intergenerational top income mobility in sweden: Capitalist dynasties in the land of equal opportunity. Journal of Public Economics, 96, 474-484.

BLANDEN, J. (2013). Cross-country rankings in intergenerational mobility: a comparison of approaches from economics and sociology. Journal of Economic Surveys, 27 (1), 38-73.

Boserup, E. (1970). Woman's Role in Economic Development. London: George Allen and Unwin Ltd.

Boyd, R. and Richerson, P. J. (1985). Culture and the Evolutionary Process. London: University of Chicago Press.

BRAINERD, E. (2017). The lasting effect of sex ratio imbalance on marriage and family: Evidence from world war ii in russia. Review of Economics and Statistics, 99, 229-242.

Calonico, S., Cattaneo, M. D. and Titiunik, R. (2014). Robust nonparametric confidence intervals for regression-discontinuity designs. Econometrica, 82 (6), 2295-2326.

Campa, P. and Serafinelli, M. (2016). Politico-economic regimes and attitudes: Female workers under state-socialism, dondena Working Paper No. 89.

Chafe, W. H. (1972). The American Woman: Her Changing Social, Economic, and Political Roles, 1920-1970. New York, Oxford University Press.

Chambers, J. and Swan, L. (2015). Perceptions of u.s. social mobility are divided (and distorted) along ideological lines. Psychological Science, 26 (4), 413-423.

Chandler, T. (1987). Four Thousand Years of Urban Growth: An Historical Census. Lewistown, NY: Edwin Mellen Press.

Charite, J., Fisman, R. and Kuziemko, I. (2016). Reference points and redistributive preferences: Experiment evidence. NBER Working Paper, 21009.

Chetty, R. and Hendren, N. (2016). The effects of neighborhoods on intergenerational mobility ii: County level estimates. Stanford University Working Paper.

-, - and KATZ, L. (2016). The effects of exposure to better neighborhoods on children: New evidence from the moving to opportunity experiment. American Economic Review, 106(4), 855-902.

- , - Kline, P. and Saez, E. (2014). Where is the land of opportunity? the geography of intergenerational mobility in the united states. The Quarterly Journal of Economics, 129 (4), 1553-1623. 
Chiappori, P.-A., Fortin, B. and Lacroix, G. (2002). Marriage market, divorce legislation, and household labor supply. Journal of Political Economy, 110, 37-72.

Снubi, J. (1982). Patronage, power and poverty in southern Italy: a tale of two cities. Cambridge University Press.

Cingano, F. and Pinotti, P. (2013). Politicians at work: The private returns and social costs of political connections. Journal of the European Economic Association, (11), 433-465.

Colonnelli, E. and Prem, M. (2017). Corruption and firms: Evidence from randomized audits in brazil. Working Paper.

Company, C. (1911). The Century Atlas: Africa. Buffalo, NY: Matthews-Northrup.

Cruces, G., Perez-Truglia, R. and Tetaz, M. (2013). Biased perceptions of income distribution and preferences for redistribution: Evidence from a survey experiment. Journal of Public Economics, 98, 100-112.

Cullen, J. (2004). The American Dream: A Short History of an Idea that Shaped a Nation. Oxford University Press.

DAHIS, R. (2015). Choosing institutions locally: Determinants of legislative size in brazil. Working Paper.

Dal Bó, E., Finan, F., Folke, O., Persson, T. and Rickne, J. (2017). Who becomes a politician? Quarterly Journal of Economics, forthcoming.

-, - and Rossi, M. A. (2013). Strengthening state capabilities: The role of financial incentives in the call to public service. Quarterly Journal of Economics, 128 (3), 1169-1218.

Dalton, J. T. and Cheuk Leung, T. (2014). Why is polygyny more prevalent in western africa? an african slave trade perspective. Economic Development and Cultural Change, 62, 599-632.

DavidaI, S. and Gilovich, T. (2015). Building a more mobile america - one income quintile at a time. Perspectives on Psychological Science, 10 (1), 60-71.

DellaVigna, S. and Kaplan, E. (2007). The fox news effect: Media bias and voting. Quarterly Journal of Economics, 122, 1187-1234.

- and Pope, D. (2016). Predicting Experimental Results: Who Knows What? Nber working paper no. 22566.

— and - (2017). What motivates effort? evidence and expert forecasts. Review of Economic Studies, (Forthcoming).

Deserranno, E. (2017). Financial incentives as signals: Experimental evidence from the recruitment of health workers. Working paper.

DiAmond, J. (1987). The Worst Mistake in the History of the Human Race. Worthington: Discover.

Drugov, M. (2015). Optimal patronage. CEPR Discussion Papers 10343. 
Economics, T. and of Women's Rights, P. (2012). Doepke, matthias and tertilt, michele and voena, alessandra. Annual Review of Economics, 4, 339-72.

EdLund, L. and Ku, H. (2013). The african slave trade and the curious case of general polygyny, mPRA Paper 52735, University Library of Munich, Germany.

Edwards, B. (1801). The History, Civil and Commercial, of the British Colonies in the West Indies. London.

Evans, P. and RAUCH, J. E. (1999). Bureaucracy and growth: A cross-national analysis of the effects of "weberian" state structures on economic growth. American Sociological Review, 64 (5), 748-765.

Faccio, M. (2006). Politically connected firms. The American economic review, 96 (1), 369-386.

-, Masulis, R. W. and McConnell, J. J. (2006). Political connections and corporate bailouts. Journal of Finance, (61), 2597-2635.

Fenske, J. (2013). African polygamy: Past and present, mPRA Paper 48526, University Library of Munich, Germany.

- and Kala, N. (2015). Climate and the slave trade. Journal of Development Economics, 112, 19-32.

- and - (2017). 1807: Economic shocks, conflict and the slave trade. Journal of Development Economics, 126, 66-76.

FERNANDEZ, R. (2007). Women, work and culture. Journal of the European Economic Association, 5, 305-332.

- (2013). Cultural change as learning: The evolution of female labor force participation over a century. American Economic Review, 103, 472-500.

- and Fogli, A. (2009). Culture: An empirical investigation of beliefs, work, and fertility. American Economic Journal: Macroeconomics, 1, 146-177.

- , - and Olivetti, C. (2004). Mothers and sons: Preference formation and female labor force dynamics. Quarterly Journal of Economics, 119, 1249-1299.

Ferraz, C. and Finan, F. (2011). Motivating politicians: The impacts of monetary incentives on quality and performance. National Bureau of Economic Research.

Finan, F., Olken, B. A. and Pande, R. (2015). The personnel economics of the state. National Bureau of Economic Research.

Fisman, R. (2001). Estimating the value of political connections. The American Economic Review, 91 (4), 1095-1102.

-, Schulz, F. and VIG, V. (2014). The private returns to public office. Journal of Political Economy, (4), 806-862. 
Folke, O., Hirano, S. and Snyder, J. M. (2011). Patronage and elections in u.s. states. American Political Science Review, 105 (3), 567-585.

—, Persson, T. and Rickne, J. (2017). Dynastic political rents. Economic Journal, (forthcoming).

Fortin, N. M. (2005). Gender role attitudes and the labour-market outcomes of women across oecd countries. Oxford Review of Economic Policy, 21, 416-438.

Francis, A. M. (2011). Sex ratios and the red dragon: using the chinese communist revolution to explore the effects of the sex ratio on women and children in taiwan. Journal of Population Economics, 24, 813-837.

Frank, R. H. (2016). Success and luck: Good fortune and the myth of meritocracy. Princeton University Press.

Gagliarducci, S. and Manacorda, M. (2017). Politics in the family: Nepotism and the hiring decisions of italian firms. Working paper.

Gelber, A. and Weinzierl, M. (2016). Optimal taxation when children's abilities depend on parents' resources. National Tax Journal, 69 (1), 11-40.

Gelman, A. and Imbens, G. (2016). Why high-order polynomials should not be used in why high-order polynomials should not be used in regression discontinuity designs. NBER Working Paper 19649.

GEorge, M. (2016). Social mobility and support for redistribution from 1980-2016: Separating the american dream from policy preferences, working paper University of Oxford.

Gilovich, T., Griffin, D. and Kahneman, D. (2002). Heuristics and Biases The Psychology of Intuitive Judgment. Cambridge University Press.

Goldin, C. and Olivetti, C. (2013). Shocking labor supply: A reassessment of the role of world war ii on women's labor supply. American Economic Review PP, 103, 257-262.

Goldin, C. D. (1991). The role of wwii in the rise of women's employment. American Economic Review, 81, 741-756.

Goldstein, J. S. (2003). War and Gender: How Gender Shapes the War System and Vice Versa. Cambridge University Press.

Gottschalk, P. and Spolaore, E. (2002). On the evaluation of economic mobility. Review of Economic Studies, 69 (1), 191-208.

GRINDLE, M. S. (2010). Constructing, deconstructing, and reconstructing career civil service systems in latin america. HKS Faculty Research Working Paper Series.

— (2012). Jobs for the Boys. Harvard University Press.

Grosjean, P. and Khattar, R. (2015). It's raining men! hallelujah?, uNSW Business School Research Paper No. 2014-ECON29C. 
Grossbard-Shechtman, S. and Neideffer, M. (1997). Women's hours of work and marriage market imbalances. In I. Persson and C. Jonung (eds.), Economics of the Family and Family Policies, London: Routledge.

Guardado, J. (2017). Office-selling, corruption, and long-term development in peru. Working paper.

Guiso, L., Sapienza, P. and Zingales, L. (2008). Social capital as good culture. Journal of the European Economic Association, 6, 295-320.

Gulzar, S. and Pasquale, B. (2016). Politicians, bureaucrats, and development: Evidence from india. American Political Science Review.

Hansen, C. W., Jensen, P. S. and SkovsgaArd, C. V. (2015). Modern gender roles and agricultural history: the neolithic inheritance. Journal of Economic Growth, 20, 365-404.

Harris, J. (1971). The African Presence in Asia: Consequences of the East African Slave Trade. Evanston, IL, Northwestern University Press.

HazAN, M. and MaOz, Y. (2002). Women's labor force participation and the dynamics of tradition. Economic Letters, 75, 193-198.

Hilger, N. (2016a). The great escape: Intergenerational mobility in the united states since 1940, working paper.

- (2016b). Upward mobility and discrimination: the case of asian-americans, working paper.

IAcoviello, M. (2006). Analysis comparativo por subsistemas. In K. Echebarría (ed.), Informe sobre la situación del servicio civil en América Latina, Washington, D.C.: Inter-American Development Bank.

ILO (2007). Global employment trends brief.

InTERnATIONAL, C. (). Demographic and health surveys. various datasets.

Iversen, T. and Rosenbluth, F. (2010). Women, Work, and Politics: The Political Economy of Gender Inequality. New Haven, Yale University Press.

Iyer, L. and MANI, A. (2011). Traveling agents: Political change and bureaucratic turnover in india. Review of Economics and Statistics.

Jäntti, M., Bratsberg, B., Roed, K., RaAum, O., Naylor, R., Osterbacka, E., Bjorklund, A. and ErIKsson, T. (2006). American exceptionalism in a new light: A comparison of intergenerational earnings mobility in the nordic countries, the united kingdom and the united states.

Jost, J., Banaji, M. and NoseK, B. (2004). A decade of system justification theory: Accumulated evidence of conscious and unconscious bolstering of the status quo. Political Psychology, 25 (6), 881-919. 
Karadja, M., Mollerstrom, J. and Seim, D. (2017). Richer (and holier) than thou? the effect of relative income improvements on demand for redistribution. Review of Economics and Statistics, 99, 201-212.

Khwaja, A. I. and Mian, A. (2005). Do lenders favor politically connected firms? rent provision in an emerging financial market. The Quarterly Journal of Economics, 120 (4), 1371-1411.

Kiszewski, A., Mellinger, A., Spielman, A., Malaney, P., Sachs, S. E. and Sachs, J. (2004). A global index representing the stability of malaria transmission. American Journal of Tropical Medicine and Hygiene, 70, 486-498.

Kling, J. R., Liebman, J. B. and Katz, L. F. (2007). Experimental analysis of neighborhood effects. Econometrica, 75 (1), 83-119.

Kuziemko, I., Buell, R., Reich, T. and Norton, M. (2014). Last-place aversion: Evidence and redistributive implications. Quarterly Journal of Economics, 129 (1).

-, Norton, M. I., Saez, E. and Stantcheva, S. (2015). How elastic are preferences for redistribution? evidence from randomized survey experiments. The American Economic Review, 105 (4), 1478-1508.

LAbonne, J. and FAfChamps, M. (2017). Do politicians' relatives get better jobs? evidence from municipal elections. Journal of Law, Economics, and Organizations, (33(2)), 268-300.

Lockwood, B. and WeInzierl, M. (2015). De gustibus non est taxandum: Theory and evidence on preference heterogeneity and redistribution. Journal of Public Economics, 124, 74-80.

- and - (2016). Positive and normative judgments implicit in us tax policy, and the costs of unequal growth and recessions. Journal of Monetary Economics, 77, 30-47.

Lovejoy, P. (1989). The impact of the atlantic slave trade on africa: A review of the literature. The Journal of African History, 30 (365-394).

- (2000). Transformations in Slavery: A History of Slavery in Africa. NewYork, Cambridge University Press.

Lowes, S., Nunn, N., Robinson, J. A. and Weigel, J. (2015). Understanding ethnic identity in africa: Evidence from the implicit association test (iat). American Economic Review PP, 105, 340-345.

Manning, P. (1990). Slavery and African Life: Occidental, Oriental, and African Slave Trades. Cambridge, UK: Cambridge University Press.

Markussen, T. and TARP, F. (2014). Political connections and land-related investment in rural vietnam. Journal of Development Economics, (110), 291-302.

Meade, A. W. and Craig, S. B. (2012). Identifying careless responses in survey data. Psychological methods, 17 (3), 437. 
Menezes-Filho, N. A., Muendler, M.-A. and Ramey, G. (2008). The structure of worker compensation in brazil, with a comparison to france and the united states. The Review of Economics and Statistics, 90 (2), 324-346.

Michalopoulos, S., Putterman, L. and Weill, D. N. (2016). The influence of ancestral lifeways on individual economic outcomes in sub-saharan africa, nBER Working Paper 21907.

Miller, J. C. (1988). Way of Death: Merchant Capitalism and the Angolan Slave Trade, 1730-1830. University of Wisconsin Press.

Murdock, G. P. (1959). Africa: Its People and their Culture History. McGraw-Hill.

— (1967). Ethnographic Atlas. Pittsburgh: University of Pittsburgh Press.

Newman, B., Johnston, C. and Lown, P. (2015). False consciousness or class awareness? local income inequality, personal economic position, and belief in american meritocracy. American Journal of Political Science, 59 (2), 326-340.

Niehues, J. and Peichl, A. (2014). Lower and upper bounds of unfair inequality: Theory and evidence for germany and the u.s. Social Choice and Welfare, 43, 73-99.

NunN, N. (2008). The long-term effects of africa's slave trades. Quarterly Journal of Economics, 128, 139-176.

- (2012). Culture and the historical process. Economic History of Developing Regions, 27, $108-126$.

- (2014). Gender and missionary influence in colonial africa. In N. N. R. J. Akyeampong E, Bates R (ed.), Africa's Development in Historical Perspective, New York: Cambridge University Press, pp. 489-512.

- and WantcheKon, L. (2011). The slave trade and origins of mistrust in africa. American Economic Review, 101, 3221-3252.

Oliver, R. (2000). The African Experience: from Olduvai Gorge to the 21st Century. Boulder, CO: Westview Press.

OrNaGHI, A. (2016). Civil service reforms: Evidence from u.s. police departments. Working paper.

Peichl, A., Dunnzlaff, L., Neumann, D. and Niehues, J. (2011). Equality of opportunity and redistribution in europe. Bulletin of Economic Inequality, 19, 99-129.

— and Ungerer, M. (2016). Equality of opportunity: East vs. west germany. Bulletin of Economic Research.

Piketty, T. (1995). Social Mobility and Redistributive Politics. The Quarterly Journal of Economics, 110 (3), 551-584.

Piraino, P. (2007). Comparable estimates of intergenerational income mobility in italy. The B.E. Journal of Economic Analysis and Policy, 7 (2). 
Rasul, I. and Rogger, D. (2015). The impact of ethnic diversity in bureaucracies: Evidence from the nigerian civil service. American Economic Review PP, 105(5), 457-461.

— and - (2017). Management of bureaucrats and public service delivery: Evidence from the nigerian civil service. Economic Journal, (fortchoming).

ReArdon, S. F. (2011). Measures of income Segregation. Tech. rep., CEPA Working Papers. Stanford, CA: Stanford Center for Education Policy Analysis.

Riondon, W. L. (1905). Plunkitt of Tammany Hall: A Series of Very Plain Talks on Very Practical Politics,. Bedford Books of St. Martin's Press,.

Robinson, J. A. and Verdier, T. (2013). The political economy of clientelism. Scandinavian Journal of Economics, 115 (2), 260-291.

Rogger, D. (2014). The Causes and Consequences of Political Interference in Bureaucratic Decision Making: Evidence from Nigeria. Tech. rep., Working paper.

RoINE, J. and WALDENSTRÖM, D. (2009). Wealth concentration over the path of development: Sweden, 1873?2006. Scandinavian Journal of Economics, 111 (1), 151-187.

- and Waldenström, D. (2015). Long run trends in the distribution of income and wealth. In F. B. A Atkinson (ed.), Handbook in Income Distribution, vol 2A, Amsterdam: NorthHolland.

Roome, W. R. M. (1924). Ethnographic survey of africa: Showing the tribes and languages; also the stations of missionary societies [map].

Rupasingha, A. and Goetz, S. J. (2008). US County-Level Social Capital Data, 1990-2005. Tech. rep., The Northeast Regional Center for Rural Development, Penn State University, University Park, PA, 2008.

Schoenherr, D. (2017). Political connections and allocative distortions. Working paper.

Shleifer, A. and Vishny, R. W. (1994). Politicians and firms. The Quarterly Journal of Economics, pp. 995-1025.

Solon, G. (2002). Cross-country differences in intergenerational earnings mobility. The Journal of Economic Perspectives, 16 (3), 59-66.

SouzA, C. (2002). Brazil's system of local government, local finance and intergovernmental relations. Paper is part of the EngKaR Research Project, 8070.

Thornton, J. (1983). Sexual demography: The impact of the slave trade on family structure. In C. Robertson and M. Klein (eds.), Women and Slavery in Africa, Madison, WI, University of Wisconsin Press, pp. 39-48.

ToniN, M. and Vlassopoulos, M. (2010). Disentangling the sources of pro-socially motivated effort: A field experiment. Journal of Public Economics, (94(11-12)), 1086-1092.

- and - (2015). Corporate philanthropy and productivity: Evidence from an online real effort experiment. Management Science, (61(8)), 1795-1811. 
UjhelyI, G. (2014). Civil service rules and policy choices: Evidence from us state governments. American Economic Journal: Economic Policy, (6(2)), 338-380.

WALDENSTRöm, D. (2016). Wealth-income ratios in a small, developing economy: Sweden, 1810-2010. Journal of Economic History, forthcoming.

WeAver, J. (2017). Jobs for sale: Corruption and misallocation in hiring. Working paper.

WeIngrod, A. (1968). Patrons, patronage, and political parties. Comparative Studies in Society and History, 10 (4), 377-400.

WeINzIERL, M. (2014). The promise of positive optimal taxation: Normative diversity and a role for equal sacrifice. Journal of Public Economics, 118, 128-142.

- (2016). Revisiting the classical view of benefit-based taxation. Economic Journal, forthcoming.

Whatley, W. (2013). The transatlantic slave trade and the evolution of political authority in west africa, african Economic History Working Paper 13/2013, African Economic History Network.

- (2014). The gun-slave cycle in the 18th century british slave trade, mPRA Paper 58741, University Library of Munich, Germany.

— and Gillezeau, R. (2011). The impact of the transatlantic slave trade on ethnic stratification in africa. The American Economic Review, 101, 571-576.

WiLson, J. (1961). The economy of patronage. Journal of Political Economy, 69, 369-380.

XU, G. (2017). The costs of patronage: Evidence from the british empire. Working Paper. 


\section{Appendix A}

\section{Appendix to Chapter 1}

\section{A.1 Additional Tables and Figures}

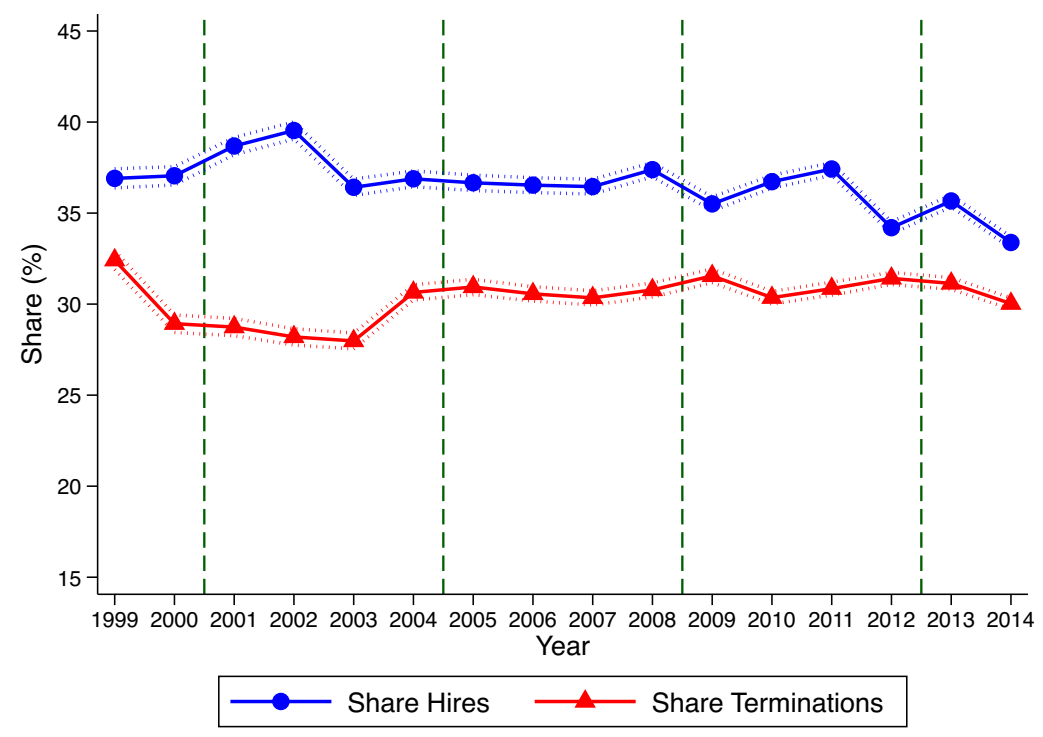

Notes: The figure shows the average share of hires and terminations in the private sector by year in Brazilian municipalities. Each observation in the data is a municipality-year pair. 95\% confidence intervals are shown as dashed lines around the means. The green lines indicate the time of local elections, which were held in November of 2000, 2004, 2008, 2012, with the mayor taking office in January of 2001, 2005, 2009, 2013.

Figure A.1: Turnover in Private Sector Employment Does Not Spike Following Elections 


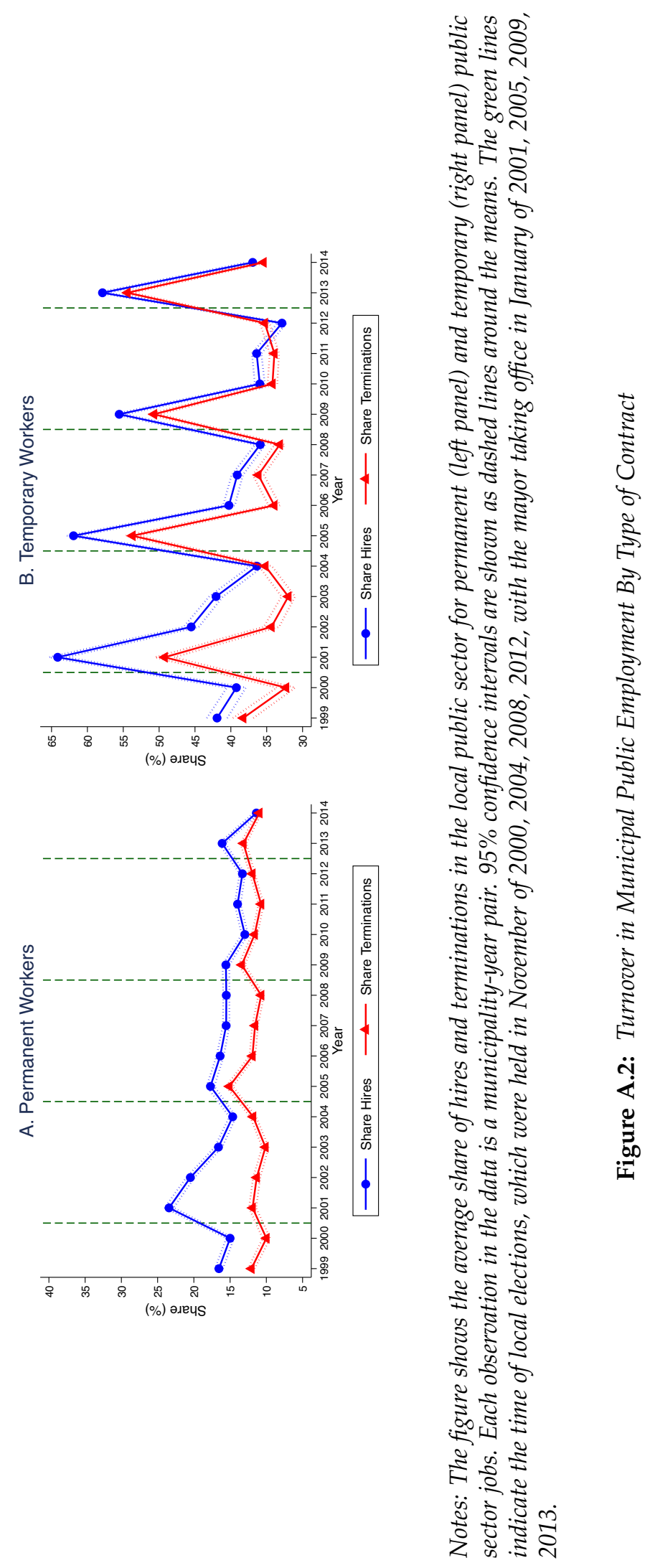



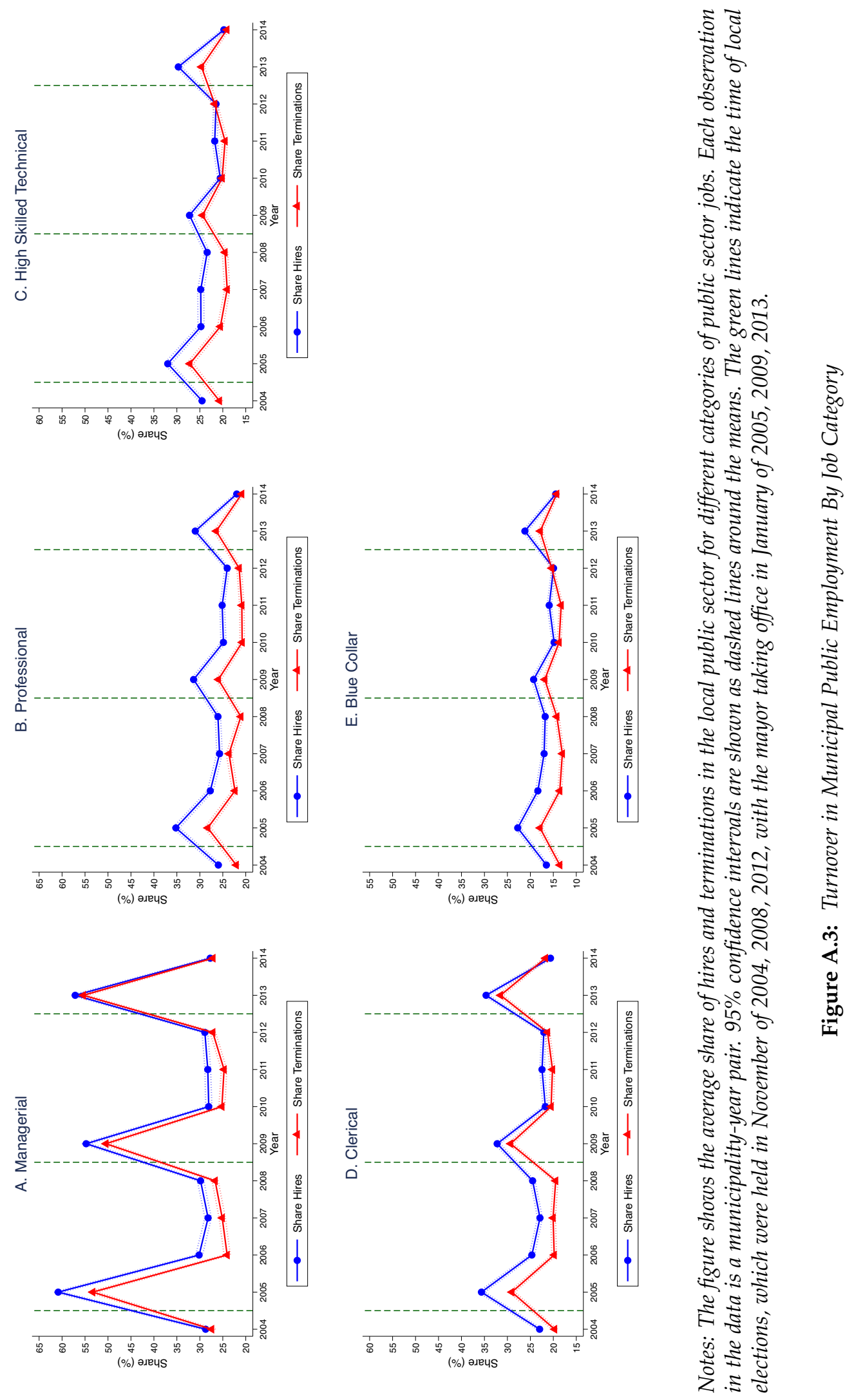


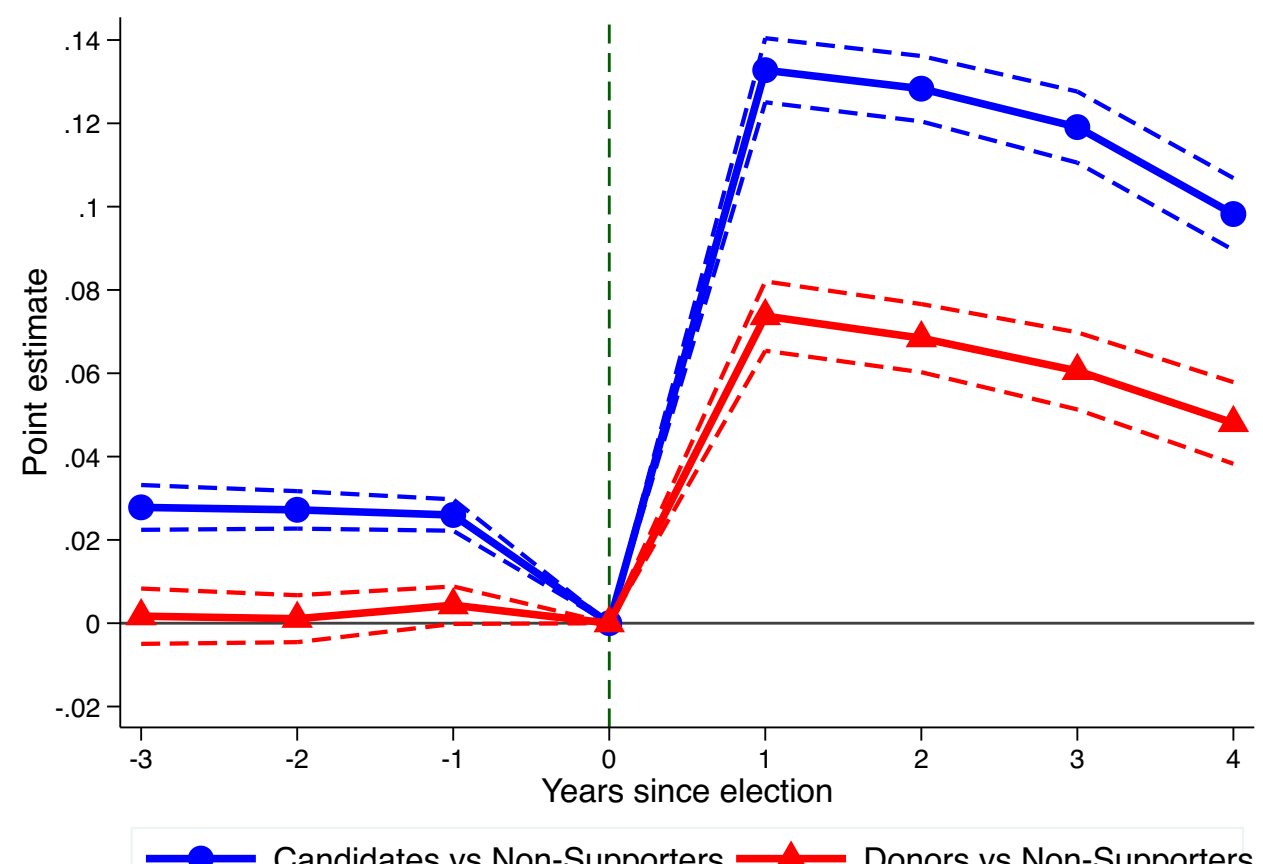

Notes: The figure presents the estimated effect of supporting the winning party on probability of employment in the public sector. The figure shows the estimated $\beta_{k}$ coefficients from equation (1.4). Estimates in blue focus on the sample of candidates, while estimates in red focus on the sample of donors. See section 1.3.3 for a description of the outcome variables. The sample of elections is 2004, 2008, 2012. The dotted lines show 95\% confidence intervals and are based on standard errors double clustered at the individual and election level.

Figure A.4: Effect of Supporting the Winning Party on Public Sector Outcomes - Non-Supporters as Control Group 


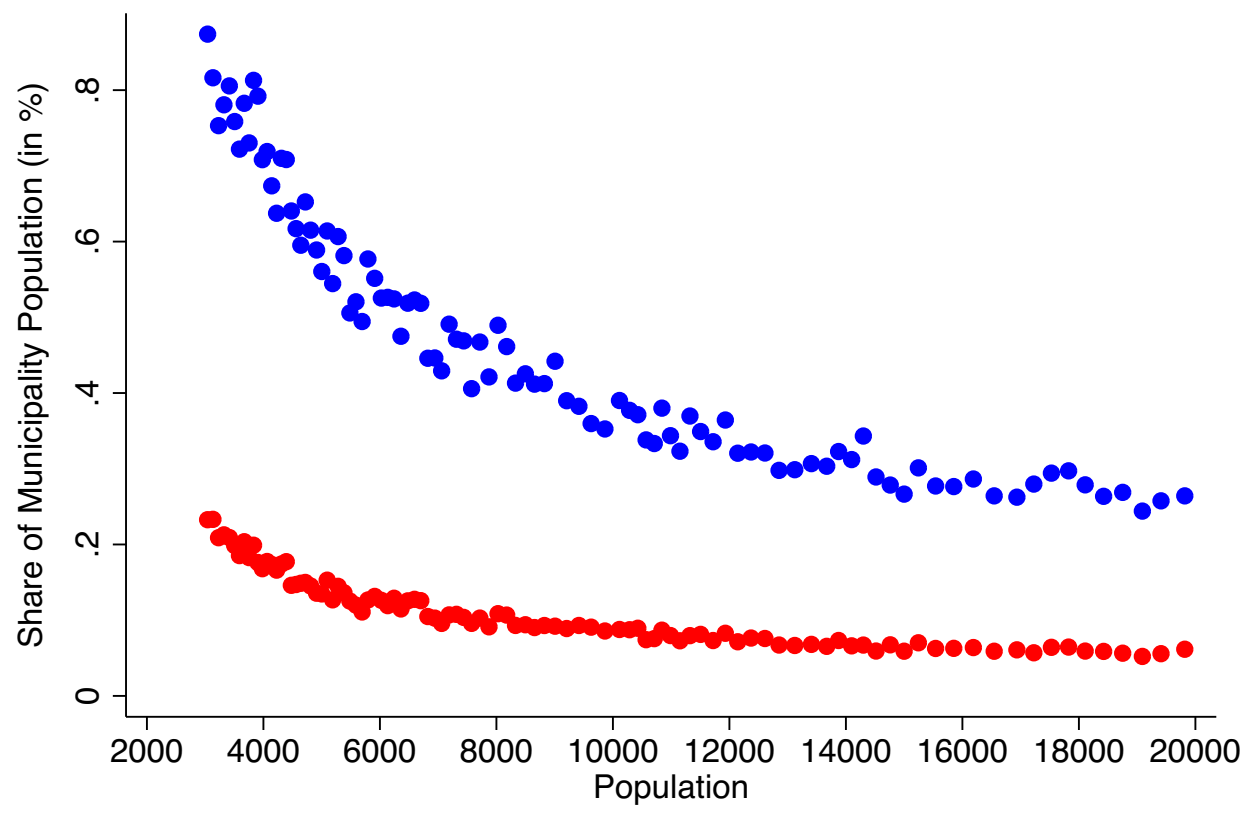

- Mayor's Supporters / Population • Employed Supporters / Population

Notes: The figure shows the distribution of the number of the mayor's supporters (local candidates and donors) as a share of the population in the municipality (in blue), and the number of these supporters who are employed as a share of the population in the municipality (in red), for municipalities with a population between 3,000 and 20,000 inhabitants.

Figure A.5: Mayor's Supporters and Employed Supporters as a Share of the Municipality Population 


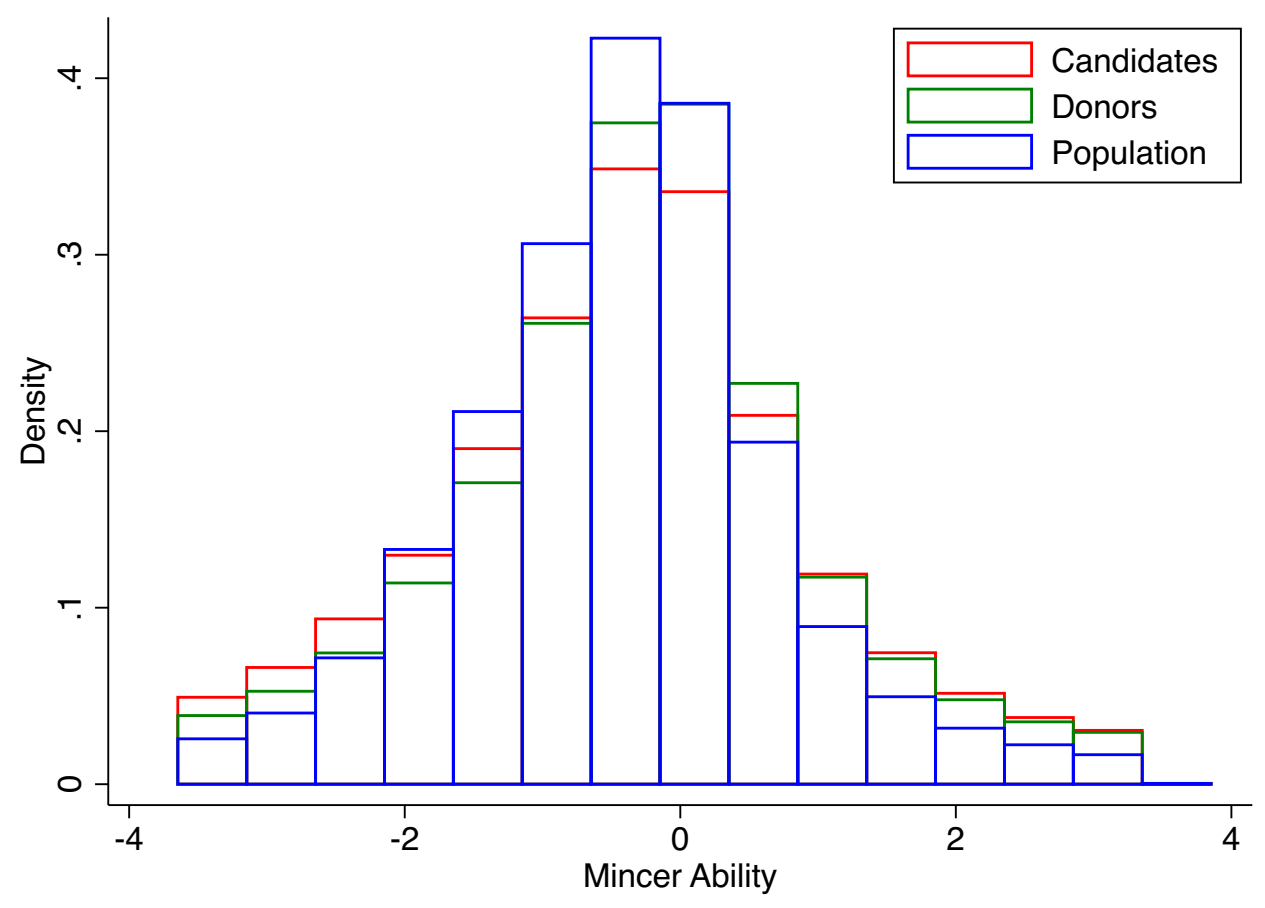

Notes: The figure shows comparisons of the distribution of the ability scores in the Brazilian population (in blue) and among supporters (candidates in red, and donors in green). See section 1.6.4 for a description of the procedure to calculate the ability scores.

Figure A.6: Distribution of Ability Scores in the Population and Among Supporters 


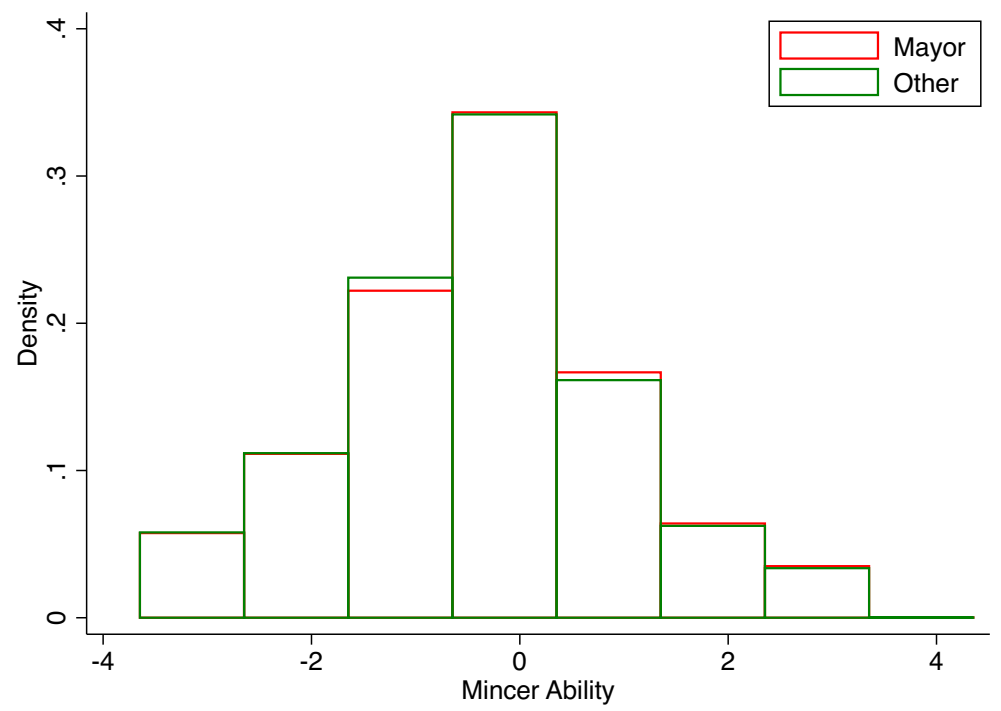

Notes: The figure shows comparisons of the distribution of the ability scores among candidates supporting the mayor (in red) or a different mayoral candidate (in green). See section 1.6.4 for a description of the procedure to calculate the ability scores.

Figure A.7: Distribution of Ability Scores Among Candidates Supporting the Mayor or a Different Mayoral Candidate 


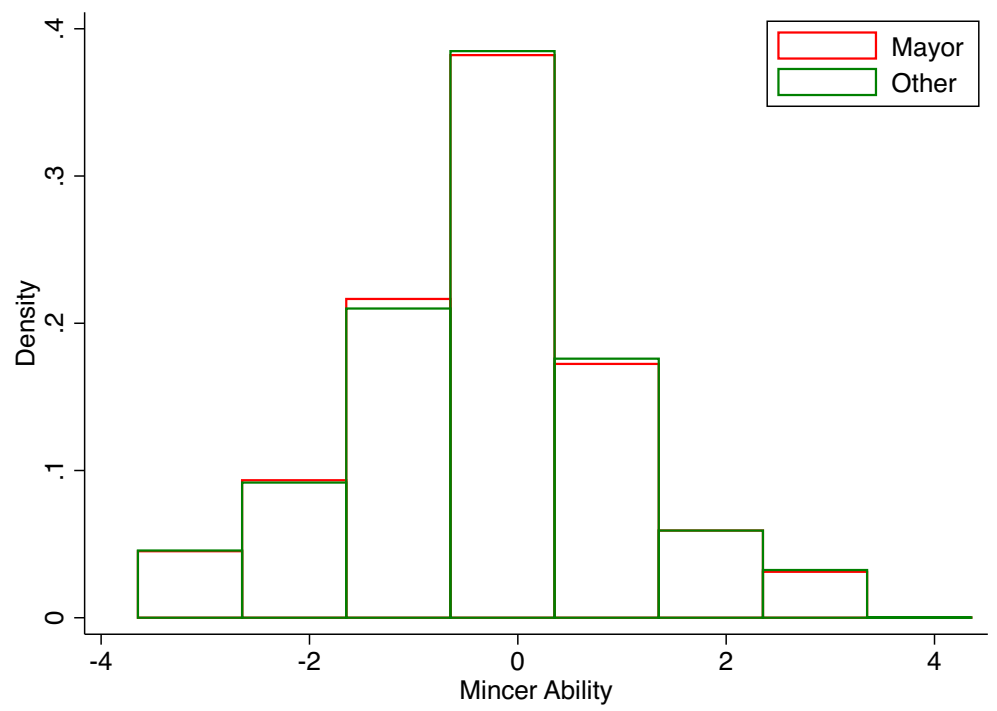

Notes: The figure shows comparisons of the distribution of the ability scores among donors supporting the mayor (in red) or a different mayoral candidate (in green). See section 1.6.4 for a description of the procedure to calculate the ability scores.

Figure A.8: Distribution of Ability Scores Among Donors Supporting the Mayor or a Different Mayoral Candidate 
Table A.1: Summary Statistics - Universe of Candidates to the Local Council

\begin{tabular}{lccccc}
\hline \hline \multicolumn{1}{c}{$\begin{array}{c}(1) \\
\text { Variable }\end{array}$} & $\begin{array}{c}(2) \\
\text { Mean }\end{array}$ & $\begin{array}{c}(3) \\
\text { Std. Dev. }\end{array}$ & $\begin{array}{c}(4) \\
\text { Min }\end{array}$ & $\begin{array}{c}(5) \\
\text { Max }\end{array}$ & $\begin{array}{c}(6) \\
\text { Observations }\end{array}$ \\
\hline Times Candidate & 1.39 & 0.74 & 1 & 4 & $1,031,083$ \\
Times Elected & 0.21 & 0.60 & 0 & 4 & $1,031,083$ \\
Ever Elected & 0.07 & 0.25 & 0 & 1 & $1,031,083$ \\
Number of Parties & 1.72 & 0.69 & 1 & 4 & 274,792 \\
Amount Spent in Race & 2,685 & 15,621 & 0 & $3,445,467$ & $1,079,728$ \\
Age & 43.48 & 10.85 & 18 & 100 & $1,435,675$ \\
Male & 0.76 & 0.43 & 0 & 1 & $1,436,252$ \\
Less than Middle School & 0.28 & 0.45 & 0 & 1 & $1,436,387$ \\
Middle School & 0.22 & 0.41 & 0 & 1 & $1,436,387$ \\
High School & 0.35 & 0.48 & 0 & 1 & $1,436,387$ \\
College & 0.16 & 0.36 & 0 & 1 & $1,436,387$ \\
\hline \hline
\end{tabular}

Notes: The table presents summary statistics on the electoral careers and demographic characteristics of the universe of candidates to a Brazilian municipal council in the 4 elections held over the 2000-2012 period. Times Candidate is the number of elections in which an individual runs, Times Elected is the number of elections in which an individual is elected to the council, Ever Elected is an indicator equal to one if the individual was ever elected to the council, Number of Parties is the number of different parties to which the candidate was affiliated (with summary statistics calculated only on the subsample of individuals running in multiple elections), Amount Spent in Race is the amount of money (in Brazilian Reals) spent by a candidate in the race (sample restricted to the 2004-2012 period), Age is the age of the individual at the time of the election, Male is an indicator for the candidate being male, Less than Middle School, Middle School, High School and College are indicator variables for a supporter's highest level of education. The unit of observation is an individual-election, except in the first four rows, where it is an individual.

Table A.2: Summary Statistics - Universe of Donors to Local Elections

\begin{tabular}{lccccc}
\hline \hline \multicolumn{1}{c}{$(1)$} & $(2)$ & $(3)$ & $(4)$ & $(5)$ & $(6)$ \\
\multicolumn{1}{c}{ Variable } & Mean & Std. Dev. & Min & Max & Observations \\
\hline Number Elections & 1.07 & 0.27 & 1 & 3 & $1,057,216$ \\
Number of Parties & 1.08 & 0.41 & 1 & 21 & $1,057,216$ \\
Amount Donated & 727,22 & 5794.79 & 0 & $5,609,230$ & $1,144,211$ \\
Donated to Winning Coalition & 0.48 & 0.50 & 0 & 1 & $1,144,211$ \\
\hline \hline
\end{tabular}

Notes: The table presents summary statistics on the universe of donors to Brazilian municipal elections in the 3 elections held over the 2004-2012 period. Number Elections is the number of elections in which an individual donated, Number of Parties is the number of different parties to which the individual donated, Amount Donated is the amount of money (in 2000 Brazilian Reals) spent by a candidate in the race, Donated to Winning Coalition is an indicator equal to one if the donation was directed to a party or a candidate in the coalition of the mayoral candidate who will be elected. The unit of observation is an individual-election for variables Amount Donated and Donated to Winning Coalition, and it is an individual for variables Number Elections and Number of Parties. 
Table A.3: Public Sector Wage Premium

\begin{tabular}{|c|c|c|c|c|c|c|}
\hline $\begin{array}{l}\text { Type of } \\
\text { Job: }\end{array}$ & $\begin{array}{c}(1) \\
\text { All } \\
\text { Jobs }\end{array}$ & $\begin{array}{c}(2) \\
\text { Managerial } \\
\text { Jobs }\end{array}$ & $\begin{array}{c}(3) \\
\text { Professional } \\
\text { Jobs }\end{array}$ & $\begin{array}{c}(4) \\
\text { High Skilled } \\
\text { Technical Jobs }\end{array}$ & $\begin{array}{c}(5) \\
\text { Clerical } \\
\text { Jobs }\end{array}$ & $\begin{array}{c}\text { Blue Collar } \\
\text { Jobs }\end{array}$ \\
\hline \multicolumn{7}{|c|}{ Panel A: Dep. Var. is Log Wage: } \\
\hline Public & $\begin{array}{c}0.072^{* * *} \\
(0.000)\end{array}$ & $\begin{array}{c}0.074^{* * *} \\
(0.000)\end{array}$ & $\begin{array}{c}0.328^{* * *} \\
(0.000)\end{array}$ & $\begin{array}{c}0.136^{* * *} \\
(0.000)\end{array}$ & $\begin{array}{c}0.066^{* * *} \\
(0.000)\end{array}$ & $\begin{array}{c}0.037^{* * *} \\
(0.000)\end{array}$ \\
\hline \multicolumn{7}{|c|}{ Panel B: Dep. Var. is Log Hourly Wage: } \\
\hline Public & $\begin{array}{c}0.160^{* * *} \\
(0.000)\end{array}$ & $\begin{array}{c}0.222^{* * *} \\
(0.000)\end{array}$ & $\begin{array}{c}0.286^{* * *} \\
(0.000)\end{array}$ & $\begin{array}{c}0.192^{* * *} \\
(0.000)\end{array}$ & $\begin{array}{c}0.183^{* * *} \\
(0.000)\end{array}$ & $\begin{array}{c}0.136^{* * *} \\
(0.000)\end{array}$ \\
\hline R-squared & 0.478 & 0.297 & 0.388 & 0.355 & 0.345 & 0.353 \\
\hline Observations & $529,460,038$ & $23,076,149$ & $42,819,113$ & $50,854,596$ & $101,602,667$ & $311,107,509$ \\
\hline
\end{tabular}

Notes: The table presents the public sector wage premium across five occupational categories. The dependent variable is the $\log$ of wage in Panel A and the $\log$ of hourly wage in Panel B, and the variables are winsorized at the $1 \%$ level. All regressions include controls for the worker's job tenure, the worker's age, municipality fixed effects, year fixed effects, and 43 occupational groups fixed effects. The sample includes all worker-job pairs in the Brazilian public and private sector over the 2003-2014 period. Standard errors are shown in parentheses. ${ }^{* * *} \mathrm{p}<0.01,{ }^{* *} \mathrm{p}<0.05,{ }^{*} \mathrm{p}<0.1$.

Table A.4: Covariates Balance for Candidates Gaining a Connection

\begin{tabular}{lcccccc}
\hline \multicolumn{1}{c}{\begin{tabular}{c}
$(1)$ \\
\multicolumn{1}{c}{ Covariate }
\end{tabular}} & $\begin{array}{c}(2) \\
\text { Coefficient }\end{array}$ & $\begin{array}{c}(3) \\
\text { P-value }\end{array}$ & $\begin{array}{c}(4) \\
\text { Mean Cont. Group }\end{array}$ & $\begin{array}{c}(5) \\
\text { Observations }\end{array}$ & $\begin{array}{c}(6) \\
\text { Supporters }\end{array}$ & $\begin{array}{c}\text { Elections } \\
\text { Earnings Public } \mathrm{t}=0\end{array}$ \\
Earnings Private $\mathrm{t}=0$ & -37.982 & 0.685 & 2521 & 126,391 & 121064 & 4147 \\
Earnings Total $\mathrm{t}=0$ & -56.279 & 0.218 & 875.1 & 126,391 & 121064 & 4147 \\
Employed Private $\mathrm{t}=0$ & -127.463 & 0.289 & 3687 & 126,391 & 121064 & 4147 \\
Employed Public $\mathrm{t}=0$ & $-0.009^{*}$ & 0.067 & 0.129 & 126,391 & 121064 & 4147 \\
Employed Any $\mathrm{t}=0$ & 0.010 & 0.146 & 0.252 & 126,391 & 121064 & 4147 \\
Employed Qualified $\mathrm{t}=0$ & -0.000 & 0.954 & 0.392 & 126,391 & 121064 & 4147 \\
Employed Unqualified $\mathrm{t}=0$ & 0.007 & 0.253 & 0.198 & 124,958 & 119826 & 4147 \\
Employed Managerial $\mathrm{t}=0$ & 0.003 & 0.275 & 0.0450 & 124,958 & 119826 & 4147 \\
Employed Professional $\mathrm{t}=0$ & 0.002 & 0.454 & 0.0270 & 125,127 & 119979 & 4147 \\
Employed HS Technical $\mathrm{t}=0$ & 0.002 & 0.497 & 0.0550 & 125,127 & 119979 & 4147 \\
Employed Clerical $\mathrm{t}=0$ & 0.000 & 0.902 & 0.0420 & 125,127 & 119979 & 4147 \\
Employed Blue Collar $\mathrm{t}=0$ & 0.001 & 0.725 & 0.0560 & 125,127 & 119979 & 4147 \\
Earnings Public $\mathrm{t}=-1$ & 0.005 & 0.153 & 0.0650 & 125,127 & 119979 & 4147 \\
Earnings Private $\mathrm{t}=-1$ & -19.453 & 0.832 & 2572 & 126,391 & 121064 & 4147 \\
Earnings Total $\mathrm{t}=-1$ & -53.125 & 0.239 & 885.3 & 126,391 & 121064 & 4147 \\
Employed Private $\mathrm{t}=-1$ & -104.022 & 0.391 & 3760 & 126,391 & 121064 & 4147 \\
Employed Public $\mathrm{t}=-1$ & -0.005 & 0.31 & 0.135 & 126,391 & 121064 & 4147 \\
Employed Any $\mathrm{t}=-1$ & 0.010 & 0.159 & 0.264 & 126,391 & 121064 & 4147 \\
Employed Qualified $\mathrm{t}=-1$ & 0.004 & 0.553 & 0.410 & 126,391 & 121064 & 4147 \\
Employed Unqualified $\mathrm{t}=-1$ & 0.006 & 0.327 & 0.204 & 124,579 & 119471 & 4147 \\
Employed Managerial $\mathrm{t}=-1$ & 0.004 & 0.173 & 0.0490 & 124,579 & 119471 & 4147 \\
Employed Professional $\mathrm{t}=-1$ & 0.003 & 0.212 & 0.0320 & 124,777 & 119647 & 4147 \\
Employed HS Technical $\mathrm{t}=-1$ & -0.001 & 0.674 & 0.0530 & 124,777 & 119647 & 4147 \\
Employed Clerical $\mathrm{t}=-1$ & 0.001 & 0.887 & 0.0440 & 124,777 & 119647 & 4147 \\
Employed Blue Collar $\mathrm{t}=-1$ & 0.004 & 0.189 & 0.0620 & 124,777 & 119647 & 4147 \\
\hline \hline
\end{tabular}


Table A.4 (continued): Covariates Balance for Candidates Gaining a Connection

\begin{tabular}{lcccccc}
\hline \multicolumn{1}{c}{\begin{tabular}{c}
$(1)$ \\
\multicolumn{1}{c}{ Covariate }
\end{tabular}} & $\begin{array}{c}(2) \\
\text { Coefficient }\end{array}$ & $\begin{array}{c}(3) \\
\text { P-value }\end{array}$ & $\begin{array}{c}(4) \\
\text { Mean Cont. Group }\end{array}$ & $\begin{array}{c}(5) \\
\text { Observations }\end{array}$ & $\begin{array}{c}(6) \\
\text { Supporters }\end{array}$ & $\begin{array}{c}(7) \\
\text { Elections }\end{array}$ \\
\hline Mincer Sample & -0.001 & 0.895 & 0.298 & 126,391 & 121064 & 4147 \\
Mincer Ability & -0.125 & 0.202 & -0.691 & 37,800 & 36585 & 4030 \\
Secondary School & -0.008 & 0.179 & 0.212 & 125,851 & 120561 & 4146 \\
High School & 0.003 & 0.637 & 0.360 & 125,851 & 120561 & 4146 \\
University Degree & 0.004 & 0.52 & 0.149 & 125,851 & 120561 & 4146 \\
Age & 0.053 & 0.739 & 43.32 & 126,290 & 120968 & 4146 \\
Male & 0.002 & 0.574 & 0.751 & 126,390 & 121063 & 4147 \\
Run Past Election & 0.006 & 0.374 & 0.328 & 126,391 & 121064 & 4147 \\
Incumbent & 0.001 & 0.905 & 0.113 & 126,391 & 121064 & 4147 \\
Contributions Received & -47.229 & 0.749 & 1832 & 126,391 & 121064 & 4147 \\
Contributions Spent & -47.344 & 0.75 & 1825 & 126,391 & 121064 & 4147 \\
\hline \hline
\end{tabular}

Notes: The table shows balance tests for candidates' covariates in the pre-election period, for the sample of candidates whose party was not already in power in the municipality. The coefficients and p-values in columns 2 and 3 are from regressions of the covariate in column 1 on an indicator for treatment status (supporting the winning mayor), controlling for margin of victory and including election (i.e. municipality times election year) times party fixed effects, focusing on mayoral races decided by a margin of victory of $5 \%$ or less. Column 4 reports the mean of the covariate in the control group, namely among supporters of the runner-up mayoral candidate. See Table 1.3 for a description of the covariates listed in column 1. P-values are based on standard errors clustered at the election level. ${ }^{* * *} \mathrm{p}<0.01,{ }^{* *} \mathrm{p}<0.05,{ }^{*} \mathrm{p}<0.1$.

Table A.5: Covariates Balance for Candidates Losing a Connection

\begin{tabular}{lcccccc}
\hline \multicolumn{1}{c}{\begin{tabular}{c}
$(1)$ \\
\multicolumn{1}{c}{ Covariate }
\end{tabular}} & $\begin{array}{c}(2) \\
\text { Coefficient }\end{array}$ & $\begin{array}{c}(3) \\
\text { P-value }\end{array}$ & $\begin{array}{c}(4) \\
\text { Mean Cont. Group }\end{array}$ & $\begin{array}{c}(5) \\
\text { Observations }\end{array}$ & $\begin{array}{c}(6) \\
\text { Supporters }\end{array}$ & $\begin{array}{c}(7) \\
\text { Elections }\end{array}$ \\
\hline Earnings Public $\mathrm{t}=0$ & 61.865 & 0.731 & 3580 & 67,898 & 65997 & 3895 \\
Earnings Private $\mathrm{t}=0$ & -37.226 & 0.549 & 814.1 & 67,898 & 65997 & 3895 \\
Earnings Total $\mathrm{t}=0$ & 76.045 & 0.729 & 4716 & 67,898 & 65997 & 3895 \\
Employed Private $\mathrm{t}=0$ & -0.000 & 0.995 & 0.108 & 67,898 & 65997 & 3895 \\
Employed Public $\mathrm{t}=0$ & 0.004 & 0.657 & 0.339 & 67,898 & 65997 & 3895 \\
Employed Any $\mathrm{t}=0$ & 0.008 & 0.443 & 0.454 & 67,898 & 65997 & 3895 \\
Employed Qualified $\mathrm{t}=0$ & 0.007 & 0.423 & 0.250 & 66,884 & 65068 & 3892 \\
Employed Unqualified $\mathrm{t}=0$ & -0.002 & 0.713 & 0.0780 & 66,884 & 65068 & 3892 \\
Employed Managerial $\mathrm{t}=0$ & -0.001 & 0.911 & 0.0610 & 67,142 & 65312 & 3892 \\
Employed Professional $\mathrm{t}=0$ & -0.007 & 0.119 & 0.0620 & 67,142 & 65312 & 3892 \\
Employed HS Technical $\mathrm{t}=0$ & 0.004 & 0.263 & 0.0470 & 67,142 & 65312 & 3892 \\
Employed Clerical $\mathrm{t}=0$ & 0.008 & 0.165 & 0.0740 & 67,142 & 65312 & 3892 \\
Employed Blue Collar $\mathrm{t}=0$ & 0.000 & 0.938 & 0.0870 & 67,142 & 65312 & 3892 \\
Earnings Public $\mathrm{t}=-1$ & 62.381 & 0.72 & 3572 & 67,898 & 65997 & 3895 \\
Earnings Private $\mathrm{t}=-1$ & -27.480 & 0.653 & 809.5 & 67,898 & 65997 & 3895 \\
Earnings Total $\mathrm{t}=-1$ & 66.368 & 0.747 & 4691 & 67,898 & 65997 & 3895 \\
Employed Private $\mathrm{t}=-1$ & 0.001 & 0.827 & 0.116 & 67,898 & 65997 & 3895 \\
Employed Public $\mathrm{t}=-1$ & 0.007 & 0.516 & 0.351 & 67,898 & 65997 & 3895 \\
Employed Any $\mathrm{t}=-1$ & 0.009 & 0.39 & 0.473 & 67,898 & 65997 & 3895 \\
Employed Qualified $\mathrm{t}=-1$ & 0.008 & 0.383 & 0.256 & 66,649 & 64842 & 3894 \\
Employed Unqualified $\mathrm{t}=-1$ & -0.001 & 0.85 & 0.0830 & 66,649 & 64842 & 3894 \\
Employed Managerial $\mathrm{t}=-1$ & -0.002 & 0.798 & 0.0690 & 66,970 & 65141 & 3894 \\
Employed Professional $\mathrm{t}=-1$ & -0.005 & 0.304 & 0.0600 & 66,970 & 65141 & 3894 \\
Employed HS Technical $\mathrm{t}=-1$ & 0.004 & 0.288 & 0.0490 & 66,970 & 65141 & 3894 \\
Employed Clerical $\mathrm{t}=-1$ & 0.009 & 0.157 & 0.0800 & 66,970 & 65141 & 3894 \\
Employed Blue Collar $\mathrm{t}=-1$ & -0.000 & 0.94 & 0.0850 & 66,970 & 65141 & 3894 \\
\hline
\end{tabular}


Table A.5 (continued): Covariates Balance for Candidates Losing a Connection

\begin{tabular}{lcccccc}
\hline \multicolumn{1}{c}{\begin{tabular}{c}
$(1)$ \\
\multicolumn{1}{c}{ Covariate }
\end{tabular}} & $\begin{array}{c}(2) \\
\text { Coefficient }\end{array}$ & $\begin{array}{c}(3) \\
\text { P-value }\end{array}$ & $\begin{array}{c}(4) \\
\text { Mean Cont. Group }\end{array}$ & $\begin{array}{c}(5) \\
\text { Observations }\end{array}$ & $\begin{array}{c}(6) \\
\text { Supporters }\end{array}$ & $\begin{array}{c}(7) \\
\text { Elections }\end{array}$ \\
\hline Mincer Sample & -0.000 & 0.986 & 0.295 & 67,898 & 65997 & 3895 \\
Mincer Ability & 0.057 & 0.734 & -0.632 & 19,883 & 19493 & 3423 \\
Secondary School & $-0.018^{* *}$ & 0.028 & 0.210 & 67,659 & 65772 & 3895 \\
High School & 0.014 & 0.152 & 0.365 & 67,659 & 65772 & 3895 \\
University Degree & 0.008 & 0.341 & 0.161 & 67,659 & 65772 & 3895 \\
Age & 0.058 & 0.774 & 43.96 & 67,858 & 65958 & 3893 \\
Male & -0.000 & 0.966 & 0.736 & 67,896 & 65995 & 3895 \\
Run Past Election & 0.001 & 0.937 & 0.392 & 67,898 & 65997 & 3895 \\
Incumbent & -0.001 & 0.833 & 0.161 & 67,898 & 65997 & 3895 \\
Contributions Received & -112.035 & 0.698 & 2578 & 67,898 & 65997 & 3895 \\
Contributions Spent & -98.041 & 0.735 & 2565 & 67,898 & 65997 & 3895 \\
\hline
\end{tabular}

Notes: The table shows balance tests for candidates' covariates in the pre-election period, for the sample of candidates whose party was already in power in the municipality. The coefficients and p-values in columns 2 and 3 are from regressions of the covariate in column 1 on an indicator for treatment status (supporting the losing mayoral candidate), controlling for margin of victory and including election (i.e. municipality times election year) times party fixed effects, focusing on mayoral races decided by a margin of victory of $5 \%$ or less. Column 4 reports the mean of the covariate in the control group, namely among supporters of the runner-up mayoral candidate. See Table 1.3 for a description of the covariates listed in column 1. P-values are based on standard errors clustered at the election level. ${ }^{* * *} \mathrm{p}<0.01,{ }^{* *} \mathrm{p}<0.05,{ }^{*} \mathrm{p}<0.1$.

Table A.6: Covariates Balance for Donors - Gaining a Connection

\begin{tabular}{lcccccc}
\hline \multicolumn{1}{c}{\begin{tabular}{c}
$(1)$ \\
\multicolumn{1}{c}{ Covariate }
\end{tabular}} & $\begin{array}{c}(2) \\
\text { Coefficient }\end{array}$ & $\begin{array}{c}(3) \\
\text { P-value }\end{array}$ & $\begin{array}{c}(4) \\
\text { Mean Cont. Group }\end{array}$ & $\begin{array}{c}(5) \\
\text { Observations }\end{array}$ & $\begin{array}{c}(6) \\
\text { Supporters }\end{array}$ & $\begin{array}{c}(7) \\
\text { Elections }\end{array}$ \\
\hline Earnings Public $\mathrm{t}=0$ & 60.336 & 0.771 & 2661 & 108,202 & 106958 & 3660 \\
Earnings Private $\mathrm{t}=0$ & -135.467 & 0.33 & 1460 & 108,202 & 106958 & 3660 \\
Earnings Total $\mathrm{t}=0$ & -242.306 & 0.476 & 4760 & 108,202 & 106958 & 3660 \\
Employed Private $\mathrm{t}=0$ & -0.001 & 0.919 & 0.190 & 108,202 & 106958 & 3660 \\
Employed Public $\mathrm{t}=0$ & 0.006 & 0.605 & 0.190 & 108,202 & 106958 & 3660 \\
Employed Any $\mathrm{t}=0$ & 0.007 & 0.676 & 0.391 & 108,202 & 106958 & 3660 \\
Employed Qualified $\mathrm{t}=0$ & 0.004 & 0.697 & 0.159 & 107,794 & 106558 & 3659 \\
Employed Unqualified $\mathrm{t}=0$ & 0.002 & 0.605 & 0.0270 & 107,794 & 106558 & 3659 \\
Employed Managerial $\mathrm{t}=0$ & 0.001 & 0.69 & 0.0290 & 107,951 & 106712 & 3660 \\
Employed Professional $\mathrm{t}=0$ & -0.000 & 0.958 & 0.0560 & 107,951 & 106712 & 3660 \\
Employed HS Technical $\mathrm{t}=0$ & 0.003 & 0.231 & 0.0280 & 107,951 & 106712 & 3660 \\
Employed Clerical $\mathrm{t}=0$ & -0.001 & 0.776 & 0.0460 & 107,951 & 106712 & 3660 \\
Employed Blue Collar $\mathrm{t}=0$ & 0.003 & 0.262 & 0.0290 & 107,951 & 106712 & 3660 \\
Earnings Public $\mathrm{t}=-1$ & 78.350 & 0.692 & 2530 & 108,202 & 106958 & 3660 \\
Earnings Private $\mathrm{t}=-1$ & -128.972 & 0.347 & 1468 & 108,202 & 106958 & 3660 \\
Earnings Total $\mathrm{t}=-1$ & -192.980 & 0.558 & 4602 & 108,202 & 106958 & 3660 \\
Employed Private $\mathrm{t}=-1$ & 0.003 & 0.815 & 0.197 & 108,202 & 106958 & 3660 \\
Employed Public $\mathrm{t}=-1$ & 0.007 & 0.535 & 0.189 & 108,202 & 106958 & 3660 \\
Employed Any $\mathrm{t}=-1$ & 0.011 & 0.538 & 0.396 & 108,202 & 106958 & 3660 \\
\hline \hline
\end{tabular}


Table A.6 (continued): Covariates Balance for Donors - Gaining a Connection

\begin{tabular}{lcccccc}
\hline \multicolumn{1}{c}{$\begin{array}{c}(1) \\
\text { Covariate }\end{array}$} & $\begin{array}{c}(2) \\
\text { Coefficient }\end{array}$ & $\begin{array}{c}(3) \\
\text { P-value }\end{array}$ & $\begin{array}{c}(4) \\
\text { Mean Cont. Group }\end{array}$ & $\begin{array}{c}(5) \\
\text { Observations }\end{array}$ & $\begin{array}{c}(6) \\
\text { Supporters }\end{array}$ & $\begin{array}{c}(7) \\
\text { Elections }\end{array}$ \\
\hline Employed Any $\mathrm{t}=-1$ & 0.011 & 0.538 & 0.396 & 108,202 & 106958 & 3660 \\
Employed Qualified $\mathrm{t}=-1$ & 0.007 & 0.472 & 0.158 & 107,798 & 106560 & 3660 \\
Employed Unqualified $\mathrm{t}=-1$ & -0.001 & 0.763 & 0.0270 & 107,798 & 106560 & 3660 \\
Employed Managerial $\mathrm{t}=-1$ & 0.002 & 0.638 & 0.0290 & 107,960 & 106719 & 3660 \\
Employed Professional $\mathrm{t}=-1$ & 0.002 & 0.719 & 0.0550 & 107,960 & 106719 & 3660 \\
Employed HS Technical $\mathrm{t}=-1$ & 0.000 & 0.863 & 0.0280 & 107,960 & 106719 & 3660 \\
Employed Clerical $\mathrm{t}=-1$ & -0.000 & 0.978 & 0.0470 & 107,960 & 106719 & 3660 \\
Employed Blue Collar $\mathrm{t}=-1$ & 0.004 & 0.18 & 0.0280 & 107,960 & 106719 & 3660 \\
Mincer Sample & 0.005 & 0.778 & 0.368 & 108,202 & 106958 & 3660 \\
Mincer Ability & -0.140 & 0.509 & 0.341 & 39,718 & 39377 & 3140 \\
Amount of Contributions & -11.304 & 0.927 & 1303 & 108,202 & 106958 & 3660 \\
\hline \hline
\end{tabular}

Notes: The table shows balance tests for donors' covariates in the pre-election period, for the sample of donors whose party was not already in power in the municipality. The coefficients and p-values in columns 2 and 3 are from regressions of the covariate in column 1 on an indicator for treatment status (supporting the winning mayor), controlling for margin of victory and including election (i.e. municipality times election year) times party fixed effects, focusing on mayoral races decided by a margin of victory of $5 \%$ or less. Column 4 reports the mean of the covariate in the control group, namely among supporters of the runner-up mayoral candidate. Amount of Contributions is the donor's amount contributed to the party and coalition of the supported mayor. See Table 1.3 for a description of the other covariates listed in column 1. P-values are based on standard errors clustered at the election level. ${ }^{* * *} \mathrm{p}<0.01,{ }^{* *} \mathrm{p}<0.05,{ }^{*} \mathrm{p}<0.1$.

Table A.7: Covariates Balance for Donors - Losing a Connection

\begin{tabular}{lcccccc}
\hline \multicolumn{1}{c}{$\begin{array}{c}(1) \\
\text { Covariate }\end{array}$} & $\begin{array}{c}(2) \\
\text { Coefficient }\end{array}$ & $\begin{array}{c}(3) \\
\text { P-value }\end{array}$ & $\begin{array}{c}(4) \\
\text { Mean Cont. Group }\end{array}$ & $\begin{array}{c}(5) \\
\text { Observations }\end{array}$ & $\begin{array}{c}(6) \\
\text { Supporters }\end{array}$ & $\begin{array}{c}(7) \\
\text { Elections }\end{array}$ \\
\hline Earnings Public $\mathrm{t}=0$ & 112.747 & 0.812 & 4029 & 80,385 & 79673 & 3144 \\
Earnings Private $\mathrm{t}=0$ & 255.871 & 0.146 & 1288 & 80,385 & 79673 & 3144 \\
Earnings Total $\mathrm{t}=0$ & 497.500 & 0.394 & 5904 & 80,385 & 79673 & 3144 \\
Employed Private $\mathrm{t}=0$ & 0.027 & 0.13 & 0.163 & 80,385 & 79673 & 3144 \\
Employed Public $\mathrm{t}=0$ & -0.008 & 0.693 & 0.282 & 80,385 & 79673 & 3144 \\
Employed Any $\mathrm{t}=0$ & 0.019 & 0.337 & 0.452 & 80,385 & 79673 & 3144 \\
Employed Qualified $\mathrm{t}=0$ & 0.002 & 0.934 & 0.230 & 79,896 & 79205 & 3138 \\
Employed Unqualified $\mathrm{t}=0$ & -0.008 & 0.203 & 0.0470 & 79,896 & 79205 & 3138 \\
Employed Managerial $\mathrm{t}=0$ & -0.008 & 0.508 & 0.0690 & 80,194 & 79487 & 3140 \\
Employed Professional $\mathrm{t}=0$ & -0.004 & 0.619 & 0.0730 & 80,194 & 79487 & 3140 \\
Employed HS Technical $\mathrm{t}=0$ & -0.002 & 0.606 & 0.0310 & 80,194 & 79487 & 3140 \\
Employed Clerical $\mathrm{t}=0$ & 0.008 & 0.312 & 0.0700 & 80,194 & 79487 & 3140 \\
Employed Blue Collar $\mathrm{t}=0$ & -0.002 & 0.715 & 0.0370 & 80,194 & 79487 & 3140 \\
Earnings Public $\mathrm{t}=-1$ & 147.803 & 0.741 & 3706 & 80,385 & 79673 & 3144 \\
Earnings Private $\mathrm{t}=-1$ & $339.123^{* *}$ & 0.042 & 1288 & 80,385 & 79673 & 3144 \\
Earnings Total $\mathrm{t}=-1$ & 643.444 & 0.25 & 5565 & 80,385 & 79673 & 3144 \\
Employed Private $\mathrm{t}=-1$ & $0.032^{*}$ & 0.069 & 0.172 & 80,385 & 79673 & 3144 \\
Employed Public $\mathrm{t}=-1$ & -0.004 & 0.831 & 0.271 & 80,385 & 79673 & 3144 \\
Employed Any $\mathrm{t}=-1$ & 0.029 & 0.129 & 0.449 & 80,385 & 79673 & 3144 \\
\hline \hline
\end{tabular}


Table A.7 (continued): Covariates Balance for Donors - Losing a Connection

\begin{tabular}{lcccccc}
\hline \multicolumn{1}{c}{$\begin{array}{c}(1) \\
\text { Covariate }\end{array}$} & $\begin{array}{c}(2) \\
\text { Coefficient }\end{array}$ & $\begin{array}{c}(3) \\
\text { P-value }\end{array}$ & $\begin{array}{c}(4) \\
\text { Mean Cont. Group }\end{array}$ & $\begin{array}{c}(5) \\
\text { Observations }\end{array}$ & $\begin{array}{c}(6) \\
\text { Supporters }\end{array}$ & $\begin{array}{c}(7) \\
\text { Elections }\end{array}$ \\
\hline Employed Qualified $\mathrm{t}=-1$ & 0.002 & 0.928 & 0.222 & 79,907 & 79217 & 3140 \\
Employed Unqualified $\mathrm{t}=-1$ & -0.006 & 0.326 & 0.0450 & 79,907 & 79217 & 3140 \\
Employed Managerial $\mathrm{t}=-1$ & -0.006 & 0.623 & 0.0660 & 80,219 & 79512 & 3142 \\
Employed Professional $\mathrm{t}=-1$ & -0.006 & 0.475 & 0.0690 & 80,219 & 79512 & 3142 \\
Employed HS Technical $\mathrm{t}=-1$ & 0.001 & 0.743 & 0.0310 & 80,219 & 79512 & 3142 \\
Employed Clerical $\mathrm{t}=-1$ & 0.007 & 0.353 & 0.0690 & 80,219 & 79512 & 3142 \\
Employed Blue Collar $\mathrm{t}=-1$ & -0.001 & 0.822 & 0.0360 & 80,219 & 79512 & 3142 \\
Mincer Sample & $0.041^{* *}$ & 0.043 & 0.369 & 80,385 & 79673 & 3144 \\
Mincer Ability & $0.641^{*}$ & 0.059 & 0.0360 & 30,748 & 30560 & 2552 \\
Amount of Contributions & -17.401 & 0.916 & 1422 & 80,385 & 79673 & 3144 \\
\hline \hline
\end{tabular}

Notes: The table shows balance tests for donors' covariates in the pre-election period, for the sample of donors whose party was already in power in the municipality. The coefficients and p-values in columns 2 and 3 are from regressions of the covariate in column 1 on an indicator for treatment status (supporting the losing mayoral candidate), controlling for margin of victory and including election (i.e. municipality times election year) times party fixed effects, focusing on mayoral races decided by a margin of victory of $5 \%$ or less. Column 4 reports the mean of the covariate in the control group, namely among supporters of the runner-up mayoral candidate. Amount of Contributions is the donor's amount contributed to the party and coalition of the supported mayor. See Table 1.3 for a description of the other covariates listed in column 1 . P-values are based on standard errors clustered at the election level. ${ }^{* * *} \mathrm{p}<0.01,{ }^{* *} \mathrm{p}<0.05,{ }^{*} \mathrm{p}<0.1$.

Table A.8: Effect of Supporting the Winning Party on Public Sector Outcomes - Optimal Bandwidth

\begin{tabular}{|c|c|c|c|c|c|c|}
\hline & (1) & $(2)$ & (3) & $(4)$ & (5) & (6) \\
\hline Dependent Variable: & \multicolumn{3}{|c|}{ Employed Public } & \multicolumn{3}{|c|}{ Earnings Public } \\
\hline Group of Supporters: & All & Candidates & Donors & All & Candidates & Donors \\
\hline Mayor & $\begin{array}{c}0.106^{* * *} \\
(0.004)\end{array}$ & $\begin{array}{c}0.125^{* * *} \\
(0.003)\end{array}$ & $\begin{array}{c}0.068^{* * *} \\
(0.008)\end{array}$ & $\begin{array}{c}1,250.230^{* * *} \\
(74.431)\end{array}$ & $\begin{array}{c}1,379.926^{* * *} \\
(53.558)\end{array}$ & $\begin{array}{c}969.554^{* * *} \\
(175.471)\end{array}$ \\
\hline Observations & $2,450,590$ & $1,807,648$ & $1,088,654$ & $2,648,076$ & $1,614,168$ & 930,998 \\
\hline R-squared & 0.319 & 0.356 & 0.289 & 0.208 & 0.239 & 0.209 \\
\hline Optimal Bandwidth & 8.753 & 11.514 & 10.108 & 9.617 & 9.943 & 8.468 \\
\hline Mean D.V. Runner-up & 0.225 & 0.239 & 0.203 & 2774 & 2569 & 3068 \\
\hline Supporters & 687975 & 448590 & 347556 & 740230 & 407157 & 298806 \\
\hline Elections & 8960 & 11194 & 5921 & 9706 & 9986 & 5128 \\
\hline
\end{tabular}

Notes: The table presents the estimated coefficients of $\beta$ from equation (1.1) using as dependent variable an indicator for employment in the public sector (columns 1-3) and public sector earnings (columns 4-6). Results in columns (1) and (4) are estimated on the sample of all supporters. Results in columns (2) and (5) are estimated on the sample of candidates to the local council, and results in columns (3) and (6) are estimated on the sample of donors. See section 1.3.3 for a description of the outcome variables. The sample is composed of supporters of the winning mayoral candidate or the close loser, using an outcome- and sample-specific margin of victory to define close races, calculated using the optimal bandwidth selection procedure following Calonico et al. (2014). The sample of elections is 2000, 2004, 2008, 2012 in columns 1, 2, 4, 5, and 2004, 2008, 2012 in columns 3, 6. "Mean D.V. Runner-up" shows the average of the dependent variable for the supporters of the runner-up in the post-election period. Robust standard errors are shown in parentheses and are double clustered at the supporter and election level. ${ }^{* *} \mathrm{p}<0.01,{ }^{* *} \mathrm{p}<0.05,{ }^{*} \mathrm{p}<0.1$. 
Table A.9: Effect of Supporting the Winning Party on Public Sector Outcomes - 3\% Margin of Victory Bandwidth

\begin{tabular}{|c|c|c|c|c|c|c|}
\hline & $(1)$ & $(2)$ & (3) & $(4)$ & (5) & (6) \\
\hline Dependent Variable: & \multicolumn{3}{|c|}{ Employed Public } & \multicolumn{3}{|c|}{ Earnings Public } \\
\hline Group of Supporters: & All & Candidates & Donors & All & Candidates & Donors \\
\hline Mayor & $\begin{array}{c}0.105^{* * *} \\
(0.006)\end{array}$ & $\begin{array}{c}0.122^{* * *} \\
(0.006)\end{array}$ & $\begin{array}{c}0.069^{* * *} \\
(0.011)\end{array}$ & $\begin{array}{c}1,253.877^{* * *} \\
(118.921)\end{array}$ & $\begin{array}{c}1,356.619^{* * *} \\
(97.073)\end{array}$ & $\begin{array}{c}884.004^{* * *} \\
(200.829)\end{array}$ \\
\hline Observations & 844,858 & 516,330 & 311,852 & 844,858 & 516,330 & 311,852 \\
\hline R-squared & 0.322 & 0.355 & 0.298 & 0.210 & 0.239 & 0.210 \\
\hline Mean D.V. Runner-up & 0.223 & 0.238 & 0.197 & 2626 & 2504 & 2835 \\
\hline Supporters & 249928 & 143897 & 101685 & 249928 & 143897 & 101685 \\
\hline Elections & 3288 & 3283 & 1906 & 3288 & 3283 & 1906 \\
\hline
\end{tabular}

Notes: The table presents the estimated coefficients of $\beta$ from equation (1.1) using as dependent variable an indicator for employment in the public sector (columns 1-3) and public sector earnings (columns 4-6). Results in columns (1) and (4) are estimated on the sample of all supporters. Results in columns (2) and (5) are estimated on the sample of candidates to the local council, and results in columns (3) and (6) are estimated on the sample of donors. See section 1.3.3 for a description of the outcome variables. The sample is composed of supporters of the winning mayoral candidate or the close loser, using a $3 \%$ margin of victory to define close races. The sample of elections is 2000, 2004, 2008, 2012 in columns 1, 2, 4, 5, and 2004, 2008, 2012 in columns 3, 6. "Mean D.V. Runner-up" shows the average of the dependent variable for the supporters of the runner-up in the post-election period. Robust standard errors are shown in parentheses and are double clustered at the supporter and election level. ${ }^{* *} \mathrm{p}<0.01,{ }^{* *} \mathrm{p}<0.05,{ }^{*} \mathrm{p}<0.1$.

Table A.10: Effect of Supporting the Winning Party on Public Sector Outcomes - 1\% Margin of Victory Bandwidth

\begin{tabular}{|c|c|c|c|c|c|c|}
\hline & (1) & (2) & (3) & (4) & (5) & (6) \\
\hline Dependent Variable: & \multicolumn{3}{|c|}{ Employed Public } & \multicolumn{3}{|c|}{ Earnings Public } \\
\hline Group of Supporters: & All & Candidates & Donors & All & Candidates & Donors \\
\hline Mayor & $\begin{array}{c}0.103^{* * *} \\
(0.011)\end{array}$ & $\begin{array}{c}0.112^{* * *} \\
(0.012)\end{array}$ & $\begin{array}{c}0.082^{* * *} \\
(0.019)\end{array}$ & $\begin{array}{c}1,289.482^{* * *} \\
(241.140)\end{array}$ & $\begin{array}{c}1,240.820^{* * *} \\
(187.805)\end{array}$ & $\begin{array}{c}984.832^{* * *} \\
(346.646)\end{array}$ \\
\hline Observations & 274,248 & 171,602 & 96,458 & 274,248 & 171,602 & 96,458 \\
\hline R-squared & 0.321 & 0.353 & 0.301 & 0.215 & 0.238 & 0.230 \\
\hline Mean D.V. Runner-up & 0.223 & 0.240 & 0.197 & 2661 & 2524 & 2963 \\
\hline Supporters & 81798 & 49089 & 31063 & 81798 & 49089 & 31063 \\
\hline Elections & 1092 & 1091 & 622 & 1092 & 1091 & 622 \\
\hline
\end{tabular}

Notes: The table presents the estimated coefficients of $\beta$ from equation (1.1) using as dependent variable an indicator for employment in the public sector (columns 1-3) and public sector earnings (columns 4-6). Results in columns (1) and (4) are estimated on the sample of all supporters. Results in columns (2) and (5) are estimated on the sample of candidates to the local council, and results in columns (3) and (6) are estimated on the sample of donors. See section 1.3.3 for a description of the outcome variables. The sample is composed of supporters of the winning mayoral candidate or the close loser, using a $1 \%$ margin of victory to define close races. The sample of elections is 2000, 2004, 2008, 2012 in columns 1, 2, 4, 5, and 2004, 2008, 2012 in columns 3, 6. "Mean D.V. Runner-up" shows the average of the dependent variable for the supporters of the runner-up in the post-election period. Robust standard errors are shown in parentheses and are double clustered at the supporter and election level. ${ }^{* * *} \mathrm{p}<0.01,{ }^{* *} \mathrm{p}<0.05,{ }^{*} \mathrm{p}<0.1$. 
Table A.11: Effect of Supporting the Winning Party on Public Sector Outcomes, By Election Cycle

\begin{tabular}{|c|c|c|c|c|}
\hline \multirow{3}{*}{$\begin{array}{l}\text { Dependent Variable: } \\
\text { Group of Supporters: }\end{array}$} & \multirow{2}{*}{\multicolumn{2}{|c|}{$\begin{array}{c}(1) \\
\text { Employed Public }\end{array}$}} & \multirow{2}{*}{\multicolumn{2}{|c|}{ Earnings Public }} \\
\hline & & & & \\
\hline & Candidates & Donors & Candidates & Donors \\
\hline \multicolumn{5}{|c|}{ Panel A: 2000 Election Cycle: } \\
\hline Mayor & $\begin{array}{c}0.094^{* * *} \\
(0.009)\end{array}$ & & $\begin{array}{c}1,026.259^{* * *} \\
(132.944)\end{array}$ & \\
\hline Observations & 242,384 & & 242,384 & \\
\hline R-squared & 0.310 & & 0.205 & \\
\hline Mean D.V. Runner-up & 0.204 & & 2027 & \\
\hline Supporters & 60596 & & 60596 & \\
\hline Elections & 1259 & & 1259 & \\
\hline \multicolumn{5}{|c|}{ Panel B: 2004 Election Cycle: } \\
\hline Mayor & $\begin{array}{c}0.128^{* * *} \\
(0.010)\end{array}$ & $\begin{array}{c}0.066^{* * *} \\
(0.021)\end{array}$ & $\begin{array}{c}1,343.418^{* * *} \\
(146.942)\end{array}$ & $\begin{array}{l}814.873^{*} \\
(456.498)\end{array}$ \\
\hline Observations & 248,732 & 89,368 & 248,732 & 89,368 \\
\hline R-squared & 0.369 & 0.356 & 0.248 & 0.260 \\
\hline Mean D.V. Runner-up & 0.248 & 0.244 & 2571 & 3947 \\
\hline Supporters & 62183 & 22287 & 62183 & 22287 \\
\hline Elections & 1431 & 769 & 1431 & 769 \\
\hline \multicolumn{5}{|c|}{ Panel C: 2008 Election Cycle: } \\
\hline Mayor & $\begin{array}{c}0.147^{* * *} \\
(0.010)\end{array}$ & $\begin{array}{c}0.062^{* * *} \\
(0.013)\end{array}$ & $\begin{array}{c}1,522.456^{* * *} \\
(156.320)\end{array}$ & $\begin{array}{l}759.917^{* *} \\
(300.431)\end{array}$ \\
\hline Observations & 225,268 & 288,752 & 225,268 & 288,752 \\
\hline R-squared & 0.380 & 0.272 & 0.255 & 0.184 \\
\hline Mean D.V. Runner-up & 0.261 & 0.185 & 2928 & 2703 \\
\hline Supporters & 56317 & 71967 & 56317 & 71967 \\
\hline Elections & 1328 & 1097 & 1328 & 1097 \\
\hline \multicolumn{5}{|c|}{ Panel D: 2012 Election Cycle: } \\
\hline Mayor & $\begin{array}{c}0.139^{* * *} \\
(0.010)\end{array}$ & $\begin{array}{c}0.075^{* * *} \\
(0.012)\end{array}$ & $\begin{array}{l}1,778.027^{* * *} \\
(160.962)\end{array}$ & $\begin{array}{c}1,019.358^{* * *} \\
(256.238)\end{array}$ \\
\hline Observations & 151,504 & 172,712 & 151,504 & 172,712 \\
\hline R-squared & 0.367 & 0.296 & 0.241 & 0.206 \\
\hline Mean D.V. Runner-up & 0.258 & 0.199 & 2866 & 2818 \\
\hline Supporters & 75752 & 86018 & 75752 & 86018 \\
\hline Elections & 1395 & 1296 & 1395 & 1296 \\
\hline
\end{tabular}

Notes: The table presents the estimated coefficients of $\beta$ from equation (1.1) using as dependent variable an indicator variable equal to one if the supporter is employed in a public sector job (columns 1-2) and public sector earnings (columns 3-4). Results in columns (1) and (3) are estimated on the sample of candidates. Results in columns (2) and (4) are estimated on the sample of donors. See section 1.3.3 for a description of the outcome variables. The sample is composed of supporters of the winning mayoral candidate or the close loser, using a 5\% margin of victory to define close races. The sample of elections is 2000 in Panel A, 2004 in Panel B, 2008 in Panel C, 2012 in Panel D. "Mean D.V. Runner-up" shows the average of the dependent variable for the supporters of the runner-up in the post-election period. Robust standard errors are shown in parentheses and are double clustered at the supporter and election level. ${ }^{* * *} \mathrm{p}<0.01,{ }^{* *} \mathrm{p}<0.05,{ }^{*} \mathrm{p}<0.1$. 
Table A.12: Effect of Supporting the Winning Party on Public Sector Outcomes - By Type of Connection

\begin{tabular}{|c|c|c|c|c|c|}
\hline \multirow{3}{*}{$\begin{array}{l}\text { Group of Supporters: } \\
\text { Connection to: }\end{array}$} & (1) & $(2)$ & (3) & $(4)$ & (5) \\
\hline & \multicolumn{2}{|c|}{ Candidates } & \multicolumn{3}{|c|}{ Donors } \\
\hline & Party & Coalition & Mayor & Party & Coalition \\
\hline \multicolumn{6}{|c|}{ Panel A: Dep. Var. is Employment Probability: } \\
\hline Mayor & $\begin{array}{c}0.136^{* * *} \\
(0.007)\end{array}$ & $\begin{array}{c}0.117^{* * *} \\
(0.006)\end{array}$ & $\begin{array}{c}0.114^{* * *} \\
(0.014)\end{array}$ & $\begin{array}{c}0.071^{* * *} \\
(0.016)\end{array}$ & $\begin{array}{c}0.033^{* * *} \\
(0.012)\end{array}$ \\
\hline R-squared & 0.395 & 0.359 & 0.351 & 0.304 & 0.271 \\
\hline Mean D.V. Runner-up & 0.243 & 0.242 & 0.211 & 0.193 & 0.187 \\
\hline \multicolumn{6}{|c|}{ Panel B: Dep. Var. is Earnings: } \\
\hline Mayor & $\begin{array}{l}1,553.211^{* * *} \\
(108.166)\end{array}$ & $\begin{array}{c}1,245.456^{* * *} \\
(94.133)\end{array}$ & $\begin{array}{c}1,713.739 * * * \\
(342.821)\end{array}$ & $\begin{array}{c}1,063.050^{* * *} \\
(349.026)\end{array}$ & $\begin{array}{c}144.292 \\
(270.998)\end{array}$ \\
\hline R-squared & 0.290 & 0.234 & 0.274 & 0.219 & 0.191 \\
\hline Mean D.V. Runner-up & 2575 & 2587 & 3338 & 2798 & 2633 \\
\hline Observations & 335,568 & 498,690 & 204,450 & 103,746 & 164,338 \\
\hline Supporters & 90367 & 141524 & 66211 & 33390 & 55359 \\
\hline Elections & 5327 & 4586 & 2151 & 1641 & 1738 \\
\hline
\end{tabular}

Notes: The table presents the estimated coefficients of $\beta$ from equation (1.1) using as dependent variables an indicator variable equal to one if the supporter is employed in a public sector job (Panel A) and public sector earnings (Panel B). Results in column 1 consider candidates running in the mayoral candidate's party. Results in column 2 consider candidates running in other parties in the mayoral candidate's coalition. Results in column 3 consider donors to a mayoral candidate. Results in column 4 consider donors to the party of the mayoral candidate (but not to the mayoral candidate directly). Results in column 5 consider donors to other parties in the mayoral candidate's coalition. See section 1.3.3 for a description of the outcome variables. The sample is composed of supporters of the winning mayoral candidate or the close loser, using a $5 \%$ margin of victory to define close races. The sample of elections is 2000, 2004, 2008, 2012 in columns 1, 2, and 2004, 2008, 2012 in columns 3, 4, 5. "Mean D.V. Runner-up" shows the average of the dependent variable for the supporters of the runner-up in the post-election period. Robust standard errors are shown in parentheses and are double clustered at the supporter and election level. ${ }^{* *} \mathrm{p}<0.01,{ }^{* *} \mathrm{p}<0.05,{ }^{*} \mathrm{p}<0.1$. 
Table A.13: Effect of Supporting the Winning Party on Public Sector Outcomes - Winning versus Losing Candidates

\begin{tabular}{lccccc}
\hline & $(1)$ & $(2)$ & & $(3)$ & $(4)$ \\
Dependent Variable: & \multicolumn{2}{c}{ Employed Public } & & \multicolumn{2}{c}{ Earnings Public } \\
\cline { 2 - 3 } \cline { 5 - 6 } Type of Candidates: & Winners & Losers & & Winners & Losers \\
\hline Mayor & $0.025^{* * *}$ & $0.148^{* * *}$ & & $484.187^{* * *}$ & $1,585.560^{* * *}$ \\
& $(0.008)$ & $(0.006)$ & & $(125.306)$ & $(84.017)$ \\
& & & & & \\
Observations & 160,918 & 705,352 & & 160,918 & 705,352 \\
R-squared & 0.457 & 0.372 & & 0.422 & 0.245 \\
Mean D.V. Runner-up & 0.259 & 0.237 & & 3199 & 2420 \\
Supporters & 41841 & 196802 & & 41841 & 196802 \\
Elections & 5322 & 5412 & & 5322 & 5412 \\
\hline
\end{tabular}

Notes: The table presents the estimated coefficients of $\beta$ from equation (1.1). The dependent variable is an indicator for employment in the public sector (columns 1-2) and public sector earnings (columns 3-4). Results in columns (1) and (3) are estimated on the sample of candidates to the council who won a seat in the council. Results in columns (2) and (4) are estimated on the sample of candidates to the council who did not win a seat. See section 1.3.3 for a description of the outcome variables. The sample is composed of supporters of the winning mayoral candidate or the close loser, using a 5\% margin of victory to define close races. The sample of elections is 2000, 2004, 2008, 2012. "Mean D.V. Runner-up" shows the average of the dependent variable for the supporters of the runner-up in the post-election period. Robust standard errors are shown in parentheses and are double clustered at the supporter and election level. ${ }^{* * *} \mathrm{p}<0.01,{ }^{* *} \mathrm{p}<0.05,{ }^{*} \mathrm{p}<0.1$.

Table A.14: Effect of Supporting the Winning Party on Public Sector Outcomes - By Type of Contract

\begin{tabular}{|c|c|c|c|c|}
\hline \multirow{3}{*}{$\begin{array}{l}\text { Group of Supporters: } \\
\text { Contract: }\end{array}$} & (1) & (2) & (3) & (4) \\
\hline & \multicolumn{2}{|c|}{ Candidates } & \multicolumn{2}{|c|}{ Donors } \\
\hline & Permanent & Temporary & Permanent & Temporary \\
\hline \multicolumn{5}{|c|}{ Panel A: Dep. Var. is Employment Probability: } \\
\hline Mayor & $\begin{array}{c}0.044^{* * *} \\
(0.004)\end{array}$ & $\begin{array}{c}0.080^{* * *} \\
(0.004)\end{array}$ & $\begin{array}{c}0.023^{* * *} \\
(0.006)\end{array}$ & $\begin{array}{c}0.044^{* * *} \\
(0.005)\end{array}$ \\
\hline R-squared & 0.259 & 0.197 & 0.208 & 0.149 \\
\hline Mean D.V. Runner-up & 0.189 & 0.0520 & 0.140 & 0.0590 \\
\hline \multicolumn{5}{|c|}{ Panel B: Dep. Var. is Earnings: } \\
\hline Mayor & $\begin{array}{l}503.924^{* * *} \\
(62.773)\end{array}$ & $\begin{array}{l}863.320^{* * *} \\
(53.721)\end{array}$ & $\begin{array}{l}313.212^{* *} \\
(139.765)\end{array}$ & $\begin{array}{l}545.484^{* * *} \\
(92.799)\end{array}$ \\
\hline R-squared & 0.169 & 0.141 & 0.148 & 0.103 \\
\hline Mean D.V. Runner-up & 2076 & 486 & 2173 & 760 \\
\hline Observations & 867,888 & 867,888 & 550,832 & 550,832 \\
\hline Supporters & 233238 & 233238 & 177590 & 177590 \\
\hline Elections & 5413 & 5413 & 3162 & 3162 \\
\hline
\end{tabular}

Notes: The table presents the estimated coefficients of $\beta$ from equation (1.1) using as dependent variables an indicator variable equal to one if the supporter is employed in a public sector job (Panel A) and public sector earnings (Panel B). Results in columns (1) and (3) consider positions with a permanent contract, while results in columns (2) and (4) consider temporary contracts. Results in columns (1) and (2) are estimated on the sample of candidates. Results in columns (3) and (4) are estimated on the sample of donors. See section 1.3.3 for a description of the outcome variables. The sample is composed of supporters of the winning mayoral candidate or the close loser, using a $5 \%$ margin of victory to define close races. The sample of elections is 2000, 2004, 2008, 2012 in columns 1, 2, and 2004, 2008, 2012 in column 3, 4. "Mean D.V. Runner-up" shows the average of the dependent variable for the supporters of the runner-up in the post-election period. Robust standard errors are shown in parentheses and are double clustered at the supporter and election level. ${ }^{* *} \mathrm{p}<0.01,{ }^{* *} \mathrm{p}<0.05,{ }^{*} \mathrm{p}<0.1$. 
Table A.15: Effect On Public Sector Outcomes of Gaining versus Losing a Connection

\begin{tabular}{|c|c|c|c|c|c|c|}
\hline \multicolumn{7}{|c|}{ Panel A: Effect of Gaining a Connection } \\
\hline \multirow{3}{*}{$\begin{array}{l}\text { Dependent Variable: } \\
\text { Group of Supporters: }\end{array}$} & (1) & (2) & (3) & $(4)$ & (5) & (6) \\
\hline & \multicolumn{3}{|c|}{ Employed Public } & \multicolumn{3}{|c|}{ Earnings Public } \\
\hline & All & Candidates & Donors & All & Candidates & Donors \\
\hline \multirow[t]{2}{*}{ Mayor*Post } & $0.101^{* * *}$ & $0.129^{* * *}$ & $0.065^{* * *}$ & $1,088.626^{* * *}$ & $1,364.300^{* * *}$ & $743.153^{* * *}$ \\
\hline & $(0.005)$ & $(0.006)$ & $(0.006)$ & $(68.251)$ & $(84.796)$ & $(91.401)$ \\
\hline Observations & $1,695,258$ & 920,516 & 774,742 & $1,695,258$ & 920,516 & 774,742 \\
\hline R-squared & 0.816 & 0.816 & 0.819 & 0.808 & 0.785 & 0.829 \\
\hline Mean D.V. Pre-election & 0.222 & 0.255 & 0.183 & 2458 & 2457 & 2460 \\
\hline Supporters & 228022 & 121064 & 106958 & 228022 & 121064 & 106958 \\
\hline Elections & 4154 & 4147 & 3660 & 4154 & 4147 & 3660 \\
\hline \multicolumn{7}{|c|}{ Panel B: Effect of Losing a Connection } \\
\hline & (1) & (2) & (3) & $(4)$ & (5) & (6) \\
\hline \multirow{2}{*}{$\begin{array}{l}\text { Dependent Variable: } \\
\text { Group of Supporters: }\end{array}$} & \multicolumn{3}{|c|}{ Employed Public } & \multicolumn{3}{|c|}{ Earnings Public } \\
\hline & All & Candidates & Donors & All & Candidates & Donors \\
\hline Loser $*$ Post & $\begin{array}{l}-0.087^{* * *} \\
(0.006)\end{array}$ & $\begin{array}{c}-0.112^{* * *} \\
(0.008)\end{array}$ & $\begin{array}{l}-0.065^{* * *} \\
(0.008)\end{array}$ & $\begin{array}{c}-1,085.737^{* * *} \\
(108.090)\end{array}$ & $\begin{array}{c}-1,395.449^{* * *} \\
(114.296)\end{array}$ & $\begin{array}{l}-828.333^{* * *} \\
(154.034)\end{array}$ \\
\hline Observations & $1,041,564$ & 482,214 & 559,350 & $1,041,564$ & 482,214 & 559,350 \\
\hline R-squared & 0.834 & 0.828 & 0.841 & 0.813 & 0.782 & 0.833 \\
\hline Mean D.V. Pre-election & 0.294 & 0.338 & 0.257 & 3467 & 3425 & 3503 \\
\hline Supporters & 145670 & 65997 & 79673 & 145670 & 65997 & 79673 \\
\hline Elections & 3911 & 3895 & 3144 & 3911 & 3895 & 3144 \\
\hline
\end{tabular}

Notes: The table presents the estimated effects of supporting the mayoral candidate who wins (Panel A) or loses (Panel B) from a more parsimonious version of equation 1.3, in which the indicator variable Mayor is interacted with the variable Post, an indicator taking value one for the post-election period, instead of an indicator variable for each period in the window $[-3,+4]$ around the election year. The dependent variable is an indicator for employment in the public sector (columns 1-3) and public sector earnings (columns 4-6). Results in columns (1) and (4) are estimated on the sample of all supporters. Results in columns (2) and (5) are estimated on the sample of candidates to the local council, and results in columns (3) and (6) are estimated on the sample of donors. See section 1.3.3 for a description of the outcome variables. The sample is composed of supporters of the winning mayoral candidate or the close loser, using a $5 \%$ margin of victory to define close races. The sample of elections is 2004, 2008, 2012. "Mean D.V. Pre-election" shows the average of the dependent variable in the four periods from $t=-3$ to $t=0$. Robust standard errors are shown in parentheses and are double clustered at the supporter and election level. ${ }^{* * *} \mathrm{p}<0.01,{ }^{* *} \mathrm{p}<0.05,{ }^{*} \mathrm{p}<0.1$.

Table A.16: Comparison of RDD and DID Estimates

\begin{tabular}{lcccccc}
\hline & $(1)$ & $(2)$ & & $(3)$ & $(4)$ \\
\hline Supporters: & \multicolumn{2}{c}{ Candidates } & & \multicolumn{2}{c}{ Donors } \\
\cline { 2 - 3 } \cline { 6 - 7 } Estimation: & RDD & DID & & RDD & DID \\
\hline Treatment Effect $\left(\beta / \beta^{D I D}\right)$ & $0.129^{* * *}$ & $0.103^{* * *}$ & & $0.065^{* * *}$ & $0.064^{* * *}$ \\
& $(0.006)$ & $(0.003)$ & & $(0.006)$ & $(0.003)$ \\
Observations (millions) & 0.921 & 199.997 & & 0.775 & 177.464 \\
R-squared & 0.816 & 0.575 & & 0.819 & 0.582 \\
\hline
\end{tabular}

Notes: The table presents a comparison of the estimated coefficient $\beta$ from columns 2 and 3 of Panel A of Table A.15 (columns 1 and 3), and the estimated coefficient $\beta^{D I D}$ from the difference-in-differences specification (1.5) (columns 2 and 4). Results in columns (1) and (2) are estimated on the sample of candidates to the local council, and results in columns (3) and (4) are estimated on the sample of donors. See section 1.3.3 for a description of the outcome variables. The sample of elections is 2004, 2008, 2012. Robust standard errors are shown in parentheses and are double clustered at the supporter and election level. ${ }^{* * *} \mathrm{p}<0.01,{ }^{* *} \mathrm{p}<0.05,{ }^{*} \mathrm{p}<0.1$. 
Table A.17: Effect of Supporting the Winning Party On Public Employment Probability Across the Public Sector Hierarchy - Optimal Bandwidth

\begin{tabular}{lccccc}
\hline & $(1)$ & $(2)$ & $(3)$ & $(4)$ & $(5)$ \\
Dep. Var. is Employment in: & $\begin{array}{c}\text { Managerial } \\
\text { Pob }\end{array}$ & $\begin{array}{c}\text { Profsional } \\
\text { Job }\end{array}$ & $\begin{array}{c}\text { High Skilled } \\
\text { Technical Job }\end{array}$ & $\begin{array}{c}\text { Clerical } \\
\text { Job }\end{array}$ & $\begin{array}{c}\text { Blue } \\
\text { Collar Job }\end{array}$ \\
\hline Panel A: All Supporters & & & & & \\
Mayor & $0.055^{* * *}$ & $0.006^{* * *}$ & $0.003^{* * *}$ & $0.032^{* * *}$ & $0.010^{* * *}$ \\
& $(0.002)$ & $(0.002)$ & $(0.001)$ & $(0.002)$ & $(0.001)$ \\
Observations & $3,006,534$ & $2,250,044$ & $3,003,044$ & $2,028,614$ & $3,152,540$ \\
R-squared & 0.117 & 0.092 & 0.066 & 0.115 & 0.085 \\
Optimal Bandwidth & 14.247 & 9.862 & 14.212 & 8.773 & 15.204 \\
Mean D.V. Runner-up & 0.0280 & 0.0600 & 0.0350 & 0.0510 & 0.0470 \\
Supporters & 874947 & 668631 & 873798 & 605401 & 916056 \\
Elections & 9954 & 7610 & 9942 & 6892 & 10395 \\
Panel B: Candidates & & & & & \\
Mayor & $0.071^{* * *}$ & $0.004^{* * *}$ & $0.004^{* * *}$ & $0.042^{* * *}$ & $0.014^{* * *}$ \\
& $(0.002)$ & $(0.002)$ & $(0.001)$ & $(0.002)$ & $(0.002)$ \\
Observations & $1,261,976$ & $1,450,934$ & $1,722,154$ & $1,195,940$ & $1,436,546$ \\
R-squared & 0.156 & 0.098 & 0.085 & 0.142 & 0.118 \\
Optimal Bandwidth & 11.295 & 13.485 & 17.475 & 10.621 & 13.360 \\
Mean D.V. Runner-up & 0.0270 & 0.0560 & 0.0430 & 0.0530 & 0.0650 \\
Supporters & 346744 & 391993 & 455950 & 330515 & 388528 \\
Elections & 8446 & 9598 & 11284 & 8021 & 9527 \\
Panel C: Donors & & & & & \\
Mayor & $0.034^{* * *}$ & 0.002 & 0.001 & $0.023^{* * *}$ & $0.007^{* * *}$ \\
Observations & $(0.003)$ & $(0.003)$ & $(0.001)$ & $(0.003)$ & $(0.001)$ \\
R-squared & $1,250,480$ & $1,232,936$ & $1,427,312$ & 976,844 & $1,500,722$ \\
Optimal Bandwidth & 0.108 & 0.111 & 0.066 & 0.111 & 0.066 \\
Mean D.V. Runner-up & 11.947 & 11.785 & 14.098 & 8.969 & 15.079 \\
Supporters & 0.0300 & 0.0620 & 0.0270 & 0.0480 & 0.0290 \\
Elections & 398797 & 392489 & 450652 & 313481 & 474197 \\
\hline & 6716 & 6645 & 7523 & 5361 & 7862 \\
\hline
\end{tabular}

Notes: The table presents the estimated coefficients of $\beta$ from equation (1.1) using as dependent variables indicators for employment in the five occupational categories of the public sector. Results in Panel A includes all supporters. Results in Panel B includes only candidates to the local council. Results in Panel C includes only donors. The dependent variables are indicators equal to one if the supporter is employed in the specific occupational category in the public sector. The sample is composed of supporters of the winning mayoral candidate or the close loser, using an outcome- and sample-specific margin of victory to define close races, calculated using the optimal bandwidth selection procedure following Calonico et al. (2014). The sample of elections is 2004, 2008, 2012. "Mean D.V. Runner-up" shows the average of the dependent variable for the supporters of the runner-up in the post-election period. Robust standard errors are shown in parentheses and are double clustered at the supporter and election level. ${ }^{* * *} \mathrm{p}<0.01$, ${ }^{* *} \mathrm{p}<0.05,{ }^{*} \mathrm{p}<0.1$. 


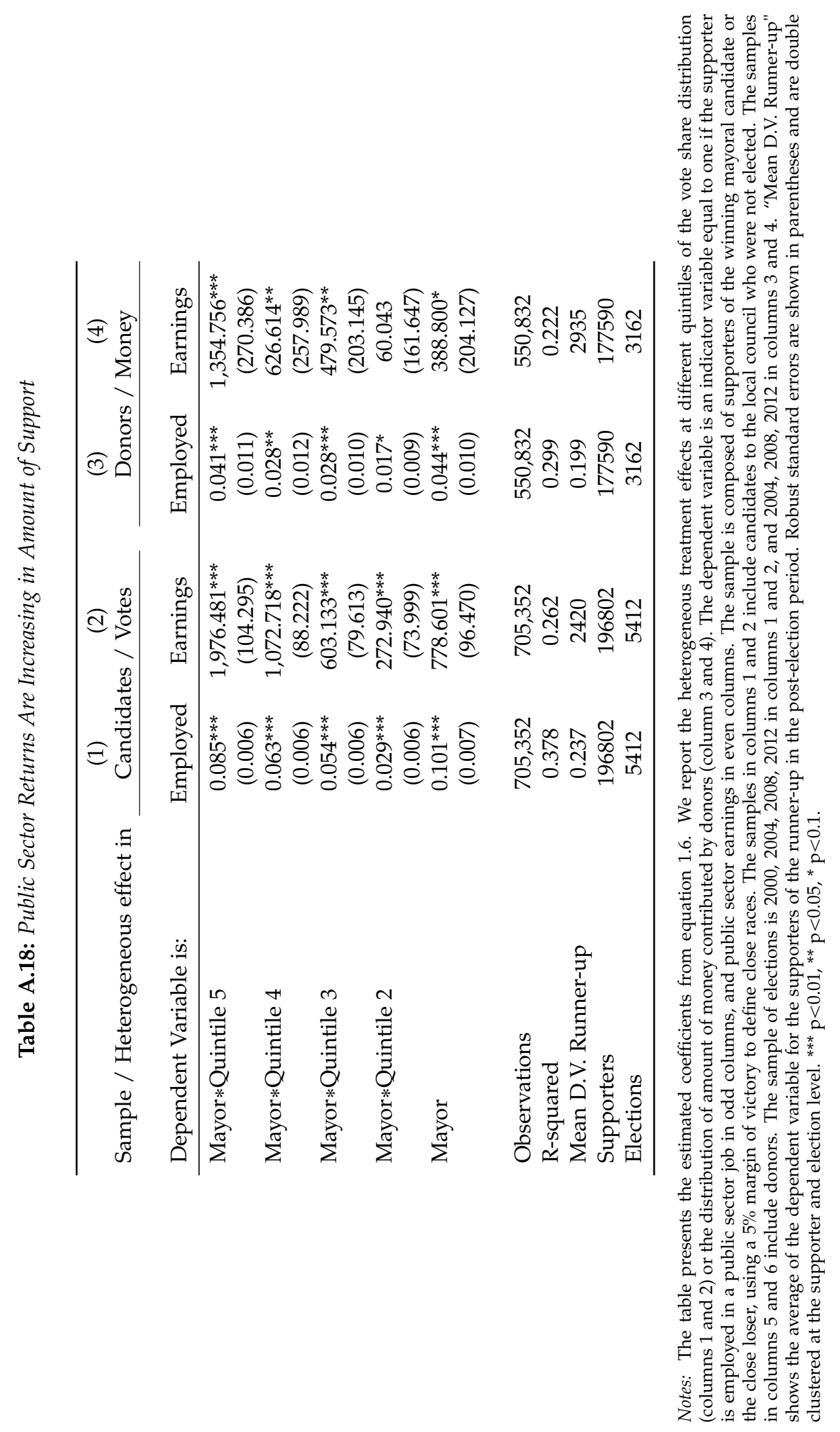


Table A.19: Patronage Decreases the Importance of Education in Public Sector Hiring - Non-Supporters as Control Group

\begin{tabular}{lccc}
\hline & $(1)$ & $(2)$ & $(3)$ \\
$\begin{array}{l}\text { Dep. Var. is Employment } \\
\text { in Public Job Requiring: }\end{array}$ & $\begin{array}{c}\text { Middle } \\
\text { School Degree }\end{array}$ & $\begin{array}{c}\text { High School } \\
\text { School Degree }\end{array}$ & $\begin{array}{c}\text { University } \\
\text { Degree }\end{array}$ \\
\hline & & & \\
Mayor*Qualified*Post & $-0.006^{* *}$ & $-0.035^{* * *}$ & $-0.133^{* * *}$ \\
& $(0.003)$ & $(0.004)$ & $(0.009)$ \\
Mayor*Post & $0.015^{* * *}$ & $0.064^{* * *}$ & $0.087^{* * *}$ \\
& $(0.003)$ & $(0.004)$ & $(0.003)$ \\
Qualified*Post & $-0.004^{* * *}$ & $0.018^{* * *}$ & $0.113^{* * *}$ \\
& $(0.001)$ & $(0.001)$ & $(0.006)$ \\
Observations & & & \\
R-squared & $181,022,074$ & $181,022,074$ & $181,022,074$ \\
Elections & 0.430 & 0.448 & 0.467 \\
\hline
\end{tabular}

Notes: The table presents the estimated coefficients from an augmented version of equation (1.5), where we add the triple interaction between Mayor ${ }_{i m t}$, Post $_{k m t}$ and Qualified ${ }_{i}$, and the double interaction between Post $t_{k m t}$ and Qualified ${ }_{i}$. Dependent variables are indicator for employment in a public sector job that requires a middle school degree (column 1), high school degree (column 2) and university degree (column 3). Qualified ${ }_{i}$ is an indicator taking value one if supporter $i$ has a middle school degree (column 1), high school degree (column 2) and university degree (column 3). The sample of elections is 2004 , 2008, 2012. Robust standard errors are shown in parentheses and are double clustered at the supporter and election level. ${ }^{* * *} \mathrm{p}<0.01,{ }^{* *} \mathrm{p}<0.05,{ }^{*} \mathrm{p}<0.1$. 
Table A.20: Favoritism Stronger for Supporters with Lower Private Sector Opportunities - Non-Supporters as Control Group

\begin{tabular}{lccc}
\hline \multicolumn{4}{c}{ Dep. Var. is Employment in Public Sector } \\
Group of Supporters: & $(1)$ & $(2)$ & $(3)$ \\
All Supporters & Candidates & Donors \\
\hline \multicolumn{4}{c}{ Panel A: Continuous Measure of Previous Private Earnings } \\
Mayor*Post*Private Earnings & $-0.004^{* * *}$ & $-0.006^{* * *}$ & $-0.002^{* * *}$ \\
& $(0.000)$ & $(0.001)$ & $(0.000)$ \\
Mayor*Post & $0.122^{* * *}$ & $0.202^{* * *}$ & $0.184^{* * *}$ \\
& $(0.005)$ & $(0.006)$ & $(0.006)$ \\
R-squared & 0.420 & 0.420 & 0.420 \\
& & & \\
Panel B: Terciles of Previous Private Earnings & & \\
Mayor*Post*Tercile 3 & $-0.049^{* * *}$ & $-0.074^{* * *}$ & $-0.019^{* * *}$ \\
& $(0.006)$ & $(0.010)$ & $(0.007)$ \\
Mayor*Post*Tercile 2 & $-0.019^{* * *}$ & $-0.025^{* *}$ & -0.004 \\
& $(0.006)$ & $(0.010)$ & $(0.007)$ \\
Mayor*Post & $0.138^{* * *}$ & $0.207^{* * *}$ & $0.076^{* * *}$ \\
& $(0.006)$ & $(0.009)$ & $(0.006)$ \\
& & & \\
R-squared & 0.420 & 0.420 & 0.420 \\
Observations & $119,464,782$ & $119,374,559$ & $119,395,105$ \\
Elections & 3067 & 3067 & 3063 \\
\hline
\end{tabular}

Notes: The table presents the estimated coefficients from an augmented version of equation (1.5). In Panel A we add

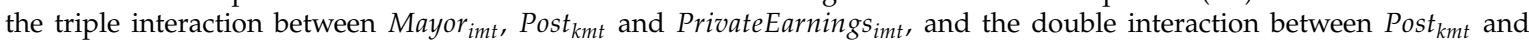
PrivateEarnings $_{i m t}$. In Panel B we add the triple interactions between Mayor $_{\text {imt }}$, Post kmt $_{\text {t }}$ and Tercile $2_{\text {imt }}$, and between Mayor $_{i m t}$, Post $t_{k m t}$ and Tercile $3_{i m t}$, and the double interaction between Post $t_{k m t}$ and Tercile $2_{i m t}$ and between Post $t_{k m t}$ and Tercile $3_{\text {imt }}$. The dependent variable in all columns is an indicator for employment in the public sector. The sample of elections is 2004, 2008, 2012. Robust standard errors are shown in parentheses and are double clustered at the supporter and election level. ${ }^{* * *} \mathrm{p}<0.01,{ }^{* *} \mathrm{p}<0.05,{ }^{*} \mathrm{p}<0.1$. 
Table A.21: Effect of Supporting the Winning Party Among Switchers and Loyals

Dep. Var. is Employment in Public Sector

(1)

(2)

\begin{tabular}{lcc} 
Type of Supporter: & Loyals to Party & Party Switchers \\
\hline Panel A: Candidates & & \\
Mayor & $0.145^{* * *}$ & $0.143^{* * *}$ \\
& $(0.018)$ & $(0.022)$ \\
& & \\
Observations & 37,586 & 25,326 \\
R-squared & 0.487 & 0.506 \\
Mean D.V. Runner-up & 0.251 & 0.266 \\
Supporters & 10702 & 7093 \\
Elections & 1949 & 1515 \\
& & \\
Panel B: Donors & & \\
Mayor & 0.069 & $0.144^{* *}$ \\
& $(0.062)$ & $(0.065)$ \\
& & \\
Observations & 2,746 & 3,374 \\
R-squared & 0.539 & 0.535 \\
Mean D.V. Runner-up & 0.335 & 0.313 \\
Supporters & 1162 & 1378 \\
Elections & 160 & 263 \\
\hline
\end{tabular}

Notes: The table presents the estimated coefficients $\beta$ from equation (1.1) using as dependent variables an indicator variable equal to one if the supporter is employed in a public sector job, for different subsample of candidates/donors who have run/donated in subsequent elections. "Loyals Party" refer to candidates (respectively, donors) who in the previous election run in (respectively, donated to) the same party of the mayoral candidate supported in the current election. "Party Switchers" refer to candidates (respectively, donors) who in the previous election run in (respectively, donated to) a different party than the one of the mayoral candidate supported in the current election. Results in Panel A are estimated on the sample of candidates. Results in Panel B are estimated on the sample of donors. The sample is restricted to supporters of the winning mayoral candidate or the close loser, using a 5\% margin of victory to define close races. The sample of elections is 2004, 2008, 2012 for candidates and 2008 and 2012 for donors. "Mean D.V. Runner-up" shows the average of the dependent variable for the supporters of the runner-up in the post-election period. Robust standard errors are shown in parentheses and are double clustered at the supporter and election level. ${ }^{* * *} \mathrm{p}<0.01,{ }^{* *} \mathrm{p}<0.05,{ }^{*} \mathrm{p}<0.1$. 


\section{Appendix B}

\section{Appendix to Chapter 2}

\section{B.1 Data Sources and Description of Variables}

The DHS surveys used in the analysis are: Benin 1996; Benin 2001; Benin 2006; Benin 2012; Burkina Faso 1993; Burkina Faso 1998; Burkina Faso 2003; Burkina Faso 2010; Cameroon 1998; Cameroon 2004; Cameroon 2011; Central African Republic 1994; Cote D'Ivoire 1998; Cote D'Ivoire 2005; Cote D’Ivoire 2011; DRC 2007; Ghana 1993; Ghana 1998; Ghana 2003; Ghana 2008; Ghana 2014; Guinea 1999; Guinea 2005; Guinea 2012; Kenya 1993; Kenya 1998; Kenya 2003; Kenya 2008; Kenya 2014; Liberia 2013; Malawi 2000; Malawi 2004; Malawi 2010; Mali 1995; Mali 2001; Mali 2006; Mali 2013; Mozambique 1997; Mozambique 2011; Namibia 1992; Namibia 2000; Niger 1992; Niger 1998; Niger 2006; Nigeria 2008; Nigeria 2013; Senegal 2005; Senegal 2010; Senegal 2012; Senegal 2014; Sierra Leone 2008; Sierra Leone 2013; Togo 1998; Togo 2013; Uganda 1995; Uganda 2011; Zambia 1992; Zambia 1996; Zambia 2001; Zambia 2007; Zambia 2013.

The main analysis uses the "Individual Recode" datasets. The falsification test using men's employment probability uses the "Men's Recode" datasets, for the surveys for which this dataset is available. Data on the coordinates of the respondent's location is taken, for the surveys for which this is available, from the "Geographic Datasets". Information on the ethnicity of a woman's husband is taken, for the surveys for which this is available, from 
the "Couples' Recode" datasets.

The Afrobarometer surveys used in the analysis are: Benin (rounds 3, 4, 5, 6); Burkina Faso (rounds 4, 5, 6); Botwsana (rounds 3, 4); Cameroon (rounds 5, 6); Cote D'Ivoire (rounds 5, 6); Gabon (round 6); Ghana (rounds 3, 4, 5, 6); Guinea (rounds 5, 6); Kenya (rounds 3, 4, 5, 6); Liberia (rounds 4, 5, 6); Madagascar (rounds 3, 4, 5, 6); Mali (rounds 3, 4, 5, 6); Malawi (rounds 4, 5, 6); Mozambique (rounds 3, 4, 5, 6); Namibia (rounds 3, 4, 5, 6); Niger (rounds 5, 6); Nigeria (rounds 3, 4, 5, 6); South Africa (rounds 3, 4, 5, 6); Senegal (rounds 3, 4, 5, 6); Sierra Leone (rounds 5, 6); Tanzania (rounds 3, 4, 5, 6); Togo (rounds 5, 6); Uganda (rounds 3, 4, 5, 6); Zambia (rounds 3, 4, 5, 6); Zimbabwe (rounds 3, 4, 5, 6).

Description of the variables used in the paper:

- Transatlantic Trade: Number of slaves taken from the respondent's ethnic group in the transatlantic slave trade, divided by the area of land historically inhabited by the group. The variable is winsorized the $5 \%$ level: for the ethnic groups with values in the top $5 \%$ of the distribution of this variable, the variable takes the value of the $95 \%$ percentile. Source: Nunn and Wantchekon (2011).

- Indian Ocean Trade: Number of slaves taken from the respondent's ethnic group in the Indian Ocean slave trade, divided by the area of land historically inhabited by the group (variable winsorized at the 5\% level). Source: Nunn and Wantchekon (2011).

- Transatlantic Trade Husband: Number of slaves taken from the woman's husband's ethnic group in the transatlantic slave trade, divided by the area of land historically inhabited by the group (variable winsorized the $5 \%$ level). Source: Nunn and Wantchekon (2011).

- Indian Ocean Trade Husband: Number of slaves taken from the woman's husband's ethnic group in the Indian Ocean slave trade, divided by the area of land historically inhabited by the group (variable winsorized at the 5\% level). Source: Nunn and Wantchekon (2011). 
- In(1+Transatlantic/Area): Logarithm of 1 plus the number of slaves taken from the respondent's ethnic group in the transatlantic slave trade divided by the area of land historically inhabited by the group. Source: Nunn and Wantchekon (2011).

- In(1+Indian Ocean/Area): Logarithm of 1 plus the number of slaves taken from the respondent's ethnic group in the Indian Ocean slave trade divided by the area of land historically inhabited by the group. Source: Nunn and Wantchekon (2011).

- FLFP (in the DHS): dummy taking value one if the respondent is employed or has ever been employed in the past 12 months. Source: DHS.

- FLFP (in the Afrobarometer): dummy taking value one if the respondent is currently employed (full time or part time) in a job that pays cash income. Source: Afrobarometer.

- Agriculture: dummy taking value one if the respondent is employed in agriculture. Source: DHS.

- Clerical: dummy taking value one if the respondent is employed in a clerical occupation. Source: DHS.

- Manual: dummy taking value one if the respondent is employed in a manual occupation. Source: DHS.

- Domestic: dummy taking value one if the respondent is employed as domestic servant. Source: DHS.

- High Ranking: dummy taking value one if the respondent is employed in the sales and service sectors, or as professional or manager. Source: DHS.

- Number of Children: number of children ever born. Source: DHS.

- Age First Birth: woman's age when first child was born. Source: DHS. 
- Share HH Decisions: the share of questions on a woman's participation in household decisions for which the woman answers that she has a say in the decision. Questions include decisions regarding: her own health care, large household purchases, daily household purchases, and visits to family and friends. Since the answer to some of these questions can be missing for some respondent, this variable should be intended as the share of decisions for which the woman has a say among the decisions for which we have non-missing information. Source: DHS.

- Share Violence: the share of questions on attitudes towards domestic violence for which the woman answers that it is justified for a husband to beat his wife. Questions include the following: in the case she goes out without telling him, if she neglects the children, if she argues with the partner, if she refuses to have sex, if she burns the food. Since the answer to some of these questions can be missing for some respondent, this variable should be intended as the share of instances for which the respondent answers that beating is justified among the questions for which we have non-missing information. Source: DHS.

- Women Rights: respondent's agreement on a scale from 1 to 5 with the statement "Women should have the same chance of being elected to political office as men" (the alternative is the statement 'Women have always been subject to traditional laws and customs, and should remain so"). Source: Afrobarometer.

- Women Politics: respondent's agreement on a scale from 1 to 5 with the statement "In our country, women should have equal rights and receive the same treatment as men do" (the alternative is the statement "Men make better political leaders than women, and should be elected rather than women"). Source: Afrobarometer.

- Married: dummy taking value one if respondent is married. Source: DHS.

- Age: age of the respondent. Source: DHS.

- Urban: dummy taking value one if respondent lives in a urban location. Source: DHS. 
- Muslim: dummy taking value one if respondent is Muslim. Source: DHS.

- Christian: dummy taking value one if respondent is Christian. Source: DHS.

- Polygyny: dummy taking value one if respondent has co-wives. Source: DHS.

- Education: respondent's number of years of education (in the DHS), and respondent's highest level of education, ranging from "No formal schooling" to "Post-graduate" (in the Afrobarometer).

- Contact explorer: dummy that takes value one if a European explorer traveled in the land of the ethnic group. The source for explorers' routes is Company (1911). Information on the land historically inhabited by the ethnic group is from Murdock (1959).

- Missions/area: the number of religious missions per square kilometer of an ethnic group's land during the colonial period. The source for the locations of missions is Roome (1924). Information on the land historically inhabited by the ethnic group is from Murdock (1959).

- Cities in 1400: the number of cities with more than 20,000 inhabitants that were present in 1400 on the land inhabited by the ethnic group. The data on the locations of the cities is from Chandler (1987). Information on the land historically inhabited by the ethnic group is from Murdock (1959).

- Malaria index: the malaria ecology of the land that was inhabited by the ethnic group. The data on malaria ecology is from Kiszewski et al. (2004). Information on the land historically inhabited by the ethnic group is from Murdock (1959).

- Railway network: dummy taking value one if a part of the railway network built by the Europeans was on the land of the ethnic group. The source for the location of the railway network is Company (1911). Information on the land historically inhabited by the ethnic group is from Murdock (1959). 
- Precolonial conflicts: the number of conflicts between 1400 and 1700 in the area inhabited by the ethnic group. Data on precolonial conflicts is from Besley and Reynal-Querol (2014). Information on the land historically inhabited by the ethnic group is from Murdock (1959).

- Settlement patterns: precolonial settlement patterns, ranging from fully nomadic to complex settlements. Source: Ethnographic Atlas (variable v30).

- Jurisdictional hierarchies: the number of jurisdictional hierarchies beyond the local community. Source: Ethnographic Atlas (variable v33).

- Distance Saharan route: the minimum distance of the centroid of the land historically inhabited by the ethnic group from the routes of the Saharan trade. Information on the historic locations of routes is from Oliver (2000). Information on the land historically inhabited by the ethnic group is from Murdock (1959).

- Distance Saharan node: the distance of the centroid of the land historically inhabited by the ethnic group from the closest city of the Saharan trade. Information on the historic locations of cities is from Oliver (2000). Information on the land historically inhabited by the ethnic group is from Murdock (1959).

- Hunting dependence: the ethnic group's historical reliance on hunting. Source: Ethnographic Atlas (variable v2)

- Gathering dependence: the ethnic group's historical reliance on gathering. Source: Ethnographic Atlas (variable v1)

- Agricultural Suitability: the average suitability to agriculture of the land historically inhabited by the ethnic group. Agricultural suitability is calculated using data on suitability for barley, foxtail millet, pearl millet, rye, sorghum, and wheat from the FAO's Global Agro-Ecological Zones database (GAEZ). Information on the land historically inhabited by the ethnic group is from Murdock (1959). 
- Domesticated Animals: dummy taking value one if the ethnic group had large domesticated animals. Source: Ethnographic Atlas (variable v40).

- Historical Participation Agriculture: historical female participation in agriculture. The variable takes values from one (only males participated) to 5 (only females participated). Source: Ethnographic Atlas (variable v54).

- Historical distance from coast: distance (in kilometers) of the centroid of the land historically inhabited by the ethnic group to the closest point along the coast. Information on the land historically inhabited by the ethnic group is from Murdock (1959).

- Mover: dummy taking value one if respondent currently lives outside the area of land historically inhabited by her ethnic group. Source for respondent's location: DHS. Information on the land historically inhabited by the ethnic group is from Murdock (1959).

- Distance Homeland: distance (in kilometers) of the location of the respondent from the centroid of the land historically inhabited by the ethnic group. The distance is zero if the variable Mover takes value zero. Source for respondent's location: DHS. Information on the land historically inhabited by the ethnic group is from Murdock (1959). 


\section{B.2 Additional Results}

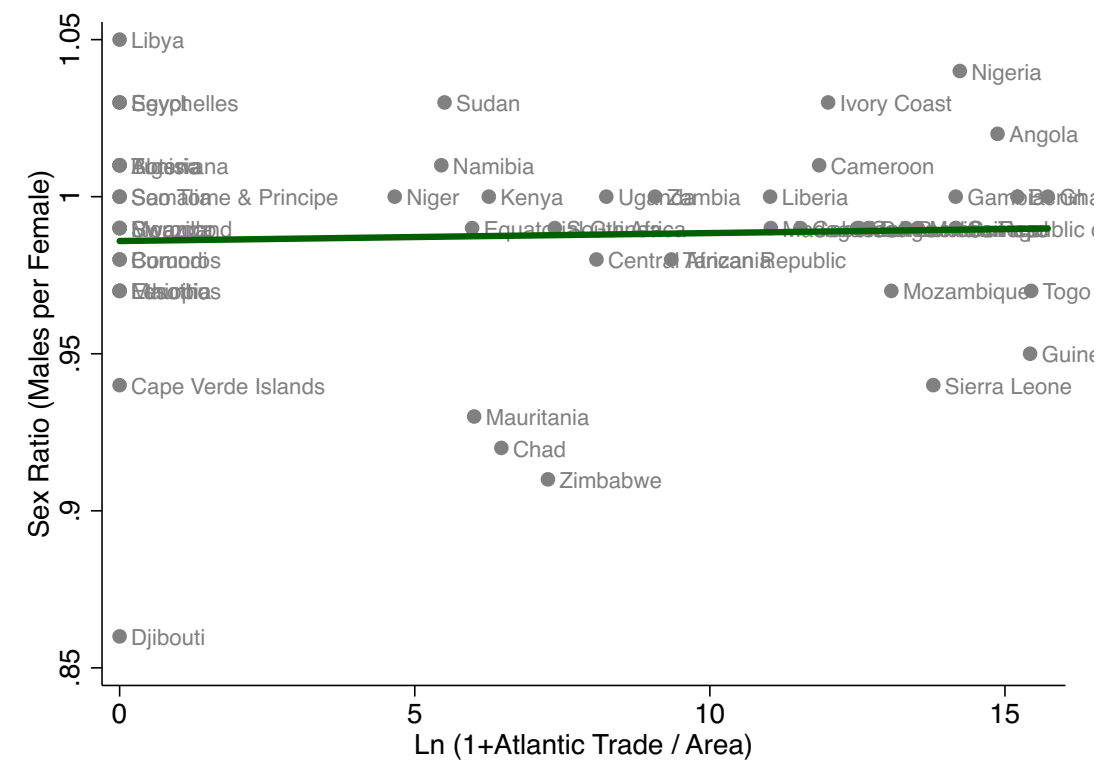

The figure presents the country-level correlation between current sex ratio and exposure to the transatlantic slave trade. Data on sex ratios are from the 2011 CIA World Factbook. Country-level data on the transatlantic slave trade are from Nunn (2008).

Figure B.1: Exposure to the Transatlantic Slave Trade and Current Sex Ratio 
Table B.1: Summary statistics, Women Sample

\begin{tabular}{|c|c|c|c|c|c|}
\hline Variable & Mean & Std. Dev. & Min. & Max. & Obs. \\
\hline \multicolumn{6}{|c|}{ Slave Trade Variables } \\
\hline Transatlantic Trade & 0.446 & 0.564 & 0 & 1.26 & 583562 \\
\hline Indian Ocean Trade & 0.01 & 0.033 & 0 & 0.15 & 583562 \\
\hline Transatlantic Trade Husband & 0.457 & 0.560 & 0 & 1.26 & 113360 \\
\hline Indian Ocean Trade Husband & 0.01 & 0.032 & 0 & 0.15 & 113360 \\
\hline $\ln (1+$ Transatlantic/Area) & 0.663 & 1.06 & 0 & 3.656 & 583562 \\
\hline $\ln (1+$ Indian Ocean/Area) & 0.029 & 0.139 & 0 & 0.999 & 583562 \\
\hline \multicolumn{6}{|c|}{ DHS Variables } \\
\hline FLFP & 0.642 & 0.479 & 0 & 1 & 583562 \\
\hline Agriculture & 0.284 & 0.451 & 0 & 1 & 569134 \\
\hline Clerical & 0.009 & 0.092 & 0 & 1 & 569134 \\
\hline Manual & 0.076 & 0.265 & 0 & 1 & 569134 \\
\hline Domestic & 0.015 & 0.12 & 0 & 1 & 569134 \\
\hline High Ranking & 0.263 & 0.44 & 0 & 1 & 569134 \\
\hline Number of Children & 3.05 & 2.893 & 0 & 24 & 583562 \\
\hline Age First Birth & 18.844 & 3.709 & 6 & 47 & 432851 \\
\hline Share HH Decisions & 0.438 & 0.413 & 0 & 1 & 350841 \\
\hline Share Violence & 0.321 & 0.373 & 0 & 1 & 443115 \\
\hline Married & 0.615 & 0.487 & 0 & 1 & 583562 \\
\hline Age & 28.417 & 9.43 & 15 & 49 & 583562 \\
\hline Urban & 0.357 & 0.479 & 0 & 1 & 583562 \\
\hline Muslim & 0.389 & 0.488 & 0 & 1 & 583562 \\
\hline Christian & 0.542 & 0.498 & 0 & 1 & 583562 \\
\hline Polygyny & 0.317 & 0.465 & 0 & 1 & 400222 \\
\hline Education (years) & 4.027 & 4.447 & 0 & 26 & 583227 \\
\hline \multicolumn{6}{|c|}{ Historical and Geographical Variables (DHS Sample) } \\
\hline Contact explorer & 0.551 & 0.497 & 0 & 1 & 583562 \\
\hline Missions/Area & 0.000166 & 0.000321 & 0 & 0.002644 & 583562 \\
\hline Cities in 1400 & 0.25 & 0.553 & 0 & 2 & 583562 \\
\hline Malaria Index & 18.3 & 9.372 & 0 & 33.95 & 583562 \\
\hline Railway network & 0.333 & 0.471 & 0 & 1 & 583562 \\
\hline Precolonial Conflicts & 0.784 & 2.225 & 0 & 10 & 583562 \\
\hline Settlement patterns & 6.312 & 1.461 & 1 & 8 & 563481 \\
\hline Jurisdictional hierarchies & 1.717 & 0.878 & 0 & 3 & 564323 \\
\hline Distance Saharan route & 1289.88 & 1269.099 & 11.883 & 4709.896 & 583562 \\
\hline Distance Saharan node & 1300.695 & 1259.739 & 113.862 & 4709.896 & 583562 \\
\hline Hunting dependence & 8.44 & 5.974 & 2.5 & 30 & 581843 \\
\hline Gathering dependence & 5.236 & 4.598 & 2.5 & 70 & 581843 \\
\hline Agricultural Suitability & 14.466 & 8.003 & 0 & 36.263 & 583562 \\
\hline Domesticated Animals & 0.968 & 0.175 & 0 & 1 & 564425 \\
\hline Historical Participation Agriculture & 3.013 & 0.953 & 1 & 5 & 470183 \\
\hline Historical distance from coast & 471.151 & 333.048 & 0.208 & 1638.367 & 583562 \\
\hline Mover & 0.578 & 0.494 & 0 & 1 & 473382 \\
\hline Distance Homeland & 140.182 & 265.64 & 0 & 3111.992 & 473382 \\
\hline
\end{tabular}


Table B.1 (continued): Summary statistics, Men Sample

\begin{tabular}{|c|c|c|c|c|c|}
\hline Variable & Mean & Std. Dev. & Min. & Max. & $\mathbf{N}$ \\
\hline \multicolumn{6}{|c|}{ Slave Trade Variables } \\
\hline Transatlantic Trade & 0.455 & 0.564 & 0 & 1.26 & 222970 \\
\hline Indian Ocean Trade & 0.01 & 0.032 & 0 & 0.15 & 222970 \\
\hline \multicolumn{6}{|c|}{ DHS Variables } \\
\hline Male Labor Force Participation & 0.828 & 0.378 & 0 & 1 & 222970 \\
\hline Married & 0.511 & 0.5 & 0 & 1 & 222970 \\
\hline Age & 31.114 & 11.92 & 15 & 97 & 222970 \\
\hline Urban & 0.377 & 0.485 & 0 & 1 & 222970 \\
\hline Muslim & 0.379 & 0.485 & 0 & 1 & 222970 \\
\hline Christian & 0.545 & 0.498 & 0 & 1 & 222970 \\
\hline Education (years) & 5.954 & 4.837 & 0 & 25 & 222664 \\
\hline \multicolumn{6}{|c|}{ Historical and Geographical Variables } \\
\hline Contact explorer & 0.566 & 0.496 & 0 & 1 & 222970 \\
\hline Missions/area & 0.000182 & 0.000352 & 0 & 0.002644 & 222970 \\
\hline Cities in 1400 & 0.243 & 0.556 & 0 & 2 & 222970 \\
\hline Malaria Index & 18.105 & 9.496 & 0 & 33.95 & 222970 \\
\hline Railway network & 0.342 & 0.474 & 0 & 1 & 222970 \\
\hline Precolonial Conflicts & 0.825 & 2.324 & 0 & 10 & 222970 \\
\hline Settlement patterns & 6.345 & 1.439 & 1 & 8 & 216482 \\
\hline Jurisdictional hierarchies & 1.696 & 0.887 & 0 & 3 & 216906 \\
\hline Distance Saharan route & 1287.902 & 1218.813 & 11.883 & 4709.896 & 222970 \\
\hline Distance Saharan node & 1297.305 & 1210.429 & 113.862 & 4709.896 & 222970 \\
\hline Hunting dependence & 8.447 & 6.039 & 2.5 & 30 & 222299 \\
\hline Gathering dependence & 5.111 & 4.502 & 2.5 & 70 & 222299 \\
\hline Agricultural Suitability & 14.723 & 8.169 & 0 & 36.263 & 222970 \\
\hline Domesticated Animals & 0.966 & 0.181 & 0 & 1 & 216969 \\
\hline
\end{tabular}


Table B.1 (continued): Summary statistics, Afrobarometer Women Sample

\begin{tabular}{|c|c|c|c|c|c|}
\hline Variable & Mean & Std. Dev. & Min. & Max. & $\mathbf{N}$ \\
\hline \multicolumn{6}{|c|}{ Slave Trade Variables } \\
\hline Transatlantic Trade & 0.369 & 0.533 & 0 & 1.26 & 55222 \\
\hline Indian Ocean Trade & 0.023 & 0.049 & 0 & 0.15 & 55222 \\
\hline \multicolumn{6}{|c|}{ Afrobarometer Variables } \\
\hline FLFP & 0.3 & 0.458 & 0 & 1 & 55222 \\
\hline Rights Politics & 3.912 & 1.445 & 1 & 5 & 43863 \\
\hline Rights General & 3.927 & 1.409 & 1 & 5 & 26253 \\
\hline Age & 34.704 & 13.134 & 18 & 130 & 55222 \\
\hline Urban & 0.369 & 0.483 & 0 & 1 & 55222 \\
\hline Muslim & 0.253 & 0.434 & 0 & 1 & 55222 \\
\hline Christian & 0.603 & 0.489 & 0 & 1 & 55222 \\
\hline Education & 3.897 & 2.044 & 1 & 10 & 55104 \\
\hline \multicolumn{6}{|c|}{ Historical and Geographical Variables } \\
\hline Contact explorer & 0.471 & 0.499 & 0 & 1 & 55086 \\
\hline Missions / Area & 0 & 0 & 0 & 0.004 & 55086 \\
\hline Cities in 1400 & 0.189 & 0.481 & 0 & 2 & 55086 \\
\hline Malaria Index & 13.85 & 9.77 & 0 & 34.64 & 55086 \\
\hline Railway network & 0.382 & 0.486 & 0 & 1 & 55086 \\
\hline Precolonial Conflicts & 0.721 & 2.036 & 0 & 10 & 55086 \\
\hline Settlement patterns & 6.29 & 1.459 & 1 & 8 & 50790 \\
\hline Jurisdictional hierarchies & 1.843 & 0.951 & 0 & 3 & 50827 \\
\hline Distance Saharan route & 2124.659 & 1578.459 & 15.19 & 5221.349 & 55086 \\
\hline Distance Saharan node & 2130.327 & 1571.67 & 113.862 & 5221.349 & 55086 \\
\hline Hunting dependence & 8.861 & 5.745 & 2.5 & 40 & 54975 \\
\hline Gathering dependence & 5.194 & 7.845 & 2.5 & 80 & 54975 \\
\hline Agricultural suitability & 15.94 & 8.56 & 0 & 39.801 & 55086 \\
\hline Domesticated Animals & 0.967 & 0.178 & 0 & 1 & 50855 \\
\hline
\end{tabular}


Table B.2: OLS estimates, Historical Determinants of FLFP

\begin{tabular}{lcc}
\hline & Coefficient & Standard Error \\
& $(1)$ & $(2)$ \\
\hline Transatlantic Trade & $0.059^{* * *}$ & $(0.013)$ \\
Indian Ocean Trade & -0.061 & $(0.175)$ \\
Contact explorer & -0.025 & $(0.018)$ \\
Missions/area & $46.829^{* *}$ & $(20.717)$ \\
Cities in 1400 & $-0.032^{* *}$ & $(0.014)$ \\
Malaria index & 0.000 & $(0.001)$ \\
Railway network & 0.022 & $(0.018)$ \\
Precolonial conflicts & $-0.014^{* * *}$ & $(0.005)$ \\
Hunting dependence & 0.001 & $(0.001)$ \\
Gathering dependence & $0.003^{* *}$ & $(0.002)$ \\
Agricultural suitability & -0.001 & $(0.001)$ \\
Domesticated Animals & -0.027 & $(0.027)$ \\
Historical Participation Agriculture & -0.003 & $(0.011)$ \\
Settlement patterns 2 & -0.022 & $(0.060)$ \\
Settlement patterns 4 & 0.060 & $(0.040)$ \\
Settlement patterns 5 & 0.043 & $(0.041)$ \\
Settlement patterns 6 & -0.066 & $(0.048)$ \\
Settlement patterns 7 & -0.008 & $(0.041)$ \\
Settlement patterns 8 & -0.050 & $(0.039)$ \\
Jurisdictional hierarchies 1 & 0.016 & $(0.031)$ \\
Jurisdictional hierarchies 2 & 0.016 & $(0.033)$ \\
Jurisdictional hierarchies 3 & 0.044 & $(0.035)$ \\
Distance Saharan route & 0.000 & $(0.000)$ \\
Distance Saharan node & -0.000 & $(0.000)$ \\
Observations & & \\
R-squared & & 470,183 \\
\hline & & 0.178 \\
\hline
\end{tabular}

Notes: Standard errors in parentheses, clustered at the ethnicity level. The unit of observation is a female respondent. The indicator variables for settlement patterns correspond to the following types of patterns: $2=$ "semi nomadic"; $3=$ "semisedentary" (excluded because of collinearity); $4=$ "compact but impermanent settlements"; $5=$ "neighborhoods of dispersed family homes"; $6=$ "separated hamlets, forming a single community"; $7=$ "compact and relatively permanent"; $8=$ "complex settlements"; the excluded category is the indicator equal to 1 ("nomadic or fully migratory"). $* * * * *, *$ indicate significance at the $1 \%, 5 \%$ and $10 \%$ level. 
Table B.3: The Transatlantic Slave Trade and Polygyny

\begin{tabular}{lccc}
\hline \hline & $\begin{array}{c}\text { Polygyny } \\
(1)\end{array}$ & $\begin{array}{c}\text { Polygyny } \\
(2)\end{array}$ & $\begin{array}{c}\text { Polygyny } \\
(3)\end{array}$ \\
\hline Translatlantic Trade & -0.008 & 0.005 & -0.001 \\
& $(0.015)$ & $(0.011)$ & $(0.010)$ \\
Observations & 400,222 & 400,222 & 386,503 \\
R-squared & 0.06 & 0.12 & 0.13 \\
Ethnic Groups & 259 & 259 & 241 \\
Country-survey FE & Yes & Yes & Yes \\
Individual Controls & No & Yes & Yes \\
Historical Controls & No & No & Yes \\
Transatlantic std. dev. & 0.564 & 0.564 & 0.564 \\
Dep. var. mean unaffected & 0.259 & 0.259 & 0.258 \\
\hline
\end{tabular}

Notes: Standard errors in parentheses, clustered at the ethnicity level. The unit of observation is a female respondent. Polygyny is an indicator variable taking value one if the respondent has co-wives. Transatlantic Trade is the number of slaves exported during the transatlantic slave trade normalized by the area of land historically inhabited by the ethnic group. Controls are described in Table 1. "Dep. var. mean unaffected" is the mean value of the dependent variable for the subsample of observations for which Transatlantic Trade is equal to zero. ${ }^{* * *}, * *, *$ indicate significance at the $1 \%, 5 \%$ and $10 \%$ level. 
Table B.4: The effect of the slave trade on FLFP, robustness to different standard errors corrections

\begin{tabular}{lcccccc}
\hline & FLFP & FLFP & FLFP & FLFP & FLFP & FLFP \\
\hline Translatlantic Trade & $0.048^{* * *}$ & $0.054^{* * *}$ & $0.059^{* * *}$ & $0.056^{* * *}$ & $0.073^{* * *}$ & $0.072^{* * *}$ \\
& $(0.013)$ & $(0.011)$ & $(0.013)$ & $(0.011)$ & $(0.012)$ & $(0.012)$ \\
& $\{0.012\}$ & $\{0.009\}$ & $\{0.011\}$ & $\{0.009\}$ & $\{0.011\}$ & $\{0.010\}$ \\
& {$[0.013]$} & {$[0.011]$} & {$[0.013]$} & {$[0.011]$} & {$[0.012]$} & {$[0.012]$} \\
& $\langle 0.009\rangle$ & $\langle 0.010\rangle$ & $\langle 0.011\rangle$ & $\langle 0.010\rangle$ & $\langle 0.011\rangle$ & $\langle 0.010\rangle$ \\
Observations & 583,562 & 563,379 & 470,183 & 563,054 & 386,503 & 386,317 \\
R-squared & 0.16 & 0.17 & 0.18 & 0.18 & 0.14 & 0.14 \\
Ethnic Groups & 261 & 261 & 261 & 261 & 261 & 261 \\
Country-survey FE & Yes & Yes & Yes & Yes & Yes & Yes \\
Individual Controls & Yes & Yes & Yes & Yes & Yes & Yes \\
Historical Controls & No & Yes & Yes & Yes & Yes & Yes \\
Hist. Part. Agriculture & No & No & Yes & No & No & No \\
Education & No & No & No & Yes & Yes & Yes \\
Polygyny & No & No & No & No & Yes & Yes \\
Transatlantic std. dev. & 0.564 & 0.564 & 0.564 & 0.564 & 0.564 & 0.564 \\
Dep. var. mean unaffected & 0.588 & 0.588 & 0.588 & 0.588 & 0.588 & 0.588 \\
\hline
\end{tabular}

Notes: The unit of observation is a female respondent. Standard errors in parentheses are clustered at the ethnicity level as in Table 1. Standard errors in curly brackets are Conley (1999) standard errors adjusted for two-dimensional spatial dependence. Standard errors in square brackets are double clustered at the ethnicity and enumeration area level. Standard errors in angle brackets are clustered by country, using a block bootstrap procedure. FLFP is an indicator variable taking value one if the respondent was ever employed in the last 12 months. Transatlantic Trade is the number of slaves exported during the transatlantic slave trade normalized by the area of land historically inhabited by the ethnic group. Controls are described in Table 1. "Dep. var. mean unaffected" is the mean value of the dependent variable for the subsample of observations for which Transatlantic Trade is equal to zero. ${ }^{* * *},{ }^{* *},{ }^{*}$ indicate significance at the $1 \%, 5 \%$ and $10 \%$ level. 
Table B.5: The effect of the slave trade on FLFP, robustness to other slave trades

\begin{tabular}{lcccccc}
\hline & $\begin{array}{c}\text { FLFP } \\
(1)\end{array}$ & $\begin{array}{c}\text { FLFP } \\
(2)\end{array}$ & $\begin{array}{c}\text { FLFP } \\
(3)\end{array}$ & $\begin{array}{c}\text { FLFP } \\
(4)\end{array}$ & $\begin{array}{c}\text { FLFP } \\
(5)\end{array}$ & $\begin{array}{c}\text { FLFP } \\
(6)\end{array}$ \\
\hline Translatlantic Trade & $0.035^{* * *}$ & $0.052^{* * *}$ & $0.046^{* * *}$ & $0.050^{* * *}$ & $0.061^{* * *}$ & $0.062^{* * *}$ \\
& $(0.011)$ & $(0.012)$ & $(0.016)$ & $(0.013)$ & $(0.014)$ & $(0.014)$ \\
Indian Ocean Trade & 0.054 & -0.069 & 0.054 & -0.035 & -0.036 & -0.031 \\
& $(0.140)$ & $(0.132)$ & $(0.146)$ & $(0.137)$ & $(0.147)$ & $(0.147)$ \\
Observations & 415,243 & 396,378 & 343,779 & 396,155 & 265,179 & 265,057 \\
R-squared & 0.18 & 0.19 & 0.19 & 0.19 & 0.15 & 0.15 \\
Ethnic Groups & 186 & 175 & 127 & 175 & 175 & 175 \\
Country-survey FE & Yes & Yes & Yes & Yes & Yes & Yes \\
Individual Controls & Yes & Yes & Yes & Yes & Yes & Yes \\
Historical Controls & No & Yes & Yes & Yes & Yes & Yes \\
Hist. Part. Agriculture & No & No & Yes & No & No & No \\
Education & No & No & No & Yes & No & Yes \\
Polygyny & No & No & No & No & Yes & Yes \\
Transatlantic std. dev. & 0.560 & 0.560 & 0.565 & 0.560 & 0.562 & 0.562 \\
Indian Ocean std. dev. & 0.035 & 0.033 & 0.035 & 0.033 & 0.033 & 0.033 \\
Dep. var. mean unaffected & 0.598 & 0.596 & 0.598 & 0.596 & 0.650 & 0.650 \\
\hline
\end{tabular}

Notes: Standard errors in parentheses, clustered at the ethnicity level. The unit of observation is a female respondent. The sample is restricted to surveys from countries that were not strongly exposed to the trans-Saharan and Red Sea slave trades, i.e. Mali, Kenya, Niger, Nigeria. FLFP is an indicator variable taking value one if the respondent was ever employed in the last 12 months. Transatlantic Trade is the number of slaves exported during the transatlantic slave trade normalized by the area of land historically inhabited by the ethnic group. Indian Ocean trade is the number of slaves exported during the Indian Ocean slave trade normalized by the area of land historically inhabited by the ethnic group. Controls are described in Table 1. "Dep. var. mean unaffected" is the mean value of the dependent variable for the subsample of observations for which Transatlantic Trade is equal to zero. ${ }^{* *},{ }^{* *}, *$ indicate significance at the $1 \%, 5 \%$ and $10 \%$ level. 
Table B.6: The effect of the slave trade on FLFP, Afrobarometer sample

\begin{tabular}{lccc}
\hline & $\begin{array}{c}\text { FLFP } \\
(1)\end{array}$ & $\begin{array}{c}\text { FLFP } \\
(2)\end{array}$ & $\begin{array}{c}\text { FLFP } \\
(3)\end{array}$ \\
\hline Translatlantic Trade & $0.035^{* * *}$ & $0.047^{* * *}$ & $0.045^{* * *}$ \\
& $(0.013)$ & $(0.010)$ & $(0.010)$ \\
Indian Ocean Trade & 0.147 & 0.266 & 0.221 \\
& $(0.186)$ & $(0.216)$ & $(0.222)$ \\
Observations & 55,222 & 50,762 & 50,668 \\
R-squared & 0.15 & 0.17 & 0.20 \\
Ethnic Groups & 313 & 286 & 286 \\
Country-survey FE & Yes & Yes & Yes \\
Individual Controls & Yes & Yes & Yes \\
Historical Controls & No & Yes & Yes \\
Education & No & No & Yes \\
Transatlantic std. dev. & 0.533 & 0.531 & 0.531 \\
Indian Ocean std. dev. & 0.049 & 0.042 & 0.042 \\
Dep. var. mean unaffected & 0.313 & 0.311 & 0.311 \\
\hline
\end{tabular}

Notes: Standard errors in parentheses, clustered at the ethnicity level. The unit of observation is a female respondent. FLFP is an indicator variable taking value one if the respondent is employed. Transatlantic Trade is the number of slaves exported during the transatlantic slave trade normalized by the area of land historically inhabited by the ethnic group. Indian Ocean trade is the number of slaves exported during the Indian Ocean slave trade normalized by the area of land historically inhabited by the ethnic group. Individual controls include age fixed effects, a dummy for the respondent being Christian, a dummy for the respondent being Muslim, and a dummy for the respondent living in an urban location. Historical controls are as in Table 1. "Dep. var. mean unaffected" is the mean value of the dependent variable for the subsample of observations for which Transatlantic Trade is equal to zero. ${ }^{* * *},{ }^{* *},{ }^{*}$ indicate significance at the $1 \%, 5 \%$ and $10 \%$ level. 


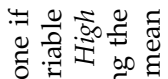

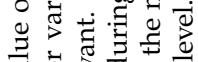

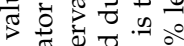

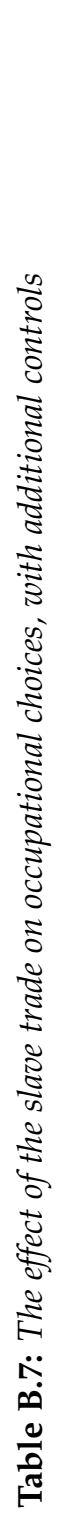

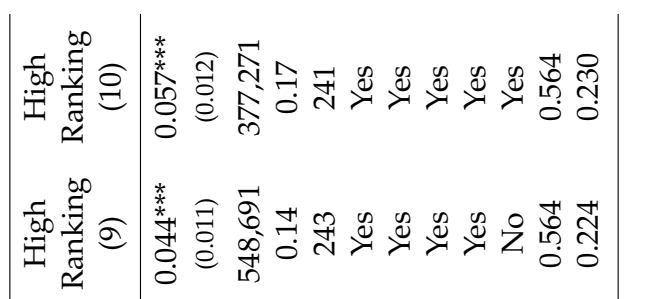

政.

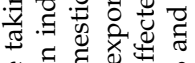

政

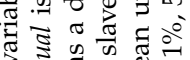

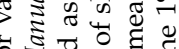

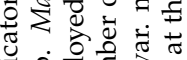

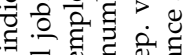

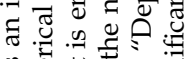

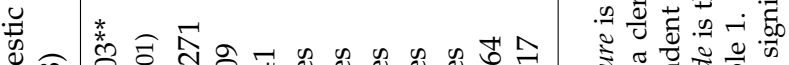

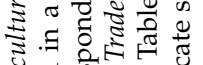

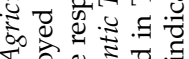

$<$ 응

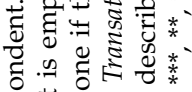

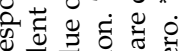

胥

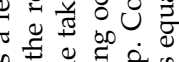

.90

胥

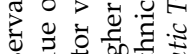

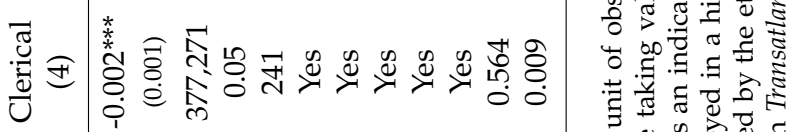

वृ.

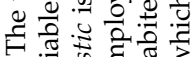

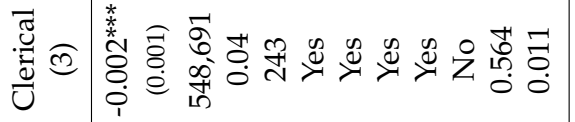

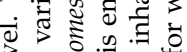

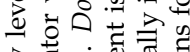

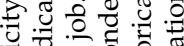

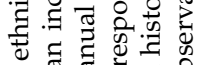

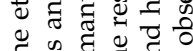

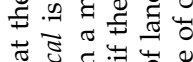

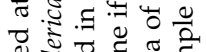

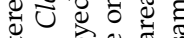

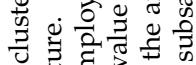

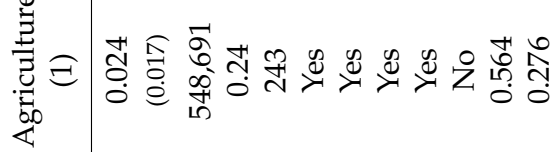

is

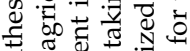

돈

\% व

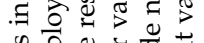

कू

वे व.

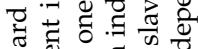

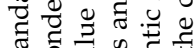

के के

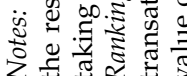


Table B.8: The effect of the slave trade on FLFP, alternative slave trade measure

\begin{tabular}{lcccccc}
\hline & FLFP & FLFP & FLFP & FLFP & FLFP & FLFP \\
& $(1)$ & $(2)$ & $(3)$ & $(4)$ & $(5)$ & $(6)$ \\
\hline $\ln (1+$ Translatlantic/Area $)$ & $0.025^{* * *}$ & $0.024^{* * *}$ & $0.029^{* * *}$ & $0.025^{* * *}$ & $0.037^{* * *}$ & $0.036^{* * *}$ \\
& $(0.007)$ & $(0.006)$ & $(0.008)$ & $(0.006)$ & $(0.008)$ & $(0.008)$ \\
$\ln (1+$ Indian Ocean/Area) & $-0.047^{*}$ & -0.038 & -0.009 & -0.043 & -0.054 & -0.049 \\
& $(0.025)$ & $(0.029)$ & $(0.036)$ & $(0.031)$ & $(0.037)$ & $(0.036)$ \\
Observations & 583,562 & 563,379 & 470,183 & 563,054 & 386,503 & 386,317 \\
R-squared & 0.16 & 0.17 & 0.18 & 0.18 & 0.14 & 0.14 \\
Ethnic Groups & 261 & 243 & 170 & 243 & 241 & 241 \\
Country-survey FE & Yes & Yes & Yes & Yes & Yes & Yes \\
Individual Controls & Yes & Yes & Yes & Yes & Yes & Yes \\
Historical Controls & No & Yes & Yes & Yes & Yes & Yes \\
Hist. Part. Agriculture & No & No & Yes & No & No & No \\
Education & No & No & No & Yes & No & Yes \\
Polygyny & No & No & No & No & Yes & Yes \\
Transatlantic std. dev. & 1.060 & 1.073 & 1.142 & 1.073 & 1.056 & 1.056 \\
Indian Ocean std. dev. & 0.139 & 0.141 & 0.153 & 0.141 & 0.140 & 0.140 \\
Dep. var. mean unaffected & 0.588 & 0.586 & 0.589 & 0.586 & 0.635 & 0.635 \\
\hline
\end{tabular}

Notes: Standard errors in parentheses, clustered at the ethnicity level. The unit of observation is a female respondent. FLFP is an indicator variable taking value one if the respondent was ever employed in the last 12 months. $\ln (1+$ Translatlantic/Area) is the log of one plus the number of slaves exported during the transatlantic slave trade normalized by the area of land historically inhabited by the ethnic group. In(1+Indian Ocean/Area) is the log of one plus the number of slaves exported during the Indian Ocean slave trade normalized by the area of land historically inhabited by the ethnic group. Controls are described in Table 1. "Dep. var. mean unaffected" is the mean value of the dependent variable for the subsample of observations for which $\ln (1+$ Transatlantic/Area $)$ is equal to zero. ${ }^{* * *},{ }^{* *},{ }^{*}$ indicate significance at the $1 \%, 5 \%$ and $10 \%$ level. 
Table B.9: The effect of the slave trade on occupational choices, alternative slave trade measure

\begin{tabular}{lccccc}
\hline & $\begin{array}{c}\text { Agriculture } \\
(1)\end{array}$ & $\begin{array}{c}\text { Clerical } \\
(2)\end{array}$ & $\begin{array}{c}\text { Manual } \\
(3)\end{array}$ & $\begin{array}{c}\text { Domestic } \\
(4)\end{array}$ & $\begin{array}{c}\text { High Ranking } \\
(5)\end{array}$ \\
\hline $\ln (1+$ Translatlantic/Area) & -0.001 & -0.000 & -0.004 & $-0.003^{* * *}$ & $0.030^{* * *}$ \\
& $(0.008)$ & $(0.000)$ & $(0.003)$ & $(0.001)$ & $(0.005)$ \\
Observations & 549,009 & 549,009 & 549,009 & 549,009 & 549,009 \\
R-squared & 0.23 & 0.02 & 0.05 & 0.07 & 0.14 \\
Ethnic Groups & 243 & 243 & 243 & 243 & 243 \\
Country-survey FE & Yes & Yes & Yes & Yes & Yes \\
Individual Controls & Yes & Yes & Yes & Yes & Yes \\
Historical Controls & Yes & Yes & Yes & Yes & Yes \\
Transatlantic std. dev. & 1.076 & 1.076 & 1.076 & 1.076 & 1.076 \\
Dep. var. mean unaffected & 0.276 & 0.011 & 0.061 & 0.026 & 0.224 \\
\hline
\end{tabular}

Notes: Standard errors in parentheses, clustered at the ethnicity level. The unit of observation is a female respondent. Agriculture is an indicator variable taking value one if the respondent is employed in agriculture. Clerical is an indicator variable taking value one if the respondent is employed in a clerical job. Manual is an indicator variable taking value one if the respondent is employed in a manual job. Domestic is an indicator variable taking value one if the respondent is employed as a domestic servant. High Ranking is an indicator variable taking value one if the respondent is employed in a higher ranking occupation. $\ln (1+$ Translatlantic/Area $)$ is the log of one plus the number of slaves exported during the transatlantic slave trade normalized by the area of land historically inhabited by the ethnic group. Controls are described in Table 1. "Dep. var. mean unaffected" is the mean value of the dependent variable for the subsample of observations for which $\ln (1+$ Transatlantic/Area $)$ is equal to zero. ${ }^{* * *},{ }^{* *},{ }^{*}$ indicate significance at the $1 \%, 5 \%$ and $10 \%$ level. 


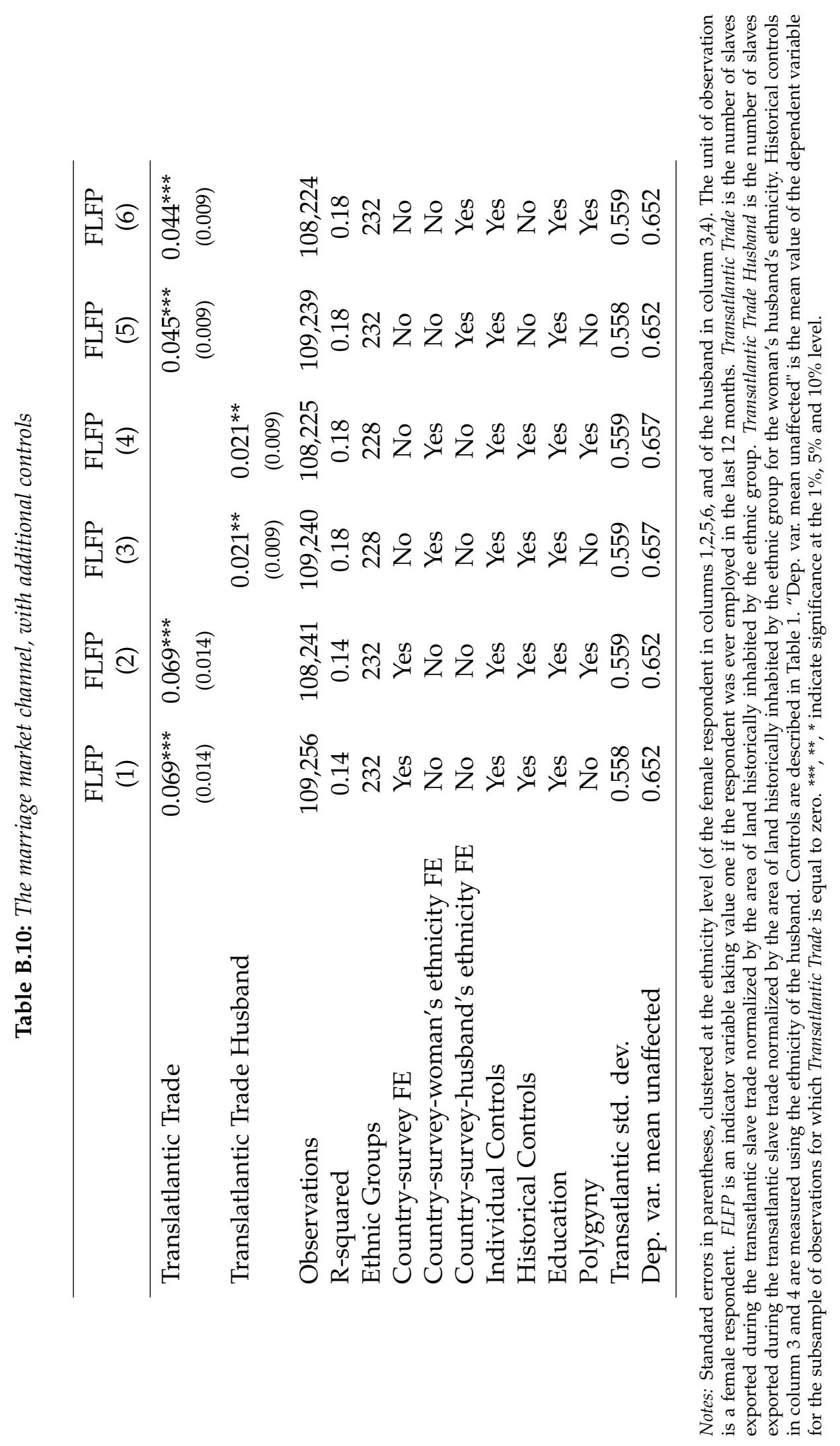


Table B.12: The cultural transmission channel, heterogeneous effects in "mover" status

\begin{tabular}{lcccc}
\hline & Mover & FLFP & FLFP & FLFP \\
& $(1)$ & $(2)$ & $(3)$ & $(4)$ \\
\hline Translatlantic Trade & $-0.155^{* * *}$ & $0.059^{* * *}$ & $0.027^{* * *}$ & $0.028^{* * *}$ \\
& $(0.042)$ & $(0.013)$ & $(0.005)$ & $(0.005)$ \\
Translatlantic Trade X Mover & & -0.006 & & \\
& & $(0.014)$ & & \\
Observations & 456,461 & 456,716 & 456,461 & 260,187 \\
R-squared & 0.77 & 0.17 & 0.32 & 0.33 \\
Ethnic Groups & 235 & 235 & 235 & 235 \\
FE & EA-survey & Country-survey & EA-survey & EA-survey \\
Individual Controls & Yes & Yes & Yes & Yes \\
Historical Controls & Yes & Yes & Yes & Yes \\
Distance Homeland & No & No & Yes & Yes \\
Transatlantic std. dev. & 0.569 & 0.569 & 0.569 & 0.548 \\
Dep. var. mean unaffected & 0.681 & 0.593 & 0.593 & 0.589 \\
\hline
\end{tabular}

Notes: Standard errors in parentheses, clustered at the ethnicity level. The unit of observation is a female respondent. Mover is an indicator variable taking value one if the respondent currently lives outside of the ethnic homeland of her ancestors. FLFP is an indicator variable taking value one if the respondent was ever employed in the last 12 months. Transatlantic Trade is the number of slaves exported during the transatlantic slave trade normalized by the area of land historically inhabited by the ethnic group. In column 4 the sample is restricted to "movers". Distance Homeland is the distance of the respondent's current location from the centroid of the land historically inhabited by her ethnic group. The specification in column 2 also includes the dummy Mover. The additional individual and historical controls are described in Table 1. "Dep. var. mean unaffected" is the mean value of the dependent variable for the subsample of observations for which Transatlantic Trade is equal to zero. ${ }^{* * *},{ }^{* *},{ }^{*}$ indicate significance at the $1 \%, 5 \%$ and $10 \%$ level. 


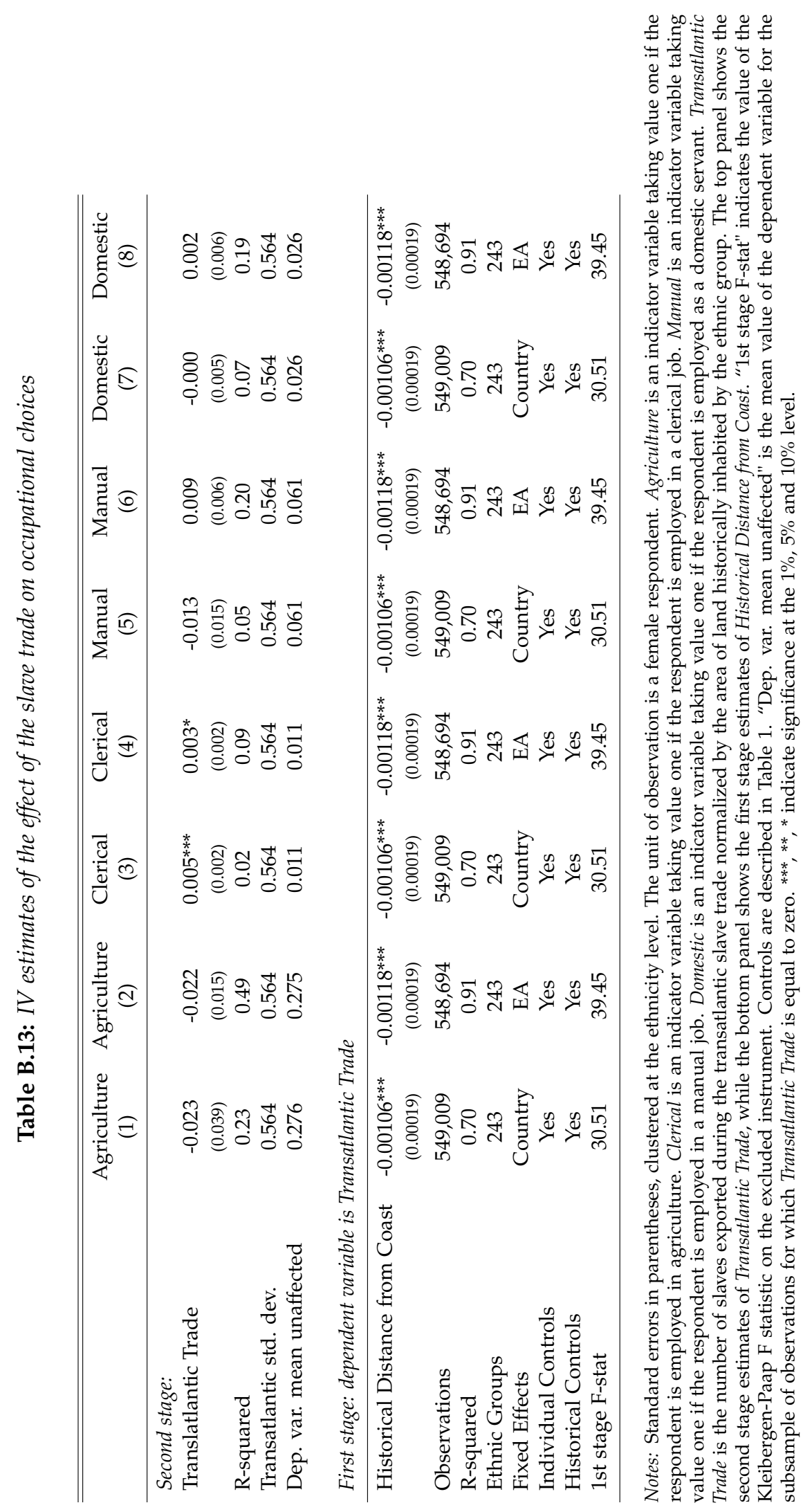




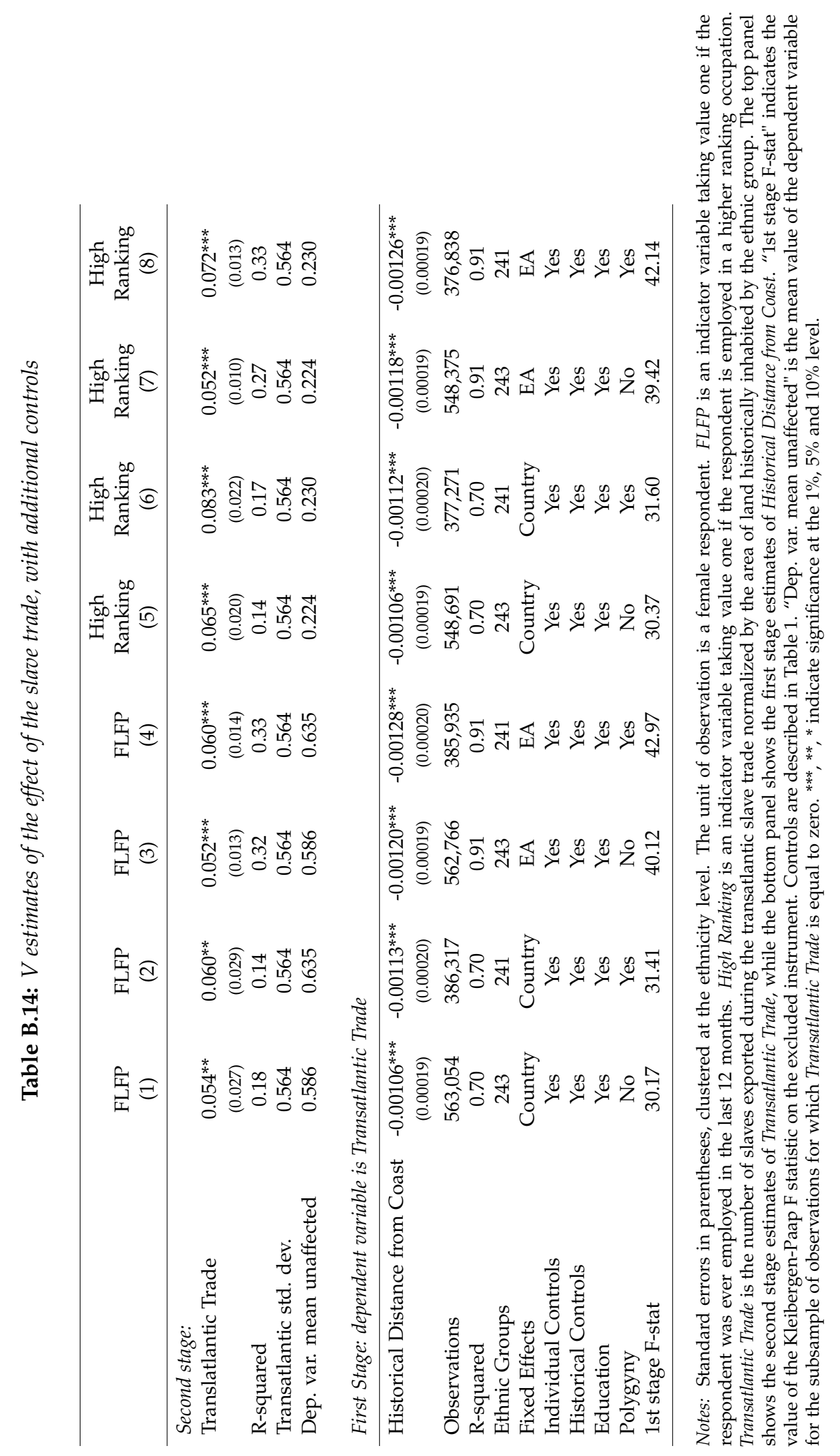




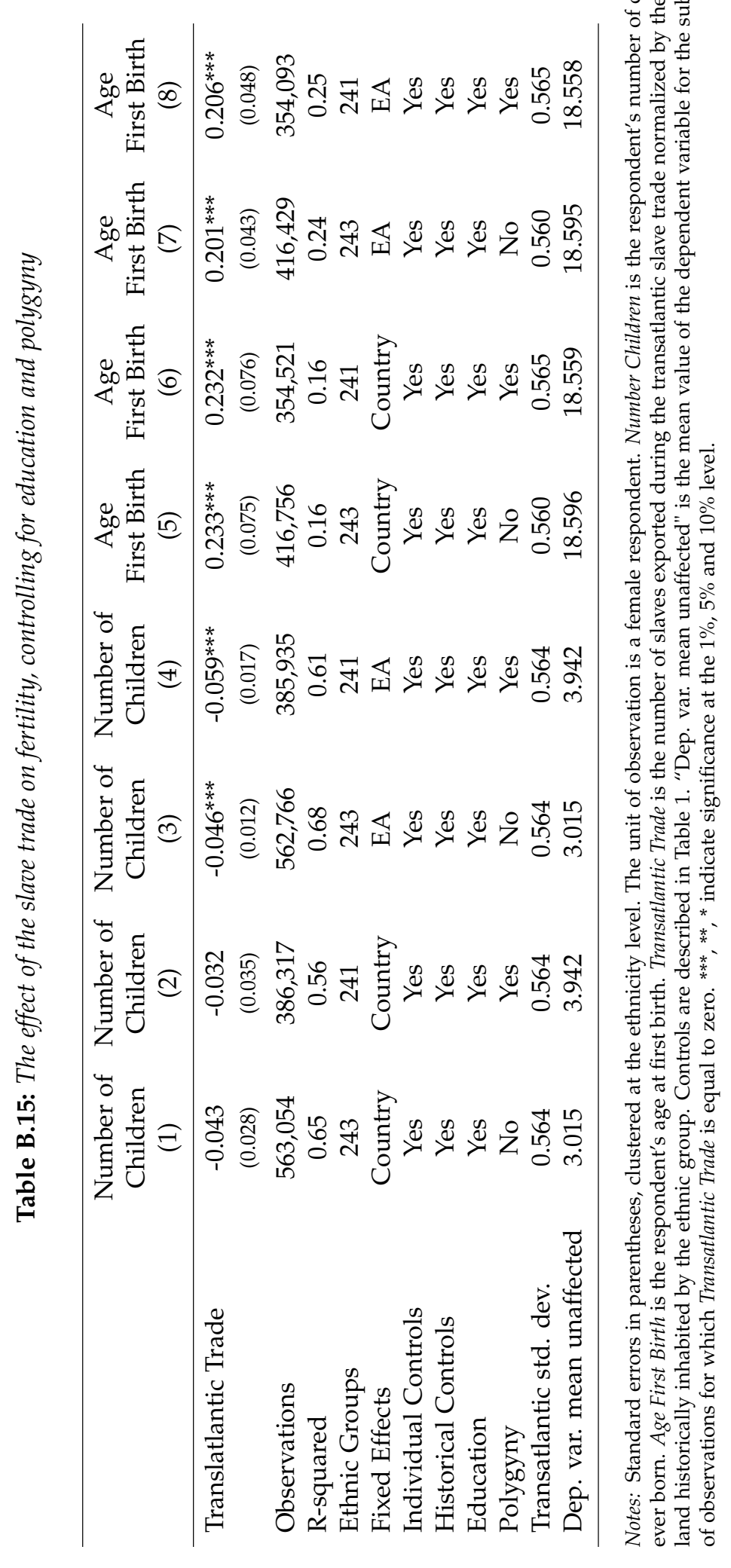


Table B.16: IV estimates of the effect of the slave trade on fertility

\begin{tabular}{lcccc}
\hline & $\begin{array}{c}\text { Number of } \\
\text { Children } \\
(1)\end{array}$ & $\begin{array}{c}\text { Number of } \\
\text { Children } \\
(2)\end{array}$ & $\begin{array}{c}\text { Age } \\
\text { First Birth } \\
(3)\end{array}$ & $\begin{array}{c}\text { Age } \\
\text { First Birth } \\
(4)\end{array}$ \\
\hline Second stage: & & & & \\
Translatlantic Trade & $-0.370^{* * *}$ & $-0.171^{* * *}$ & $0.937^{* * *}$ & $0.547^{* * *}$ \\
& $(0.117)$ & $(0.049)$ & $(0.250)$ & $(0.130)$ \\
R-squared & 0.63 & 0.67 & 0.11 & 0.20 \\
Transatlantic std. dev. & 0.564 & 0.564 & 0.560 & 0.560 \\
Dep. var. mean unaffected & 3.015 & 3.015 & 18.596 & 18.596 \\
& & & & \\
First Stage: dependent variable is Transatlantic Trade & & & \\
\hline Historical Distance from Coast & $-0.00107^{* * *}$ & $-0.00120^{* * *}$ & $-0.00108^{* * *}$ & $-0.00121^{* * *}$ \\
& $(0.00019)$ & $(0.00019)$ & $(0.00020)$ & $(0.00019)$ \\
Observations & 563,379 & 563,092 & 416,965 & 416,639 \\
R-squared & 0.70 & 0.91 & 0.69 & 0.91 \\
Ethnic Groups & 243 & 243 & 243 & 243 \\
Fixed Effects & Country & EA & Country & EA \\
Individual Controls & Yes & Yes & Yes & Yes \\
Historical Controls & Yes & Yes & Yes & Yes \\
1st stage F-stat & 30.30 & 40.15 & 30.54 & 39.85 \\
\hline
\end{tabular}

Notes: Standard errors in parentheses, clustered at the ethnicity level. The unit of observation is a female respondent. Number Children is the respondent's number of children ever born. Age First Birth is the respondent's age at first birth Transatlantic Trade is the number of slaves exported during the transatlantic slave trade normalized by the area of land historically inhabited by the ethnic group. The top panel shows the second stage estimates of Transatlantic Trade, while the bottom panel shows the first stage estimates of Historical Distance from Coast. "1st stage F-stat" indicates the value of the Kleibergen-Paap F statistic on the excluded instrument. Controls are described in Table 1. "Dep. var. mean unaffected" is the mean value of the dependent variable for the subsample of observations for which Transatlantic Trade is equal to zero. ${ }^{* * *}$, **, * indicate significance at the $1 \%, 5 \%$ and $10 \%$ level. 


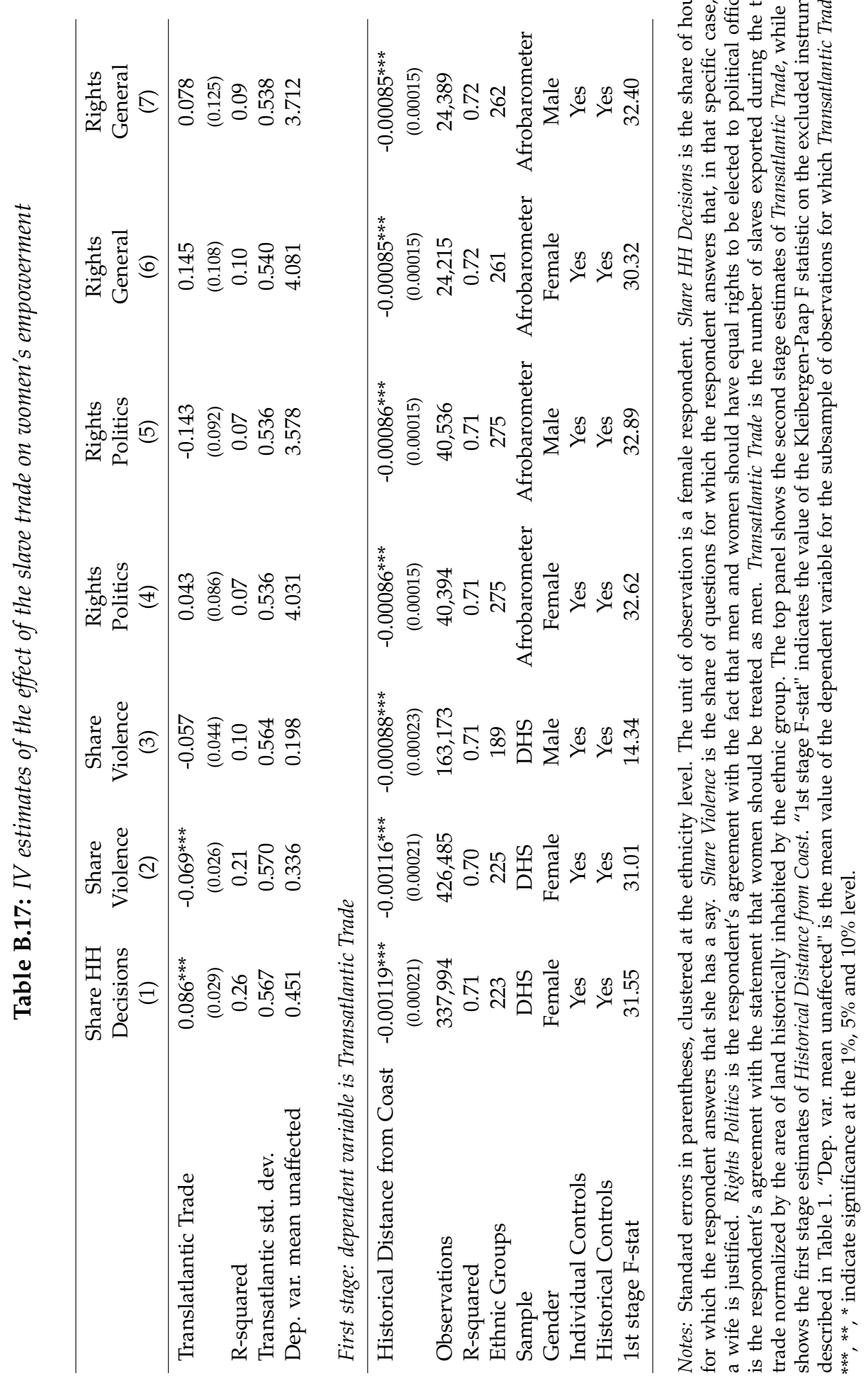




\section{B.3 Duration of the shock}

I examine whether a longer exposure to the transatlantic slave trade led to a larger long-run effect on FLFP.

To perform this test, we can compare ethnicities from which very similar number of slaves were exported, but whose lengths of exposure differ. In other words, we would like to compare, for example, ethnicity A to ethnicity B, which exported a very similar number of slaves, but one was exposed to the transatlantic slave trade for 100 years and the other for 300 years. Then, if ethnicities exposed for more centuries are characterized by higher FLFP, this would suggest that the length of exposure to the shock matters; if instead we find that these ethnicities are not significantly different in terms of FLFP, this would suggest that the duration of exposure per se has no significant effect on the persistence of the shock.

The raw slave trade data contain information on exposure to the transatlantic slave trade during specific centuries: in the 1600s, in the 1700s, and in the 1800s (no ethnic group in my sample was exposed to the transatlantic slave trade before the 17th century). While finding ethnic groups with a very similar magnitude of exposure, and yet with a different length of exposure is challenging, we can approximate this in the following way. I restrict the analysis to the 120 ethnic groups in my sample with a non-zero number of slaves exported during the transatlantic slave trade. I then group them on the basis of the magnitude of the exposure to the shock: in the first subset we have ethnicities with a value of the transatlantic slave trade variable of less than 1 , in the second subset we have ethnicities with a value between 1 and 2, and so forth. ${ }^{1}$ I then focus on the 5 subsets that have variation in the length of exposure to the slave trade. Each of these subsets include ethnic groups with exposures to the slave trade that were similar in magnitude, but different in duration. For example, four ethnicities have a value of the export measure between 2 and 3; however, two of these ethic groups (the Gurma and the Nupe) were exposed to the shock for 2 centuries, while

\footnotetext{
${ }^{1}$ To perform this exercise, I take advantage of the full distribution of the slave trade export measure, and I do not use the winsorized version of the variable as in the main analysis. As it is clear in what follows, since I will be comparing ethnicities with similar levels of exposure, the presence of outliers in the slave trade export measure is not a concern for this exercise.
} 
Table B.18: Does the duration of the historical shock matter?

\begin{tabular}{lcc}
\hline & $\begin{array}{c}\text { FLFP } \\
(1)\end{array}$ & $\begin{array}{c}\text { FLFP } \\
(2)\end{array}$ \\
\hline Translatlantic Trade & $0.034^{* *}$ & \\
& $(0.014)$ & \\
Length Exposure & & 0.016 \\
& & $(0.013)$ \\
Observations & 343,922 & 343,922 \\
R-squared & 0.15 & 0.16 \\
Ethnic Groups & 113 & 113 \\
\hline
\end{tabular}

Notes: Standard errors in parentheses, clustered at the ethnicity level. The unit of observation is a female respondent. FLFP is an indicator variable taking value one if the respondent was ever employed in the last 12 months. Transatlantic Trade is the number of slaves exported during the transatlantic slave trade normalized by the area of land historically inhabited by the ethnic group. Length Exposure measures the number of centuries in which the respondent's ethnic group was exposed to the transatlantic slave trade. Both columns include country-survey fixed effects, age fixed effects, a dummy for the respondent being married, a dummy for the respondent being Muslim, a dummy for the respondent being Christian and a dummy for the respondent living in a urban location, and the number of slaves exported during the Indian Ocean slave trade normalized by the area of land historically inhabited by the ethnic group. Column 2 includes fixed effects for the magnitude of the exposure of the ethnic group to the transatlantic slave trade, as explained in the main text. $* * * * *, *$ indicate significance at the $1 \%, 5 \%$ and $10 \%$ level.

the other two ethnic groups (the Susu and the Temne) were exposed for 3 centuries.

To perform the test, I estimate a regression where I include 5 dummies for the 5 subsets described above, and where the variable of interest is Length Exposure, which measures the number of centuries of exposure to the transatlantic slave trade (it takes values from 1 to 3). First, in column 1 of Table A17, I show that even in this smaller subsample of observations we still find a significant and positive effect of the number of slaves taken from a woman's ethnic group on her likelihood of being employed. In column 2 I show the estimated coefficient on Length Exposure, which is not statistically significant. I take these results as suggestive evidence that, conditional on the magnitude of the shock, the length of exposure to the transatlantic slave trade does not matter in explaining current variation in FLFP. 


\section{Appendix C}

\section{Appendix to Chapter 3}

\section{C.1 Survey Information}

We collected data in three waves. The first smaller pilot wave (Wave A) consisted of only the survey part (without a treatment) of about 500 respondents in February 2016. We append this wave to the main wave for the descriptive analysis of perceptions in Section $3.3^{1}$ The second and main wave (Wave B) with the perception treatment was conducted in September 2016. We conducted a third wave (Wave C) in the United States in October 2016 to ensure robustness and increase sample size in the U.S. The only difference between Wave B and Wave $\mathrm{C}$ was that in the latter all respondents were asked the questions on mobility for very hard-working people. Follow-up surveys were conducted in the US about one week after wave $B$ and wave $C$, respectively.

We report the full text of the U.S. version of the survey in Section C.4, and the links to the survey in each country in Section C.3.

Table C.1 reports the number of respondents for each survey wave and country. Table C.2 summarizes the 8 randomization groups of Wave B. Wave C had only 4 randomization groups (Group 1-Group 4). Table C.3 reports the share of respondents with strange answer patterns in the "ladder" mobility question. Table C.4 shows that respondents assigned

\footnotetext{
${ }^{1}$ We conducted a small additional survey in the US in April 2016, in order to collect additional responses from the less populous states. We use responses from this additional wave in section 3.3.4.
} 
to different randomization groups are not different in terms of baseline demographic characteristics.

Table C.1: Survey waves, Dates and Sample Sizes

\begin{tabular}{lcc}
\hline & Sample size & Date \\
\hline Wave A - US & 499 & February 2016 \\
Wave A - US Extra & 204 & April 2016 \\
Wave A - UK & 550 & February 2016 \\
Wave A - France & 550 & February 2016 \\
Wave A - Italy & 548 & February 2016 \\
Wave A - Sweden & 495 & February 2016 \\
Wave B - US & 2002 & September 2016 \\
Wave B - Follow Up & 423 & September 2016 \\
Wave B - UK & 1598 & September 2016 \\
Wave B - France & 1598 & September 2016 \\
Wave B - Italy & 1595 & September 2016 \\
Wave B - Sweden & 999 & September 2016 \\
Wave C - US & 2000 & October 2016 \\
Wave C - Follow Up & 586 & October 2016 \\
\hline
\end{tabular}


Table C.2: Randomization Groups

\begin{tabular}{lccc}
\hline \hline & Treatment/Control & $\begin{array}{c}\text { Saw govt. block before/after } \\
\text { mobility questions }\end{array}$ & Effort/talent \\
\hline Group 1 & Control & Before & Effort \\
Group 2 & Treatment & Before & Effort \\
Group 3 & Control & After & Effort \\
Group 4 & Treatment & After & Effort \\
Group 5 & Control & Before & Talent \\
Group 6 & Treatment & Before & Talent \\
Group 7 & Control & After & Talent \\
Group 8 & Treatment & After & Talent \\
\hline
\end{tabular}

Notes: "Before" and "After" refer to whether the block was seen before or after main perception treatment (or the equivalent place in the survey for the control group).

Table C.3: Response Patterns

\begin{tabular}{lcc}
\hline & Waves A & Waves B and C \\
\hline 100 in any quintile & 0.05 & 0.04 \\
100 in quintile Q2/Q3/Q4/Q5 & 0.03 & 0.02 \\
0 in quintile Q1/Q2/Q3 & 0.12 & 0.12 \\
20 in each quintile & 0.06 & 0.06 \\
\hline
\end{tabular}

Notes: The table shows the share of respondents whose responses to the ladder question on perceptions exhibits any of the patterns described, namely: whether the respondent puts the number 100 in any of the quintiles, puts the number 100 in any of the quintiles except Q1, puts the number 0 in the quintiles Q1, Q2, or Q3, and finally, puts the same number (20) in all of the quintiles. 
Table C.4: Covariates Balance Across Groups

\begin{tabular}{lccc}
\hline & & Government & Effort \\
& Treated & Questions & Questions \\
& $(1)$ & $(2)$ & $(3)$ \\
\hline Male & 0.99 & 0.51 & 0.70 \\
Age & 0.45 & 0.42 & 0.58 \\
Married & 0.35 & 0.70 & 0.45 \\
Has children & 0.60 & 0.13 & 0.33 \\
Native & 0.17 & 0.73 & 0.84 \\
Employed & 0.92 & 0.73 & 0.58 \\
Unemployed & 0.23 & 0.59 & 0.41 \\
Not in labor force & 0.79 & 0.86 & 0.79 \\
Has university degree & 0.61 & 0.42 & 0.00 \\
Left-wing & 0.91 & 0.98 & 0.12 \\
\hline
\end{tabular}

Notes: The table shows the $\mathrm{p}$-value from a series of regressions of the form $y_{i c}=\alpha+\beta$ Covariate $_{i}+\gamma_{c}+\epsilon_{i c}$, where Covariate $_{i}$ is the variable listed in the row and $\gamma_{c}$ are country fixed effects. In the column "Treated", $y_{i c}$ is a dummy equal to one if the respondent was in the treatment group and zero if she was in the control group. In column (2), $y_{i c}$ is a dummy equal to one if the respondent saw the three survey questions on fairness and government whose order was randomized (described in the text) before the main perception treatment (or the equivalent place in the survey for those not treated by the main perception treatment). In column (3), $y_{i c}$ is a dummy equal to one if the respondent was asked about the mobility prospects of very hard-working children, and equal to zero is she was asked about the mobility prospects of very talented children. 


\section{C.2 Variable Definitions}

\section{Demographic variables:}

Male: respondent is male.

Young: respondent is younger than 45 years old.

African-American: respondent is African-American (asked in the U.S. only).

Children: respondent has at least one child.

Rich: respondent's household income is above the 75th percentile of the respondents' household income distribution in the country.

College: respondent has college degree.

Left-wing: respondent's views on economic issues are liberal or very liberal.

Right-wing: respondent's views on economic issues are conservatives or very conservatives. Moved up: dummy equal to one if the level of status of the respondent's job is higher than his father's one.

Immigrant: dummy equal to one if at least one of the respondent's parents is not born in the country.

\section{Mobility Perceptions:}

$Q 1$ to $Q[X]$ : perceived probability of being in the Xth quintile as an adult for a child with parents in the first quintile.

Q1 to $Q[X]$ Effort: perceived probability of being in the Xth quintile as an adult for a hard-working child with parents in the first quintile.

Q1 to Q4 (Qual.): qualitative question on perceived chances, on a scale from 1 to 5 , of moving from the first to the fourth quintile, where 1 is "Close to zero", 2 is "Low", 3 is "Fairly low", 4 is "Fairly high" and 5 is "High".

Q1 to Q5 (Qual.): qualitative question on perceived chances, on a scale from 1 to 5 , of moving from the first to the fifth quintile, where 1 is "Close to zero", 2 is "Low", 3 is "Fairly low", 4 is "Fairly high" and 5 is "High". 


\section{Perceptions of Fairness:}

Economic System Fair: dummy equal to one if respondent believes that the economic system in her country is basically fair, since all have an equal opportunity to succeed.

American Dream Alive: dummy equal to one if respondent agrees or strongly agrees with the statement "In [country] everybody has a chance to make it and be economically successful" (equal to zero if neither agrees nor disagrees, disagrees, or strongly disagrees).

Effort Reason Poor: dummy equal to one if respondent believes that "Lack of effort on his or her own part" is a more important determinant of why a person is poor than "Circumstances beyond his or her control".

Effort Reason Rich: dummy equal to one if respondent believes that "Because she or he worked harder than others" is a more important determinant of why a person is poor than "Because she or he had more advantages than others".

Unequal Opp. Problem: dummy equal to one if the respondent believes that if children from poor and rich backgrounds have unequal opportunities in life this is "A problem" or "A serious problem" or "A very serious problem" (equal to zero if it is "Not a problem" or "A small problem").

Unequal Opp. No Problem: dummy equal to one if the respondent believes that if children

from poor and rich backgrounds have unequal opportunities in life this is "Not a problem" or "A small problem".

Unequal Opp. Very Serious Problem: dummy equal to one if the respondent believes that if children from poor and rich backgrounds have unequal opportunities in life this is "A very serious problem".

\section{Policy Preferences and Role of Government:}

Tax Rate Top 1: Average income tax rate for households in the top 1\% of the income distribution.

Tax Rate Bottom 50: Average income tax rate for households in the bottom 50\% of the income distribution. 
Support Estate Tax: Dummy equal to one if respondent is in favor of the estate tax (defined as answering 4 or 5 on a scale from 1 to 5 , where 1 means "do not support at all" and 5 means "strongly support").

Budget Safety Net: share of current government budget that should be allocated to safety net policies.

Budget Opp.: share of current government budget that should be allocated to education and health.

Support Equality Opp. Policies: respondent's support, on a scale from 1 to 5, for policies to increase the opportunities for children born in poor families and to foster more equality of opportunity. The respondent was told that "to finance an expansion of policies promoting equal opportunity, it would have to be the case that either other policies are scaled down or taxes are raised".

Government Interv.: respondent's support, on a scale from 1 to 7 , for government intervention to make the opportunities for children from poor and rich families less unequal.

Lowering Taxes Better: dummy equal to one if the respondent believes that "lowering taxes on wealthy people and corporations to encourage more investment in economic growth" would do more to make the opportunities for children from poor and rich families less unequal than "raising taxes on wealthy people and corporations to expand programs for the poor". Trust Govt.: dummy equal to one if the respondent answers that she can trust the government to do what is right "Most of the time" or "Always" (it takes value zero if the answer is "Never" or "Only some of the time").

Never trust government: dummy equal to one if the respondent answers that she can never trust the government to do what is right.

Govt. Tools: dummy equal to one if the respondent answers that to reduce the inequality of opportunities between children born in poor and rich families the government has the ability and the tools to do "Some" or "A lot" (it takes value zero if the answer is "Nothing at all" or "Not much").

Government has no tools: dummy equal to one if the respondent answers that to reduce the 
inequality of opportunities between children born in poor and rich families the government has the ability and the tools to do "Nothing at all" or "Not much."

Prefer Low Govt. Intervention: dummy equal to one if the respondent prefers a low degree of government intervention to make the opportunities for children from poor and rich families less unequal (at point 4 or below on the scale from 1 to 7 ).

Negative View of Government: dummy equal to one if the respondent answers that she can "never" trust the government, or that to reduce the inequality of opportunities between children born in poor and rich families the government has the ability and the tools to do "Nothing at all" or "Not much," or that she supports little government intervention (less than 5 on the scale from 1 to 7 of the variable Government Interv.), or that "lowering taxes on wealthy people and corporations to encourage more investment in economic growth" would be the better way to equalize opportunities. 


\section{C.3 Links to surveys}

- Survey U.S.: https://harvard.az1.qualtrics.com/SE/?SID=SV5dxninfErZ246X3

- Survey U.K.: https://harvard.az1.qualtrics.com/SE/?SID=SV 7 TCttX32sJZGUnP

- Survey France: https://harvard.az1.qualtrics.com/SE/?SID=SV $55 x x j d 0 V S E V n H B b$

- Survey Italy: https://harvard.az1.qualtrics.com/SE/?SID=SV $z m y M M B 2 l T$ Jgoeh

- Survey Sweden: https://harvard.az1.qualtrics.com/SE/?SID=SV $c$ ZxXzaGNNjn6w5L

\section{C.4 Detailed Survey Questionnaires}

Answer options are in italic, separated by a semicolon.

1. See Figure C.3

Yes, I would like to take part in this study, and confirm that I AM A U.S. RESIDENT and am 18 or older; No, I would not like to participate.

2. What is your gender?

Male; Female

3. What is your age?

4. What was your TOTAL household income, before taxes, last year (2015)? $\$ 0$ - \$9,999; \$10,000 - \$14,999; \$15,000 - \$19,999; \$20,000 - \$29,999; \$30,000 - \$39,999; $\$ 40,000$ - \$49,999; \$50,000 - \$69,999; \$70,000 - \$89,999; \$90,000 - \$109,999; \$110,000 $\$ 149,999 ; \$ 150,000$ - \$199,999; \$200,000+

5. Please indicate your marital status Single; Married; Other

6. How many children do you have?

I do not have children; $1 ; 2 ; 3 ; 4 ; 5$ or more 
7. How would you describe your ethnicity/race?

European American/White; African American/Black; Hispanic/Latino; Asian/Asian American; Other

8. Were you born in the United States?

Yes; No

9. Were both of your parents born in the United States?

Yes; No

10. Where was your father born?

Unites States; South or Central America, or Mexico; Canada; Europe; Asia; Africa; Oceania

11. In which state do you live?

12. In which ZIP code do you live?

13. Which category best describes your highest level of education?

Eighth Grade or less; Some High School; High School degree / GED; Some College; 2-year College Degree; 4-year College Degree; Master's Degree; Doctoral Degree; Professional Degree $(J D, M D, M B A)$

14. Which category best describes your father's highest level of education?

Eighth Grade or less; Some High School; High School degree / GED; Some College; 2-year College Degree; 4-year College Degree; Master's Degree; Doctoral Degree; Professional Degree (JD, MD, MBA); I come from a single-parent family and my father was not present

15. Which category best describes your mother's highest level of education?

Eighth Grade or less; Some High School; High School degree / GED; Some College; 2-year College Degree; 4-year College Degree; Master's Degree; Doctoral Degree; Professional Degree (JD, MD, MBA); I come from a single-parent family and my mother was not present 
16. What is your current employment status?

Full-time employee; Part-time employee; Self-employed or small business owner; Unemployed and looking for work; Student; Not in labor force (for example: retired, or full-time parent)

17. If you compare your job (or your last job if you currently don't have a job) with the job your father had while you were growing up, would you say that the level of status of your job is:

Much higher than my father's; Higher than my father's; About equal to my father's; Lower than my father's; Much lower than my father's; My father did not have a job while I was growing up OR I come from a single-parent family

18. If you compare your job (or your last job if you currently don't have a job) with the job your mother had while you were growing up, would you say that the level of status of your job is:

Much higher than my mother's; Higher than my mother's; About equal to my mother's; Lower than my mother's; Much lower than my mother's; My mother did not have a job while I was growing up OR I come from a single-parent family

19. When you were growing up, compared with American families back then, would you say your family income was:

Far below average; Below average; Average; Above average; Far above average

20. Right now, compared with American families, would you say your own household income is:

Far below average; Below average; Average; Above average; Far above average

21. On economic policy matters, where do you see yourself on the liberal/conservative spectrum?

Very liberal; Liberal; Moderate; Conservative; Very conservative 
22. Before proceeding to the next set of questions, we want to ask for your feedback about the responses you provided so far. It is vital to our study that we only include responses from people who devoted their full attention to this study. This will not affect in any way the payment you will receive for taking this survey. In your honest opinion, should we use your responses, or should we discard your responses since you did not devote your full attention to the questions so far?

Yes, I have devoted full attention to the questions so far and I think you should use my responses for your study; No, I have not devoted full attention to the questions so far and I think you should not use my responses for your study.

23. Do you think the economic system in the United States is:

Basically fair, since all Americans have an equal opportunity to succeed; Basically unfair, since all Americans do not have an equal opportunity to succeed

24. Which has more to do with why a person is poor? Lack of effort on his or her own part; Circumstances beyond his or her control

25. Which has more to do with why a person is rich? Because she or he worked harder than others; Because she or he had more advantages than others

26. How much of the time do you think you can trust the government to do what is right? Never; Only some of the time; Most of the time; Always

27. If children from poor and rich backgrounds have unequal opportunities in life, do you think this is:

Not a problem at all; A small problem; A problem; A serious problem; A very serious problem

28. To reduce the inequality of opportunities between children born in poor and rich families, the government has the ability and the tools to do:

Nothing at all; Not much; Some; A lot 
29. We would now like to ask you what you think about the life opportunities of children from very poor families.

For the following questions, we focus on 500 families that represent the U.S. population. We divide them into five groups on the basis of their income, with each group containing 100 families. These groups are: the poorest 100 families, the second poorest 100 families, the middle 100 families, the second richest 100 families, and the richest 100 families.

In the following questions, we will ask you to evaluate the chances that children born in one of the poorest 100 families, once they grow up, will belong to any of these income groups.

Please fill out the entries to the right of the figure below to tell us, in your opinion, how many out of 100 children coming from the poorest 100 families will grow up to be in each income group.

From our experience, this question will take you at the very least 1 minute to answer. Please note that your entries need to add up to 100 or you will not be able to move on to the next page.

Figure 3.1 here.

30. Do you think the chances that a child from the poorest 100 families will grow up to be among the richest 100 families are:

Close to zero; Low; Fairly low; Fairly high; High

31. Do you think the chances that a child from the poorest 100 families will grow up to be among the second richest 100 families are:

Close to zero; Low; Fairly low; Fairly high; High

32. We are still interested in the life opportunities of children from very poor families, but we now focus on a different group of poor children.

From our experience, this question will take you at the very least 45 seconds to answer. 
Consider 100 children coming from the poorest 100 families.

These children are very determined and put in hard work both at school and, later in life, when finding a job and doing that job.

Please fill out the entries to the right of the figure below to tell us, in your opinion, how many out of these 100 children will grow up to be in each income group.

Please note that your entries need to add up to 100 or you will not be able to move on to the next page.

Figure 3.1 here.

33. Do you think the chances that one of these hard working children will grow up to be among the richest 100 families are:

Close to zero; Low; Fairly low; Fairly high; High

34. Do you think the chances that one of these hard working children will grow up to be among the second richest 100 families are:

Close to zero; Low; Fairly low; Fairly high; High

35. We are still interested in the life opportunities of children from very poor families, but we now focus on a different group of poor children.

From our experience, this question will take you at the very least 45 seconds to answer. Consider 100 children coming from the poorest 100 families.

These children are very talented.

Please fill out the entries to the right of the figure below to tell us, in your opinion, how many out of these 100 children will grow up to be in each income group.

Please note that your entries need to add up to 100 or you will not be able to move on to the next page.

Figure 3.1 here. 
36. Do you think the chances that one of these talented children will grow up to be among the richest 100 families are:

Close to zero; Low; Fairly low; Fairly high; High

37. Do you think the chances that one of these talented children will grow up to be among the second richest 100 families are:

Close to zero; Low; Fairly low; Fairly high; High

38. How do you feel about the following statement?

"In the United States everybody has a chance to make it and be economically successful."

Strongly agree; Agree; Neither agree nor disagree; Disagree; Strongly disagree

39. Some people think that the government should not concern itself with making the opportunities for children from poor and rich families less unequal. Others think that the government should do everything in its power to make the opportunities for children from poor and rich families less unequal. Think of a score of 1 as meaning that the government should not concern itself with making the opportunities for children from poor and rich families less unequal, and a score of 7 meaning that the government should do everything in its power to reduce this inequality of opportunities.

What score between 1 and 7 comes closest to the way you feel?

\section{$1 ; 2 ; 3 ; 4 ; 5 ; 6 ; 7$}

40. What do you think would do more to make the opportunities for children from poor and rich families less unequal?

Lowering taxes on wealthy people and corporations to encourage more investment in economic growth; Raising taxes on wealthy people and corporations to expand programs for the poor.

41. Do you support more policies to increase the opportunities for children born in poor families and to foster more equality of opportunity, such as education policies? 
Naturally, to finance an expansion of policies promoting equal opportunity, it would have to be the case that either other policies are scaled down or taxes are raised.

I very strongly oppose more policies promoting equality of opportunity; I oppose more policies promoting equality of opportunity; I am indifferent; I support more policies promoting equality of opportunity; I very strongly support more policies promoting equality of opportunity.

42. In the next two questions, we ask you to think about the total level of funds that the government raises and spends today on various policies. For the purpose of these questions, suppose that the level of government spending is fixed at its current level and cannot be changed. We will ask about your views on two aspects:

- First, on the fair split of the tax burden to raise this level of funds.

- Second, on how you think the government should spend this level of funds.

\section{See Figure C.1}

44. We now ask you how you would like to spend the total government budget. Suppose that you are the person deciding on the U.S. budget for the next year. You can choose how you want to divide the budget (in percent) between the following 6 categories: See Figure C.2

45. The estate tax is a tax on the transfer of wealth from a deceased person to her heirs. This tax applies only to individuals with wealth above a certain threshold. On a scale from 1 to 5, how would you rate your support for the estate tax, where 1 means do not support at all and 5 means strongly support?

\section{$1 ; 2 ; 3 ; 4 ; 5$}

46. Do you feel that this survey was biased? Yes, left-wing bias; Yes, right-wing bias; No, it did not feel bias

47. Please feel free to give us any feedback or impression regarding this survey. 
The government currently raises a certain amount of revenue through the income tax in order to sustain the current level of public spending. In you view, what would be the fair split of the tax burden to sustain public spending?

The income tax* rate is the percentage of your income that you pay in federal income tax. For example, if you earn $\$ 30,000$ and you pay $\$ 3,000$ in income taxes, your income tax rate is $10 \%$.

Please use the sliders below to tell us how much you think each of the following groups should pay as a percentage of their total income.

While you adjust the four sliders for each group, the fifth bar at the bottom moves in order to show you how much of the current revenue you have been able to raise so far. The bar appears red as long as you have not raised enough revenue, or if you have raised more money than what is needed.

You will only be able to move to the next question when you meet the revenue target and the bar becomes green.

\section{The top 1\% (Richest)}

The next $\mathbf{9} \%$ (Only $1 \%$ of households earn more, $\mathbf{9 0} \%$ earn less)

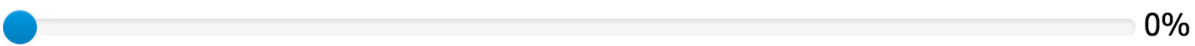

The next $\mathbf{4 0} \%$ (Only $\mathbf{1 0} \%$ earn more, $50 \%$ earn less)

The bottom 50\% (Poorest)

\section{Revenue raised}

You have not raised enough revenue.

Figure C.1: Question on preferred income tax rates for various income groups 
1) Defense and National Security, which refers to the costs of the Defense department and the costs of supporting security operations in foreign countries.

2) Public Infrastructure, which includes, among others, transport infrastructure like roads, bridges and airports, and water infrastructure.

3) Spending on Schooling and Higher Education, including help for children from low income families to attend school and university.

\section{4) Social Security, Medicare, Disability Insurance and Supplementary Security Income}

(SSI), which provide income support and help with health care expenses to the elderly and the disabled.

5) Social Insurance and Income Support Programs. This covers help to the unemployed (through unemployment insurance) and help for low income families (such as through Food stamps or the earned income tax credit (EITC), a tax credit for low-income working families)

6) Public Spending on Health, such as Medicaid for the poor (a healthcare program for low income families) or tax subsidies to help families buy health insurance.

Please enter the percent of the budget you would assign to each spending category (the total must sum to 100):

Defense and National Security

Public Infrastructure

Spending on Schooling and Higher Education

Social Security, Medicare, Disability Insurance and Supplementary Security Income (SSI)

Social Insurance and Income Support Programs

Public Spending on Health

Figure C.2: Question on preferred allocation of government budget 
We are a non-partisan group of academic researchers from Harvard. Our goal is to understand how information we see and hear in the media influences views on policies. No matter what your political views are, this is an important question and by completing this survey, you are contributing to our knowledge as a society. You might not agree with all the information presented, and that is perfectly fine. Our survey will give you an opportunity to express your own views.

It is very important for the success of our research that you answer honestly and read the questions very carefully before answering. Anytime you don't know an answer, just give your best guess. However, please be sure to spend enough time reading and understanding the question. To ensure the quality of survey data, your responses will be subject to sophisticated statistical control methods. Responding without adequate effort may result in your responses being flagged for low quality.

It is also very important for the success of our research project that you complete the entire survey, once you have started. This survey should take (on average) about 10 minutes to complete.

Notes: Your participation in this study is purely voluntary. Your name will never be recorded. Results may include summary data, but you will never be identified. If you have any question about this study, you may contact us at socialsciencestudies@gmail.com

Figure C.3: First page of the survey (English version) 


\section{van HARVARD}

UNIVERSITY

Recent academic research has been exploring the link between one's family background and one's chances of making it in life. These recent academic studies have leveraged new large-scale datasets to explore the opportunities available to children from different family backgrounds and their chances of making it in life.

We will now show you two short animations that summarize the two key findings of these studies. Please proceed to the next page when you are ready.

Figure C.4: Treatment animation - introduction 
(a) First screen

(a)

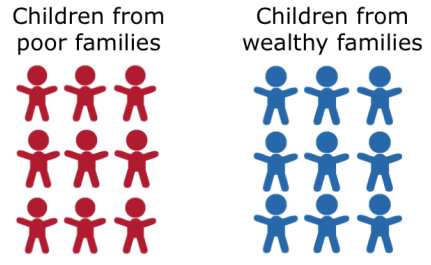

What does recent research tell us about how children from poor families will do when they grow up?

(b)

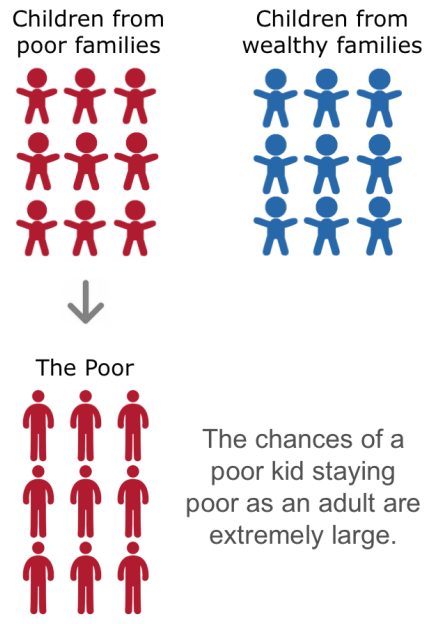

(c)

Only very few kids from poor families will ever make it and become rich.

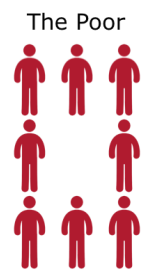

The Wealthy

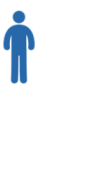

REPLAY

\section{(b) Second screen}

(d)

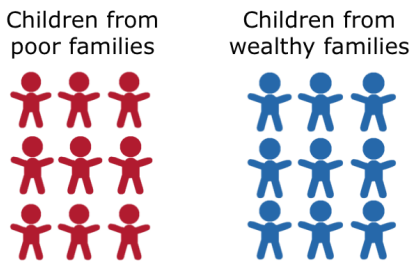

What does recent research tell us about how children from rich families will do when they grow up?

(e)

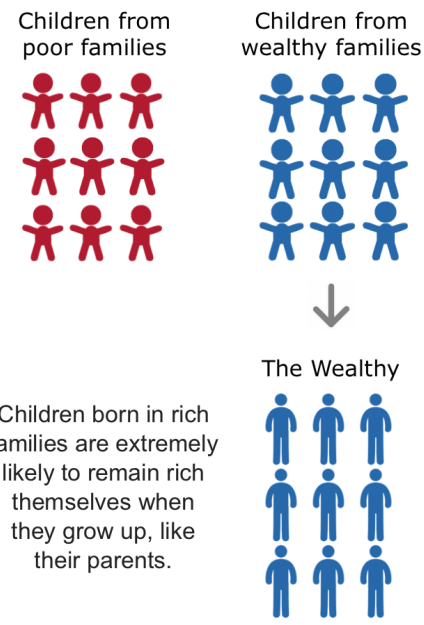

(f)

It is extremely rare for a child from a rich family to become poor later in life.

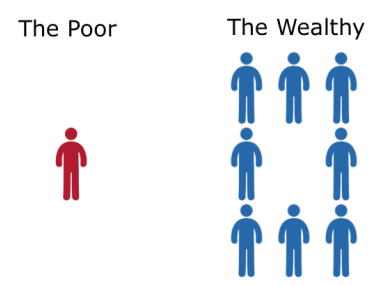

Figure C.5: Treatment animation 


\section{C.5 Additional Tables and Figures}

Table C.5: Detailed perceived transition probabilities

\begin{tabular}{lcccccccc}
\hline & Q1 to & Q1 to & Q1 to & Q1 to & Q1 to & Q1 to Q4 & Q1 to Q5 & Obs. \\
& Q1 & Q2 & Q3 & Q4 & Q5 & $\begin{array}{c}\text { (Qual.) } \\
(6)\end{array}$ & $(7)$ & $(8)$ \\
& $(1)$ & $(2)$ & $(3)$ & $(4)$ & $(5)$ & $(6)$ & & \\
& & & & & & & & \\
All Countries & & & & & & & \\
All & 34.04 & 22.64 & 21.82 & 11.21 & 10.29 & 0.43 & 0.31 & 6,880 \\
Left & 37.55 & 23.00 & 20.27 & 10.06 & 9.12 & 0.35 & 0.23 & 2,276 \\
Right & 32.25 & 22.67 & 22.91 & 11.70 & 10.47 & 0.46 & 0.32 & 2,206 \\
US & & & & & & & & \\
All & 32.16 & 21.83 & 22.32 & 11.98 & 11.72 & 0.46 & 0.34 & 2,170 \\
Left & 37.37 & 21.67 & 19.33 & 11.10 & 10.53 & 0.35 & 0.25 & 577 \\
Right & 29.45 & 21.96 & 24.14 & 12.49 & 11.96 & 0.53 & 0.38 & 652 \\
UK & & & & & & & & \\
All & 37.77 & 22.25 & 19.39 & 10.62 & 9.97 & 0.37 & 0.27 & 1,290 \\
Left & 42.88 & 23.20 & 16.85 & 8.63 & 8.44 & 0.23 & 0.14 & 406 \\
Right & 36.20 & 22.00 & 19.71 & 11.52 & 10.57 & 0.41 & 0.26 & 304 \\
France & & & & & & & & \\
All & 35.26 & 23.60 & 21.51 & 10.53 & 9.10 & 0.42 & 0.29 & 1,297 \\
Left & 38.36 & 23.07 & 20.48 & 9.56 & 8.54 & 0.40 & 0.26 & 451 \\
Right & 32.70 & 23.76 & 22.59 & 11.47 & 9.47 & 0.46 & 0.31 & 501 \\
Italy & & & & & & & & \\
All & 33.61 & 23.13 & 21.87 & 11.25 & 10.14 & 0.40 & 0.29 & 1,242 \\
Left & 34.77 & 23.54 & 21.80 & 10.51 & 9.38 & 0.34 & 0.25 & 554 \\
Right & 33.55 & 22.85 & 22.13 & 11.18 & 10.29 & 0.41 & 0.31 & 402 \\
Sweden & & & & & & & & \\
All & 32.00 & 23.10 & 24.52 & 11.16 & 9.21 & 0.47 & 0.33 & 881 \\
Left & 34.51 & 24.22 & 23.66 & 9.95 & 7.66 & 0.43 & 0.27 & 288 \\
Right & 31.88 & 22.79 & 24.79 & 11.31 & 9.24 & 0.45 & 0.29 & 347 \\
\hline & & & & & & & &
\end{tabular}

Notes: The table reports mobility perceptions. Respondents are split according to their self-reported political affiliation. Political views are assessed on a five point scale, ranging from "Very liberal (1)" to "Very conservative (5)." "All" refers to the average across all respondents. Left-wing respondents have views on economic issues that are "Liberal" or "Very liberal." Right-wing respondents have views on economic issues that are "Conservative" or "Very conservative." Column $j$ for $j=\{1,2,3,4,5\}$ shows the perceived probability of a child from from the bottom quintile to move to quintile $j$. Columns 6 (respectively, 7 ) shows the proportion of respondents who believe that the chance of moving from the first to the fourth (respectively, to the fifth) quintile is "fairly low," "fairly high," or "high." Column 8 reports the number of observations for each row. 
Table C.6: The perceived role of effort

\begin{tabular}{|c|c|c|c|c|c|c|c|c|c|c|}
\hline & \multicolumn{5}{|c|}{$\begin{array}{l}\text { Panel A: Perceived Transition } \\
\text { Probabilities Conditional on Effort }\end{array}$} & \multicolumn{5}{|c|}{$\begin{array}{c}\text { Panel B: \% Difference Between } \\
\text { Perceived Transition Probabilities } \\
\text { Conditional and Unconditional on Effort }\end{array}$} \\
\hline & $\begin{array}{l}\text { US } \\
(1)\end{array}$ & $\begin{array}{l}\text { UK } \\
(2)\end{array}$ & $\begin{array}{l}\text { France } \\
\text { (3) }\end{array}$ & $\begin{array}{c}\text { Italy } \\
(4)\end{array}$ & $\begin{array}{l}\text { Sweden } \\
\text { (5) }\end{array}$ & $\begin{array}{l}\text { US } \\
(1)\end{array}$ & $\begin{array}{l}\text { UK } \\
(2)\end{array}$ & $\begin{array}{c}\text { France } \\
\text { (3) }\end{array}$ & $\begin{array}{l}\text { Italy } \\
(4)\end{array}$ & $\begin{array}{l}\text { Sweden } \\
\text { (5) }\end{array}$ \\
\hline Q1 to Q5 & 12.47 & 12.54 & 11.39 & 10.86 & 12.57 & $\begin{array}{l}0.06 \\
(0.00)\end{array}$ & $\begin{array}{l}0.26 \\
(0.00)\end{array}$ & $\begin{array}{l}0.25 \\
(0.00)\end{array}$ & $\begin{array}{l}0.07 \\
(0.00)\end{array}$ & $\begin{array}{l}0.36 \\
(0.00)\end{array}$ \\
\hline $\mathrm{Q} 1$ to $\mathrm{Q} 4$ & 14.83 & 15.20 & 15.03 & 14.22 & 17.96 & $\begin{array}{l}0.24 \\
(0.00)\end{array}$ & $\begin{array}{l}0.43 \\
(0.00)\end{array}$ & $\begin{array}{l}0.43 \\
(0.00)\end{array}$ & $\begin{array}{l}0.26 \\
(0.00)\end{array}$ & $\begin{array}{l}0.61 \\
(0.00)\end{array}$ \\
\hline Q1 to Q3 & 29.33 & 26.38 & 29.39 & 27.61 & 31.82 & $\begin{array}{l}0.31 \\
(0.00)\end{array}$ & $\begin{array}{l}0.36 \\
(0.00)\end{array}$ & $\begin{array}{l}0.37 \\
(0.00)\end{array}$ & $\begin{array}{l}0.26 \\
(0.00)\end{array}$ & $\begin{array}{l}0.30 \\
(0.00)\end{array}$ \\
\hline $\mathrm{Q} 1$ to $\mathrm{Q} 2$ & 21.14 & 22.09 & 20.91 & 22.53 & 19.72 & $\begin{array}{l}-0.03 \\
(0.01)\end{array}$ & $\begin{array}{l}-0.01 \\
(0.58)\end{array}$ & $\begin{array}{l}-0.11 \\
(0.00)\end{array}$ & $\begin{array}{l}-0.03 \\
(0.27)\end{array}$ & $\begin{array}{l}-0.15 \\
(0.00)\end{array}$ \\
\hline $\mathrm{Q} 1$ to $\mathrm{Q} 1$ & 22.23 & 23.79 & 23.28 & 24.78 & 17.93 & $\begin{array}{l}-0.31 \\
(0.00)\end{array}$ & $\begin{array}{l}-0.37 \\
(0.00)\end{array}$ & $\begin{array}{l}-0.34 \\
(0.00)\end{array}$ & $\begin{array}{l}-0.26 \\
(0.00)\end{array}$ & $\begin{array}{l}-0.44 \\
(0.00)\end{array}$ \\
\hline Obs. & 1,735 & 900 & 908 & 872 & 656 & 1,735 & 900 & 908 & 872 & 656 \\
\hline
\end{tabular}

Notes: The five rows of Panel A of the table report the average perceived probability that a child born to parents in the bottom quintile of the income distribution will be in quintile 5, 4, 3, 2, and 1 respectively, when adult if that child "works very hard," i.e., based on our survey question that asks respondents to think conditional on individual hard work. The five rows of Panel B of the table report the percent change in the perceived probability of a child born in a family from the bottom quintile to be in quintile 5, 4, 3, 2, and 1 respectively, when adult conditional on effort relative to the unconditional case. P-values in parentheses. 
Table C.7: Heterogeneity in perceptions: partial effects

\begin{tabular}{lcccc}
\hline & Q1 to Q1 & Q1 to Q4 or Q5 & Q1 to Q4 (Qual.) & $\begin{array}{c}\text { Q1 to Q5 (Qual.) } \\
\text { Male }\end{array}$ \\
& $2.090^{* * *}$ & -1.034 & $(3)$ & $(4)$ \\
Young & $(0.741)$ & $(0.669)$ & $-0.026^{*}$ & $-0.048^{* * *}$ \\
& $1.858^{* *}$ & -0.387 & $0.015)$ & $(0.014)$ \\
Has Children & $(0.769)$ & $(0.693)$ & $0.073^{* * *}$ & $0.095^{* * *}$ \\
& $-2.328^{* * *}$ & $1.749^{* *}$ & $(0.016)$ & $(0.014)$ \\
Rich & $(0.776)$ & $(0.700)$ & $0.027^{*}$ & $0.049^{* * *}$ \\
& $1.694^{*}$ & -0.661 & $(0.016)$ & $(0.014)$ \\
College & $(0.966)$ & $(0.871)$ & -0.013 & $-0.032^{*}$ \\
& $4.843^{* * *}$ & $-4.444^{* * *}$ & $(0.020)$ & $(0.018)$ \\
Right & $(0.780)$ & $(0.704)$ & $-0.034^{* *}$ & $-0.058^{* * *}$ \\
& $-2.468^{* * *}$ & 0.960 & $(0.016)$ & $(0.014)$ \\
Moved up & $(0.789)$ & $(0.711)$ & $0.080^{* * *}$ & $0.041^{* * *}$ \\
& $-1.890^{* *}$ & 0.861 & $(0.016)$ & $(0.015)$ \\
Immigrant & $(0.767)$ & $(0.692)$ & 0.021 & 0.011 \\
& $-1.819^{*}$ & 1.249 & $(0.016)$ & $(0.014)$ \\
Obs. & $(1.028)$ & $(0.927)$ & $0.044^{* *}$ & $0.049^{* *}$ \\
Country-wave FE & 4,290 & 4,290 & $(0.021)$ & $(0.019)$ \\
Mean Dep. Var. & 34.17 & 20.97 & 4,290 & 4,290 \\
& & & Yes & Yes \\
& & & 0.38 & 0.27 \\
\hline
\end{tabular}

Notes: The dependent variable in column 1 (respectively, column 2) is the perceived probability that a child born to parents in the bottom quintile of the income distribution will be in the bottom quintile (respectively, in the fourth or fifth quintile) when adult. The dependent variables in columns 3 and 4 are defined as in Table C.5. Regressors are indicator variables for gender, age less than 45 , having children, being in the top quartile of the income distribution, having a college degree, right-wing political affiliation, having a job with a status higher than father, having at least one of the parents not born in the country. "Mean Dep. Var" is the mean of the dependent variable. Standard errors in parentheses. ${ }^{*} p<0.1{ }^{* *} p<0.05,{ }^{* * *} p<0.01$ 
Table C.8: The perceived role of talent

\begin{tabular}{|c|c|c|c|c|c|c|c|c|c|c|}
\hline & \multicolumn{5}{|c|}{$\begin{array}{l}\text { Panel A: Perceived Transition } \\
\text { Probabilities Conditional on Talent }\end{array}$} & \multicolumn{5}{|c|}{$\begin{array}{c}\text { Panel B: \% Difference Between } \\
\text { Perceived Transition Probabilities } \\
\text { Conditional and Unconditional on Talent }\end{array}$} \\
\hline & $\begin{array}{l}\text { US } \\
(1)\end{array}$ & $\begin{array}{l}\text { UK } \\
(2)\end{array}$ & $\begin{array}{c}\text { France } \\
(3)\end{array}$ & $\begin{array}{l}\text { Italy } \\
(4)\end{array}$ & $\begin{array}{l}\text { Sweden } \\
\text { (5) }\end{array}$ & $\begin{array}{l}\text { US } \\
(1)\end{array}$ & $\begin{array}{l}\text { UK } \\
(2)\end{array}$ & $\begin{array}{c}\text { France } \\
\text { (3) }\end{array}$ & $\begin{array}{l}\text { Italy } \\
(4)\end{array}$ & $\begin{array}{l}\text { Sweden } \\
\text { (5) }\end{array}$ \\
\hline Q1 to Q5 & 14.03 & 9.59 & 11.83 & 12.25 & 10.70 & $\begin{array}{c}0.20 \\
(0.00)\end{array}$ & $\begin{array}{l}-0.04 \\
(0.09)\end{array}$ & $\begin{array}{c}0.30 \\
(0.00)\end{array}$ & $\begin{array}{c}0.21 \\
(0.05)\end{array}$ & $\begin{array}{l}0.16 \\
(0.31)\end{array}$ \\
\hline Q1 to Q4 & 14.59 & 13.37 & 15.06 & 13.77 & 14.49 & $\begin{array}{c}0.22 \\
(0.00)\end{array}$ & $\begin{array}{c}0.26 \\
(0.00)\end{array}$ & $\begin{array}{c}0.43 \\
(0.00)\end{array}$ & $\begin{array}{c}0.22 \\
(0.00)\end{array}$ & $\begin{array}{l}0.30 \\
(0.00)\end{array}$ \\
\hline Q1 to Q3 & 26.96 & 26.84 & 30.83 & 27.82 & 32.02 & $\begin{array}{c}0.21 \\
(0.00)\end{array}$ & $\begin{array}{c}0.38 \\
(0.00)\end{array}$ & $\begin{array}{c}0.43 \\
(0.00)\end{array}$ & $\begin{array}{c}0.27 \\
(0.00)\end{array}$ & $\begin{array}{c}0.31 \\
(0.00)\end{array}$ \\
\hline $\mathrm{Q} 1$ to $\mathrm{Q} 2$ & 21.08 & 22.74 & 20.58 & 22.91 & 21.58 & $\begin{array}{l}-0.03 \\
(0.96)\end{array}$ & $\begin{array}{c}0.02 \\
(0.35)\end{array}$ & $\begin{array}{l}-0.13 \\
(0.00)\end{array}$ & $\begin{array}{l}-0.01 \\
(0.61)\end{array}$ & $\begin{array}{l}-0.07 \\
(0.14)\end{array}$ \\
\hline Q1 to Q1 & 23.34 & 27.45 & 21.70 & 23.25 & 21.22 & $\begin{array}{l}-0.27 \\
(0.00)\end{array}$ & $\begin{array}{l}-0.27 \\
(0.00)\end{array}$ & $\begin{array}{l}-0.38 \\
(0.00)\end{array}$ & $\begin{array}{l}-0.31 \\
(0.00)\end{array}$ & $\begin{array}{l}-0.34 \\
(0.00)\end{array}$ \\
\hline Obs. & 435 & 390 & 389 & 370 & 225 & 435 & 390 & 389 & 370 & 225 \\
\hline
\end{tabular}

Notes: The five rows of Panel A of the table report the average perceived probability that a child born to parents in the bottom quintile of the income distribution will be in quintile 5, 4, 3, 2, and 1 respectively, when adult if that child is very talented, i.e., based on our survey question that asks respondents to think conditional on individual talent. The five rows of Panel B of the table report the percent change in the perceived probability of a child born in a family from the bottom quintile to be in quintile 5, 4, 3, 2, and 1 respectively, when adult conditional on talent relative to the unconditional case. P-values in parentheses. 
Table C.9: Heterogeneity in perceptions conditional on effort: partial effects

\begin{tabular}{|c|c|c|c|c|c|c|}
\hline & $\begin{array}{l}\text { Q1 to } Q 1 \\
\text { (1) }\end{array}$ & $\begin{array}{l}\text { Q1 to Q4 or Q5 } \\
\text { (2) }\end{array}$ & $\begin{array}{l}\text { Q1 to Q4 (Qual.) } \\
\text { (3) }\end{array}$ & $\begin{array}{l}\text { Q1 to Q5 (Qual.) } \\
\text { (4) }\end{array}$ & $\begin{array}{l}\text { Diff } \\
\text { Q1 to Q1 } \\
\text { (5) }\end{array}$ & $\begin{array}{c}\text { Diff } \\
\text { Q1 to Q4 or Q5 } \\
(6)\end{array}$ \\
\hline Male & $\begin{array}{l}1.800^{* *} \\
(0.863)\end{array}$ & $\begin{array}{l}-1.215 \\
(0.861)\end{array}$ & $\begin{array}{l}-0.023 \\
(0.019)\end{array}$ & $\begin{array}{l}-0.037^{*} \\
(0.020)\end{array}$ & $\begin{array}{c}0.894 \\
(0.805)\end{array}$ & $\begin{array}{l}-0.661 \\
(0.692)\end{array}$ \\
\hline Young & $\begin{array}{l}1.999^{* *} \\
(0.890)\end{array}$ & $\begin{array}{l}2.358^{* * *} \\
(0.888)\end{array}$ & $\begin{array}{c}0.060^{* * *} \\
(0.020)\end{array}$ & $\begin{array}{c}0.098^{* * *} \\
(0.021)\end{array}$ & $\begin{array}{l}1.608^{*} \\
(0.830)\end{array}$ & $\begin{array}{l}1.716^{* *} \\
(0.714)\end{array}$ \\
\hline Has Children & $\begin{array}{l}-0.307 \\
(0.899)\end{array}$ & $\begin{array}{c}0.610 \\
(0.896)\end{array}$ & $\begin{array}{c}0.031 \\
(0.020)\end{array}$ & $\begin{array}{c}0.074^{* * *} \\
(0.021)\end{array}$ & $\begin{array}{l}1.790^{* *} \\
(0.838)\end{array}$ & $\begin{array}{c}-0.972 \\
(0.721)\end{array}$ \\
\hline Rich & $\begin{array}{c}1.344 \\
(1.127)\end{array}$ & $\begin{array}{c}0.532 \\
(1.124)\end{array}$ & $\begin{array}{l}-0.005 \\
(0.025)\end{array}$ & $\begin{array}{l}-0.023 \\
(0.026)\end{array}$ & $\begin{array}{l}-0.358 \\
(1.051)\end{array}$ & $\begin{array}{c}0.660 \\
(0.904)\end{array}$ \\
\hline College & $\begin{array}{l}-0.816 \\
(0.905)\end{array}$ & $\begin{array}{l}-2.584^{* * *} \\
(0.903)\end{array}$ & $\begin{array}{l}-0.015 \\
(0.020)\end{array}$ & $\begin{array}{c}-0.076^{* * *} \\
(0.021)\end{array}$ & $\begin{array}{c}-5.422^{* * *} \\
(0.844)\end{array}$ & $\begin{array}{c}2.146^{* * *} \\
(0.726)\end{array}$ \\
\hline Right & $\begin{array}{c}-3.496^{* * *} \\
(0.913)\end{array}$ & $\begin{array}{c}2.785^{* * *} \\
(0.911)\end{array}$ & $\begin{array}{c}0.057^{* * *} \\
(0.020)\end{array}$ & $\begin{array}{c}0.069^{* * *} \\
(0.021)\end{array}$ & $\begin{array}{l}-0.625 \\
(0.852)\end{array}$ & $\begin{array}{l}1.981^{* * *} \\
(0.733)\end{array}$ \\
\hline Moved up & $\begin{array}{l}-1.601^{*} \\
(0.890)\end{array}$ & $\begin{array}{l}1.188 \\
(0.888)\end{array}$ & $\begin{array}{c}0.023 \\
(0.020)\end{array}$ & $\begin{array}{c}0.014 \\
(0.021)\end{array}$ & $\begin{array}{c}0.779 \\
(0.830)\end{array}$ & $\begin{array}{l}-0.382 \\
(0.714)\end{array}$ \\
\hline Immigrant & $\begin{array}{l}-0.918 \\
(1.197)\end{array}$ & $\begin{array}{c}0.684 \\
(1.193)\end{array}$ & $\begin{array}{c}0.028 \\
(0.027)\end{array}$ & $\begin{array}{l}0.066^{* *} \\
(0.028)\end{array}$ & $\begin{array}{l}1.146 \\
(1.116)\end{array}$ & $\begin{array}{l}-0.138 \\
(0.960)\end{array}$ \\
\hline Obs. & 2,543 & 2,543 & 2,543 & 2,543 & 2,543 & 2,543 \\
\hline Country-wave FE & Yes & Yes & Yes & Yes & Yes & Yes \\
\hline Mean Dep. Var. & 23.48 & 25.19 & 0.66 & 0.51 & -10.24 & 3.83 \\
\hline
\end{tabular}

Notes: The dependent variables in columns 1-4 are defined as in Table C.7 but conditional on effort. The dependent variable in column 5 (respectively, 6 ) is the difference between the perceived probability conditional on effort and the unconditional probability that a child born to parents in the bottom quintile of the income distribution will be in the bottom quintile (respectively, in the fourth or fifth quintile) when adult. Regressors are defined as in Table C.7. "Mean Dep. Var" is the mean of the dependent variable. Standard errors in parentheses. ${ }^{*} p<0.1,{ }^{* *} p<0.05,{ }^{* * *} p<0.01$ 
Table C.10: Heterogeneity in perceptions conditional on talent: partial effects

\begin{tabular}{|c|c|c|c|c|c|c|}
\hline & $\begin{array}{l}\text { Q1 to Q1 } \\
\text { (1) }\end{array}$ & $\begin{array}{l}\text { Q1 to Q4 or Q5 } \\
\text { (2) }\end{array}$ & $\begin{array}{l}\text { Q1 to Q4 (Qual.) } \\
\text { (3) }\end{array}$ & $\begin{array}{l}\text { Q1 to Q5 (Qual.) } \\
(4)\end{array}$ & $\begin{array}{l}\text { Diff } \\
\text { Q1 to Q1 } \\
\text { (5) }\end{array}$ & $\begin{array}{c}\text { Diff } \\
\text { Q1 to Q4 or Q5 } \\
(6)\end{array}$ \\
\hline Male & $\begin{array}{c}2.793^{* * *} \\
(1.039)\end{array}$ & $\begin{array}{l}-2.440^{* *} \\
(1.015)\end{array}$ & $\begin{array}{l}-0.030 \\
(0.023)\end{array}$ & $\begin{array}{c}-0.068^{* * *} \\
(0.024)\end{array}$ & $\begin{array}{l}-1.081 \\
(0.946)\end{array}$ & $\begin{array}{l}-0.622 \\
(0.862)\end{array}$ \\
\hline Young & $\begin{array}{c}3.253^{* * *} \\
(1.085)\end{array}$ & $\begin{array}{l}-0.576 \\
(1.060)\end{array}$ & $\begin{array}{l}0.044^{*} \\
(0.024)\end{array}$ & $\begin{array}{l}0.056^{* *} \\
(0.025)\end{array}$ & $\begin{array}{l}-0.758 \\
(0.988)\end{array}$ & $\begin{array}{c}1.372 \\
(0.900)\end{array}$ \\
\hline Has Children & $\begin{array}{l}-1.741 \\
(1.103)\end{array}$ & $\begin{array}{l}1.106 \\
(1.078)\end{array}$ & $\begin{array}{c}0.031 \\
(0.024)\end{array}$ & $\begin{array}{c}0.019 \\
(0.025)\end{array}$ & $\begin{array}{c}0.932 \\
(1.005)\end{array}$ & $\begin{array}{l}-0.708 \\
(0.916)\end{array}$ \\
\hline Rich & $\begin{array}{c}0.441 \\
(1.349)\end{array}$ & $\begin{array}{l}-1.797 \\
(1.318)\end{array}$ & $\begin{array}{c}0.027 \\
(0.030)\end{array}$ & $\begin{array}{c}0.032 \\
(0.031)\end{array}$ & $\begin{array}{l}-1.120 \\
(1.228)\end{array}$ & $\begin{array}{c}-0.531 \\
(1.119)\end{array}$ \\
\hline College & $\begin{array}{l}2.560^{* *} \\
(1.103)\end{array}$ & $\begin{array}{c}-3.169^{* * *} \\
(1.078)\end{array}$ & $\begin{array}{l}-0.027 \\
(0.024)\end{array}$ & $\begin{array}{c}-0.087^{* * *} \\
(0.025)\end{array}$ & $\begin{array}{l}-2.501^{* *} \\
(1.004)\end{array}$ & $\begin{array}{c}0.903 \\
(0.915)\end{array}$ \\
\hline Right & $\begin{array}{c}-2.957^{* * *} \\
(1.112)\end{array}$ & $\begin{array}{c}3.483^{* * *} \\
(1.086)\end{array}$ & $\begin{array}{c}0.072^{* * *} \\
(0.025)\end{array}$ & $\begin{array}{c}0.085^{* * *} \\
(0.026)\end{array}$ & $\begin{array}{l}-1.144 \\
(1.012)\end{array}$ & $\begin{array}{l}2.262^{* *} \\
(0.922)\end{array}$ \\
\hline Moved up & $\begin{array}{c}-1.174 \\
(1.080)\end{array}$ & $\begin{array}{l}-0.363 \\
(1.055)\end{array}$ & $\begin{array}{l}-0.011 \\
(0.024)\end{array}$ & $\begin{array}{c}0.001 \\
(0.025)\end{array}$ & $\begin{array}{l}-0.163 \\
(0.983)\end{array}$ & $\begin{array}{l}-0.126 \\
(0.896)\end{array}$ \\
\hline Immigrant & $\begin{array}{l}-2.703^{*} \\
(1.443)\end{array}$ & $\begin{array}{l}3.571^{* *} \\
(1.410)\end{array}$ & $\begin{array}{l}0.069^{* *} \\
(0.032)\end{array}$ & $\begin{array}{l}0.075^{* *} \\
(0.033)\end{array}$ & $\begin{array}{l}-1.282 \\
(1.313)\end{array}$ & $\begin{array}{l}1.859 \\
(1.197)\end{array}$ \\
\hline Obs. & 1,747 & 1,747 & 1,747 & 1,747 & 1,747 & 1,747 \\
\hline Country-wave FE & Yes & Yes & Yes & Yes & Yes & Yes \\
\hline Mean Dep. Var. & 23.53 & 26.18 & 0.66 & 0.52 & -11.31 & 5.78 \\
\hline
\end{tabular}

Notes: The dependent variables in columns 1-4 are defined as in Table C.7 but conditional on talent. The dependent variable in column 5 (respectively, 6 ) is the difference between the perceived probability conditional on talent and the unconditional probability that a child born to parents in the bottom quintile of the income distribution will be in the bottom quintile (respectively, in the fourth or fifth quintile) when adult. Regressors are defined as in Table C.7. "Mean Dep. Var" is the mean of the dependent variable. Standard errors in parentheses. ${ }^{*} p<0.1{ }^{* *} p<0.05, * * * p<0.01$ 
Table C.11: Commuting Zone Characteristics and Mobility Perceptions: Partial Effects

\begin{tabular}{lcccc}
\hline & $\begin{array}{c}\text { Q1 to Q1 } \\
(1)\end{array}$ & $\begin{array}{c}\text { Q1 to Q4 or Q5 } \\
(2)\end{array}$ & $\begin{array}{c}\text { Q1 to Q4 (Qual.) } \\
(3)\end{array}$ & $\begin{array}{c}\text { Q1 to Q5 (Qual.) } \\
(4)\end{array}$ \\
\hline Racial Segregation & $-0.075^{* *}$ & 0.035 & $0.089^{* *}$ & $0.080^{* *}$ \\
& $(0.037)$ & $(0.035)$ & $(0.044)$ & $(0.038)$ \\
Income Segregation & $0.076^{* *}$ & -0.046 & $-0.068^{*}$ & $-0.077^{*}$ \\
& $(0.036)$ & $(0.035)$ & $(0.039)$ & $(0.041)$ \\
Social Capital Index & 0.050 & $-0.060^{*}$ & $-0.092^{* * *}$ & $-0.075^{* *}$ \\
& $(0.037)$ & $(0.033)$ & $(0.032)$ & $(0.037)$ \\
Gini & -0.025 & 0.052 & -0.041 & 0.038 \\
& $(0.035)$ & $(0.036)$ & $(0.038)$ & $(0.037)$ \\
Manufacturing Share & -0.010 & 0.039 & -0.034 & -0.001 \\
& $(0.027)$ & $(0.028)$ & $(0.028)$ & $(0.031)$ \\
College Grad Rate & -0.006 & -0.011 & -0.007 & 0.014 \\
& $(0.026)$ & $(0.025)$ & $(0.029)$ & $(0.031)$ \\
Obs. & 1,635 & 1,635 & 1,635 & 1,635 \\
\hline
\end{tabular}

Notes: "Racial Segregation" is a Multi-group Theil Index calculated at the census-tract level over four groups (White alone, Black alone, Hispanic, and Other) and aggregated at the commuting zone level, "Income Segregation" is measured by a weighted average of two-group Theil indices, as in Reardon (2011), at the commuting zone level, "Social Capital Index" is the social capital index from Rupasingha and Goetz (2008) at the commuting zone-level, "Gini" is the commuting zone-level Gini coefficient, "Manufacturing Share" is the share of employed persons 16 and older working in manufacturing from the 2000 census at the commuting zone-level, "College Grad Rate" is the residual from a regression of graduation rate (the share of undergraduate students that complete their degree in 150\% of normal time) on household income per capita in 2000, aggregated at the commuting zone level. The regressors are from Chetty et al. (2014). Please refer to Chetty et al. (2014) for a detailed explanation of the construction of the commuting zone-level regressors. All regressions control for survey wave fixed effects and include all covariates in Table C.7. The dependent variables are defined as in Table C.7. All variables normalized to have mean 0 and standard deviation 1 in the estimation sample. Standard errors in parentheses, clustered at the commuting zone level. ${ }^{*} p<0.1{ }^{* *} p<0.05,{ }^{* * *} p<0.01$ 


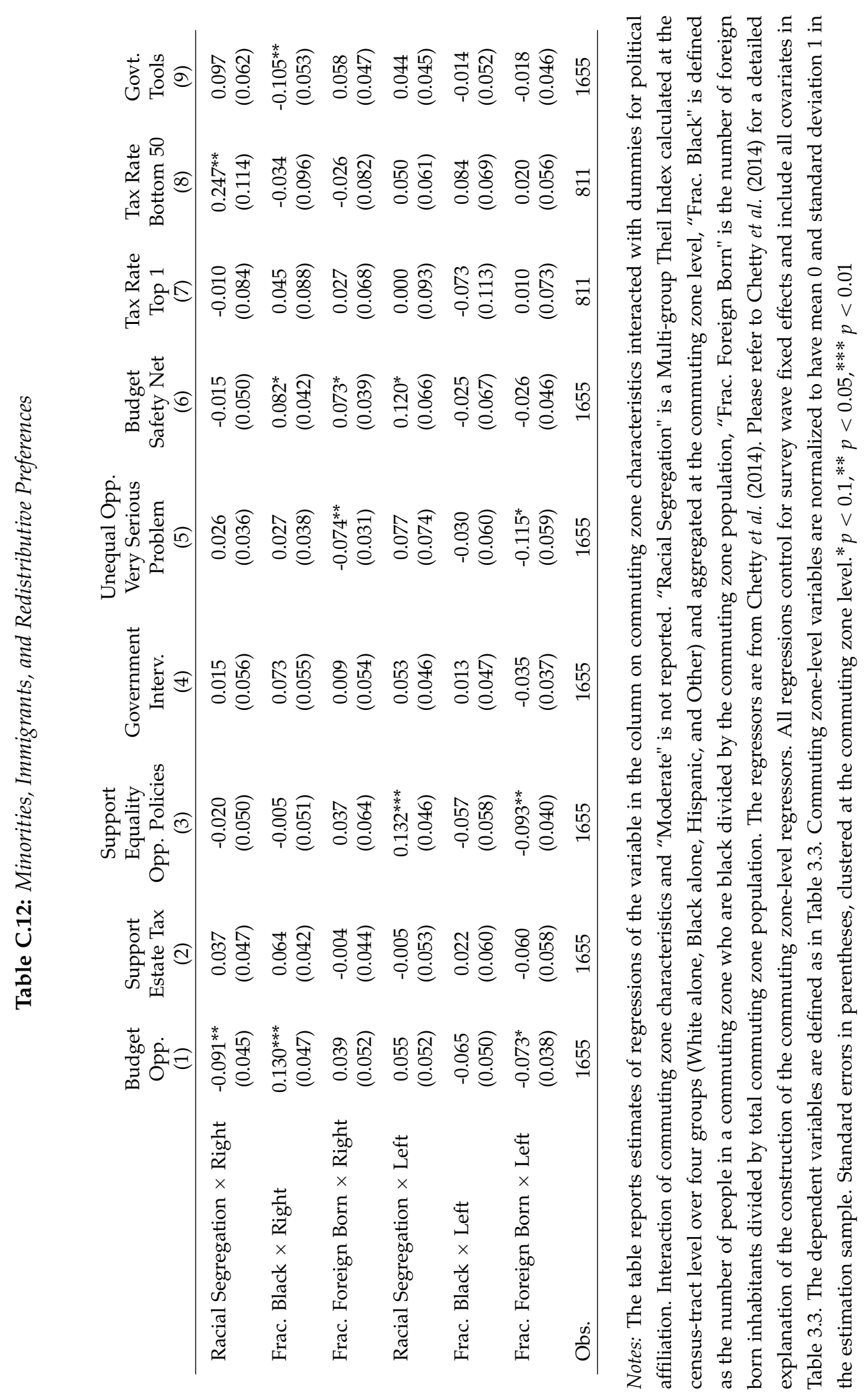




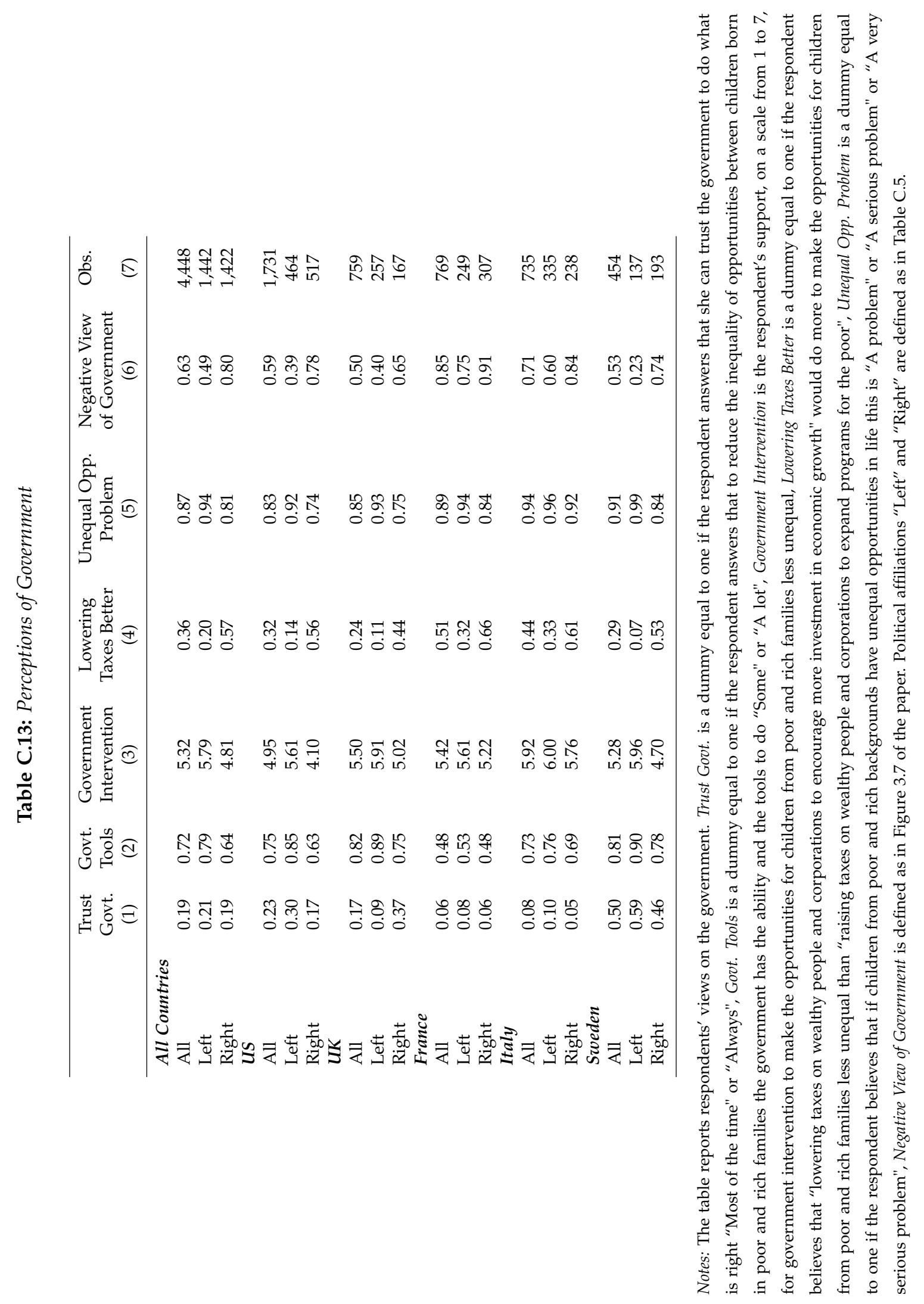




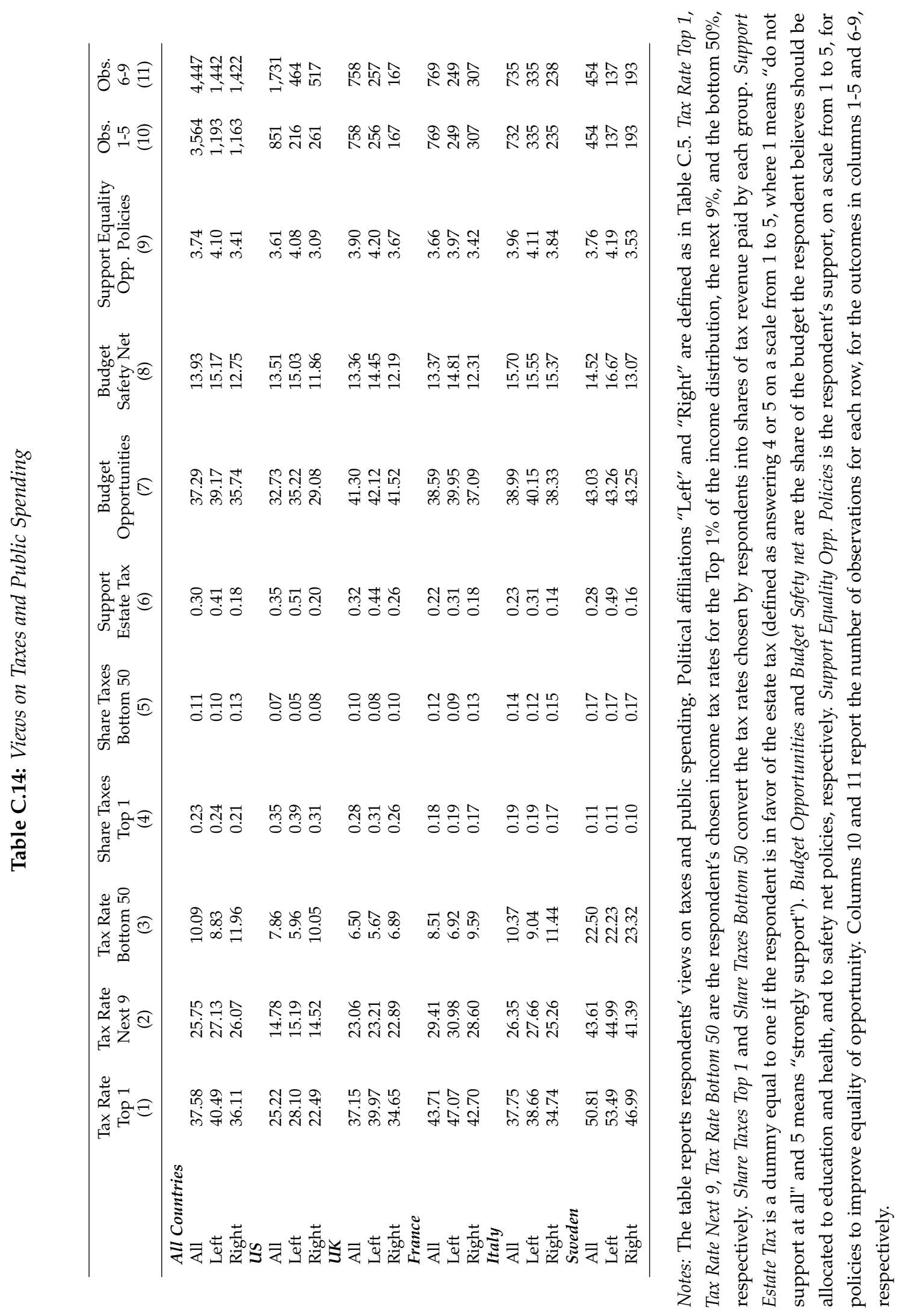




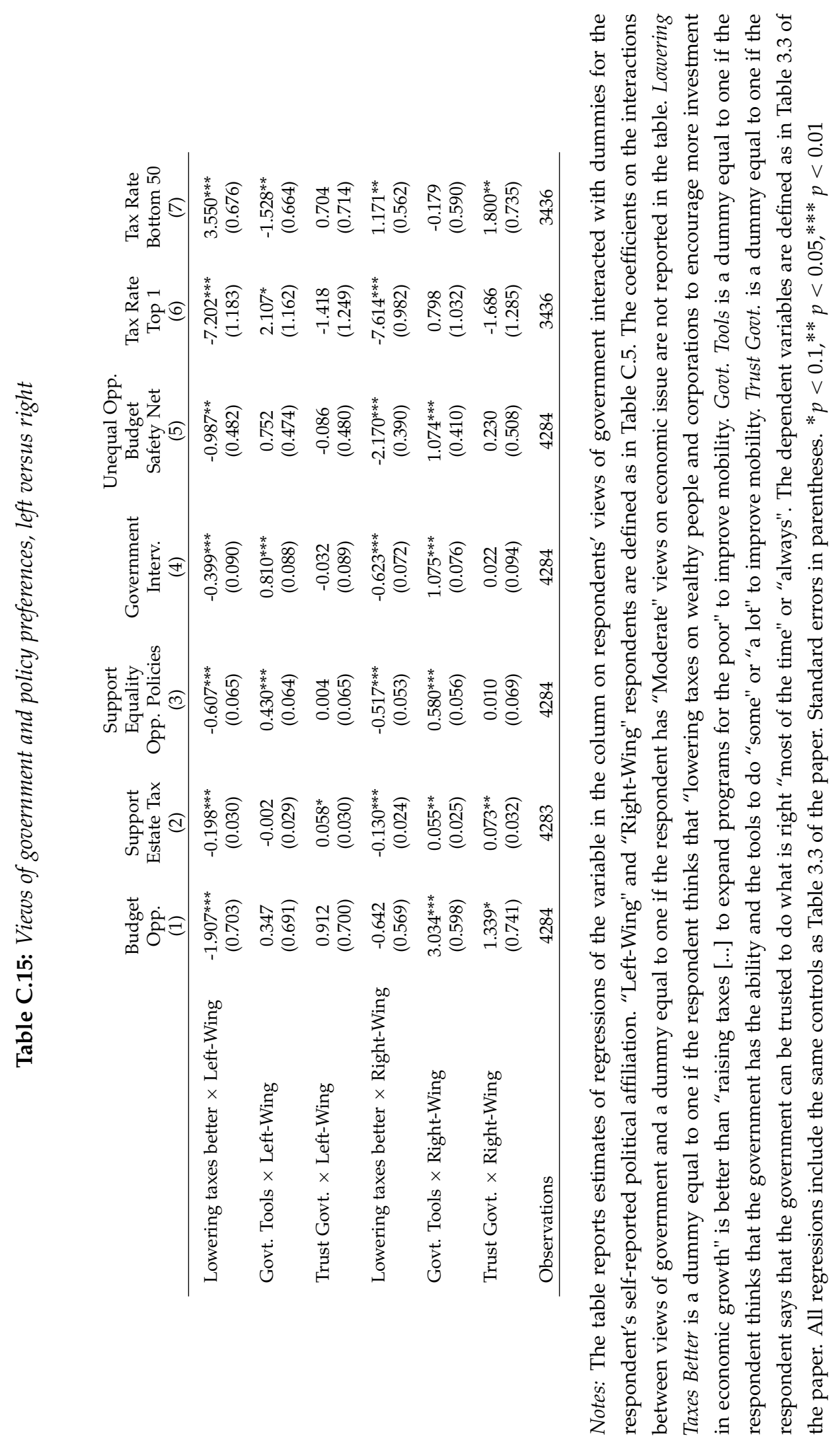




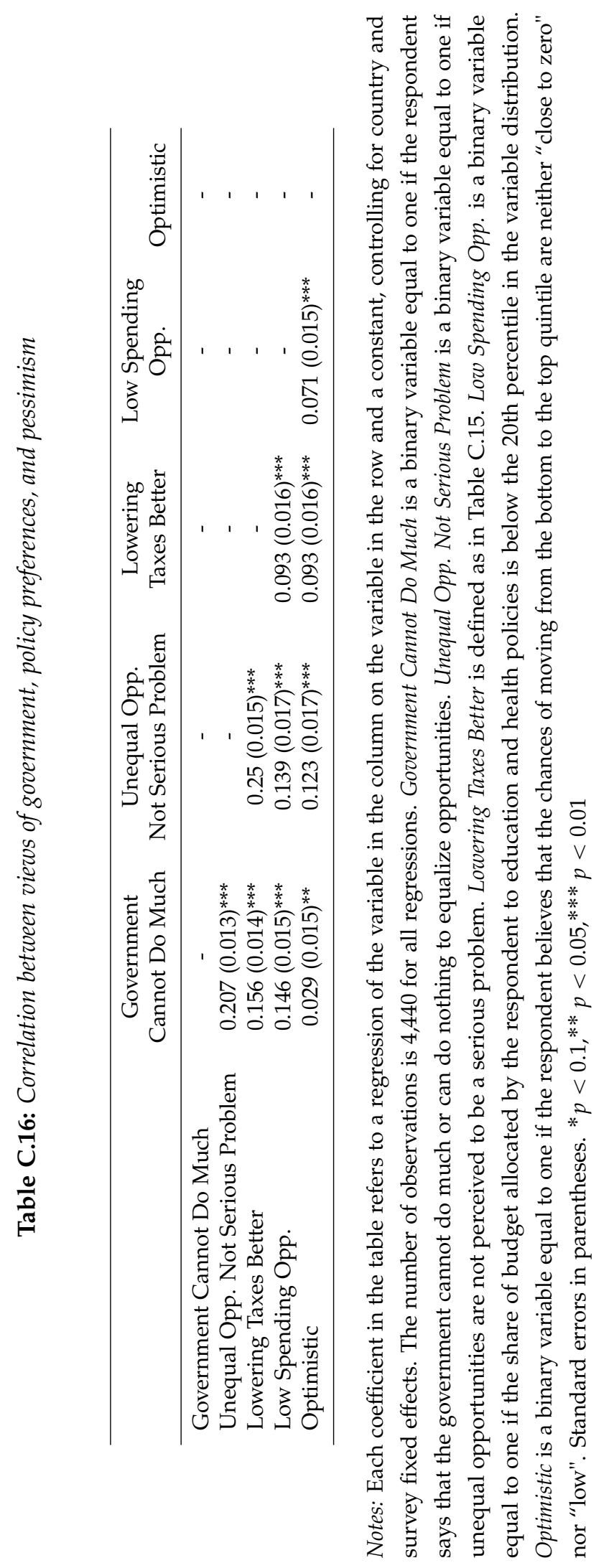




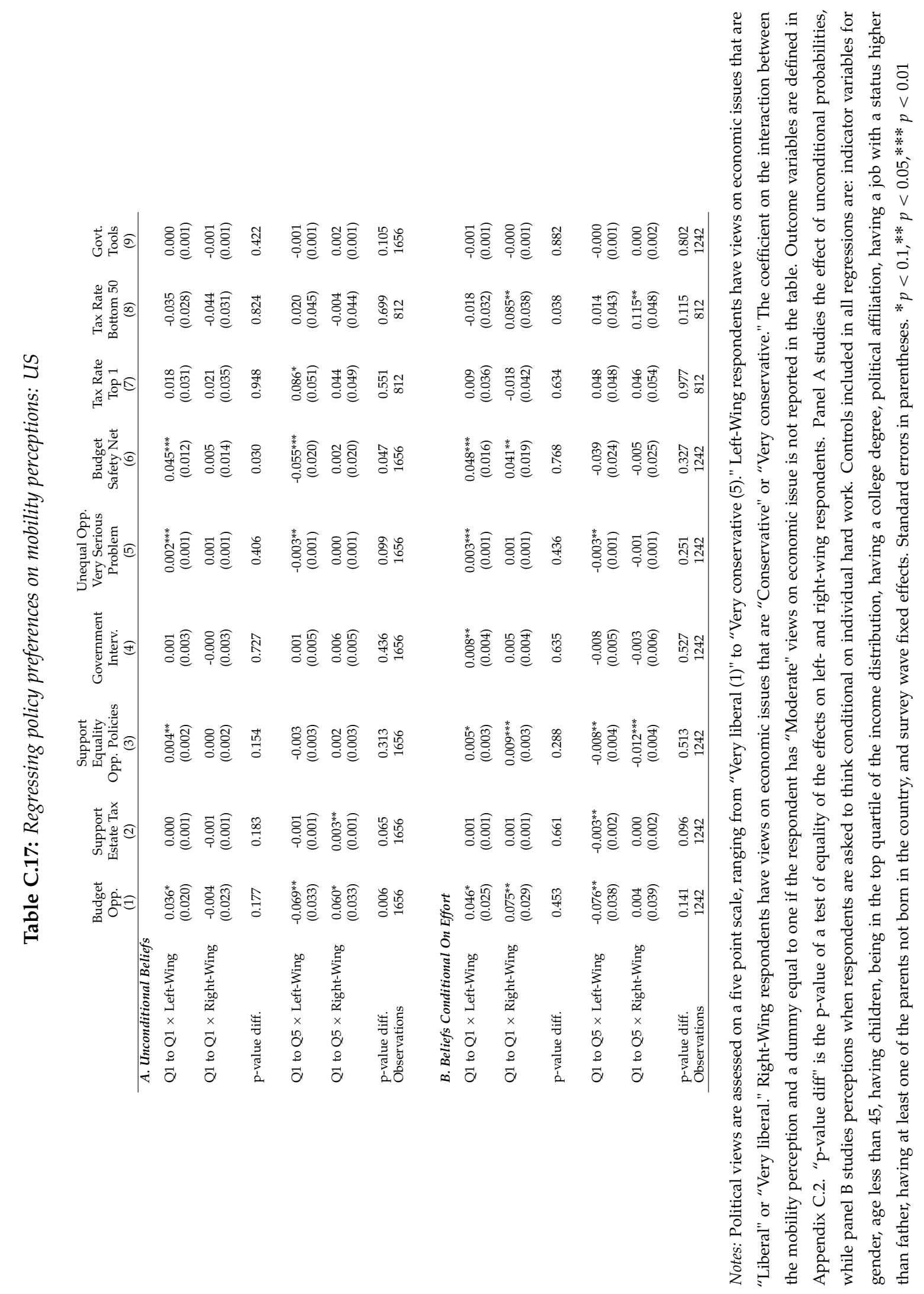




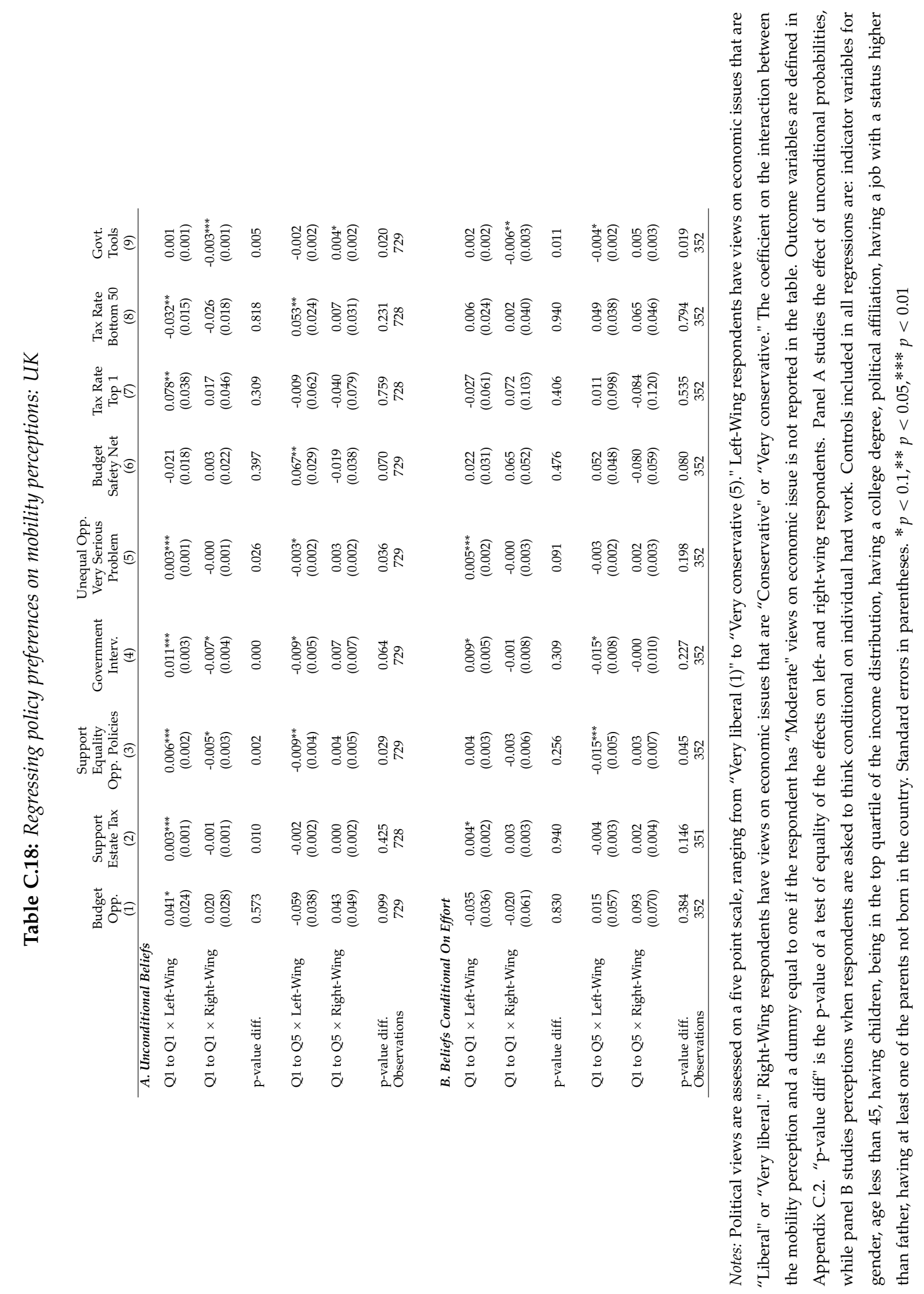




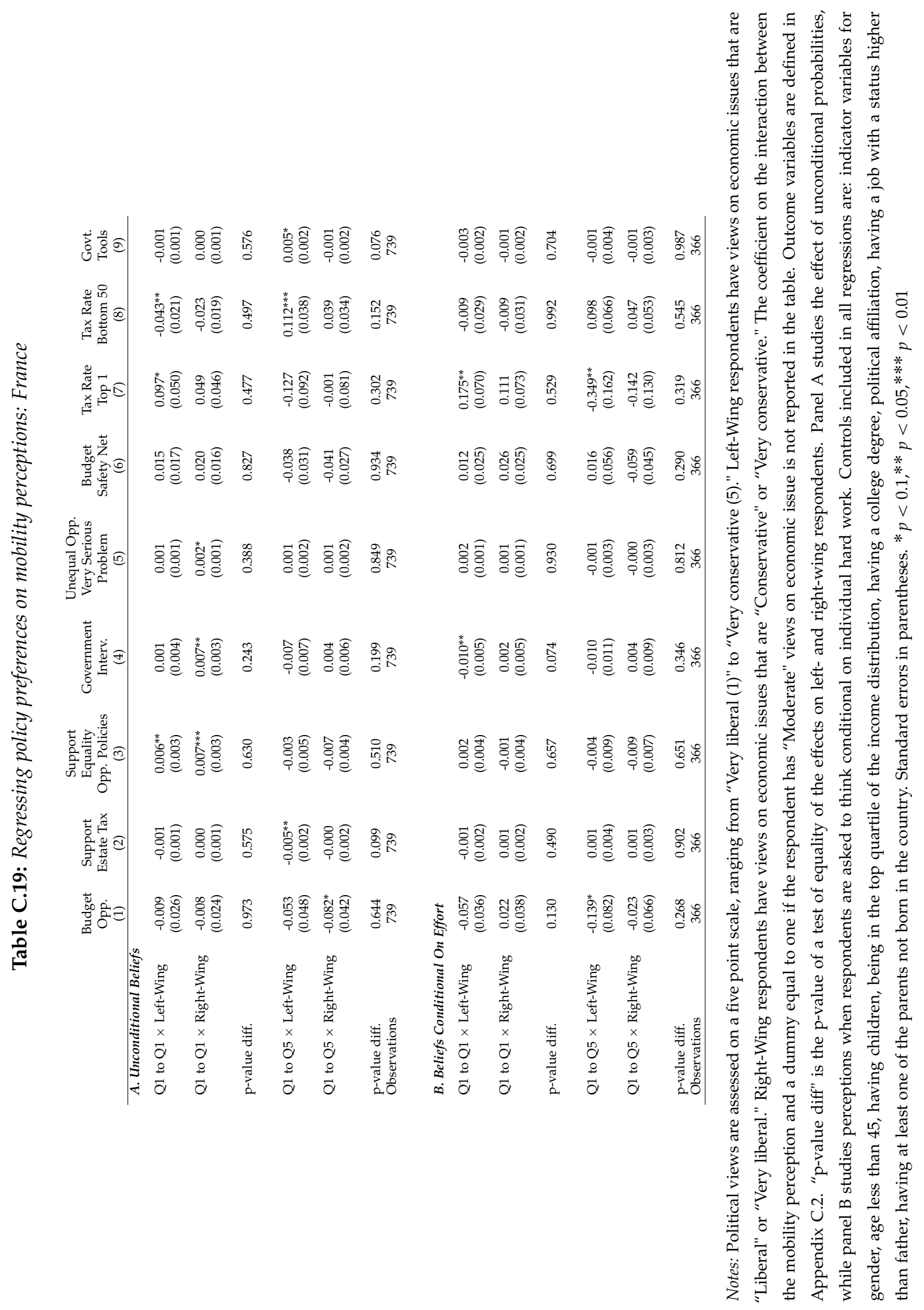




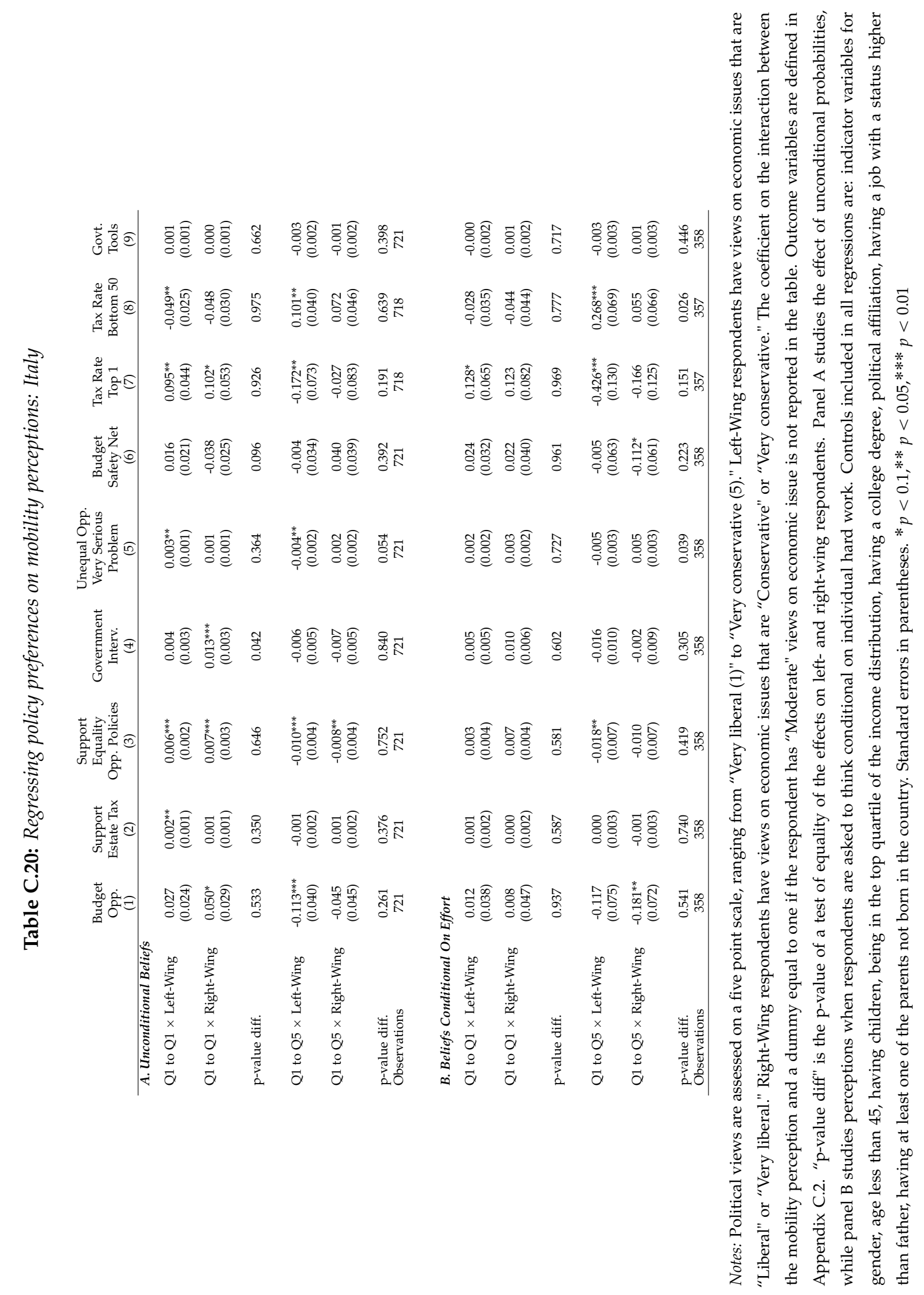




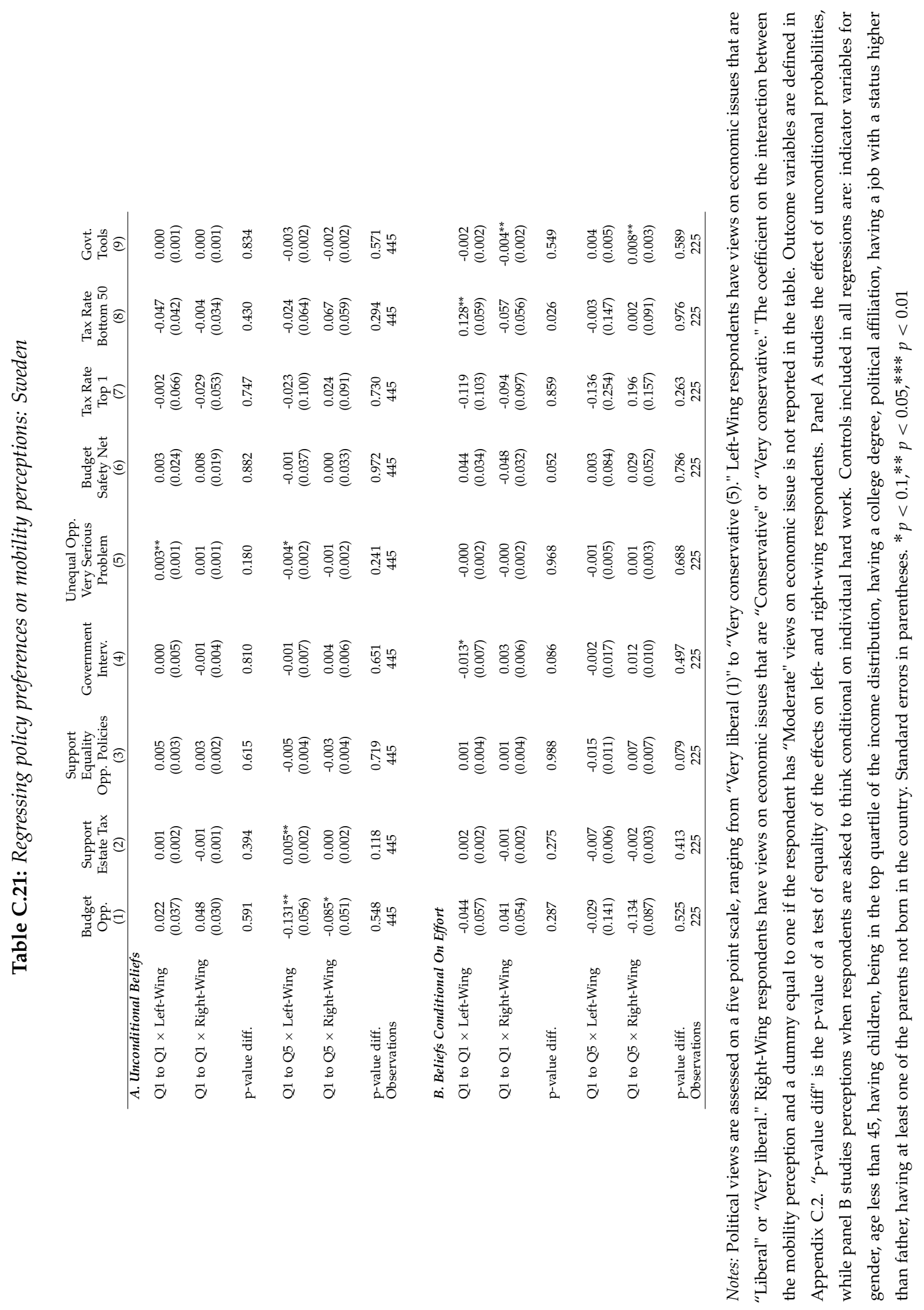


Table C.22: Persistence of Treatment Effects on Mobility Perceptions - Left-Wing respondents

\begin{tabular}{|c|c|c|c|}
\hline & $\begin{array}{c}\text { First Survey } \\
\text { All Respondents } \\
\text { (1) } \\
\end{array}$ & $\begin{array}{c}\text { First Survey } \\
\text { Who Took Follow Up } \\
(2)\end{array}$ & $\begin{array}{l}\text { Follow up } \\
\text { Respondents } \\
\text { (3) }\end{array}$ \\
\hline \multicolumn{4}{|c|}{$Q 1$ to $Q 1$} \\
\hline Treated & $\begin{array}{c}8.532^{* * *} \\
(1.806)\end{array}$ & $\begin{array}{l}9.544^{* *} \\
(3.691)\end{array}$ & $\begin{array}{l}7.841^{* *} \\
(3.625)\end{array}$ \\
\hline \multicolumn{4}{|c|}{$Q 1$ to $Q 2$} \\
\hline Treated & $\begin{array}{l}-1.386 \\
(0.854)\end{array}$ & $\begin{array}{l}-0.264 \\
(1.883)\end{array}$ & $\begin{array}{l}-1.340 \\
(2.014)\end{array}$ \\
\hline \multicolumn{4}{|c|}{$Q 1$ to $Q 3$} \\
\hline Treated & $\begin{array}{c}-4.404^{* * * *} \\
(0.863)\end{array}$ & $\begin{array}{c}-5.666^{* * *} \\
(1.946)\end{array}$ & $\begin{array}{c}-6.252^{* * * *} \\
(2.015)\end{array}$ \\
\hline \multicolumn{4}{|c|}{$Q 1$ to $Q 4$} \\
\hline Treated & $\begin{array}{c}-2.348^{* * *} \\
(0.635)\end{array}$ & $\begin{array}{c}-2.679^{* *} \\
(1.214)\end{array}$ & $\begin{array}{l}-1.790 \\
(1.331)\end{array}$ \\
\hline \multicolumn{4}{|c|}{$Q 1$ to $Q 5$} \\
\hline Treated & $\begin{array}{l}-0.394 \\
(1.058)\end{array}$ & $\begin{array}{l}-0.936 \\
(2.506)\end{array}$ & $\begin{array}{c}1.541 \\
(1.951)\end{array}$ \\
\hline \multicolumn{4}{|c|}{ Q1 to Q4 (Qual.) } \\
\hline Treated & $\begin{array}{c}-0.197^{* * *} \\
(0.058)\end{array}$ & $\begin{array}{l}-0.210^{*} \\
(0.125)\end{array}$ & $\begin{array}{c}-0.315^{* *} \\
(0.131)\end{array}$ \\
\hline \multicolumn{4}{|c|}{ Q1 to Q5 (Qual.) } \\
\hline Treated & $\begin{array}{c}-0.169^{* *} \\
(0.066)\end{array}$ & $\begin{array}{l}-0.217 \\
(0.136)\end{array}$ & $\begin{array}{l}-0.233^{*} \\
(0.135)\end{array}$ \\
\hline Obs. & 916 & 214 & 214 \\
\hline
\end{tabular}

Notes: The coefficients and standard error in row $j$ refer to a regression of the variable listed in row $j$ on a dummy for being in the treatment group. Column 1 shows the first round effects on the full sample of respondents in the first round, while column 2 limits the sample to respondents who also took the follow up survey. Column 3 shows the second round effects. All regressions include the same controls as Table 3.3 of the paper. All dependent variables are defined as in Table 3.4 of the paper. The samples in all columns include only respondents who have views on economic issues that are "Liberal" or "Very liberal." Standard errors in parentheses. ${ }^{*} p<0.1, * * p<0.05,{ }^{* * *} p<0.01$ 
Table C.23: Persistence of Treatment Effects on Mobility Perceptions - Right-Wing respondents

\begin{tabular}{|c|c|c|c|}
\hline & $\begin{array}{c}\text { First Survey } \\
\text { All Respondents } \\
\text { (1) }\end{array}$ & $\begin{array}{c}\text { First Survey } \\
\text { Who Took Follow Up } \\
(2)\end{array}$ & $\begin{array}{l}\text { Follow up } \\
\text { Respondents } \\
\text { (3) }\end{array}$ \\
\hline \multicolumn{4}{|c|}{$Q 1$ to $Q 1$} \\
\hline Treated & $\begin{array}{c}9.763^{* * *} \\
(1.555)\end{array}$ & $\begin{array}{l}7.650^{* *} \\
(2.990)\end{array}$ & $\begin{array}{l}5.015^{*} \\
(2.838)\end{array}$ \\
\hline \multicolumn{4}{|c|}{$Q 1$ to $Q 2$} \\
\hline Treated & $\begin{array}{c}-1.544^{* *} \\
(0.765)\end{array}$ & $\begin{array}{l}-2.705^{*} \\
(1.474)\end{array}$ & $\begin{array}{c}-0.291 \\
(1.658)\end{array}$ \\
\hline \multicolumn{4}{|c|}{$Q 1$ to $Q 3$} \\
\hline Treated & $\begin{array}{c}-6.581^{* * *} \\
(0.932)\end{array}$ & $\begin{array}{c}-6.901^{* * *} \\
(1.884)\end{array}$ & $\begin{array}{l}-3.038^{*} \\
(1.769)\end{array}$ \\
\hline \multicolumn{4}{|c|}{$Q 1$ to $Q 4$} \\
\hline Treated & $\begin{array}{c}-1.932^{* * *} \\
(0.597)\end{array}$ & $\begin{array}{c}0.179 \\
(1.170)\end{array}$ & $\begin{array}{l}-1.851 \\
(1.188)\end{array}$ \\
\hline \multicolumn{4}{|c|}{$Q 1$ to $Q 5$} \\
\hline Treated & $\begin{array}{c}0.294 \\
(1.016)\end{array}$ & $\begin{array}{c}1.778 \\
(1.847)\end{array}$ & $\begin{array}{c}0.165 \\
(1.699)\end{array}$ \\
\hline \multicolumn{4}{|c|}{ Q1 to Q4 (Qual.) } \\
\hline Treated & $\begin{array}{c}-0.309^{* * *} \\
(0.056)\end{array}$ & $\begin{array}{l}-0.149 \\
(0.107)\end{array}$ & $\begin{array}{l}-0.029 \\
(0.110)\end{array}$ \\
\hline \multicolumn{4}{|c|}{ Q1 to Q5 (Qual.) } \\
\hline Treated & $\begin{array}{c}-0.313^{* * *} \\
(0.062)\end{array}$ & $\begin{array}{l}-0.060 \\
(0.128)\end{array}$ & $\begin{array}{c}0.042 \\
(0.126)\end{array}$ \\
\hline Obs. & 1033 & 264 & 264 \\
\hline
\end{tabular}

Notes: The coefficients and standard error in row $j$ refer to a regression of the variable listed in row $j$ on a dummy for being in the treatment group. Column 1 shows the first round effects on the full sample of respondents in the first round, while column 2 limits the sample to respondents who also took the follow up survey. Column 3 shows the second round effects. All regressions include the same controls as Table 3.3 of the paper. All dependent variables are defined as in Table 3.4 of the paper. The samples in all columns include only respondents who have views on economic issues that are "Conservative" or "Very conservative." Standard errors in parentheses. ${ }^{*} p<0.1{ }^{* *} p<0.05{ }^{* * *} p<0.01$ 

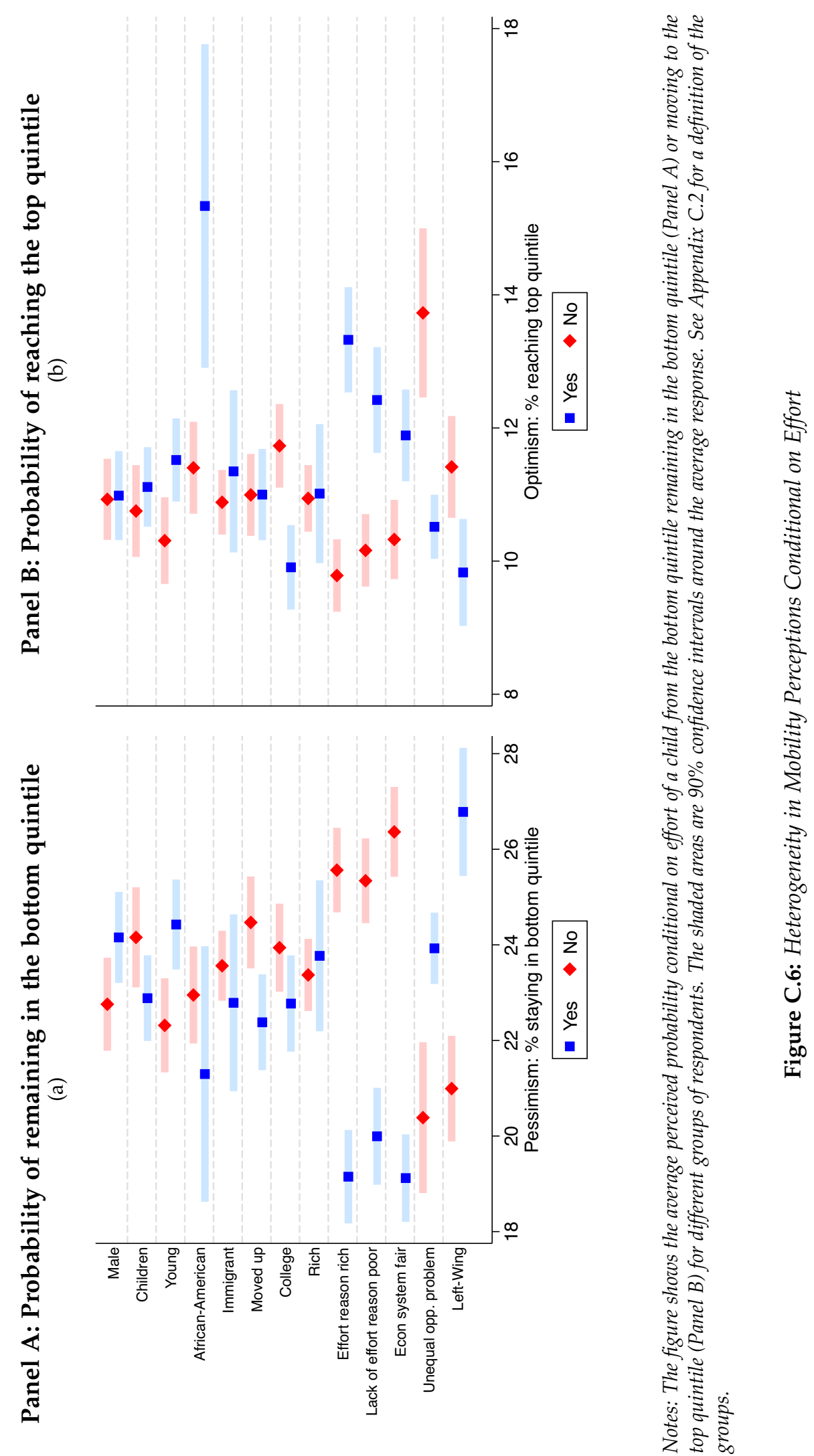

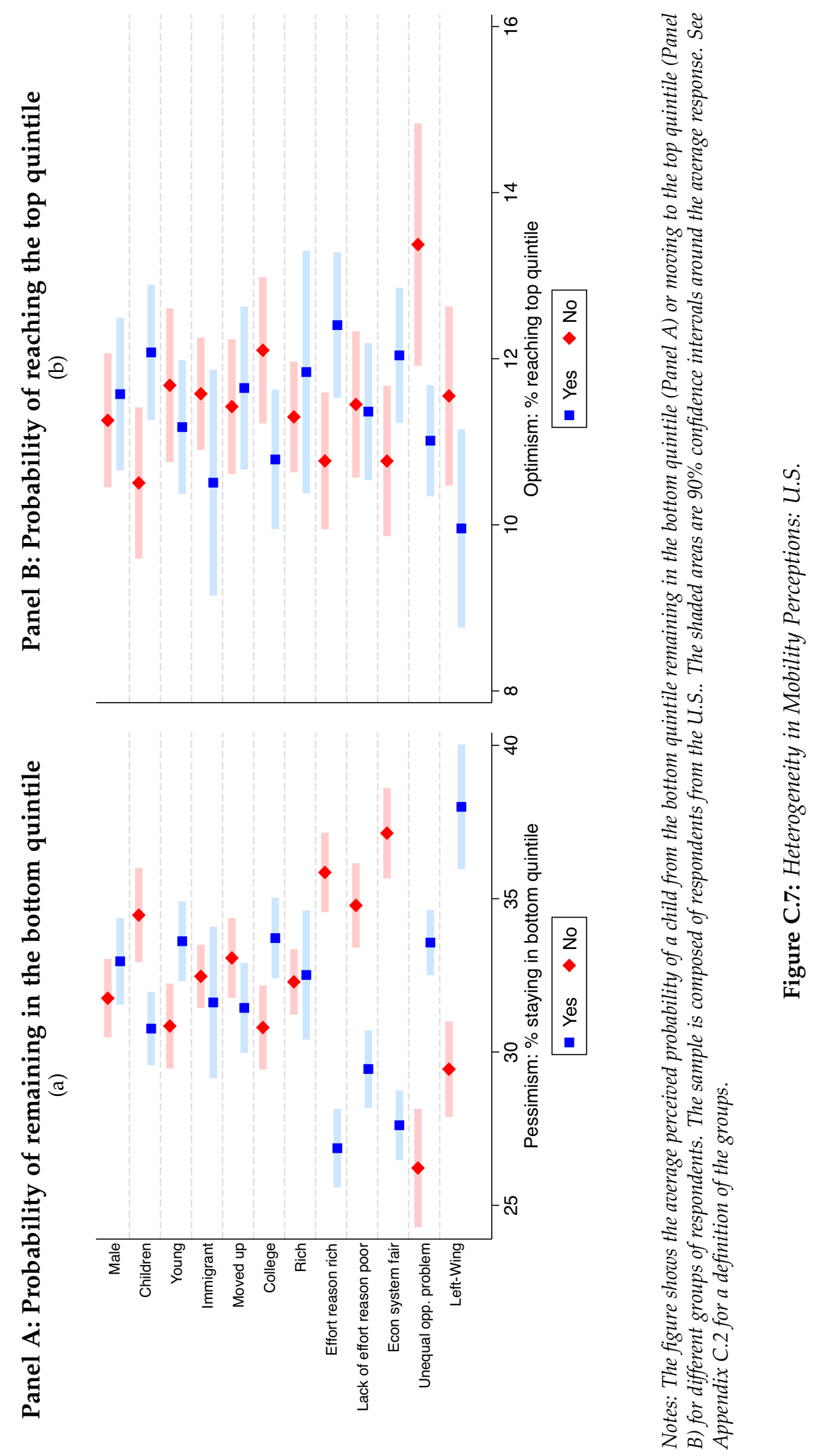

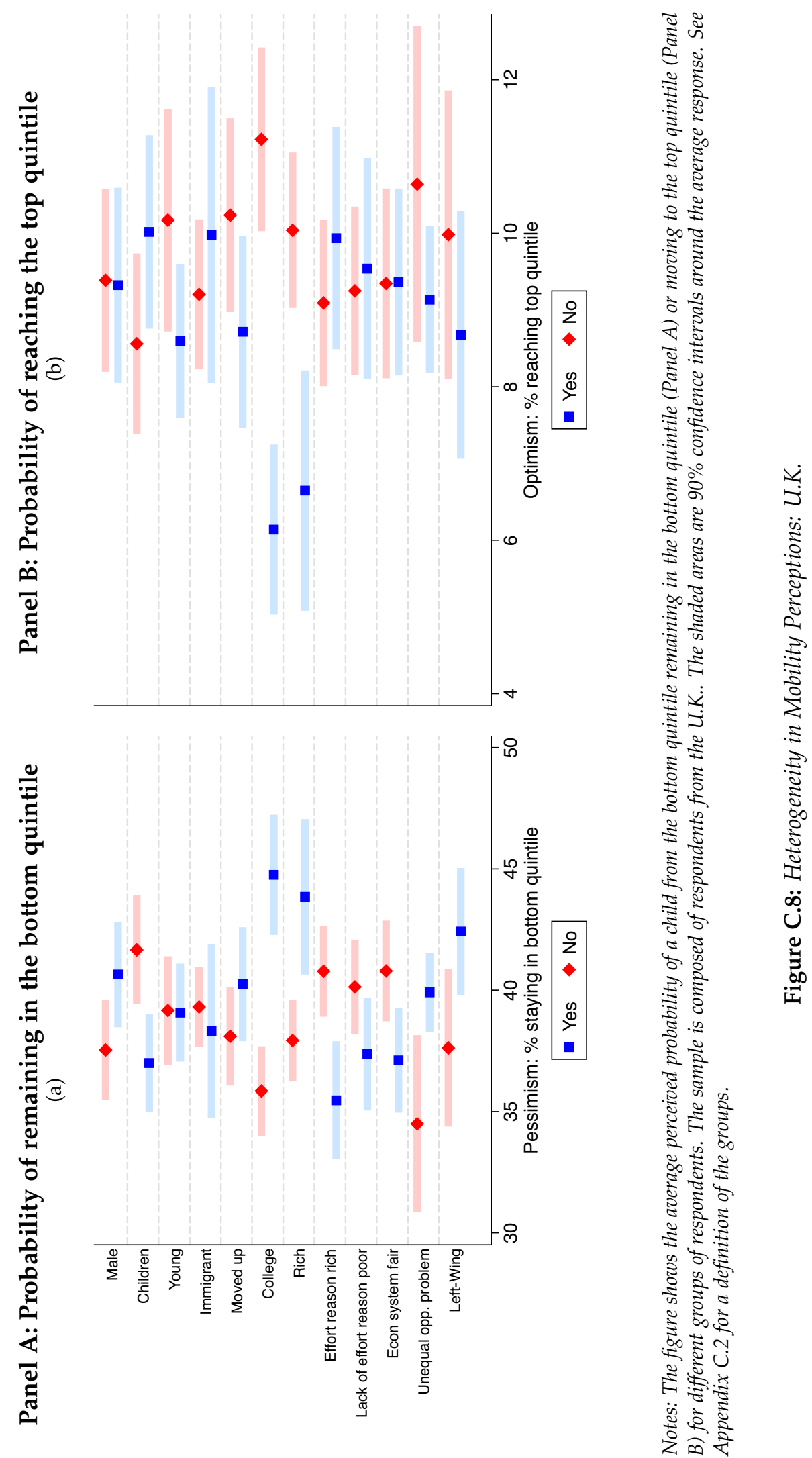

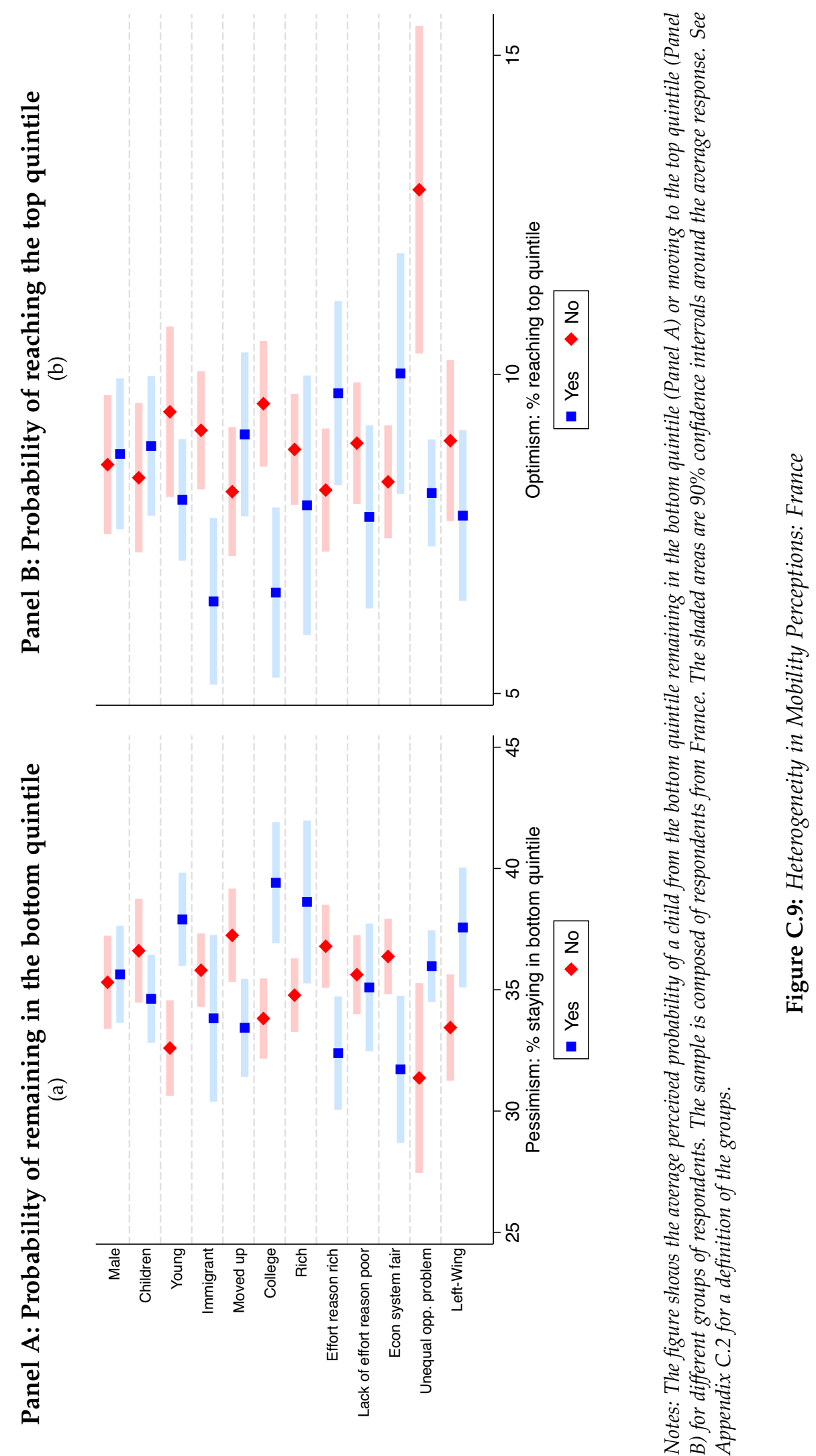

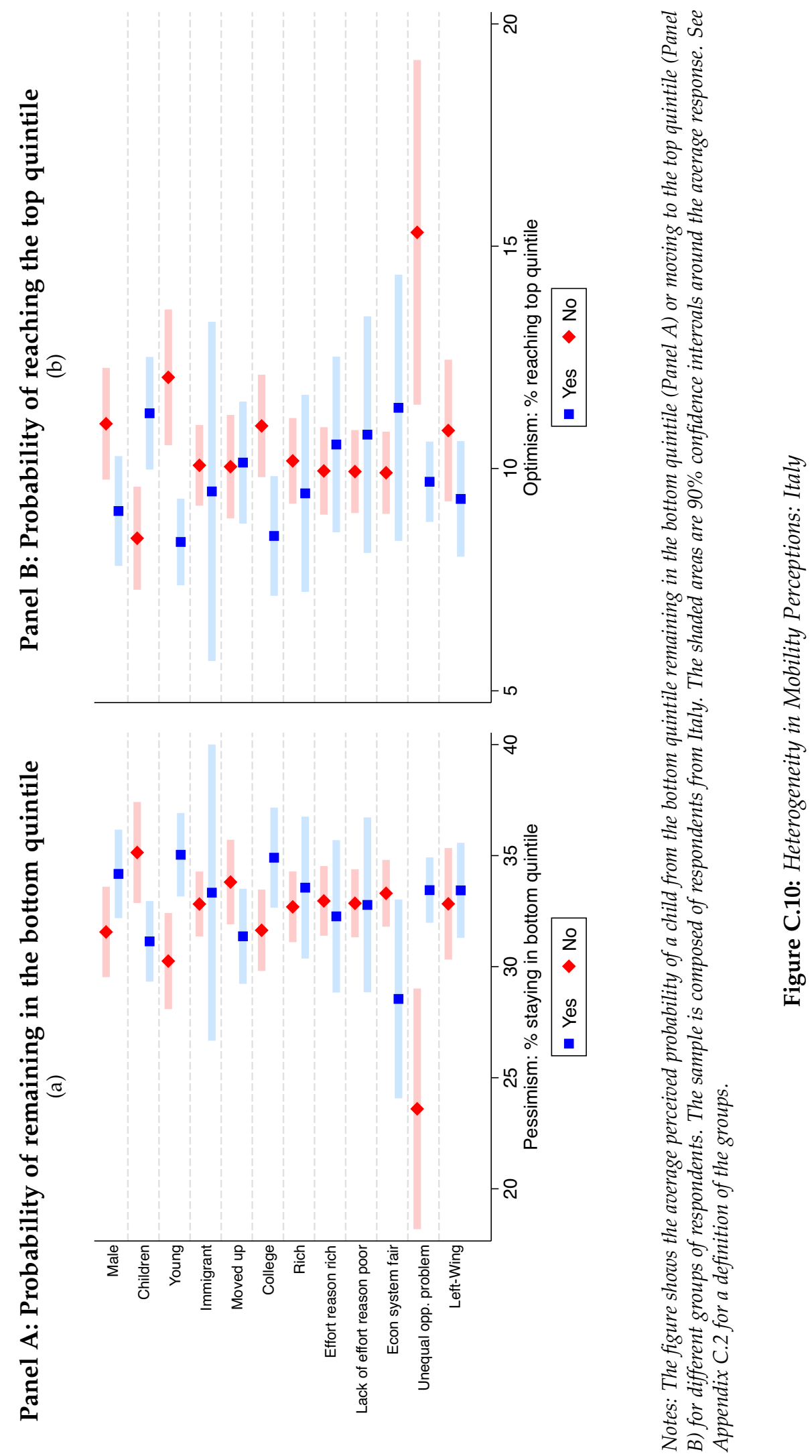

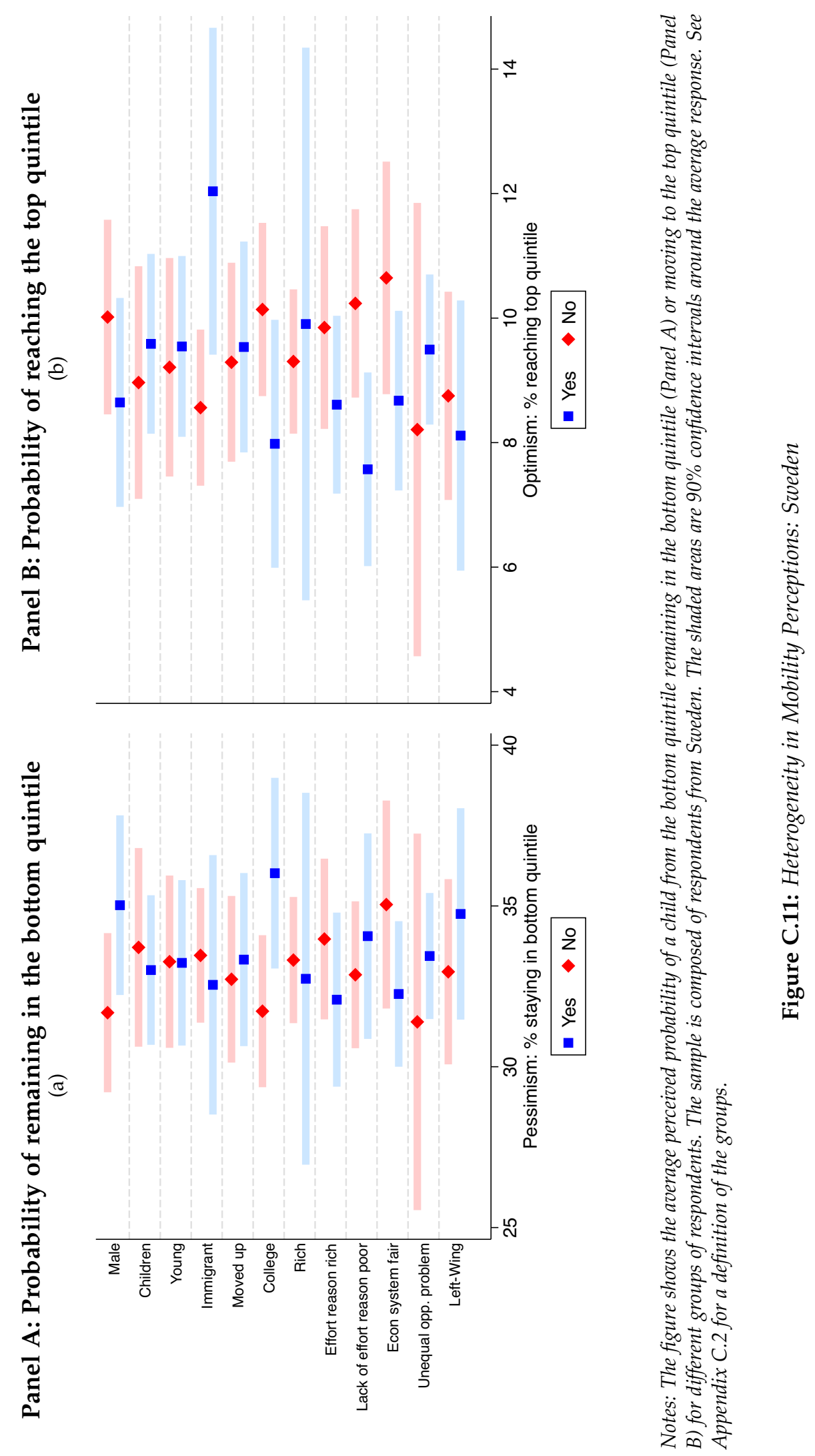


\section{Perceived and actual Q1 to Q5: All states (Left panel) and Omitting South-Eastern States (Right Panel)}

(a)

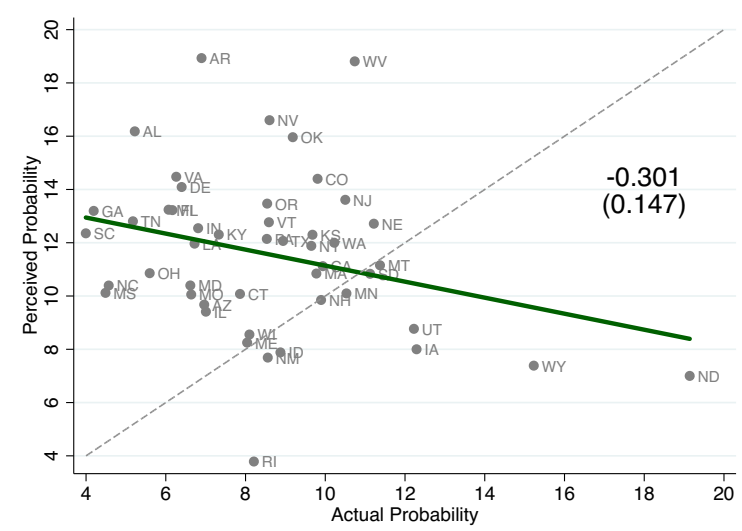

(b)

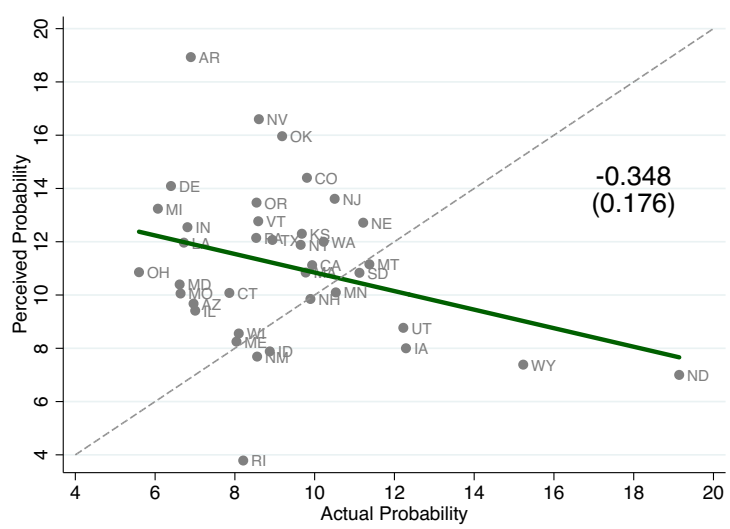

\section{Perceived and actual Q1 to Q1 (Left panel) and Q1 to Q4 (Right panel)}

(c)

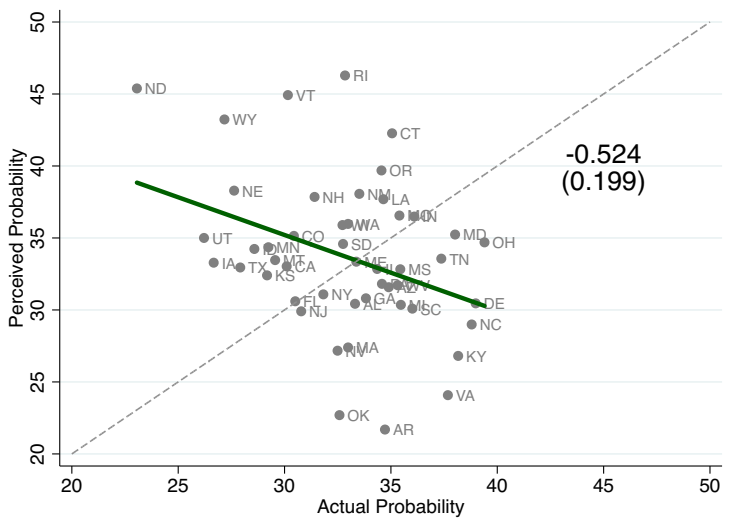

(d)

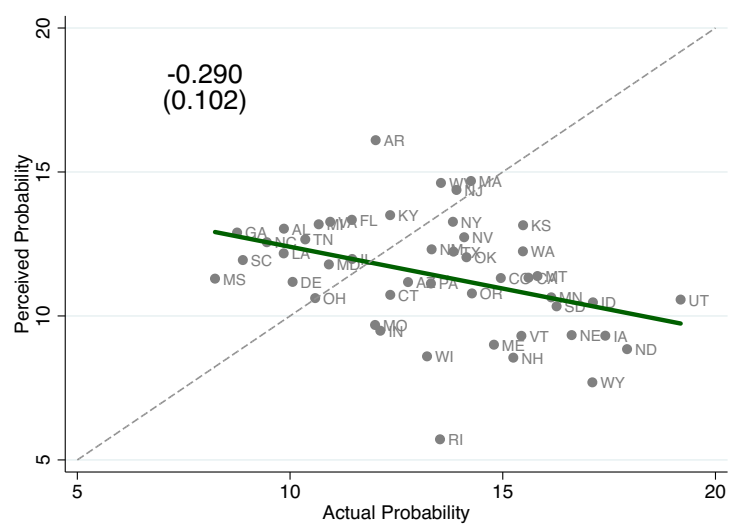

Notes: The figure shows the average perceived probability in each state ( $y$ axis) against the actual probability in the state ( $x$ axis), together with the best-fit line and the coefficient and standard error of the slope. The dotted line is the 45 degree line. See the notes to Figure 3.6.

Figure C.12: Actual and Perceived Transition Probabilities Across U.S. States 


\section{C.6 (Mis)perceptions of inequality}

We conducted an additional, small survey in the U.S. (484 respondents) to elicit respondents' perceptions of inequality. The survey had no treatment component, and asked the same questions on perceptions of mobility as our main surveys.

We asked questions about inequality in i) income, ii) capital income more specifically, and iii) wealth. For each of these three variables, we asked respondents about their perceived shares of the top $1 \%$, the top $10 \%$, and the bottom $50 \%$. We also asked respondents about their perceived income tax rates for different groups of taxpayers. The additional questions are reported below.

\section{New Questionnaire Questions:}

1. What percent of total national income in the United States do you think goes to the top $1 \%$ richest households? (Please enter a number between 0 and 100 to indicate the percent $(\%))$.

2. What percent of total national income do you think goes to the top $10 \%$ richest households?

3. Finally, what percent of total national income do you think goes to the bottom $50 \%$ (poorest) households?

4. Now think about total income coming from capital in the United States. This is income that comes for instance from interest on savings in your bank account or mutual fund, in the form of capital gains or dividends from holding stock in companies, or from investing in a business.

Take the top $1 \%$ richest households by capital income (the $1 \%$ of households with the

most capital income). What percent of total capital income in the United States do you think goes to these households? (Please enter a number between 0 and 100 to indicate the percent $(\%))$.

5. What percent of total capital income do you think goes to the top $10 \%$ richest house- 
holds?

6. Finally, what percent of total capital income do you think goes to the bottom $50 \%$ (poorest) households?

7. Now think about the total wealth in the United States.

Take the top $1 \%$ wealthiest households (the $1 \%$ of households with the most wealth). What percent of total wealth in the United States do you think goes to these households? (Please enter a number between 0 and 100 to indicate the percent $(\%)$ ).

8. What percent of total wealth do you think goes to the top $10 \%$ wealthiest households?

9. Finally, what percent of total wealth do you think goes to the bottom $50 \%$ (least wealthy) households?

10. Please use the sliders below to tell us how much you think each of the following groups currently pays in income tax as a percentage of their total income.

- The top $1 \%$ (Richest)

- The next 9\% (Only 1\% of households earn more, 90\% earn less)

- The next $40 \%$ (Only 10\% earn more, 50\% earn less)

- The bottom 50\% (Poorest) 
(a) Panel A:

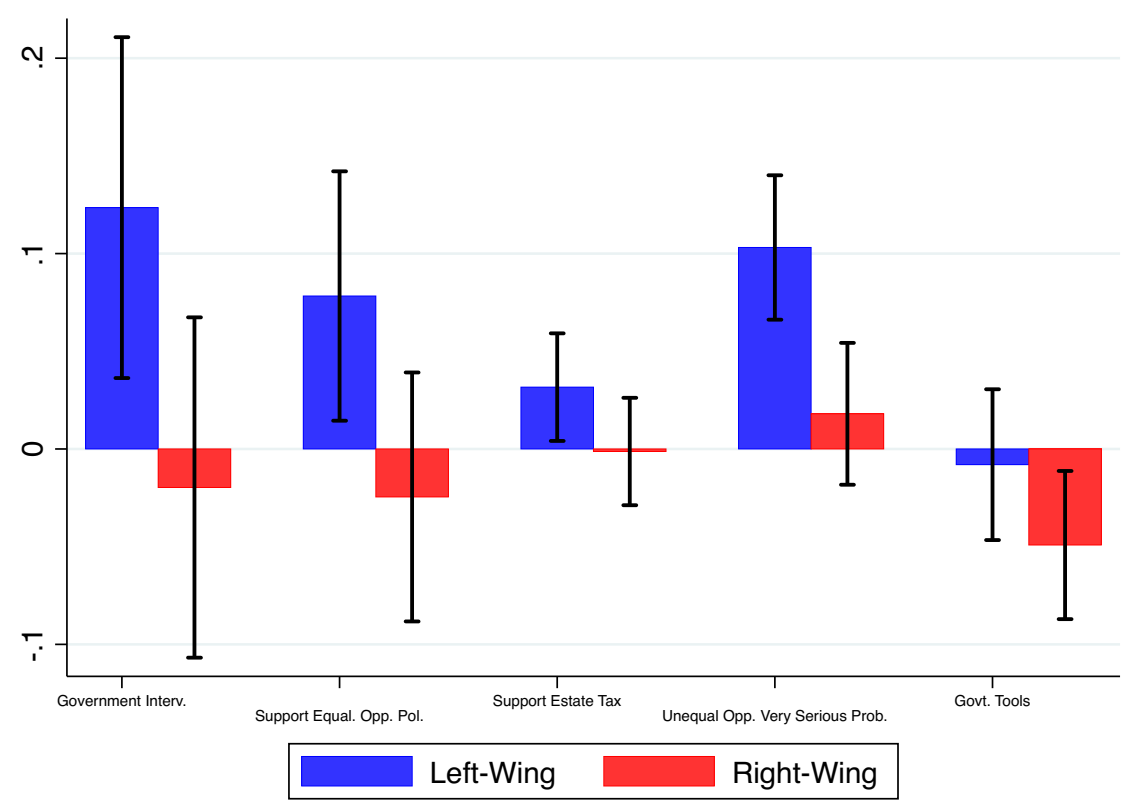

(b) Panel B:

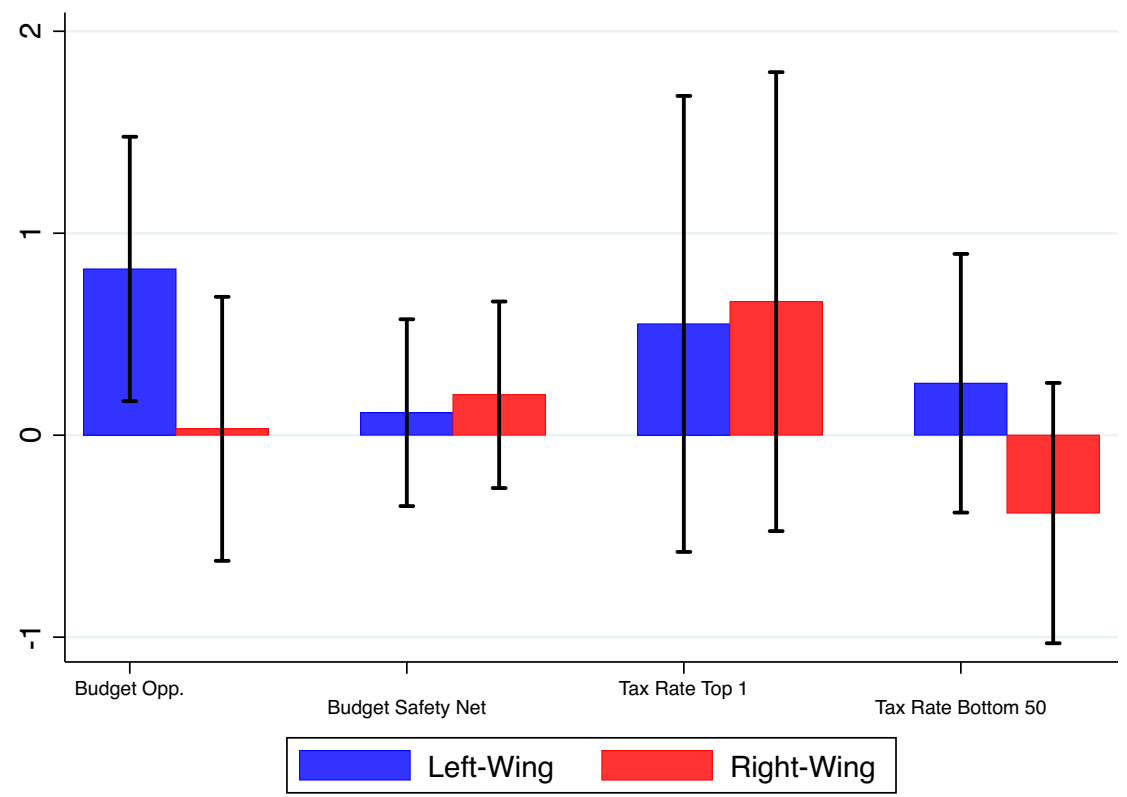

Notes: The figures shows the treatment effects for left-wing and right-wing respondents from Panel A of Table 3.6, together with $90 \%$ confidence intervals. See the notes to Table 3.6.

Figure C.13: Heterogeneity in Treatment Effects By Political Affiliation 


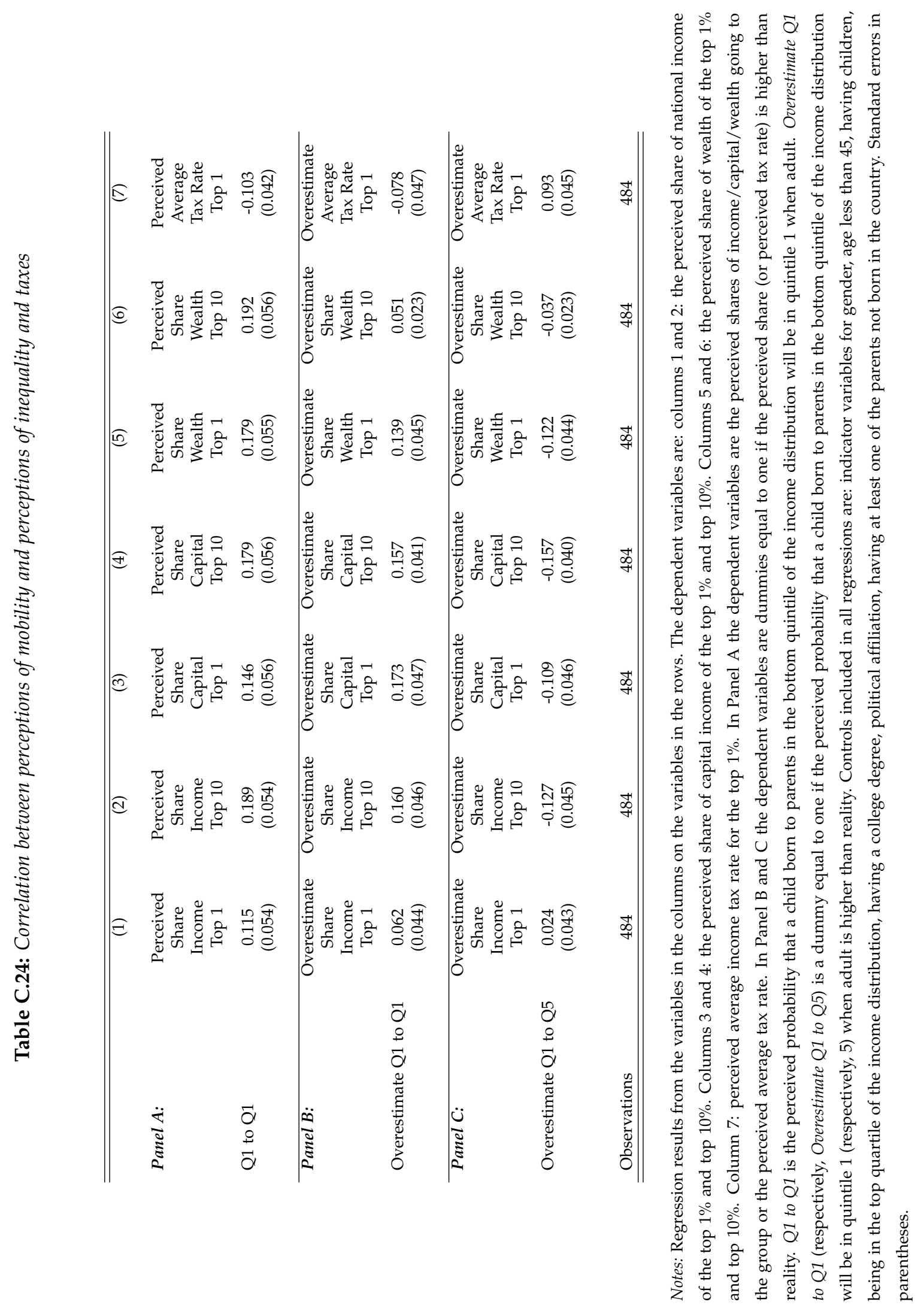


A: Shares to the top $1 \%$

(a)

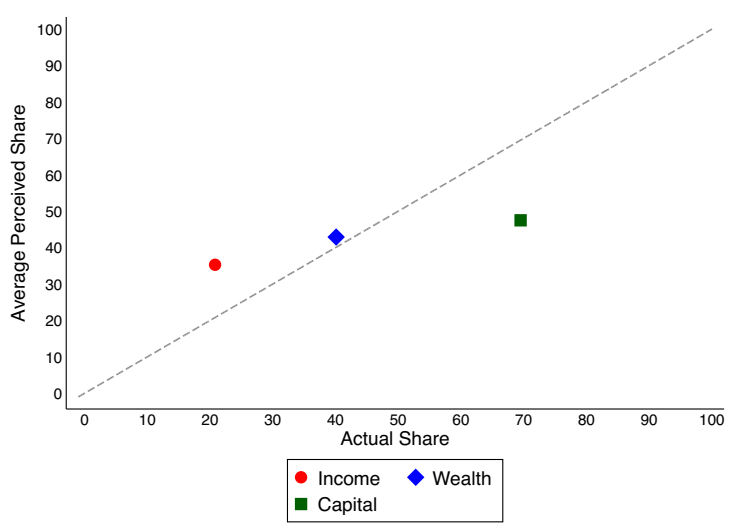

B: Shares to the top $10 \%$

(b)

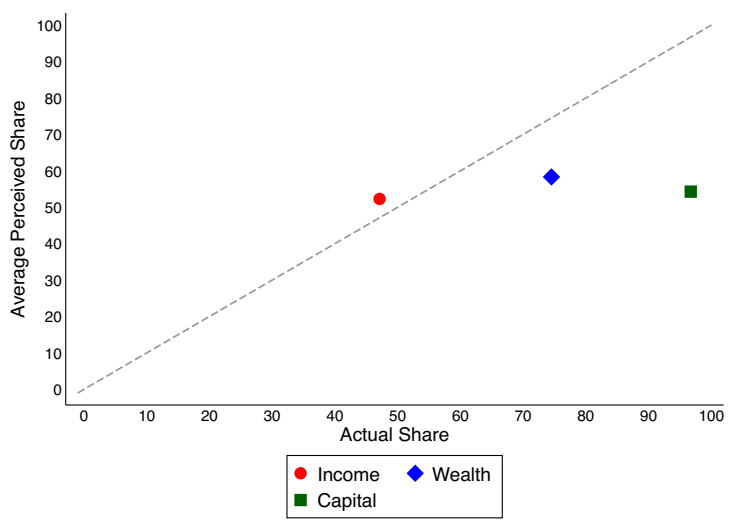

C: Shares to the bottom $50 \%$

(c)

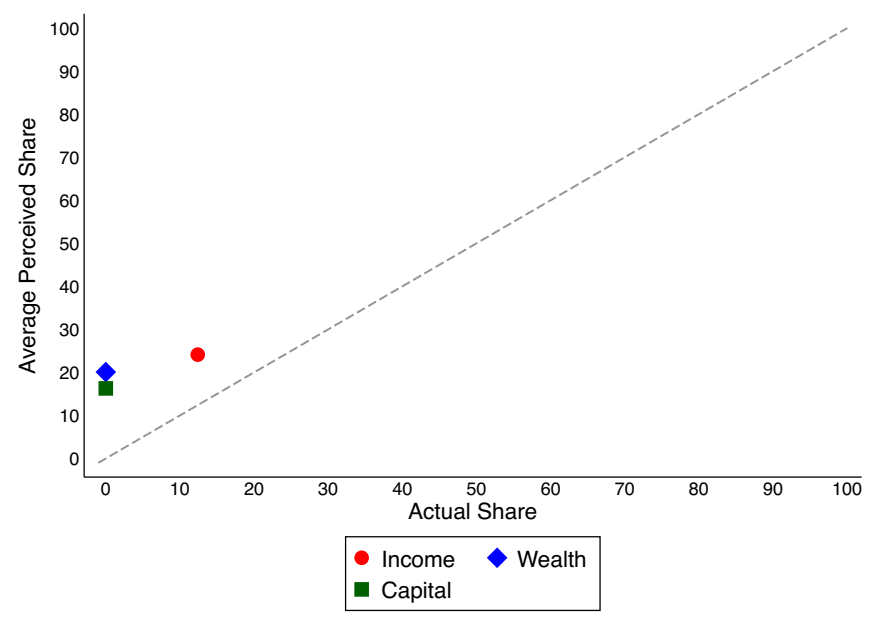

Notes: The figure shows the average perceived share (y axis) of total income, capital income, and wealth going to the top $1 \%$ of households (Panel A), to the top 10\% of households (Panel B) and to the bottom 50\% of households (Panel C) against the actual shares ( $x$ axis). The dotted line is the 45 degree line. Data on actual shares of capital income is from Saez and Zucman (2015). Data on actual shares of national income and wealth is from the World Wealth and Income Database.

Figure C.14: Actual and Perceived Inequality 


\section{C.7 Data Sources for Population Statistics}

- U.S.: U.S. Census Bureau, Current Population Survey. Income brackets (annual gross household income) are: less than $\$ 20,000 ; \$ 20,000-\$ 40,000 ; \$ 40,000-\$ 70,000$; more than $\$ 70,000$.

- U.K.: data on gender, age, and income is from Eurostat Census Data. Data on share of married, native, employed, unemployed, and college educated individuals is from the Office of National Statistics. Income brackets (monthly net household income) are: less than $£ 1,500$; $£ 1,500-£ 2,500$; $£ 2,500-£ 3,000$; more than $£ 3,000$.

- France: data on gender, age, and income is from Eurostat Census Data. Data on share of married, native, employed, unemployed, and college educated individuals is from INSEE. Income brackets (monthly net household income, in Euros) are: less than 1,500; 1,500-2,500; 2,500-2,000; more than 3,000.

- Italy: data on gender and age is from Eurostat Census Data. Data on income is from the Bank of Italy. Data on share of married, native, employed, unemployed, and college educated individuals is from ISTAT. Income brackets (monthly net household income, in Euros) are: less than 1,500; 1,500-,2450; 2,450-3,350; more than 3,350.

- Sweden: data on gender, age, and income is from Eurostat Census Data. Data on share of married, native, employed, unemployed, and college educated individuals is from Statistics Sweden. Income brackets (monthly gross household income, in SEK) are: less than 33,000; 33,000-42,000; 42,000-58,000; more than 58,000.

\section{C.8 Information on construction of the French transition matrix}

Our methodology is inspired by Piraino (2007). We perform a two-stage regression based on two samples: a sample of sons who reported their fathers' socioeconomic characteristics and a sample of adult men ("pseudo fathers") whose age was consistent with that of the actual fathers. Once the samples are selected, the steps required for this empirical strategy are: 
1. estimate an income equation from the older sample;

2. use the estimated coefficients to predict fathers' incomes on the basis of sons' reports;

3. construct a transition matrix based on these results.

\section{Sample selection:}

- Sample of fathers: from the 1985 wave of the "Formation et Qualification professionnelle, INSEE" survey. They are men born between 1927 and 1947, who have at least one child and who have less than four older sister and brothers. We restrict the sample to individuals with positive income that are above half of the annual minimum wage and discard self-employed individuals because we do not have information on income from self-employment. The final sample has about 4500 fathers.

- Sample of sons: from the 2003 wave of the "Formation et Qualification professionnelle, INSEE survey. They are born between 1963 and 1973, with fathers born between 1927 and 1947. We therefore measure income of the pseudo fathers when sons are 12-22. We further restrict the sample to those individuals who report a basic set of their father's demographic characteristics, have less than four older siblings, and, similarly to the fathers' sample, have positive income, are above half of the annual minimum wage and are not self-employed. The final sample has 1279 sons.

Variables to construct income of pseudo fathers: educational level, occupation category, year of birth, indicator for whether father lived in Paris. 